\begin{abstract}
UNIVERSIDADE DE SÃO PAULO
ESCOLA DE ENGENHARIA DE SÃO CARLOS

DEPARTAMENTO DE ENGENHARIA DE ESTRUTURAS
\end{abstract}

MARIANE FILIAGI PASTORE

\title{
ANÁLISE DE PILARES ESBELTOS DE CONCRETO \\ ARMADO DE SEÇÃO RETANGULAR SUBMETIDOS \\ À FLEXÃO COMPOSTA OBLÍQUA
}

SÃO CARLOS 



\title{
Análise de pilares esbeltos de concreto armado de seção retangular submetidos à flexão composta oblíqua
}

\author{
VERSÃO CORRIGIDA
}

A versão original encontra-se na Escola de Engenharia de São Carlos

Dissertação apresentada ao Programa de PósGraduação em Engenharia Civil (Engenharia de Estruturas) da Escola de Engenharia de São Carlos da Universidade de São Paulo para obtenção do título de Mestre em Ciências.

Área de concentração: Estruturas

Orientador:

Prof. Dr. Vladimir Guilherme Haach 
AUTORIZO A REPRODUÇÃO TOTAL OU PARCIAL DESTE TRABALHO, POR QUALQUER MEIO CONVENCIONAL OU ELETRÔNICO, PARA FINS DE ESTUDO E PESQUISA, DESDE QUE CITADA A FONTE.

Ficha catalográfica elaborada pela Biblioteca Prof. Dr. Sérgio Rodrigues Fontes da EESC/USP com os dados inseridos pelo(a) autor(a).

\begin{tabular}{|c|c|}
\hline \multirow[t]{3}{*}{ P293a } & $\begin{array}{l}\text { Pastore, Mariane Filiagi } \\
\text { ANÁLISE DE PILARES ESBELTOS DE CONCRETO ARMADO DE } \\
\text { SEÇÃO RETANGULAR SUBMETIDOS À FLEXÃO COMPOSTA OBLÍLUA / } \\
\text { Mariane Filiagi Pastore; orientador Vladimir Guilherme } \\
\text { Haach. São Carlos, } 2020 \text {. }\end{array}$ \\
\hline & $\begin{array}{l}\text { Dissertação (Mestrado) - Programa de } \\
\text { Pós-Graduação em Engenharia Civil(Engenharia de } \\
\text { Estruturas) e Área de Concentração em Estruturas -- } \\
\text { Escola de Engenharia de São Carlos da Universidade de } \\
\text { São Paulo, } 2020 \text {. }\end{array}$ \\
\hline & $\begin{array}{l}\text { 1. Pilares esbeltos. 2. Flexão composta oblíqua. } \\
\text { 3. Métodos aproximados. 4. Método Geral. I. Título. }\end{array}$ \\
\hline
\end{tabular}

Eduardo Graziosi Silva - CRB - 8/8907 


\section{FOLHA DE JULGAMENTO}

Candidata: Engenheira MARIANE FILIAGI PASTORE.

Título da dissertação: "Análise de pilares esbeltos de concreto armado de seção retangular submetidos à flexão composta oblíqua".

Data da defesa: 03/08/2020

Comissāo Julgadora

Prof. Associado Vladimir Guilherme Haach

(Orientador)

(Escola de Engenharia de São Carlos - EESC/USP)

Prof. Dr. Leandro Mouta Trautwein

(Universidade Estadual de Campinas/UNICAMP)

Prof. Dr. Fernando Menezes de Almeida Filho

(Universidade Federal de São Carlos/UFSCar)
Resultado

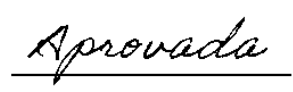

Aprovada

Aprovada

Coordenador do Programa de Pós-Graduação em Engenharia Civil

(Engenharia de Estruturas):

Prof. Associado Vladimir Guilherme Haach

Presidente da Comissão de Pós-Graduação:

Prof. Titular Murilo Araujo Romero 



\section{AGRADECIMENTOS}

Agradeço primeiramente a Deus por me guiar e me dar sabedoria e perseverança para que pudesse realizar este trabalho.

Aos meus pais, Jaqueline e Marco, pelo amor e apoio incondicional em todos os momentos. Aos meus irmãos, Marcus e Rafael, por todo suporte e companheirismo.

Ao meu orientador Prof. Vladimir Guilherme Haach pela disposição, orientação e paciência ao longo dessa trajetória.

À Prof ${ }^{\mathrm{a}}$ Ana Lúcia El Debs e ao Prof. Ricardo Carrazedo pelas sugestões apresentadas no exame de qualificação.

Ao amigo e Prof. Rubens Migliore pelo auxílio na automatização do programa.

Aos colegas da turma de mestrado, Aline, Anne, Camila, Ray, Tainá e Thomas, que compartilharam comigo momentos de estudo e descontração ao longo dessa jornada. Em especial à minha amiga Adriana, que caminhou junto comigo e foi indispensável durante toda trajetória, obrigada pelo companheirismo diário e por todos os momentos compartilhados.

Às amigas de longa data - Beatriz G., Letícia, Marcela, Natalia, Victória, Bruna, Beatriz Z., Luane, Ana Paula - agradeço pela amizade sincera e por estarem sempre presentes, ainda que distantes fisicamente.

Às minhas primas Camila, Joyce, tia Marinha e madrinha Joana, pelo carinho e apoio psicológico, tornando a caminhada mais leve.

Aos funcionários e professores do Departamento de Estruturas da EESC-USP por toda assistência durante a realização desse trabalho.

Aos professores do Departamento de Estruturas da Faculdade de Engenharia Civil da Universidade Estadual de Campinas (FEC-UNICAMP) pelos conhecimentos transmitidos e pelo incentivo dado para cursar o mestrado.

À Coordenação de Aperfeiçoamento de Pessoal de Nível Superior (CAPES) pela bolsa de estudos concedida para desenvolvimento desta pesquisa.

Meus sinceros agradecimentos a todos que estiveram presentes nessa jornada, me apoiando e acreditando no meu potencial. 

"O êxito da vida não se mede pelo caminho que você conquistou, mas sim pelas dificuldades que superou no caminho."

(Abraham Lincoln) 



\section{RESUMO}

\section{PASTORE, M. F. Análise de pilares esbeltos de concreto armado de seção retangular}

submetidos à flexão composta oblíqua. 2020. 175p. Dissertação (Mestrado em Ciências Engenharia Civil (Engenharia de Estruturas)) - Escola de Engenharia de São Carlos, Universidade de São Paulo, São Carlos, 2020.

No projeto de pilares esbeltos de concreto armado é indispensável a análise de sua estabilidade. Nas situações em que os efeitos de segunda ordem não podem ser desprezados, a análise de pilares pode ser realizada por métodos aproximados ou pelo Método Geral. O objetivo deste trabalho foi analisar o comportamento de pilares de concreto armado esbeltos $\left(90 \leq \lambda_{\max } \leq\right.$ 140) de seção retangular submetidos à flexão composta oblíqua, de acordo com quatro diferentes métodos de cálculo prescritos na ABNT NBR 6118:2014. Foram analisados 9.720 casos de simulações diferentes, variando a relação entre lados da seção transversal $(1: 1,3: 1$ e 5:1), o índice de esbeltez (90,115 e 140), a taxa de armadura (2\%, 3\% e 4\%), a força normal reduzida $(0,3 ; 0,4 ; 0,5 ; 0,6)$, o momento fletor reduzido $(0,05 ; 0,10$ e 0,15$)$, a proporção entre momentos da base e topo $(-1 ;-0,5 ; 0 ; 0,5 ; 1)$, o ângulo de atuação do momento $\left(30^{\circ}, 45^{\circ}\right.$ e $\left.60^{\circ}\right)$ e o coeficiente de fluência ( 0 e 2 ). O processamento dos pilares foi realizado no programa SecTrans e para obter todos os resultados foi necessário implementar uma rotina de automatização no programa. As variáveis consideradas mais importantes para obtenção de padrão de comportamento foram índice de esbeltez máxima, força normal reduzida, momento fletor reduzido e a relação entre lados da seção transversal $(b / h)$. Foi constatado que a rigidez adimensional $\kappa$, calculada no Método Acoplado a diagramas, deve atender a uma certa rigidez adimensional mínima $k_{\text {min }}$. Embora a ABNT NBR 6118:2014 permita desprezar o efeito da fluência para pilares com esbeltez $\lambda \leq 90$, observou-se a importância da consideração da fluência para todos os níveis de esbeltez estudados, inclusive $\lambda=90$. Por fim, todos os métodos aproximados resultaram em valores maiores do momento total solicitante em relação ao Método Geral para as situações consideradas válidas, entretanto na maioria dos casos conduziram a valores exagerados, sendo supostamente inviáveis economicamente. Esta constatação pode inviabilizar o uso prático dos métodos aproximados na flexão oblíqua quando é disponível rotinas de cálculo adequadas considerando o Método Geral com resultados teoricamente mais precisos.

Palavras-chave: Pilares esbeltos. Flexão composta oblíqua. Métodos aproximados. Método Geral. 



\begin{abstract}
PASTORE, M. F. Analysis of slender reinforced concrete columns of rectangular crosssection subjected to combined biaxial bending and axial load. 2020. 175p. Dissertation (M.Sc. in Civil Engineering (Structural Engineering)) - Sao Carlos School of Engineering, University of Sao Paulo, Sao Carlos, 2020.

In the design of slender reinforced concrete (RC) columns, it is essential to check their stability. In situations where second-order effects cannot be neglected, column analysis can be carried out using approximate methods or the General Nonlinear Method. The objective of this work was to analyse the behaviour of slender reinforced concrete columns $\left(90 \leq \lambda_{\max } \leq 140\right)$ of rectangular cross-section subjected to combined axial loads and biaxial bending according to four different calculation methods presented in the Brazilian design code for concrete structures named ABNT NBR 6118: 2014. These four methods were compared with a total of 9,720 simulations which considered the following parameters: cross-section geometric ratio $(1: 1 ; 3: 1$ and 5:1), slenderness index (90;115 and 140), reinforcement ratio (2\%;3\% and 4\%), relative axial load $(0,3 ; 0,4 ; 0,5 ; 0,6)$, relative bending moment, proportion between bending moments of the base and top $(-1 ;-0,5 ; 0 ; 0,5 ; 1)$, biaxial bending angle with respect to the horizontal axis $\left(30^{\circ} ; 45^{\circ}\right.$ and $\left.60^{\circ}\right)$ and creep coefficient (0 and 2). The columns were processed using the software SecTrans and an automation routine was implemented in the program to obtain all results. Results showed that the comparison of the approximate methods and the General Method was mainly influenced by the slenderness index, the relative axial load, the relative bending moment and the cross-section geometric ratio (width/height). In the Method Coupled to diagrams, the dimensionless stiffness $\kappa$ must meet a certain minimum dimensionless stiffness $k_{\min }$ in order to the calculations be valid. Although ABNT NBR 6118: 2014 allows to neglect the creep effect for columns with slenderness ratio less than or equal to 90, it was observed the importance of considering creep for all levels of slenderness studied including $\lambda=90$. Finally, the approximate methods resulted in higher values of final design bending moments than the General Method for all valid situations, however in most cases they led to exaggerated values, being supposedly economically unavaible. This finding may make impractical the use of approximate methods in these situations when calculation routines that consider the General Method are readily available with theoretically more accurate results.
\end{abstract}

Keywords: Slender columns. Combined biaxial bending and axial load. Approximate methods. General Nonlinear Method. 



\section{LISTA DE SÍMBOLOS E ABREVIATURAS}

a) Letras minúsculas
a - Acidental
a - Deslocamento lateral (flecha)
b - Dimensão de pilar retangular paralela à Linha Neutra
d - Altura útil
- Derivada
e $\quad$ - Excentricidade da Força normal paralela a uma certa direção
f $\quad$ - Resistência
h - Dimensão da seção transversal paralela a uma certa direção
i - Raio de giração da seção em relação a uma certa direção
n - Quantidade
r $\quad$ - Raio de curvatura
q - Carga distribuída
s - Comprimento de uma corda
t $\quad$ - Tempo
w - Deslocamento lateral (flecha)
x - Altura da linha neutra a partir da borda mais comprimida da seção
y - Limite de escoamento do aço

b) Letras maiúsculas
A - Área da seção transversal
E - Módulo de deformação
F $\quad$ - Força de compressão
- Ação externa
I - Inércia da seção transversal 
L - Comprimento teórico

M - Momento fletor

$\mathrm{N}$ - Força normal

V - Força cortante

c) Letras gregas

$\alpha \quad$ - Ângulo de inclinação da linha neutra

- Coeficiente

$\beta \quad$ - Coeficiente

$\varepsilon \quad$ - Deformação longitudinal específica

$\gamma \quad$ - Coeficiente de ponderação

$\theta \quad$ - Rotação

- Giro da linha elástica entre duas seções

- Desaprumo

$\kappa \quad$ - Rigidez adimensional

$\lambda \quad$ - Esbeltez de pilar em relação a um certo eixo de referência

$\mu \quad$ - Momento fletor normal reduzido

$v \quad$ - Força normal reduzida

$\xi \quad$ - Excentricidade relativa

$\rho \quad$ - Taxa geométrica de armadura

$\sigma \quad$ - Tensão normal

$\phi \quad$ - Diâmetro das barras da armadura

$\varphi \quad$ - Coeficiente de fluência

$\chi \quad$ - Fator de amplificação entre momentos total e de primeira ordem

$\omega \quad$ - Taxa mecânica de armadura 
d) Símbolos subscritos com letras minúsculas

c - Concreto

- Comprimido

- Fluência (creep)

- Referido à seção bruta

d - Valor de cálculo

e - Equivalente

f $\quad$ - Ponderação de ações

g - Ação permanente

i - Número sequencial

n $\quad$ - Número de barras de aço

$\mathrm{s} \quad-$ Aço

x e y - Direções ortogonais cartesianas

e) Símbolos subscritos com letras maiúsculas

A - Extremidade de pilar com maior momento fletor

B - Extremidade de pilar com menor momento fletor

C - Meio de pilar em balanço

$\mathrm{R}$ - Esforço resistente

S - Esforço solicitante

f) Símbolos compostos

1/r - Curvatura

$\mathrm{C}_{\mathrm{m}} \quad$ - Percentual de altura do pilar com momento máximo de $2^{\mathrm{a}}$ ordem local

EI - Rigidez à flexão

$\mathrm{EI}_{\mathrm{c}}$ - Rigidez à flexão da seção bruta de concreto

$\mathrm{EI}_{\mathrm{sec}}$ - Rigidez à flexão secante

$\mathrm{M}_{1 \mathrm{~d} . \mathrm{mín}^{-}}$Momento mínimo de primeira ordem 
$\alpha_{b} \quad$ - Parâmetro para determinação da seção crítica

$\gamma_{\mathrm{n} 1} \quad$ - Coeficiente adicional de ponderação

$\lambda_{1} \quad$ - Esbeltez limite

$\infty \quad$ - Tempo infinito

g) Abreviaturas com letras minúsculas

$$
\begin{aligned}
& \text { apl - Carga aplicada } \\
& \text { aprox.- Aproximado } \\
& \text { base } \quad \text { - Extremidade inferior de pilar } \\
& \text { cr } \quad \text { - Carga crítica } \\
& \text { interm - Seção intermediária de pilar } \\
& \text { mín - Mínimo } \\
& \text { sec - Secante } \\
& \text { topo - Extremidade superior de pilar } \\
& \text { tot } \quad \text { - Momento total de primeira e de segunda ordem } \\
& \text { xx e yy- Componentes de flexão composta normal }
\end{aligned}
$$

h) Abreviaturas com letras maiúsculas

ABNT- Associação Brasileira de Normas Técnicas

ACI - American Concrete Institute

AISC - American Institute of Steel Construction

CEB - Comitê Europeu de Concreto

ELU - Estado limite último

LN - Linha neutra

NBR - Norma Brasileira Registrada

NLF - Não linearidade física

NLG - Não linearidade geométrica 


\section{LISTA DE FIGURAS}

Figura 1-1 - Edifício com pilares esbeltos em concreto armado. ................................. 30

Figura 1-2 - Ilustração de não linearidade de uma estrutura de concreto. ................... 31

Figura 2-1 - Solicitações de pilar submetido à flexão composta oblíqua....................... 38

Figura 2-2 - Seção de concreto armado submetida à flexão composta oblíqua............ 38

Figura 2-3 - Superfície de interação. ......................................................................... 40

Figura 2-4 - Exemplo de uma curva aproximada de interação..................................... 41

Figura 2-5 - Curvatura na flexão simples. ............................................................... 43

Figura 2-6 - Deformação de um pilar submetido à flexão composta oblíqua................ 45

Figura 2-7 - Diagrama momento-curvatura ............................................................ 47

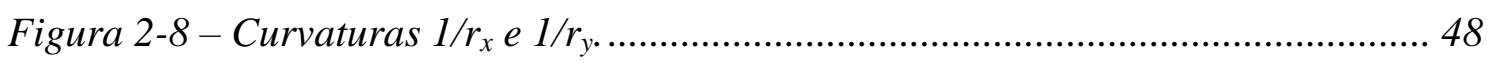

Figura 2-9 - Ilustração do fenômeno de instabilidade ................................................ 50

Figura 2-10 - Comprimentos equivalentes para situações usuais................................ 52

Figura 2-11 - Pilares com curvaturas simples e dupla ............................................... 56

Figura 2-12 - Pilares submetidos a efeitos locais de segunda ordem .......................... 57

Figura 2-13 - Ilustração de esforços atuantes em um lance de pilar............................ 59

Figura 2-14 - Imperfeições geométricas locais: a) Elementos de travamento (tracionado ou comprimido); b) Falta de retilineidade no pilar e c) Desaprumo do pilar

Figura 2-15 - Envoltória mínima de primeira ordem. 62

Figura 2-16 - Representação de momentos de segunda ordem local em um lance de pilar. 63

Figura 2-17 - Envoltória mínima para efeitos totais (primeira e segunda ordem)....... 65

Figura 2-18 - Verificação de momentos fletores solicitantes......................................... 66

Figura 2-19 - Fluência no diagrama tensão-deformação ........................................... 68

Figura 3-1 - Linha elástica senoidal. ...................................................................... 71

Figura 3-2 - Linha elástica de pilar em balanço e de pilar bi rotulado......................... 73

Figura 3-3 - Esquema para consideração de não linearidades em pilares. .................. 73

Figura 3-4 - Gráfico para obtenção da expressão de אaproximado............................. 78

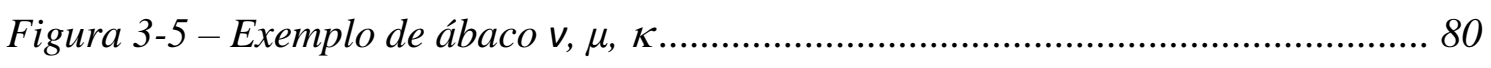

Figura 3-6 - Diagrama carga-deslocamento com carregamento incremental. ............. 81

Figura 3-7 - Determinação da carga crítica na flexão oblíqua. ................................... 82

Figura 3-8 - Discretização da deformada de pilar...................................................... 83 
Figura 3-9 - Transformação de vínculos para obtenção da viga conjugada. 85

Figura 3-10 - Pilar bi rotulado real e pilar conjugado. 86

Figura 3-11 - Pesos elásticos e diagramas do pilar conjugado. 87

Figura 3-12 - Momentos fletores de segunda ordem e novo carregamento. . 87

Figura 3-13 - Ilustração do processo de convergência pela analogia de Mohr. 88

Figura 3-14 - Características de métodos de cálculo de pilares. 89

Figura 4-1 - Entrada de dados da seção transversal de pilar do programa SecTrans. 92

Figura 4-2 - Inserção de armaduras passivas do programa SecTrans. 92

Figura 4-3 - Inserção das propriedades do concreto do programa SecTrans. 93

Figura 4-4 - Diagramas de verificação de estabilidade do pilar do programa SecTrans. 94

Figura 4-5 -Relatório de resultados processados do programa SecTrans. 94

Figura 4-6 - Geometria das seções transversais estudadas (dimensões em cm). 99

Figura 5-1 - Geometria da seção transversal do Exemplo de aplicação. 104

Figura 5-2 - Flexão atuante nas extremidades do lance de pilar. 105

Figura 5-3 - Momentos fletores na base e no topo do pilar. 105

Figura 5-4 - Amplificação do momento inicial com fluência. 110

Figura 5-5 - Relação entre a normal reduzida de Euler $v_{e}$ e a normal reduzida aplicada $v=0,3$ dos Exemplos de Aplicação. 112

Figura 5-6 - Variação da relação $v_{e} / v$ com a esbeltez máxima $\lambda$............................. 113

Figura 5-7 - Valores mínimos da rigidez adimensional $\kappa_{\text {min }}$..................................... 115

Figura 5-8 - Valores mínimos da relação $\kappa_{\text {min }} / f_{\text {cd }}$ para $v=0,4$............................... 116

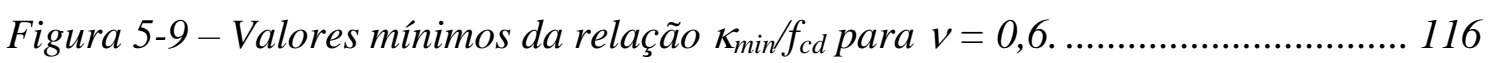

Figura 6-1 - Relação entre momentos totais com e sem fluência................................ 118

Figura 6-2 - Momentos totais relativos com e sem fluência em relação à normal reduzida.

Figura 6-3 - Momentos totais relativos com e sem fluência em relação à taxa de armadura. 125

Figura 6-4 - Momentos totais relativos com e sem fluência relação à taxa de armadura. 126

Figura 6-5 - Amplificação da flexão inicial variando a esbeltez e a normal reduzida. 128

Figura 6-6 - Representação de momentos solicitantes e envoltória resistente.

Figura 6-7 - Variação da direção da flexão com a resistência da seção.

Figura 6-8 - Relação entre os ângulos calculados em relação aos ângulos iniciais de flexão, de acordo com o alongamento da seção transversal. 134 
Figura 6-9 - Representação de gráfico entre momentos totais solicitantes e resistentes. 136

Figura 6-10 - Solicitação relativa pelo Método de Curvatura aproximada. 139

Figura 6-11 - Solicitação relativa pelo Método de Curvatura aproximada

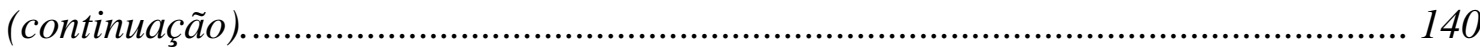

Figura 6-12 - Solicitação relativa pelo Método de Rigidez. ....................................... 142

Figura 6-13 - Solicitação relativa pelo Método de Rigidez segundo a relação b/h.... 142

Figura 6-14 - Solicitação relativa pelo Método Acoplado a diagramas..................... 145

Figura 6-15 - Solicitação relativa pelo Método Acoplado a diagramas (continuação). 146

Figura 6-16 - Solicitação total por Método Aproximado em relação ao Método Geral.

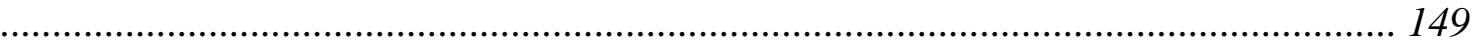

Figura A-1 - Resultados com o Método de Curvatura aproximada ............................ 164

Figura A-2 - Resultados com o Método de Rigidez adimensional.............................. 168

Figura A-3 - Diagrama momento-normal-curvatura para direção x......................... 169

Figura A-4 - Diagrama normal-momento-curvatura para direção y........................ 171

Figura A-5 - Resultados com o Método Acoplado a diagramas. ................................ 173

Figura A-6 - Momentos totais ao longo do pilar pelo método geral........................... 174 



\section{LISTA DE TABELAS}

Tabela 1-1 - Recomendações da ABNT NBR 6118:2014 para dimensionamento de pilares. 32

Tabela 2-1 - Determinação de valores de $\alpha_{b}$ segundo a norma ABNT NBR 6118:2014 55

Tabela 4-1 - Índice de esbeltez e comprimento equivalente de pilares estudados 99

Tabela 4-2 - Arranjos de armadura para as seções transversais estudadas. 100

Tabela 5-1 - Resumo de resultados para momento total do Exemplo 1. 108

Tabela 5-2 - Resumo de resultados para momento total do Exemplo 2. 108

Tabela 5-3 - Resumo de resultados para momento total do Exemplo 3. 109

Tabela 5-4 - Resumo de resultados para momento total do Exemplo 4. 109

Tabela 5-5 - Valores da normal reduzida de Euler para os Exemplos de Aplicação com $v=0,3$.

Tabela 6-1 - Momento resistente para seção transversal com $\mathrm{b} / \mathrm{h}=1$.

Tabela 6-2 - Momento resistente para seção transversal com $\mathrm{b} / \mathrm{h}=3$.

Tabela 6-3 - Momento resistente para seção transversal com $b / h=5$.

Tabela 6-4 - Momento resistente segundo a direção de flexão do Exemplo de Aplicação 3. 133

Tabela 6-5 - Quantidade de casos válidos encontrados em cada região. 148 



\section{SUMÁRIO}

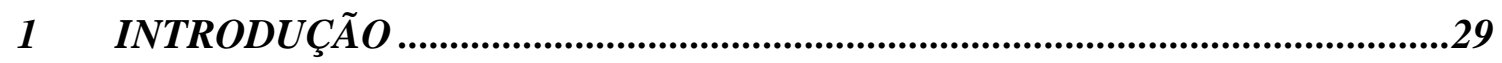

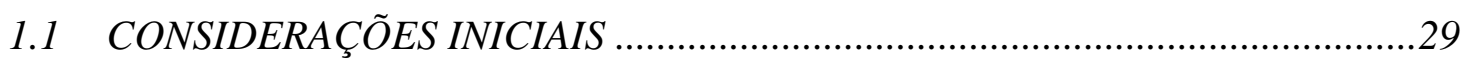

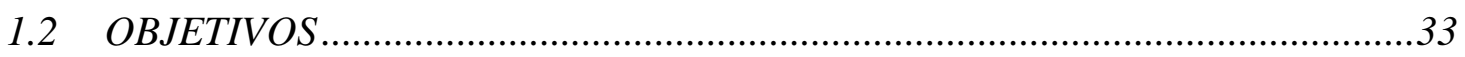

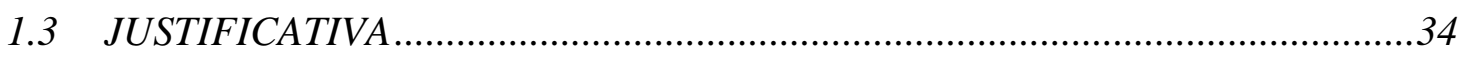

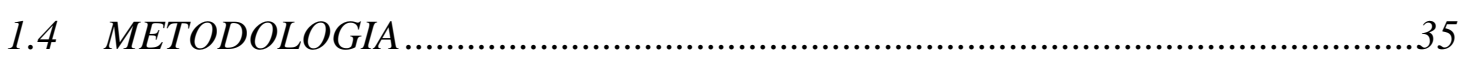

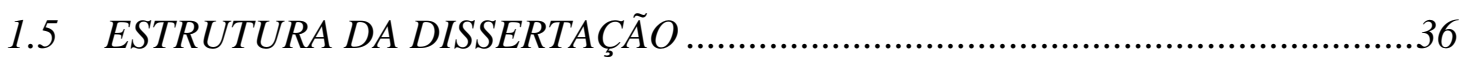

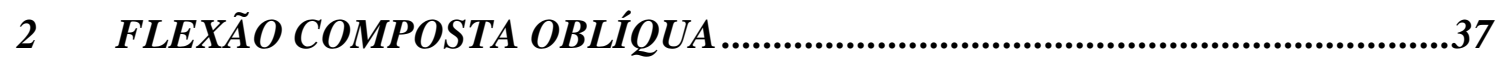

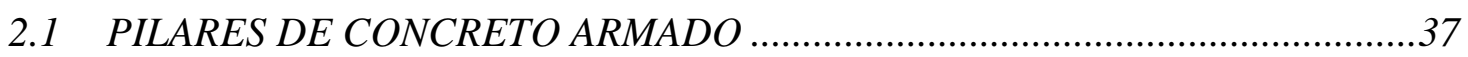

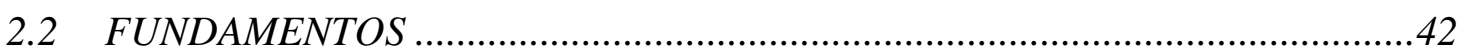

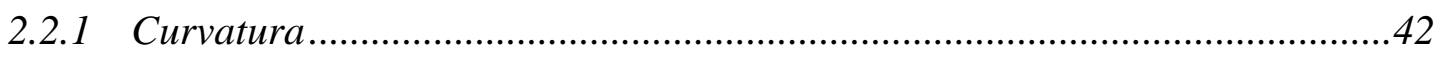

2.2.2 Relação momento fletor-curvatura …………………………………….......4

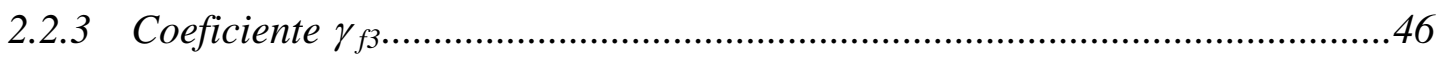

2.3 DIAGRAMA MOMENTO FLETOR-NORMAL-CURVATURA ……………........46

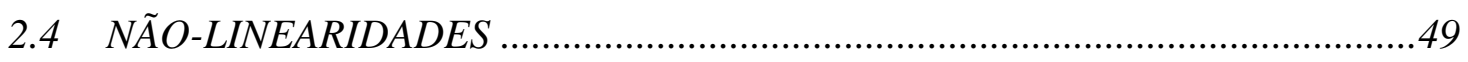

2.4.1 Não-linearidade física $(N L F)$..................................................................49

2.4.2 Não-linearidade geométrica $(N L G)$..........................................................49

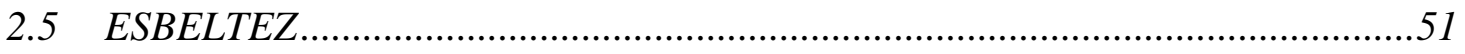

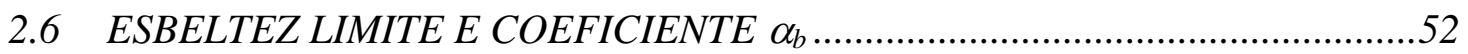

2.7 SOLICITAÇÕES EM PILARES ………………………………………......58

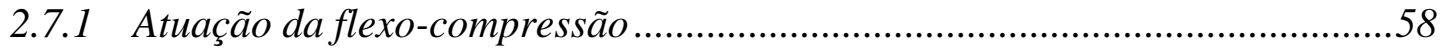

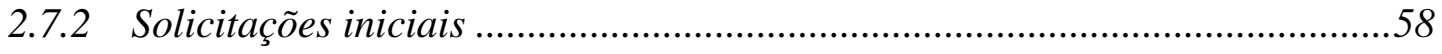

2.7.3 Imperfeições geométricas ...................................................................59

2.7.4 Efeitos locais de segunda ordem............................................................62

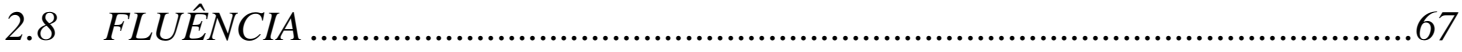

3 EFEITOS DE SEGUNDA ORDEM EM PILARES ……………........................71

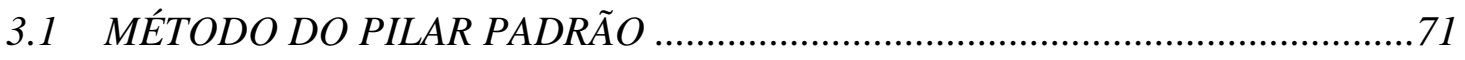

3.2 MÉTODO DO PILAR PADRÃO COM CURVATURA APROXIMADA................74

3.3 MÉTODO DO PILAR PADRÃO COM RIGIDEZ ADIMENSIONAL ..................76

3.4 MÉTODO DO PILAR PADRÃO ACOPLADO A DIAGRAMAS ………………....79

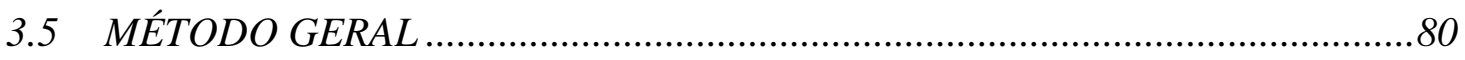

3.5.1 Diferenças finitas ............................................................................... 81

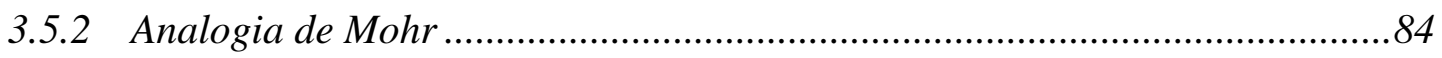




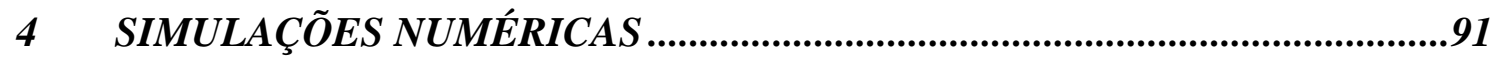

4.1 PROGRAMA SECTRANS ......................................................................... 91

4.2 AUTOMATIZAÇÃO DO PROGRAMA.............................................................95

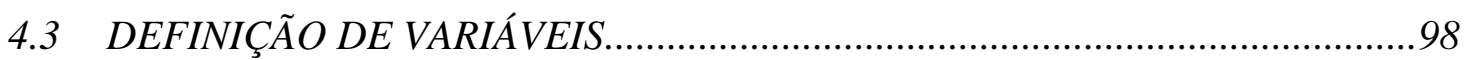

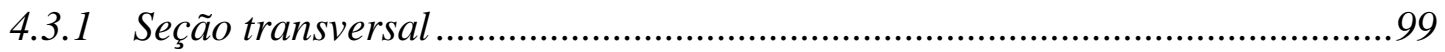

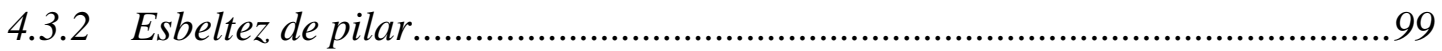

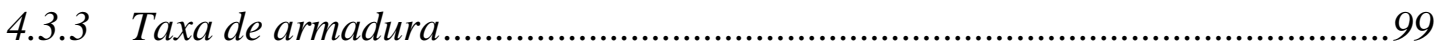

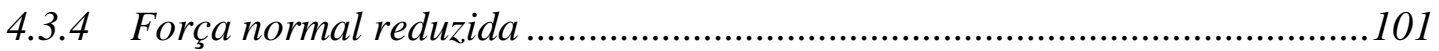

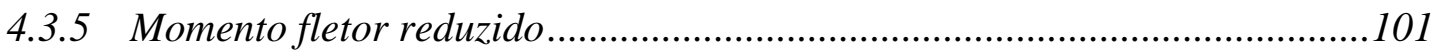

4.3.6 Direção de momento fletor oblíquo ............................................................101

4.3.7 Proporção entre momentos da base e do topo de pilar ................................101

4.3.8 Coeficiente de fluência .................................................................................102

$5 \quad$ EXEMPLOS DE APLICAÇА̃O

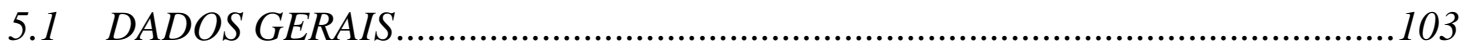

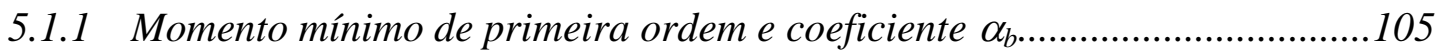

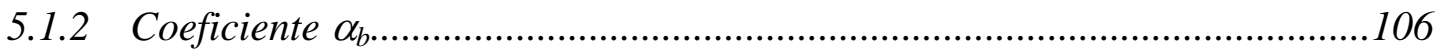

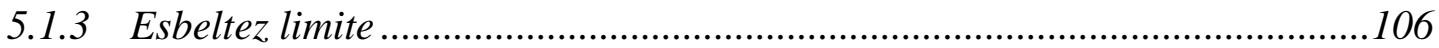

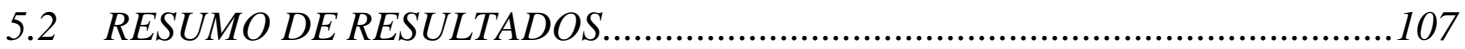

5.3 RIGIDEZ ADIMENSIONAL MÍNIMA .......................................................114

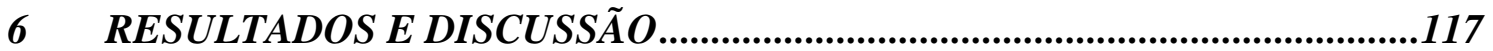

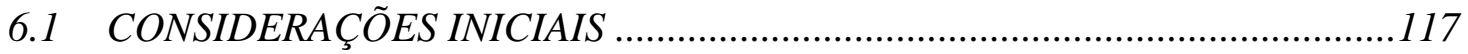

6.2 EFEITO DA FLUÊNCIA SOBRE A SOLICITAÇÃO TOTAL ..........................117

6.3 EFEITO DA FLUENNCIA SOBRE A CAPACIDADE RESISTENTE...................120

6.4 AMPLIFICAÇÃO DA SOLICITAÇÃO ….......................................................127

6.5 RELAÇÃO ENTRE MÉTODOS APROXIMADOS E O MÉTODO GERAL......129

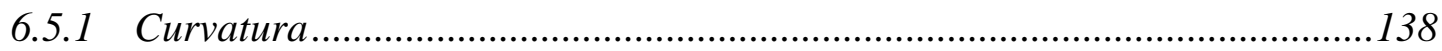

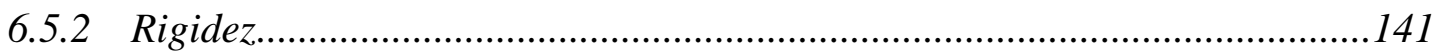

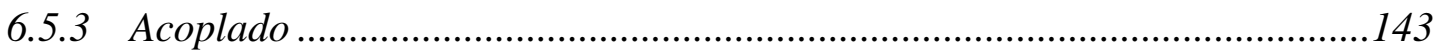

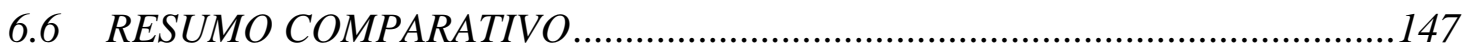

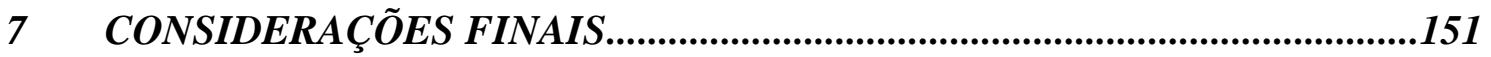

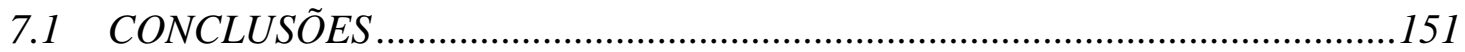

7.2 RECOMENDAÇÕES PARA TRABALHOS FUTUROS...................................154

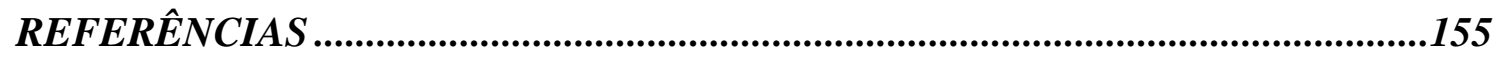




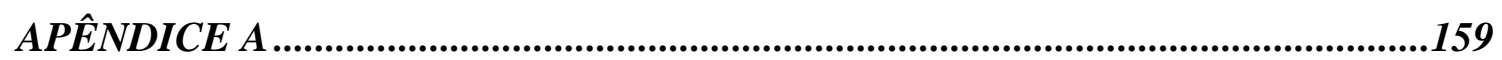

A.1 PILAR PADRÃO COM CURVATURA APROXIMADA ………………….......159

A.1.1 Carga crítica de Euler ..............................................................................160

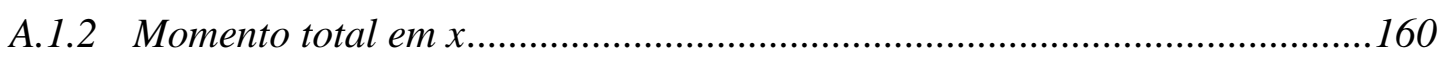

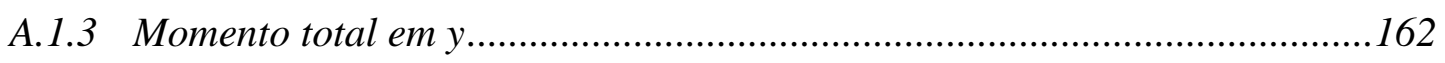

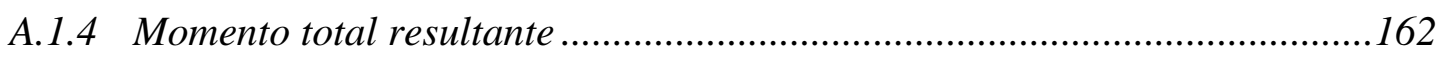

A.1.5 Envoltória de momento mínimo total..........................................................

A.2 PILAR PADRÃO COM RIGIDEZ ADIMENSIONAL_.....................................164

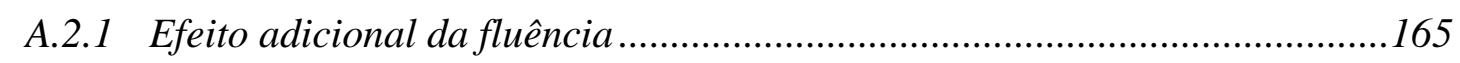

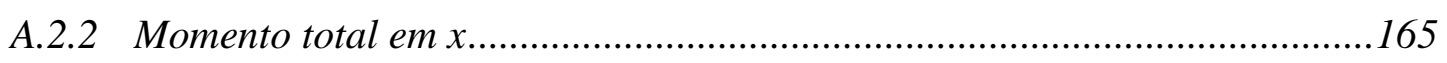

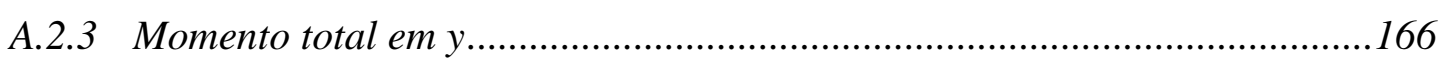

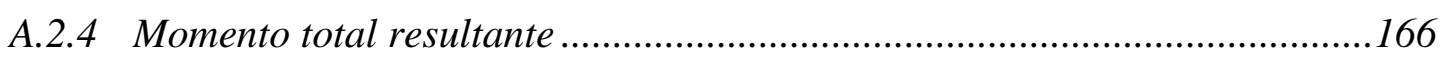

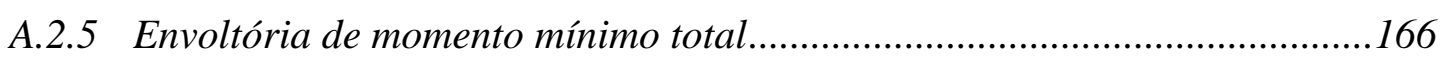

A.3 PILAR PADRÃO ACOPLADO A DIAGRAMAS …………………………........

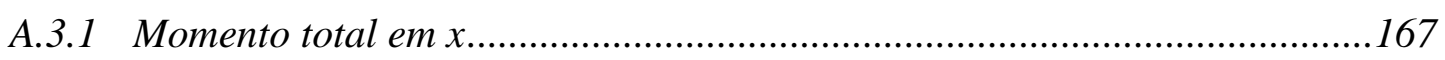

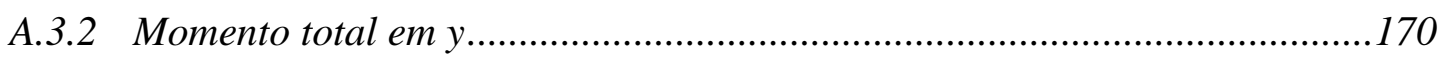

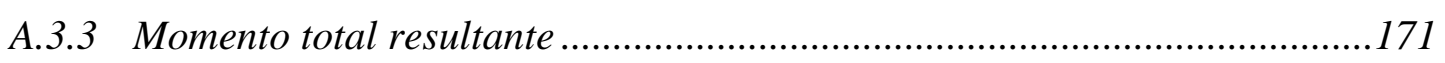

A.3.4 Envoltória de momento mínimo total.........................................................172

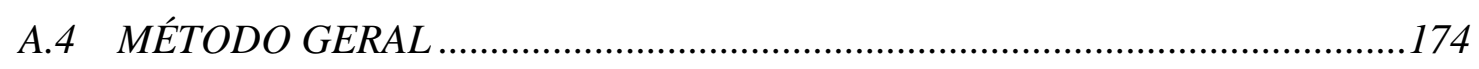

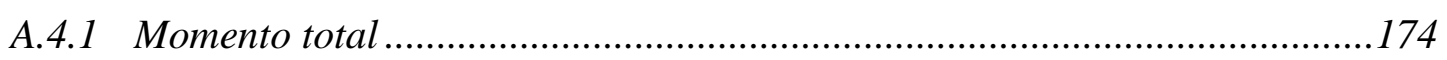

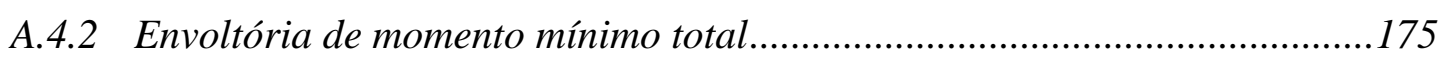





\section{INTRODUÇÃO}

\subsection{CONSIDERAÇÕES INICIAIS}

Neste Capítulo é apresentada a importância do estudo do comportamento de pilares de concreto armado submetidos à flexão composta oblíqua na área de projetos estruturais, uma vez que este comportamento é de alta complexidade. Em seguida, são apresentados os objetivos, a justificativa e a metodologia utilizada para a realização da presente pesquisa.

Os pilares são elementos estruturais de eixo reto, disposto na vertical, onde a força normal de compressão é predominante. Sua função principal é basicamente resistir às solicitações provenientes da aplicação das ações verticais e horizontais na estrutura e transmiti-las aos elementos de fundação.

Pilares geralmente estão submetidos à flexão composta oblíqua, ou seja, são solicitados por momentos fletores nas duas direções principais de inércia e por força normal, predominantemente de compressão. Uma das principais dificuldades para o dimensionamento de pilares em comparação com outros elementos que usualmente compõem uma estrutura de concreto armado (lajes e vigas) é a dificuldade em identificar qual é o esforço crítico que atua neste elemento e em qual seção este atua.

Outro aspecto que torna o dimensionamento de pilares complexo é a consideração dos efeitos de segunda ordem em razão da não-linearidade física e geométrica, seja ela avaliada de modo aproximado ou refinado.

A análise da estabilidade de pilares em concreto armado de forma aproximada com uso de tabelas e ábacos apresenta resultados pouco precisos e mais conservadores, podendo conduzir a estruturas mais robustas e com maior consumo de material em relação à necessidade segurança estrutural. Por outro lado, existem processos de cálculo mais rigorosos que pretensamente aproximam os resultados da situação mais realista e podem otimizar o processo de 
dimensionamento ao custo de maior tempo consumido pelo grande número de operações e processos iterativos, os quais são possíveis apenas com auxílio computacional.

A Figura 1-1 apresenta um edifício construído no município de Porto Alegre, no Brasil, para abrigar a Regional do Banco do Brasil a qual possui pilares excessivamente esbeltos nas fachadas. Neste caso, a análise sofisticada é indispensável.

Os Engenheiros Estruturais tentam evitar, quando possível, estruturas com pilares muito esbeltos, pois nesse caso o Estado Limite Último é decorrente da instabilidade, isto é, à falta de equilíbrio da posição deformada da barra antes da ocorrência da ruína tradicional por ruptura do concreto à compressão ou por alongamento excessivo da armadura.

\section{Figura 1-1 - Edifício com pilares esbeltos em concreto armado.}

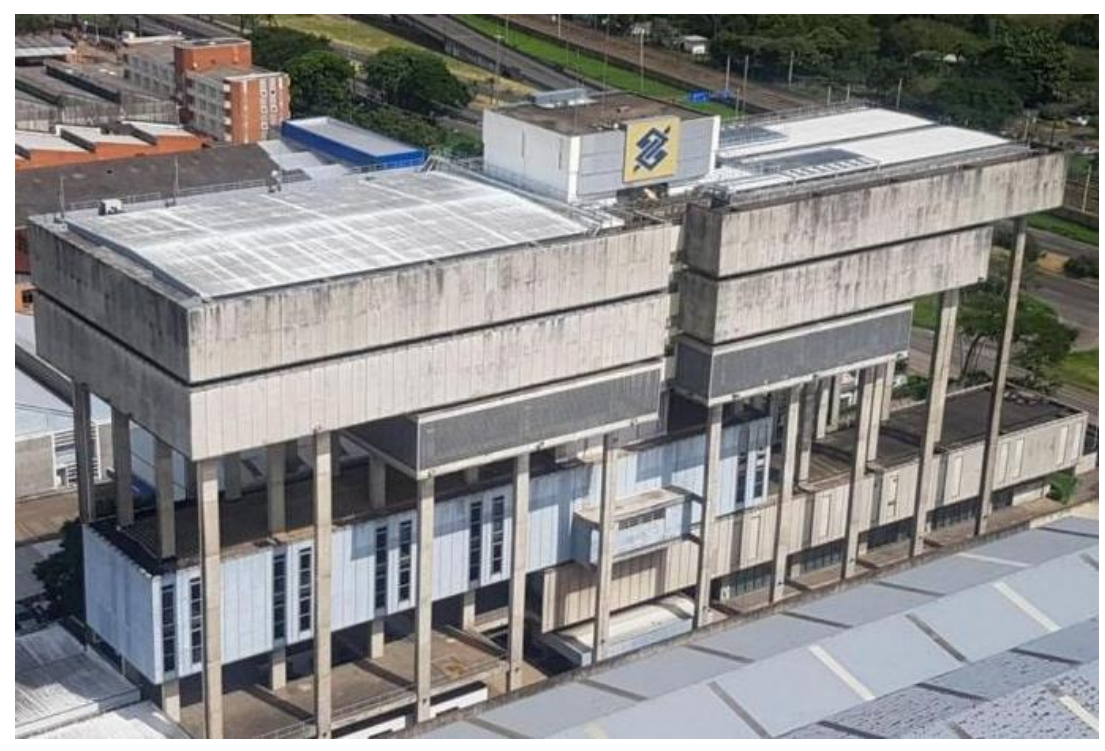

Fonte: FRACALOSSI (2013)

O concreto armado é um material que possui, em si próprio, comportamento essencialmente não linear em regime de serviço e, especialmente, em regime de ruptura. Basicamente, existem dois fatores principais que geram o comportamento não linear de uma estrutura de concreto armado à medida que o carregamento é aplicado (FUSCO, 1981):

a) Alteração das propriedades dos materiais que compõem a estrutura, designada por não-linearidade física (NLF): As tensões não são proporcionais às deformações em razão das características físicas do material; o concreto, por exemplo, não é um material homogêneo e sofre o fenômeno da fissuração e da fluência; 
b) Alteração da geometria da estrutura, designada por não-linearidade geométrica (NLG): Os esforços e, consequentemente, as tensões e as deformações são afetadas pelo estado de deslocamento da estrutura; não há uma relação linear entre essas grandezas, tal como ocorre em barras dúcteis sujeitas à flambagem.

A Figura 1-2 ilustra a resposta de deslocamento da estrutura que não é diretamente proporcional à intensidade de aplicação do carregamento externo em virtude dos dois fatores citados.

Figura 1-2 - Ilustração de não linearidade de uma estrutura de concreto.

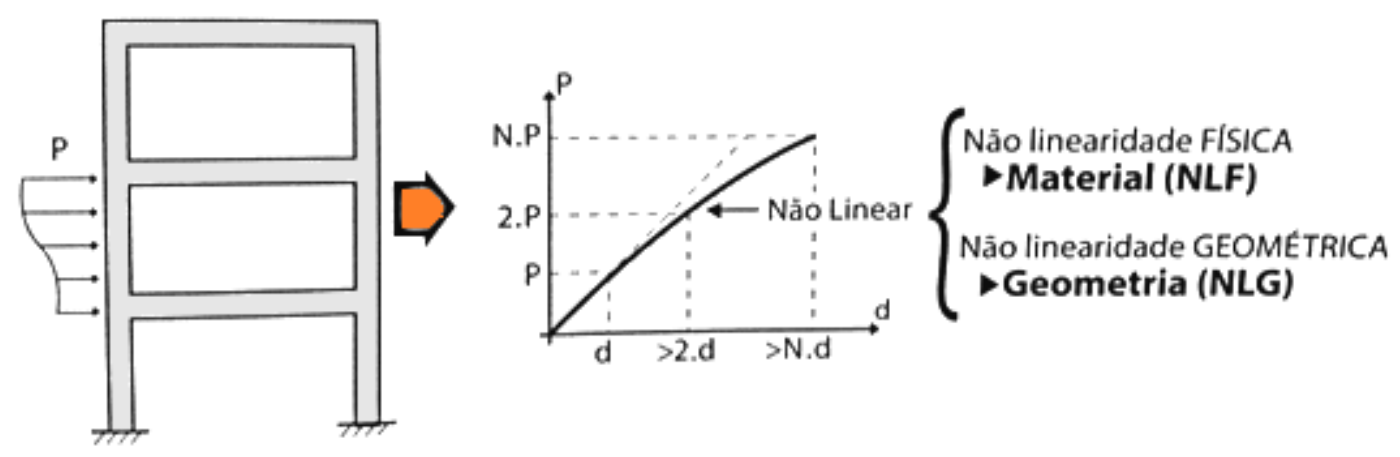

Fonte: Adaptado de KIMURA (2018)

No dimensionamento de um lance de pilar são chamados efeitos de primeira ordem aqueles cuja análise é realizada considerando o equilíbrio da estrutura com um determinado nível de solicitações em sua configuração geométrica inicial não deformada. Quando a análise do equilíbrio é efetuada considerando a configuração deformada desse lance, os esforços adicionais de flexão são identificados como efeitos de segunda ordem local e são somados àqueles obtidos com a análise de primeira ordem local.

Para pilares esbeltos, os efeitos de segunda ordem local são de grande importância e sua análise é indispensável. Neste caso, é necessária análise rigorosa da não linearidade física (decorrente do comportamento do material) e geométrica (decorrente dos deslocamentos adicionais) do elemento em estudo.

Nas situações em que os efeitos de segunda ordem local não podem ser desprezados, o item 15.8.3 da norma ABNT NBR 6118:2014 permite a análise daqueles efeitos utilizando métodos aproximados e o método geral, com a consideração ou não da fluência. 
Esta norma permite utilizar quatro métodos diferentes para a análise dos efeitos locais de segunda ordem para o dimensionamento de pilares conforme a esbeltez do lance de pilar:

a) Método do pilar padrão com curvatura aproximada;

b) Método do pilar padrão com rigidez $\kappa(k a p a)$ aproximada;

c) Método do pilar padrão acoplado a diagramas momento fletor-força normalcurvatura;

d) Método geral.

A Tabela 1-1 resume as recomendações da norma ABNT NBR 6118:2014 quanto a desprezar ou não os efeitos de segunda ordem local e o efeito de fluência para o dimensionamento de pilares segundo o índice de esbeltez $\lambda$.

Tabela 1-1 - Recomendações da ABNT NBR 6118:2014 para dimensionamento de pilares.

Métodos de cálculo para efeitos de segunda ordem

\begin{tabular}{|c|c|c|c|c|c|c|}
\hline \multirow{2}{*}{ Esbeltez } & \multirow{2}{*}{$\begin{array}{l}\text { Desprezar } \\
\text { efeitos locais } \\
\text { de segunda } \\
\text { ordem }\end{array}$} & \multirow{2}{*}{$\begin{array}{l}\text { Desprezar } \\
\text { efeito de } \\
\text { fluência }\end{array}$} & \multicolumn{3}{|c|}{ Métodos aproximados } & \multirow[b]{2}{*}{$\begin{array}{l}\text { Método ge- } \\
\text { ral }\end{array}$} \\
\hline & & & $\begin{array}{l}\text { Pilar padrão } \\
\text { com curvatura } \\
\text { aproximada }\end{array}$ & $\begin{array}{c}\text { Pilar padrão } \\
\text { com rigidez } \\
\text { adimensional }\end{array}$ & $\begin{array}{c}\text { Pilar padrão } \\
\text { acoplado a } \\
\text { diagramas N, } \\
\mathrm{M}, 1 / \mathrm{r}\end{array}$ & \\
\hline $\begin{array}{c}\lambda \leq \lambda_{1} \\
\text { (pouco esbelto) }\end{array}$ & Permitido & Permitido & Permitido & Permitido & Permitido & Permitido \\
\hline $\begin{array}{l}0<\lambda \leq 90 \text { (media- } \\
\text { namente esbelto) }\end{array}$ & $\begin{array}{l}\text { Não permiti- } \\
\text { do }\end{array}$ & Permitido & Permitido & Permitido & Permitido & Permitido \\
\hline $\begin{array}{c}90<\lambda \leq 140 \text { (esbel- } \\
\text { to) }\end{array}$ & $\begin{array}{l}\text { Não permiti- } \\
\text { do }\end{array}$ & $\begin{array}{l}\text { Não permiti- } \\
\text { do }\end{array}$ & Não permitidoI & Não permitido & Permitido & Permitido \\
\hline $\begin{array}{c}140<\lambda \leq 200 \text { (ex- } \\
\text { cessivamente es- } \\
\text { belto) }\end{array}$ & $\begin{array}{l}\text { Não permiti- } \\
\text { do }\end{array}$ & $\begin{array}{l}\text { Não permiti- } \\
\text { do }\end{array}$ & Não permitido & Não permitido & $\begin{array}{l}\text { Não permiti- } \\
\text { do }\end{array}$ & Permitido \\
\hline
\end{tabular}

Fonte: Adaptado de PIRES (2006).

No caso particular da flexão composta oblíqua de pilar com seção retangular e esbeltez menor ou igual a 90, o item 15.8.3.3.5 da norma ABNT NBR 6118:2014 permite aplicar os métodos aproximados considerando o pilar padrão. Neste item da norma não há nenhuma especificação de método aproximado para pilares com esbeltez maior que 90. É importante 
ressaltar que a consideração da fluência é obrigatória em pilares com índice de esbeltez $\lambda>90$.

A verificação de pilares submetidos à flexão composta oblíqua é realizada por meio da construção de envoltórias mínima e de envoltórias resistente, além da análise das solicitações a que o pilar está submetido. Pela quantidade e complexidade de cálculos numéricos a serem realizados, a resolução por meio do computador é mais viável e pode fornecer valores com precisão e rapidez suficiente. Neste caso, a verificação quanto ao Estado Limite Último é realizada para seções transversais com armadura previamente estabelecida.

O presente trabalho estudou o comportamento de pilares esbeltos de concreto armado submetidos à flexão composta oblíqua. Para a realização do estudo foi utilizado o programa computacional SecTrans desenvolvido exclusivamente para fins acadêmicos pelo Prof. Dr. Vladimir Guilherme Haach. O trabalho tem como público-alvo os Engenheiros de Estruturas, além de alunos de graduação e de pós-graduação.

\subsection{OBJETIVOS}

O objetivo geral do trabalho foi estudar o comportamento de pilares de concreto armado esbeltos (esbeltez entre 90 e 140) de seção retangular submetidos à flexão composta oblíqua em conformidade com os diferentes métodos de análise prescritos na norma ABNT NBR 6118:2014 com variação da seção transversal, do índice de esbeltez, da distribuição de momentos, da taxa de armadura, da força normal reduzida, do momento fletor reduzido e do coeficiente de fluência.

Para atingir o objetivo geral deste estudo foram traçados os seguintes objetivos específicos:

a) Implementar uma rotina de automatização no software SecTrans para permitir a entrada de dados por meio de arquivo de texto com todas as variações de casos de pilares a serem analisados e para obter como resultado um arquivo de saída no formato de planilha eletrônica com os momentos solicitantes e resistentes de todas as simulações;

b) Comparar a relação entre o Momento Fletor Solicitante Total e o Momento Resistente último da seção com os principais métodos para análise de efeitos locais de 
segunda ordem em pilares sujeitos à flexão composta oblíqua e a relação entre Momentos Fletores Solicitantes Totais obtidos pelos métodos aproximados e o método geral (método de referência);

c) Analisar a influência dos parâmetros impostos no comportamento do pilar;

d) Avaliar a aplicabilidade dos métodos aproximados para pilares com índice de esbeltez maior que 90 em comparação com o Método Geral.

\subsection{JUSTIFICATIVA}

A evolução tecnológica dos materiais aliada ao aprimoramento de modelos computacionais cada vez mais complexos possibilitam a utilização de estruturas cada vez mais esbeltas. Com o aumento da esbeltez dos elementos estruturais e dos carregamentos, o deslocamento do eixo do pilar gera esforços adicionais (efeitos locais de segunda ordem), aumentando o risco da ocorrência de instabilidade do pilar ou mesmo do seu colapso.

No dimensionamento de pilares esbeltos é imprescindível a consideração dos momentos decorrentes dos deslocamentos provocados pelos esforços iniciais (efeitos de segunda ordem), como também a análise de seu equilíbrio e capacidade resistente. A análise da estabilidade pode ser efetuada considerando as não linearidades física e geométrica por meio de métodos aproximados ou por processos mais rigorosos como o método geral.

Os métodos aproximados têm como vantagens a sua simplicidade e rapidez conduzindo a dimensionamentos seguros, no entanto muitas vezes são contra a economia. Por outro lado, existem processos de cálculo mais rigorosos que apresentam resultados mais precisos e otimizados, porém sendo viáveis apenas com auxílio computacional.

O item 15.8.3.3.5 da ABNT NBR 6118:2014 permite a utilização dos métodos aproximados de cálculo para pilares submetidos à flexão composta oblíqua com $\lambda \leq 90$, não sendo mencionada a aplicabilidade ou não desses métodos para valores acima desse índice de esbeltez. Em decorrência da omissão da ABNT NBR 6118:2014 e escassez de trabalhos envolvendo pilares com índice de esbeltez maiores 90, este trabalho visa dar continuidade aos estudos de pilares esbeltos submetidos à flexão composta oblíqua e tem como justificativa a necessidade de testar a aplicabilidade de métodos de cálculo existentes com intuito de fornecer subsídios para obtenção de soluções mais rápidas sem comprometer a segurança estrutural. 


\subsection{METODOLOGIA}

A metodologia deste estudo envolveu cinco etapas principais: revisão bibliográfica do tema; automatização do programa SecTrans; resolução de Exemplo de aplicação; simulações numéricas; e análise e discussão de resultados.

Primeiramente foi realizada revisão bibliográfica com objetivo de identificar as principais variáveis para o comportamento de pilares de concreto armado submetidos à flexão composta oblíqua, e para isso, foram estudados os principais métodos para análise dos efeitos locais de segunda ordem e identificadas as principais variáveis que influenciam o resultado. Além disso, foram coletados estudos já realizados neste âmbito para enquadrar o presente trabalho dentro do contexto científico atual.

Visando facilitar o processo de análise, a segunda etapa consistiu em adequação pela autora do programa SecTrans de forma a automatizar a entrada de dados e a saída de resultado. Este programa foi desenvolvido no Departamento de Engenharia de Estruturas da EESCUSP pelo Prof. Dr. Vladimir Guilherme Haach.

Esta adequação se deve ao fato da necessidade de analisar inúmeras variáveis e, portanto, foi inviável simular um conjunto de dados por vez. A ideia foi criar uma base de dados de entrada de todas as variações desejadas para uma determinada seção transversal e realizar o processamento de dados de modo automático. Para a análise dos resultados foram obtidos os vetores resultantes solicitantes e resistentes críticos e o ângulo destes vetores em relação ao eixo cartesiano para cada um dos métodos de cálculo.

Após a definição de todos os modelos a serem analisados, a terceira etapa consistiu na realização de processamento no programa SecTrans comparando os resultados utilizando os três métodos aproximados descritos na ABNT NBR 6118:2014 e o método geral. Para a discussão qualificada dos resultados, foi julgado pertinente apresentar o detalhamento de Exemplos de aplicação registrando as principais passagens numéricas envolvidas nessa análise, o qual está indicado no Apêndice A.

Para a análise dos resultados, foram realizados gráficos comparando os momentos solicitantes totais obtidos com cada um dos Métodos aproximados em comparação ao método de referência, no caso o Método Geral. Foi feito um gráfico para cada variável discutida no texto, de forma a observar o seu comportamento no pilar. Também foram comparados os momentos solicitantes com e sem a consideração da fluência, com o intuito de avaliar a sua importância. 
Com base nas análises deste item, foram elaboradas as conclusões possíveis e pertinentes ao assunto em questão.

\subsection{ESTRUTURA DA DISSERTAÇÃO}

O corpo da dissertação foi organizado em sete capítulos. No Capítulo 1 é realizada a apresentação do trabalho, com a introdução sobre o tema a ser estudado, abordando os objetivos, a justificativa da pesquisa e a metodologia empregada na construção do trabalho.

O Capítulo 2 aborda aspectos teóricos encontrados na literatura sobre o comportamento de pilares de forma a apresentar uma revisão bibliográfica dos fatores envolvidos no processo de cálculo de um lance de pilar, como diagrama momento-normal-curvatura, índice de esbeltez, esbeltez limite e efeitos locais.

O Capítulo 3 descreve os métodos de cálculo para análise dos efeitos locais de segunda ordem presentes na ABNT NBR 6118:2014, sendo eles: Método de Curvatura aproximada, Método de Rigidez aproximada, Método Acoplado a diagramas e Método Geral.

O Capítulo 4 apresenta de maneira geral o funcionamento do programa SecTrans e posteriormente as etapas do processo de automatização implementadas no programa. Neste capítulo também é definido as variáveis utilizadas nas simulações numéricas.

No Capítulo 5 são apresentados quatro exemplos de aplicação como forma de ilustrar o desenvolvimento das etapas deste estudo, variando entre eles o índice de esbeltez. É apresentado o detalhamento do roteiro utilizado para analisar um dentre todos casos processados no Apêndice A.

O Capítulo 6 traz os resultados obtidos e suas discussões. São apresentados e analisados gráficos dos Métodos aproximados de cálculo em comparação ao Método Geral. É analisada também a influência das variáveis discutidas ao longo do texto.

Por fim, no Capítulo 7 são expostas as conclusões obtidas ao longo do trabalho, de acordo com as análises dos resultados, além de apresentar sugestões para trabalhos futuros. 


\section{FLEXÃO COMPOSTA OBLÍQUA}

\subsection{PILARES DE CONCRETO ARMADO}

A solicitação envolvendo aplicação de força normal geralmente de compressão e excêntrica agindo fora dos eixos principais de inércia da seção transversal é denominada de Flexão Composta Oblíqua. O momento fletor causado pela excentricidade da força normal em pilares de edifícios pode ser decomposto em duas direções perpendiculares e coincidentes com os eixos de simetria da seção, conforme ilustra a Figura 2-1. Nesta Figura, é indicada a decomposição da flexão oblíqua em duas parcelas de flexão nas direções principais de inércia, mas a Linha Neutra não é perpendicular ao plano de atuação do momento resultante.

Como a Linha Neutra não é perpendicular ao plano de ação do momento fletor, a profundidade $x_{l n}$ e o ângulo de orientação da linha neutra $\alpha$ são incógnitas do problema. A Figura 2-2 ilustra as deformações e as tensões em uma seção de concreto armado submetida à flexão composta oblíqua.

Com a notação da Figura 2-2, para certa seção qualquer de concreto armado submetida a uma força normal de compressão $N_{d}$ e momentos fletores $M_{x d}$ e $M_{y d}$, é possível escrever as seguintes equações de equilíbrio da seção transversal com as Eq. (2-1) até (2-3):

$$
\begin{gathered}
N_{d}=F_{d}=\iint_{A_{c c}} \sigma_{c d} \cdot d x \cdot d y+\sum_{i=1}^{n} A_{s i} \cdot \sigma_{s i d} \\
M_{x d}=F_{d} \cdot e_{x}=\iint_{A_{c c}} \sigma_{c d} \cdot x \cdot d x \cdot d y+\sum_{i=1}^{n} A_{s i} \cdot \sigma_{s i d} \cdot x_{s i} \\
M_{y d}=F_{d} \cdot e_{y}=\iint_{A_{c c}} \sigma_{c d} \cdot y \cdot d x \cdot d y+\sum_{i=1}^{n} A_{s i} \cdot \sigma_{s i d} \cdot y
\end{gathered}
$$

onde: $A_{c c}$ é a área líquida de concreto da seção resistindo às tensões de compressão;

$A_{s i}$ é a área de aço de uma barra de aço genérica i; 
$\sigma_{c d}$ é a tensão normal de compressão em ponto genérico de coordenadas x e y;

$\sigma_{\text {sid }}$ é a tensão no aço em uma barra genérica $\mathrm{i}$;

$n$ é número de barras de aço da armadura.

Figura 2-1 - Solicitações de pilar submetido à flexão composta oblíqua.

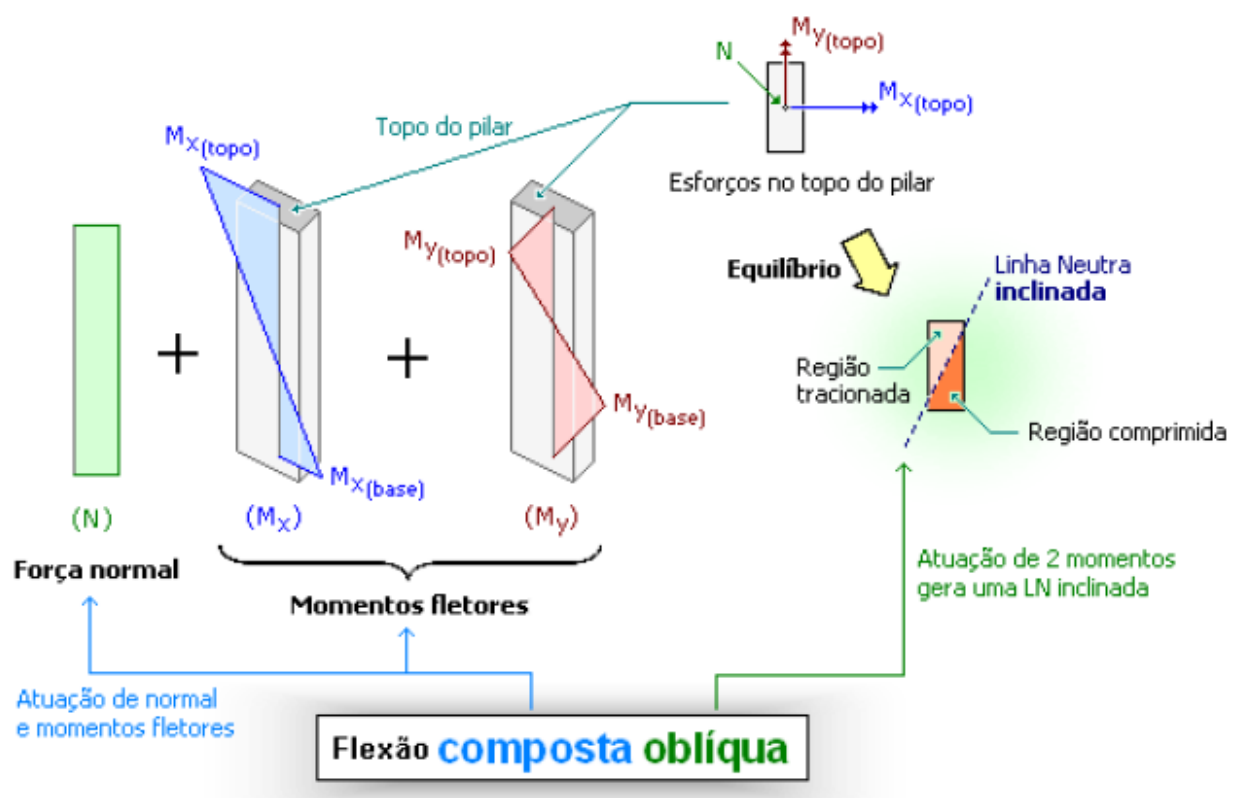

Fonte: KIMURA (2019).

Figura 2-2 - Seção de concreto armado submetida à flexão composta oblíqua.

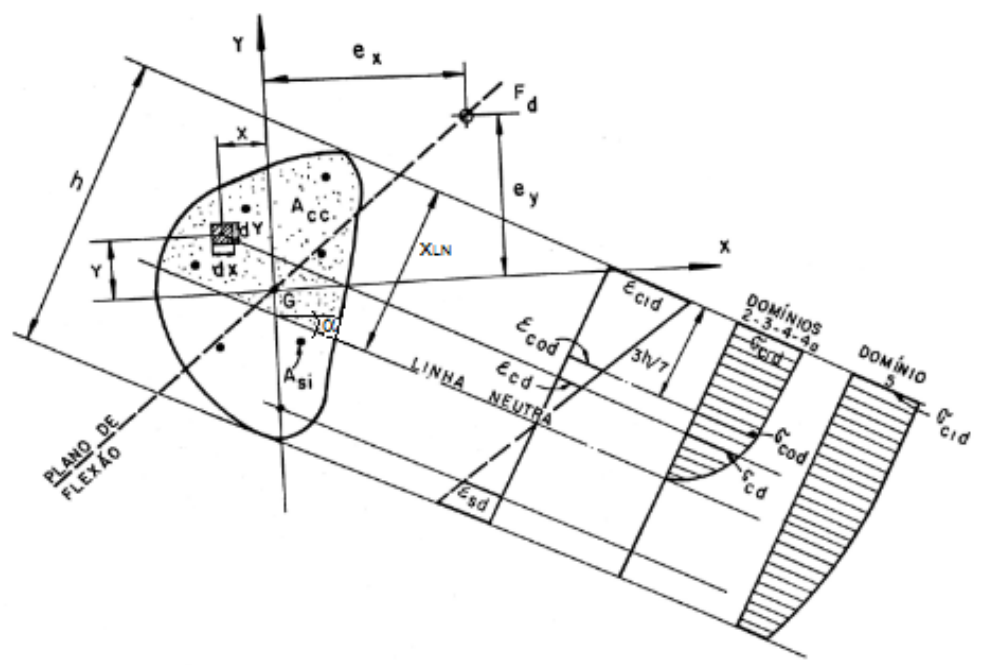

Fonte: FUSCO (1981) 
Segundo o item 17.2.2 da norma ABNT NBR 6118:2014, a resistência última de uma seção de concreto armado submetida a solicitações normais deve ser calculada admitindo-se as seguintes hipóteses básicas:

a) As seções transversais permanecem planas após a deformação e até o estado limite último. As deformações são proporcionais à distância até a Linha Neutra da seção em cada ponto;

b) É admitida aderência perfeita entre o concreto e a armadura. Dessa forma, a deformação nas barras é a mesma nas fibras de concreto que estão imediatamente no seu entorno;

c) As tensões de tração no concreto, normais à seção transversal, devem ser desprezadas no ELU e somente o aço resiste a essas tensões;

d) A distribuição de tensões no concreto segue o modelo do diagrama parábolaretângulo proposto no item 8.2.10.1 da norma ABNT NBR 6118:2014.

Admitindo a hipótese de seções planas, resulta a distribuição plana linear de deformações normais ao longo da seção transversal, como é ilustrado na Figura 2-2.

Para a resolução das equações de equilíbrio é necessário conhecer dois parâmetros: a profundidade da linha neutra $x_{L N}$ e o ângulo de inclinação da linha neutra $\alpha$. Neste caso, podem ser adotados valores para essas duas incógnitas e verificar se as Eqs. (2-1) até (2-3) são satisfeitas. Caso contrário, adotam-se outros valores, até que o equilíbrio entre os esforços solicitantes e resistentes seja satisfeito. Tem-se, portanto, um problema de solução iterativa.

Sendo conhecidas as deformações últimas dos materiais concreto e aço e escolhida a inclinação $\alpha$ da linha neutra e fixada a profundidade da zona comprimida podem ser calculadas todas as tensões para no concreto. No caso deste estudo com $\mathrm{f}_{\text {ck }}<50 \mathrm{MPa}$ foram fixados o valor de $\varepsilon_{s d}=10 \%$ no domínio 2 , o valor de $\varepsilon_{c l d}=3,5 \%$ nos domínios 3 e 4 e o valor de $\varepsilon_{c 0 d}=2 \%$ no domínio 5. Estes limites são diferentes para concretos mais resistentes, mas conceitualmente equivalentes. As Equações de equilíbrio (2-1) até (2-3) fornecem os valores dos esforços solicitantes correspondentes $N_{d}, M_{x d}$ e $M_{y d}$.

Variando a profundidade $x_{L N}$ da zona comprimida e, para cada profundidade, variando a inclinação $\alpha$ da linha neutra, são obtidos todos os possíveis ternos de valores $N_{d}, M_{x d}$ e $M_{y d}$ que conduzem uma dada seção ao Estado Limite Último (ELU) de ruptura por compressão do concreto ou de alongamento excessivo do aço. 
Esses ternos de valores podem ser representados por meio de superfícies de iteração ou por meio de diagramas de interação. A Figura 2-3 ilustra os traços da superfície de interação com os planos cartesianos formados pelo terno de esforços. Estes traços são rebatidos em planos cartesianos e identificados por diagramas de interação.

Figura 2-3 - Superfície de interação.

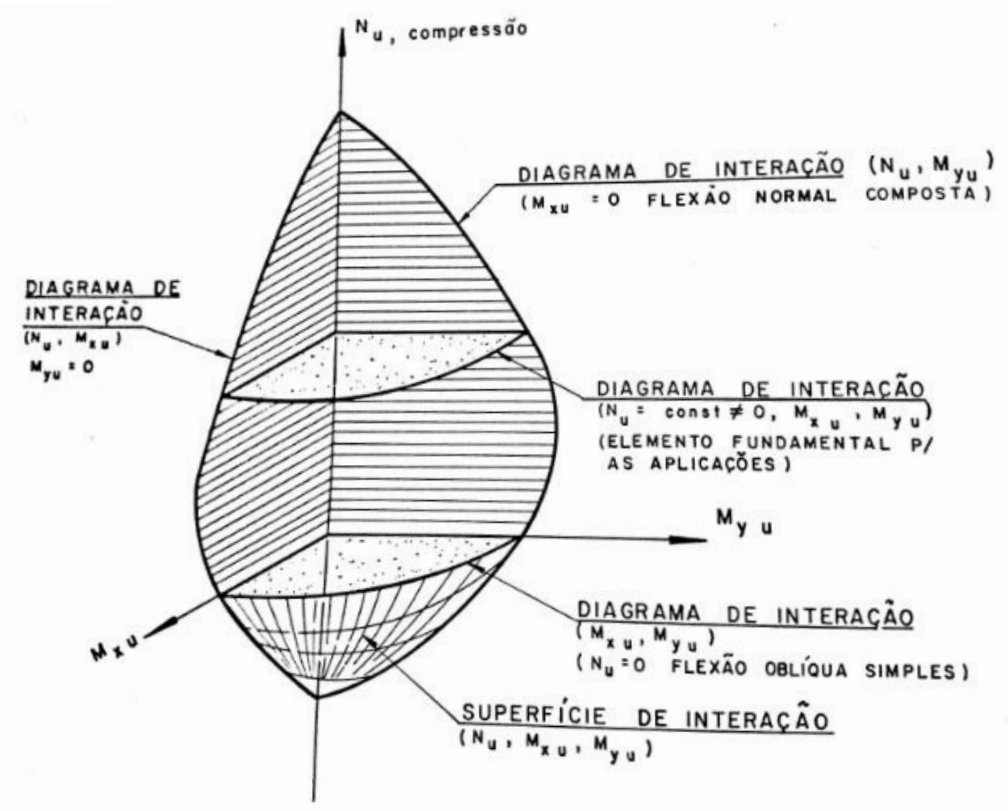

Fonte: (FUSCO, 1981)

Com os diagramas de interação é possível obter esforços solicitantes reduzidos segundo as Eqs. (2-4) até (2-6) para uma determinada taxa geométrica $\rho$ ou mecânica $\omega$ de armadura.

$$
\begin{gathered}
v_{d}=\frac{N_{d}}{A_{c} \cdot f_{c d}} \\
\mu_{x d}=\frac{M_{x d}}{A_{c} \cdot h_{y} \cdot f_{c d}}=v_{d} \cdot \frac{e_{y}}{h_{y}} \\
\mu_{y d}=\frac{M_{y d}}{A_{c} \cdot h_{x} \cdot f_{c d}}=v_{d} \cdot \frac{e_{x}}{h_{x}} \\
\omega=\frac{A_{s}}{A_{c}} \cdot \frac{f_{y d}}{f_{c d}}
\end{gathered}
$$


sendo $A_{c}=h_{x} \cdot h_{y}$ a área bruta da seção retangular de concreto; $h_{x}$ e $h_{y}$ as dimensões da seção transversal; $e_{x}$ e $e_{y}$ as excentricidades da Força Normal paralelas aos eixos coordenados e $A_{s}$ a área total de barras de armadura longitudinal, de acordo com o arranjo escolhido.

As curvas de interação dependem de fatores como geometria da seção, características mecânicas do aço e do concreto, além do arranjo da armadura. A construção computacional destas curvas pode apresentar alto grau de precisão. No entanto, existem propostas de aproximações da curva $N, M_{x}, M_{y}$, tal como do item 17.2.5.2 da norma ABNT NBR 6118:2014, a qual fornece uma expressão aproximada de interação expressa por:

$$
\left(\frac{M_{R d, x}}{M_{R d, x x}}\right)^{\alpha}+\left(\frac{M_{R d, y}}{M_{R d, y y}}\right)^{\alpha}=1
$$

sendo $M_{R d, x}$ e $M_{R d, y}$ as componentes do momento resistente de cálculo em flexão composta oblíqua e $M_{R d, x x}$ e $M_{R d, y y}$ os momentos de cálculo em flexão composta normal para cada direção particular.

Em geral e a favor da segurança, o valor do expoente $\alpha$ é tomado como sendo igual a 1,0. No caso de seções retangulares, pode ser adotado $\alpha=1,2$. Essa relação representada pela Eq. (2-7) é exemplificada na Figura 2-4.

Figura 2-4 - Exemplo de uma curva aproximada de interação.

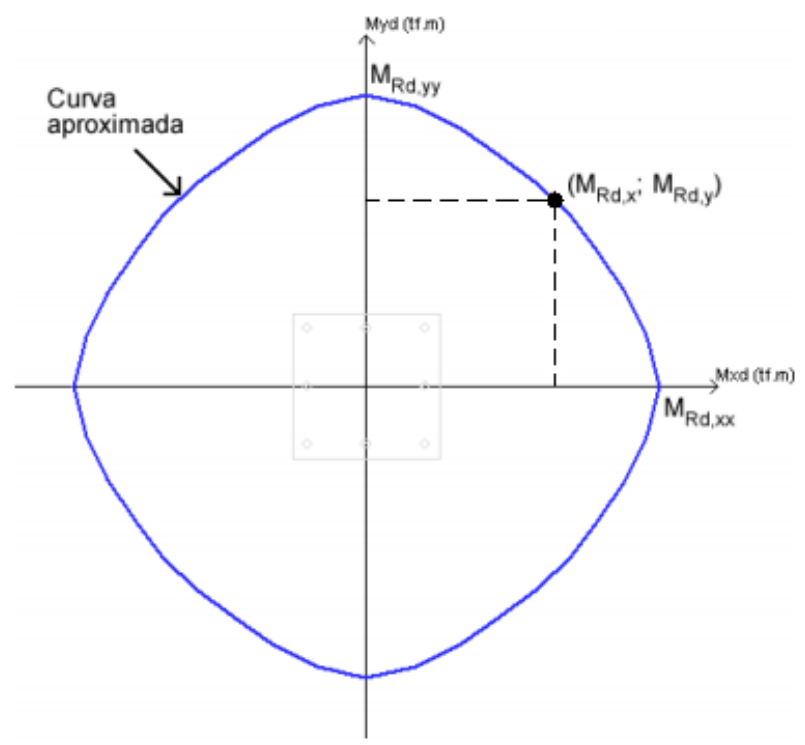

Fonte: KIMURA (2019). 


\subsection{FUNDAMENTOS}

A análise do comportamento de um pilar isolado de concreto armado requer o domínio de conceitos importantes: curvatura e relação momento-curvatura dentre outros, os quais são apresentados a seguir.

\subsubsection{Curvatura}

Curvatura é a variação do ângulo de rotação ao longo de um trecho $d \theta / d s$, sendo mais comum definir como o inverso do raio de curvatura $1 / r$. Na prática e como os valores numéricos reais são pequenos, é usual expressar em unidades de $\mathrm{km}^{-1} \mathrm{em} \% \mathrm{~m}^{-1}$.

Uma barra sujeita à flexão simples ou composta sofre deformação em decorrência da aplicação de momentos até atingir equilíbrio e sua configuração deformada é denominada linha elástica. Para um material de comportamento linear que obedeça a Lei de Hooke, a curvatura do eixo da barra na posição deformada é expressa pela equação diferencial completa da linha elástica:

$$
\frac{1}{r}=\frac{\frac{d^{2} y}{d x^{2}}}{\left[1+\left(\frac{d y}{d x}\right)^{2}\right]^{3 / 2}}= \pm \frac{M}{E I}
$$

onde $\frac{1}{r}$ é a curvatura da barra e $E I$ é a rigidez correspondente ao plano de flexão.

Como o momento fletor $M$ é variável ao longo da barra, a linha elástica apresenta curvatura variável para cada coordenada longitudinal $x$. Para pequenas deformações, a Eq. (2-8) pode ser simplificada para:

$$
\frac{1}{r}=\frac{d^{2} y}{d x^{2}}= \pm \frac{M}{E I}
$$

A dedução da equação da linha elástica e respectiva curvatura de uma barra submetida à flexão simples considerando a deformação de duas seções transversais infinitamente próximas entre si pode ser realizada segundo a notação da Figura 2-5 (FUSCO, 1981) a partir dos $\operatorname{arcos} \widehat{A B}$ e $\widehat{C D}$ que representam as variações de comprimento das fibras de extremidade da seção transversal: 


$$
\begin{gathered}
A B=r \cdot d \varphi=d s \\
C D=(r+y) \cdot d \varphi=r \cdot d \varphi+y \cdot d \varphi=d s+y \cdot d \varphi
\end{gathered}
$$

Figura 2-5 - Curvatura na flexão simples.

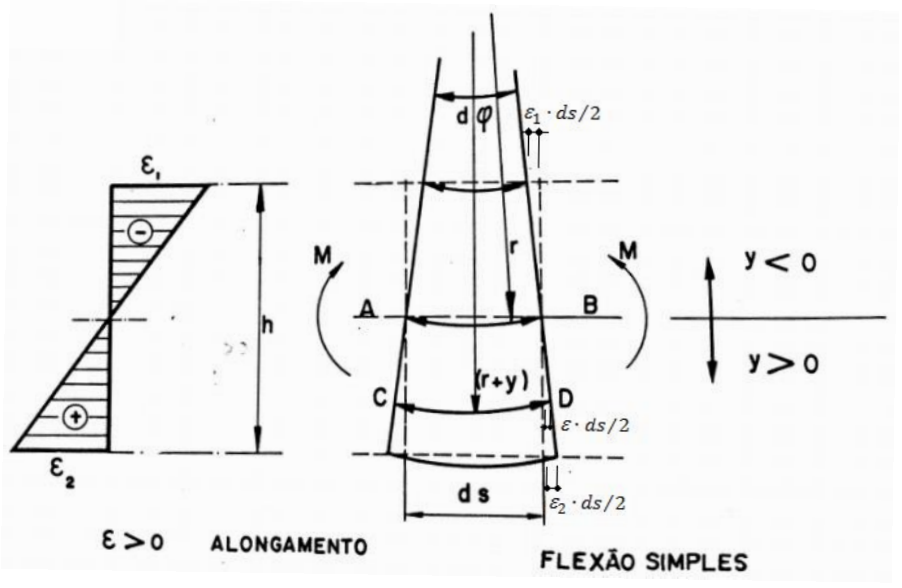

Fonte: (FUSCO, 1981).

Relacionando o alongamento da fibra $\widehat{C D}$, resulta:

$$
\begin{gathered}
\widehat{C D}=(1+) \cdot d s \\
y \cdot d \varphi=\varepsilon \cdot d s \\
\frac{1}{r}=\frac{d \varphi}{d s}=\frac{\varepsilon}{y}
\end{gathered}
$$

Aplicando a expressão acima às fibras extremas, é obtida a curvatura:

$$
\frac{1}{r}=\frac{\varepsilon_{2}}{y_{2}}=\frac{\varepsilon_{1}}{y_{1}}>0
$$

sendo: $\varepsilon_{2}>0$ e $y_{2}>0 ; \varepsilon_{1}<0$ e $y_{1}<0$.

Desse modo, resulta:

$$
\frac{1}{r}=\frac{\varepsilon_{1}-\varepsilon_{2}}{y_{1}-y_{2}}=\frac{\left|\varepsilon_{1}\right|+\varepsilon_{2}}{\left|y_{1}\right|+y_{2}}=\frac{\left|\varepsilon_{1}\right|+\varepsilon_{2}}{h}
$$


No caso de uma viga de concreto armado, com deformações extremas $\varepsilon_{c}$ no concreto comprimido e $\varepsilon_{s}$ na armadura de tração, geralmente são substituídas a deformação e a posição da região tracionada por $\varepsilon_{l}=\varepsilon_{s}$ e $h \approx d$, podendo ser obtido:

$$
\frac{1}{r}=\frac{\varepsilon_{c}+\varepsilon_{s}}{d}
$$

onde $\varepsilon_{c}$ e $\varepsilon_{s}$ são considerados em valor absoluto e $d$ é a altura útil da seção transversal.

Admitindo linearidade física do material, é determinada a deformação em função da tensão e a tensão em função da ordenada y de cada fibra:

$$
\begin{gathered}
\varepsilon=\frac{\sigma}{E} \\
\sigma=\frac{M}{I} y
\end{gathered}
$$

Substituindo a Eq. (2-12) na Eq. (2-13), é obtida a equação diferencial da linha elástica para barras submetidas à flexão simples:

$$
\frac{1}{r}=\frac{\varepsilon}{y}=\frac{M}{E I}
$$

É possível notar que há relação entre a curvatura, o momento fletor interno e a rigidez. No caso do concreto armado, essa relação não é linear, devido à não-linearidade física do material. Quando um pilar de um edifício convencional de múltiplos pavimentos está submetido à flexão composta oblíqua, o eixo deformado é uma curva reversa e o plano de flexão é variável de seção para seção em virtude da própria deformação da barra, conforme é ilustrado na Figura 2-6.

\subsubsection{Relação momento fletor-curvatura}

Quando a relação momento-curvatura de uma seção é definida para diferentes níveis de solicitação, é obtido o diagrama $M-1 / r$. Com a presença concomitante de uma força normal na seção a relação momento-curvatura continua válida, porém dependente diretamente do valor da força normal. Esse diagrama é ferramenta essencial no cálculo dos efeitos locais de segunda ordem de um pilar. 
Figura 2-6 - Deformação de um pilar submetido à flexão composta oblíqua.

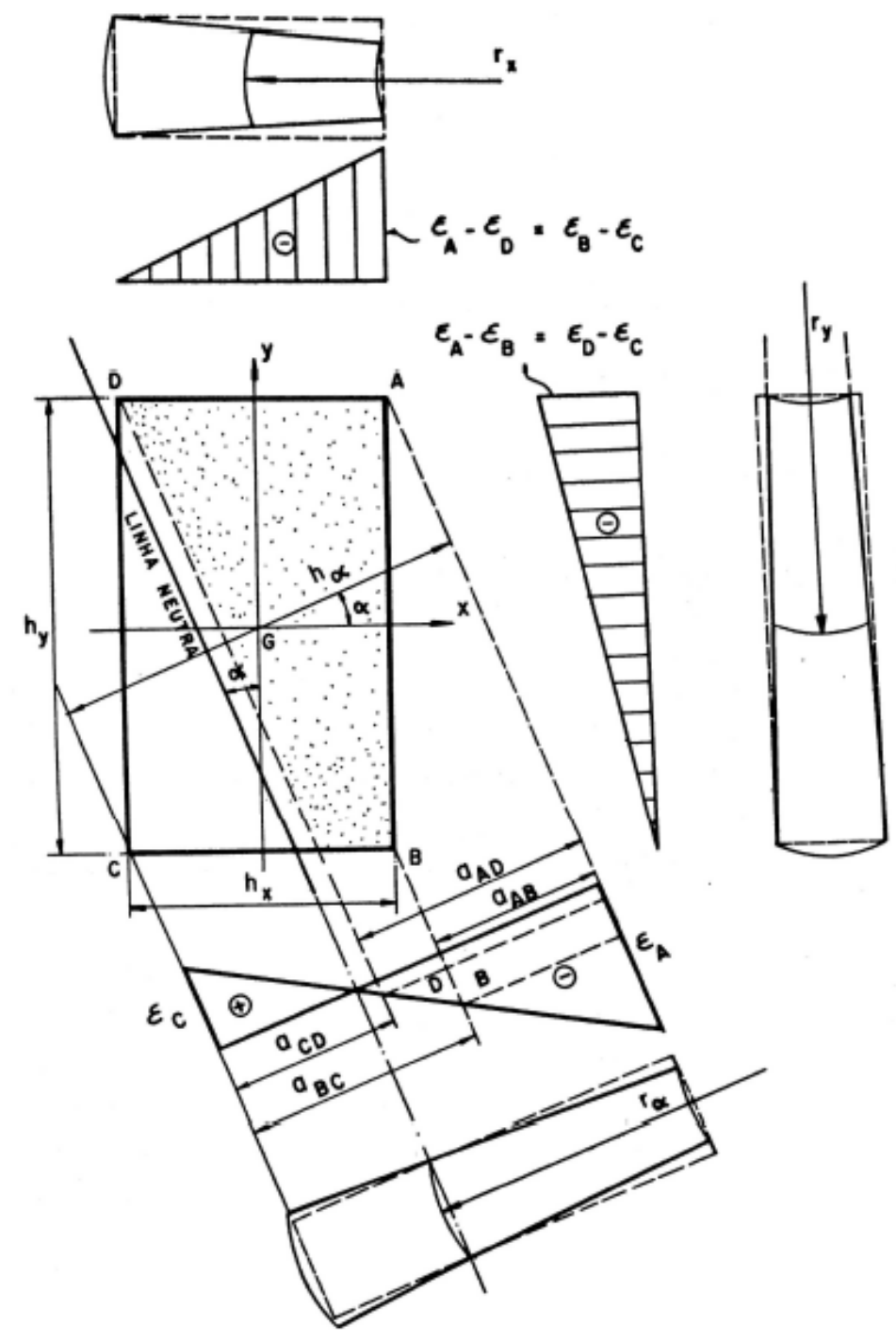

Fonte: (FUSCO, 1981)

FRANÇA (1984) realizou um estudo detalhado das relações momento-curvatura e força normal-deformação longitudinal e por fim apresentou formulação geral e integrada das relações momento-curvatura em peças submetidas à flexão composta oblíqua.

Segundo o item 15.3.1 da norma ABNT NBR 6118:2014, o principal efeito da nãolinearidade física pode ser considerado por meio da construção da relação momento-curvatura para cada seção com armadura conhecida e para o valor da força normal atuante. Também pode ser utilizada a formulação de segurança na obtenção dos efeitos de segunda ordem majorando as ações por $\frac{\gamma_{f}}{\gamma_{f 3}} \operatorname{com} \gamma_{f 3}=1,1$, as quais posteriormente são majorados por $\gamma_{f}$. 


\subsubsection{Coeficiente $\gamma_{f 3}$}

O coeficiente ponderador das ações $\gamma_{f}$ (usualmente igual a 1,4) é o resultado da multiplicação de três fatores: $\gamma_{f}=\gamma_{f 1} \cdot \gamma_{f 2} \cdot \gamma_{f 3}$.

O primeiro fator $\gamma_{f 1}$ depende da variabilidade das ações. O segundo $\gamma_{f 2}$ considera a simultaneidade das ações, isto é, a probabilidade de ações de origens distintas ocorrerem simultaneamente. $\mathrm{O}$ terceiro fator $\gamma_{f 3}$ pondera os desvios que podem ocorrer entre a situação física de construção e aproximações teóricas feitas em projeto.

O item 15.3.1 da norma ABNT NBR 6118:2014 sugere que o fator $\gamma_{f 3}$, referente a aproximações de projeto, seja retirado do coeficiente total na análise dos esforços de segunda ordem, esforços estes que possuem resposta não-linear. No entanto, o resultado final deve ser majorado por $\gamma_{f 3}$. Essa abordagem gera resultados menores de momentos atuantes e deslocamentos, resultando em dimensionamento mais econômico. A norma citada sugere que o valor do fator $\gamma_{f 3}$ seja opcional e preferencialmente 1,1 , ocorrendo resultados numéricos mais conservadores quando adotado $\gamma_{f 3}=1,0$.

\subsection{DIAGRAMA MOMENTO FLETOR-NORMAL-CURVATURA}

Segundo o item 15.3 da norma ABNT NBR 6118:2014, a deformabilidade dos elementos deve ser calculada com base nos diagramas tensão-deformação dos materiais com a tensão de pico do concreto igual a $1,1 f_{c d}$. A curva tradicional utilizando $0,85 f_{c d}$, neste caso, serve somente para definir o momento resistente último de cálculo $M_{R d}$ no ELU e não para extrair a rigidez.

O intuito da norma é definir uma rigidez $E I_{s e c}$ representativa de tal forma a uniformizar a condição das seções ao longo de um lance de pilar no Estado Limite Último. Sendo assim, a tensão de pico do concreto é elevada em $30 \%$ em relação ao valor de $0,85 f_{c d}(0,85 \cdot 1,3 \approx 1,1)$. Portanto, e exclusivamente para avaliar a deformabilidade de um lance pilar com influência direta no cálculo dos efeitos de segunda ordem, deve ser utilizado $1,1 f_{c d}$ na construção da relação momento-curvatura. 
O diagrama $N, M, 1 / r$ proposto pela ABNT NBR 6118:2014 é ilustrado na Figura 2-7.

Figura 2-7 - Diagrama momento-curvatura.

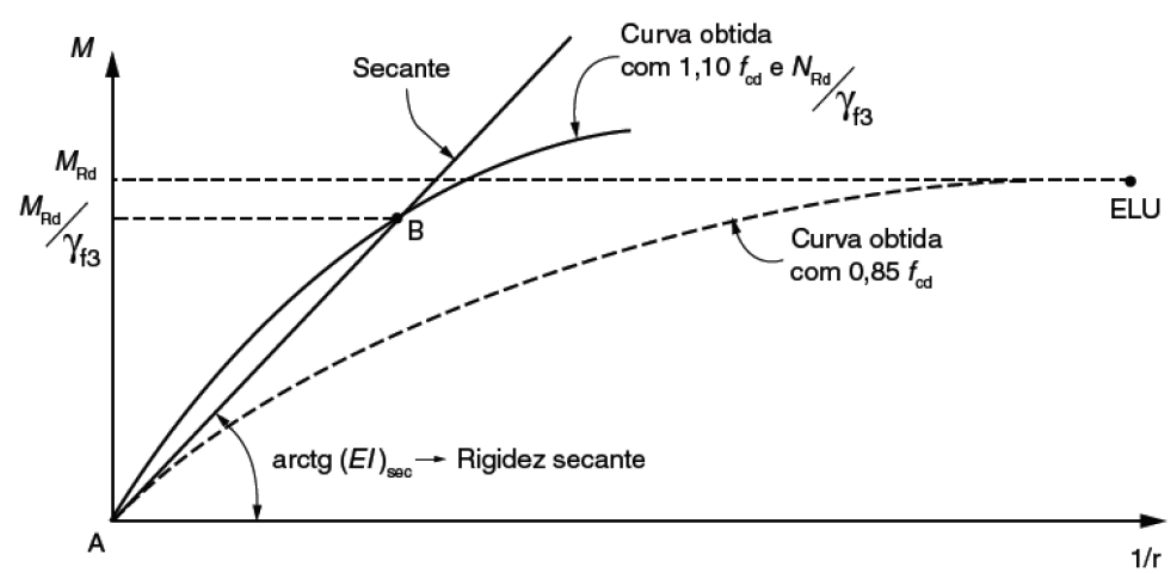

Fonte: ABNT NBR 6118:2014

Na curva obtida com $1,1 f_{c d}$ é encontrado o valor de rigidez secante $E I_{\text {sec }}$ para cada momento $M$ de cada seção ao longo do comprimento do pilar. Como forma de simplificar o problema e ainda ficar a favor da segurança, pode ser extraída uma rigidez única, a partir da linearização do diagrama momento fletor-força normal-curvatura, tal como proposto por (FRANÇA, 1991), a qual pode ser adotada para qualquer outra seção do pilar.

Portanto, a curva de linha contínua $\mathrm{AB}$ da Figura 2-7, obtida considerando o valor da força normal igual a $\frac{N_{R d}}{\gamma_{f 3}}$, pode ser linearizada pela reta $\mathrm{AB}$, sendo esta utilizada na determinação das deformações da barra. Novamente, a curva tracejada para $0,85 f_{c d}$ é utilizada apenas para definir o esforço resistente $M_{R d}$ correspondente ao valor de $N_{R d}$ máximo, sem outra utilização. De fato, a rigor a curva tracejada pode ser suprimida do diagrama de iteração para efeito exclusivo de obtenção da rigidez secante.

KETTERMANN (2001) observou que a alteração da tensão de pico do diagrama tensão-deformação de $0,85 f_{c d}$ para $1.1 f_{c d}$, traz resultados mais adequados para os casos de pilares com maior índice de esbeltez e um certo nível de carregamento aplicado. Nestes casos, utilizando tensão de pico $1,1 f_{c d}$ seria possível, para o mesmo pilar, aplicar o carregamento com uma excentricidade maior e em muitos casos obter um deslocamento menor no topo. Trata-se de trabalhar com valores últimos e relacionar com valores de serviço.

No caso de pilar submetido por momentos fletores nas duas direções, o correto seria avaliar a rigidez EI de forma acoplada, isto é, considerar que os esforços em uma direção in- 
fluenciam na definição da rigidez na outra direção. Para um momento solicitante $M_{s}$, com componentes nas direções $x$ e $y$, resulta configuração deformada com curvatura $1 / r_{x} e 1 / r_{y}$.

Para a solução exata considerando a variação da rigidez EI em função da ação simultânea de duas componentes de momentos é necessária a utilização de programas computacionais. No entanto, o processo de linearização da curvatura utilizado na flexão composta normal proposto por FRANÇA (1991) também pode ser aplicado para flexão composta oblíqua.

Assim, o problema pode ser resolvido de forma desacoplada bastando determinar as deformações em pontos da seção transversal perpendiculares a uma certa posição da Linha Neutra, tal como exemplificado na Figura 2-8 (CARDOSO JÚNIOR, 2014). Nesta Figura estão indicadas as curvaturas em duas direções ortogonais, as quais estão relacionadas com a curvatura na direção da oblíqua da Linha Neutra.

CECCON (2008) mostrou que é possível calcular os efeitos de segunda ordem em pilares de seção retangular utilizando o desacoplamento das flexões nas direções dos eixos centrais principais de inércia, empregando a rigidez secante para cada direção independente, de forma a ficar a favor da segurança.

Figura 2-8-Curvaturas $1 / r_{x}$ e $1 / r_{y}$.
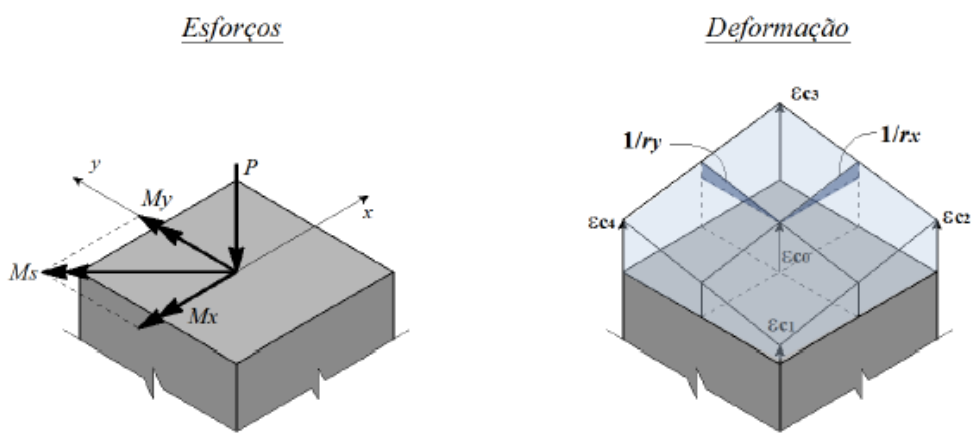

Fonte: CARDOSO JÚNIOR (2014)

No entanto CHEREN (2010) mostrou que, de modo oposto para as seções retangulares, o desacoplamento não pode ser usado para todas as seções com formato geométrico em " $L$ ", uma vez que foram encontrados casos particulares onde a condição de segurança não foi atingida. 


\subsection{NÃO-LINEARIDADES}

\subsubsection{Não-linearidade física (NLF)}

A linearidade física exprime a aplicabilidade da Lei de Hooke, estando, portanto, relacionada ao comportamento do material. No caso do concreto, a formação e a abertura de fissuras acarretam a perda de proporcionalidade entre tensão e deformação, sendo um dos fenômenos responsáveis pela resposta não linear deste material. Há duas maneiras de considerar a NLF: aproximada ou refinada.

a) Não-linearidade física de forma aproximada

Uma solução aproximada para consideração da NLF no cálculo de um lance de pilar pode ser exemplificada quando se utiliza uma fórmula aproximada para o cálculo da curvatura e rigidez de uma seção transversal do pilar, tal como é considerado nos métodos aproximados de cálculo, como o Método de Curvatura aproximada e o de Rigidez aproximada, respectivamente. Ambos tratam o comportamento do material de forma simplificada.

b) Não-linearidade física de forma refinada

Uma maneira mais refinada de tratar a não linearidade física em uma estrutura é por meio do uso de relações momento-curvatura para cada seção, construído a partir da armadura previamente conhecida e do valor das solicitações atuantes. A partir desse diagrama, é obtida a rigidez secante $E I$ da barra correspondente a um determinado valor de momento fletor considerando a reta secante à curva, analogamente à Figura 2-7 para o caso de elementos comprimidos. Esta forma de consideração é encontrada no Método Acoplado a diagramas.

\subsubsection{Não-linearidade geométrica (NLG)}

Assim como a não-linearidade física, a não-linearidade geométrica também gera resposta não-linear de uma estrutura. No entanto, esse comportamento não ocorre devido a alterações no material, mas sim devido a mudanças na geometria dos elementos estruturais à medida que um certo carregamento é aplicado.

Para valores relativamente grandes de deslocamentos, a deformação lateral de um membro pode trazer como consequência o aparecimento de momentos fletores adicionais (de- 
nominados de segunda ordem) em virtude da presença de uma força normal. A NLG é decorrente desse tipo de comportamento não linear. Neste caso, os efeitos não lineares estão associados às equações de equilíbrio, as quais consideram a configuração deformada e as relações deformação-deslocamento (PEREIRA, 2002).

A análise da estrutura em sua posição deformada em casos como a instabilidade de pilar é de extrema importância. Neste caso, quando a força aplicada é menor que a carga crítica, o deslocamento resultante na extremidade livre do pilar é nulo. Porém, quando a força aplicada é maior que a carga crítica, o deslocamento passa a existir.

O fenômeno de instabilidade de barras retas axialmente comprimidas pode ser caracterizado pela presença do ponto de bifurcação do equilíbrio no diagrama que relaciona a carga $\mathrm{F}$ aplicada com o máximo deslocamento lateral $a$ da barra indicado na Figura 2-9. Quando aplicadas cargas de compressão $F<F_{c r}$, não ocorre deslocamento lateral e, para cargas de compressão $F \geq F_{c r}$, o deslocamento lateral pode ocorrer para um lado ou para o lado oposto em seções transversais simétricas.

Da mesma forma que a NLF, a NLG pode ser considerada de forma aproximada ou refinada.

Figura 2-9 - Ilustração do fenômeno de instabilidade.
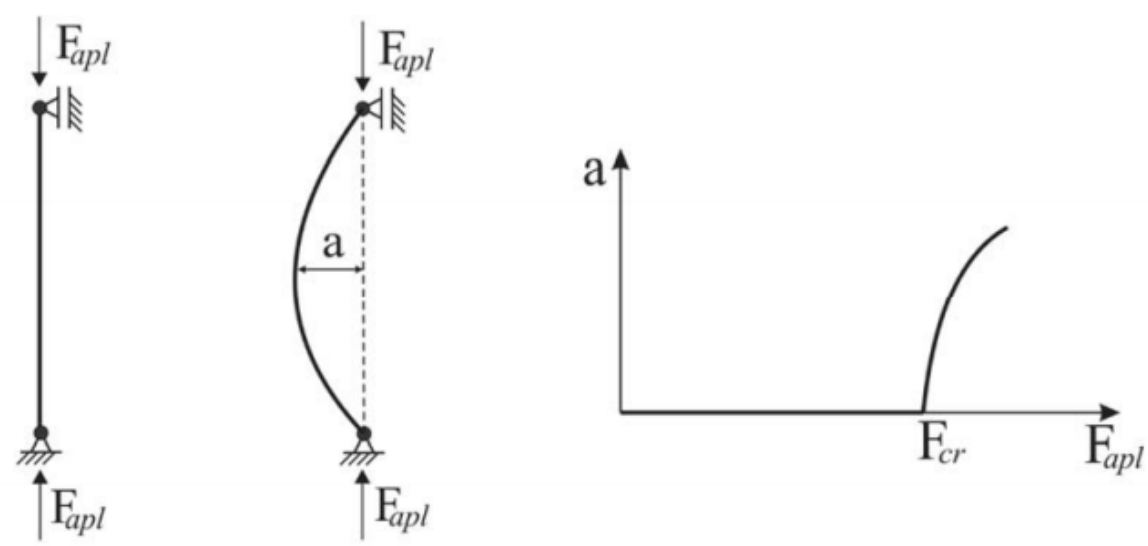

Fonte: PINTO (2017)

a) Não-linearidade geométrica de forma aproximada

A consideração da NLG de forma aproximada leva em conta que a forma final da posição de equilíbrio é pré-determinada, permitindo a solução matemática do problema. Esta é a forma utilizada no cálculo dos efeitos de segunda ordem por meio dos métodos aproximados 
indicados na norma ABNT NBR 6118:2014 (método do pilar padrão), onde é suposto que a forma final de equilíbrio da estrutura analisada é uma curva senoidal.

b) Não-linearidade geométrica de forma refinada

Existem diversos processos numéricos que tratam a não-linearidade geométrica de forma refinada. Basicamente são cálculos iterativos em que é procurada a posição final de equilíbrio da estrutura ou parte dela. Por ser um processo iterativo, é necessária a definição de tolerâncias para obtenção da convergência do método.

Existem formulações baseadas na introdução de variações de esforços entre cada iteração, bem como outras, mais sofisticadas, que corrigem a matriz de rigidez dos elementos de tal forma a simular a variação da geometria da estrutura à medida que o carregamento é aplicado sobre a mesma (KIMURA, 2019). Essa é uma das formas aplicadas no cálculo dos efeitos de segunda ordem local por meio do Método Geral.

\subsection{ESBELTEZ}

A esbeltez $\lambda$ é uma grandeza que depende do comprimento e das condições de contorno do pilar, da área e do momento de inércia da seção transversal, sendo expressa por:

$$
\lambda=\frac{L_{e}}{i}
$$

Sendo $L_{e}$ o comprimento equivalente do pilar e $i$ o raio de giração da seção transversal na direção analisada obtido por:

$$
i=\sqrt{\frac{I_{c}}{A_{c}}}
$$

Onde $I_{c}$ é o momento de inércia e $A_{c}$ é a área bruta da seção transversal do pilar.

O comprimento equivalente do pilar depende da vinculação na base e no topo do pilar. A Figura 2-10 ilustra alguns casos teóricos mais usuais, sendo o primeiro caso aquele correspondente à situação básica relacionada ao dimensionamento de pilares de edifícios usuais (com a presença de restrições à livre translação e à livre rotação nas extremidades quando aplicada ação lateral externa) e o último caso aquele correspondente à situação de galpões (sem restrições à translação e à rotação na extremidade superior quando aplicada ação lateral). 
Fisicamente, o comprimento equivalente pode ser entendido como a distância entre pontos de momentos nulos ou de pontos de inversão de curvatura ao longo do eixo do pilar.

Como este trabalho analisa apenas pilares com seção transversal retangular, a Eq. (2-15) pode ser simplificada para:

$$
\lambda=\sqrt{12} \cdot \frac{L_{e}}{h}
$$

Segundo a norma ABNT NBR 6118:2014 quando da análise dos efeitos locais de segunda ordem de pilares com índice de esbeltez superior a 140, os esforços solicitantes finais de cálculo devem ser multiplicados por coeficiente adicional, conforme a relação seguinte:

$$
\gamma_{n 1}=\frac{\lambda}{140}
$$

Figura 2-10 - Comprimentos equivalentes para situações usuais.

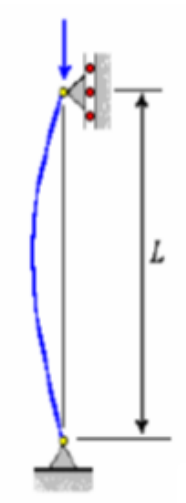

$L_{e}=L$

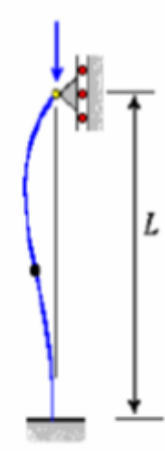

$L_{\imath}=0.699 \mathrm{~L}$

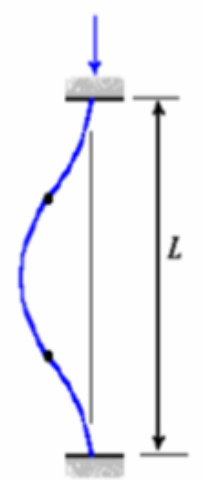

$L_{e}=0.5 L$

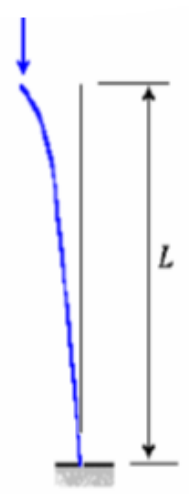

$L_{2}=2 L$

Fonte: http://www.aero.usyd.edu.au/structures/mos/index.html.

\subsection{ESBELTEZ LIMITE E COEFICIENTE $\alpha_{b}$}

O conceito de esbeltez limite decorre de análises teóricas de pilares considerando o material como elástico-linear. Segundo SOUZA (2003) as normas em geral estabelecem um valor limite $\lambda_{1}$ em função da redução da capacidade resistente no Estado Limite Último quando comparada com a capacidade resistente obtida de acordo com a teoria de primeira ordem. $\mathrm{O}$ valor dessa redução é definido arbitrariamente, não devendo ser superior a 5\% no ACI/95, ou a $10 \%$ no $\mathrm{CEB} / 90$. 
Segundo a norma ABNT NBR 6118:2014, o valor de $\lambda_{l}$ depende de diversos fatores, sendo os principais:

a) A excentricidade relativa de primeira ordem $\frac{e_{1}}{h}$ na extremidade do pilar onde ocorre o momento de primeira ordem de maior valor absoluto;

b) A vinculação dos extremos do elemento isolado;

c) A forma do diagrama de momentos de primeira ordem.

SOUZA et al. (1992) deduziram uma expressão para avaliação da esbeltez limite em pilares de concreto armado, válida para seções retangulares quando a excentricidade relativa de primeira ordem $\frac{e_{1}}{h}$ é menor que 0,6 e admitindo perda máxima de $10 \%$ na capacidade resistente do pilar:

$$
\lambda_{1}=100 \sqrt{\frac{0,6}{(4-\omega)\left(1+3 \frac{e_{1}}{h}\right)}}
$$

Onde $\omega$ é a taxa mecânica de armadura e $\frac{e_{1}}{h}$ é a excentricidade relativa de primeira ordem.

É interessante observar que a reescrevendo a Eq. (2-5) ou (2-6) é possível determinar a excentricidade relativa em cada direção para seções retangulares com:

$$
\begin{gathered}
\frac{e_{1 y}}{h_{y}}=\frac{\mu_{x, d}}{v_{d}} \\
\frac{e_{1 x}}{h_{x}}=\frac{\mu_{y, d}}{v_{d}}
\end{gathered}
$$

SOUZA et al. (1998 apud SOUZA, 2003) desenvolveram um estudo de casos de pilares de seção retangular com excentricidades iguais e de mesmo sentido e armaduras iguais distribuídas ao longo de dois lados opostos, analisando e simulando 115 pilares, para diferentes índices de esbeltez, amplitudes de excentricidades, taxas de armadura e relação entre as excentricidades extremas.

Baseado nos resultados obtidos nesses dois trabalhos, foram propostas relações para avaliação do valor de $\lambda_{l}$ para diversos casos práticos: 


$$
\begin{gathered}
\lambda_{1}=\alpha\left(42-50 \frac{e_{1 A}}{h}\right) \quad \text { para } \frac{e_{1 A}}{h} \leq 0,34 \\
\lambda_{1}=25 \alpha \quad \quad \text { para } 0,34 \leq \frac{e_{1 A}}{h} \leq 0,75 \\
\lambda_{1}=\alpha\left(13+16 \frac{e_{1 A}}{h}\right) \quad \text { para } \frac{e_{1 A}}{h} \geq 0,75 \\
\lambda_{1} \leq 80
\end{gathered}
$$

Onde $\frac{e_{1 A}}{h}$ é a maior excentricidade de primeira ordem existente nos extremos do pilar e os índices $A$ e $B$ são referidos ao maior e ao menor momento fletor de primeira ordem que ocorrem nas extremidades do pilar, respectivamente, com sinais iguais quando tracionam a mesma face do pilar e com sinais diferentes em caso oposto.

O limite indicado na Eq. (2-17) foi escolhido de forma arbitrária e procurou limitar o índice de esbeltez máximo absoluto para a dispensa dos efeitos de segunda ordem. Para a determinação do coeficiente $\alpha$, SOUZA et al. (1998 apud SOUZA, 2003) utilizaram metodologia semelhante à utilizada para a determinação de $\lambda_{1}$, ou seja, considerando perda de $10 \%$ da capacidade resistente do pilar e obtiveram as seguintes relações:

$$
\begin{array}{ll}
\alpha=1,35-0,35 \frac{e_{1 B}}{e_{1 A}} & \text { para } \frac{e_{1 A}}{h}=0,05 \\
\alpha=1,60-0,36 \frac{e_{1 B}}{e_{1 A}} & \text { para } \frac{e_{1 A}}{h}=0,10
\end{array}
$$

Para efeito prático, deve ser fixada a equação de $\alpha$ de acordo com a excentricidade mínima adotada no projeto de pilares. Caso fosse respeitado o momento mínimo de $0,10 h N_{d}$, a excentricidade $\frac{e_{1}}{h}$ seria no mínimo igual a 0,10, podendo ser utilizada a Eq. (2-19) (SOUZA T. J., 2003).

Segundo a versão 2003 da norma ABNT NBR 6118, os esforços locais de segunda ordem em elementos isolados podiam ser desprezados quando o índice de esbeltez $\lambda$ fosse menor que o valor limite $\lambda_{1}$ calculado pela Eq. (2-20). Essa mesma expressão consta na atual norma ABNT NBR 6118:2014. 


$$
\lambda_{1}=\frac{12,5}{\alpha_{b}}\left(2+\frac{e_{1}}{h}\right) \quad \text { para } 35 \leq \lambda_{1} \leq 90
$$

Sendo $\mathrm{e}_{1}$ a excentricidade de primeira ordem, não incluindo a excentricidade acidental. $\mathrm{O}$ valor $\alpha_{b}$ deve ser adotado conforme a Tabela 2-1 deste texto e apresentada a seguir (ABNT NBR 6118:2014).

Tabela 2-1 - Determinação de valores de $\alpha_{b}$ segundo a norma ABNT NBR 6118:2014

\begin{tabular}{lc}
\hline \multicolumn{1}{c}{ Vínculos e ações em pilares } & Coeficiente $\alpha_{b}$ \\
\hline Bi rotulados sem ações transversais* & $\alpha_{b}=0,6+0,4 \frac{M_{B}}{M_{A}}$ \\
& $0,4 \leq \alpha_{b} \leq 1$ \\
\hline Em balanço* & $\alpha_{b}=0,8+0,2 \frac{M_{C}}{M_{A}}$ \\
& $0,85 \leq \alpha_{b} \leq 1$ \\
\hline
\end{tabular}

a) Bi rotulados com ações transversais significativas ao longo da altura ou b) Bi rotulados ou em balanço com momentos menores que o momento mínimo

Observações*:

a) $M_{A}$ e $M_{B}$ são os momentos de primeira ordem nos extremos do pilar. Deve ser adotado para $M_{A} \mathrm{o}$ maior valor absoluto ao longo do pilar bi rotulado, e para $M_{B}$ o sinal positivo, se tracionar a mesma face que $M_{A}$, e negativo, em caso contrário.

b) $M_{A}$ é o momento de primeira ordem no engaste e $M_{C}$ é o momento de primeira ordem no meio do pilar em balanço.

O fator $\alpha_{b}$ tem origem na norma americana ACI 318/95, com a notação $C_{m}$. Este parâmetro representa o percentual da altura do pilar onde ocorre o momento máximo de segunda ordem local.

Um pilar esbelto sujeito a carga axial e momentos de extremidade sofre deslocamento lateral e apresenta um diagrama de momento fletores conforme o sentido de aplicação de momentos nas extremidades. Quando a flexão atuante nas extremidades traciona o mesmo lado da seção transversal, a curvatura do elemento é única ou simples, tal como indicado na imagem da Figura 2-11 a). Por outro lado, quando a flexão nas extremidades promove tração 
em lados opostos da seção transversal, a curvatura é reversa ou dupla e está exemplificada na imagem da Figura 2-11 b).

Figura 2-11-Pilares com curvaturas simples e dupla.

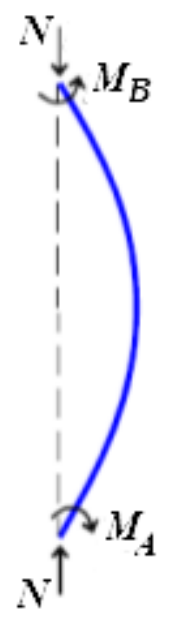

a) $M_{B} / M_{A}>0$
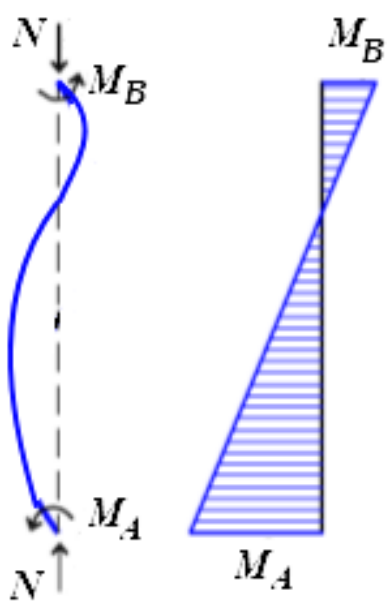

b) $M_{B} / M_{A}<0$

Fonte: adaptado de AGUIAR (2000).

Como resultado, os momentos fletores adicionais de segunda ordem variam ao longo do comprimento do pilar com valores nulos nas extremidades para os casos de pilares bi rotulados. Se os momentos aplicados nas extremidades forem iguais (em magnitude e em sentido), a determinação da seção crítica que corresponde ao momento máximo é imediata e corresponde à seção do meio do vão.

No entanto, quando os momentos aplicados são de sentidos opostos nas duas extremidades, a curvatura da peça é diferente e a determinação da seção crítica não é imediata, como ilustrado na Figura 2-12. A solução para a equação diferencial que inclui comportamento de material inelástico como o concreto armado é considerada complexa (TIKKA \& MIRZA, 2004).

Nesse sentido, a norma americana ACI 318/95 permite o uso de um fator de diagrama de momento equivalente uniforme $C_{m}$ como forma de considerar o efeito do momento fletor de segunda ordem ao longo do pilar decorrente da aplicação de momentos desiguais nas extremidades. O coeficiente $C_{m}$ foi introduzido pela norma americana com o intuito de evitar cálculos extensos. Austin (1961 apud TIKKA e MIRZA, 2004) propôs a seguinte expressão para pilares bi rotulados: 


$$
C_{m}=0,6+0,4 \frac{M_{B}}{M_{A}} \geq 0,4
$$

Figura 2-12 - Pilares submetidos a efeitos locais de segunda ordem.
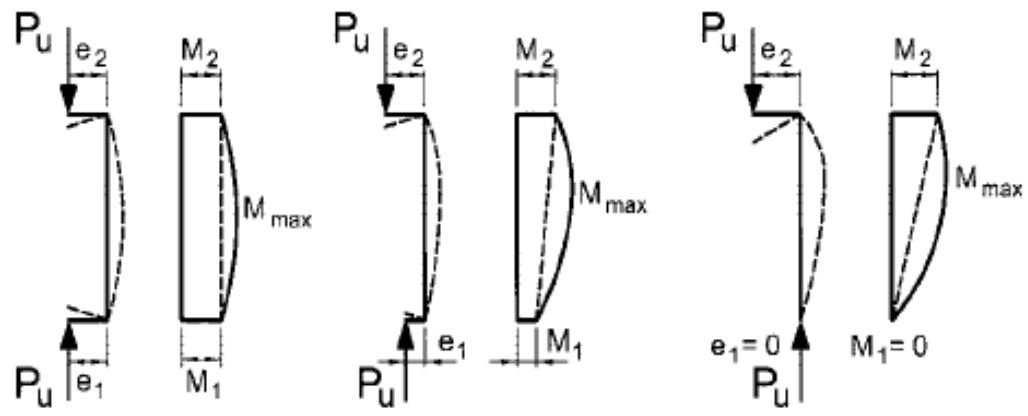
(a) $\frac{M_{1}}{M_{2}}=1.0$
(b) $1.0>\frac{M_{1}}{M_{2}}>0.0$
(c) $\frac{M_{1}}{M_{2}}=0.0$
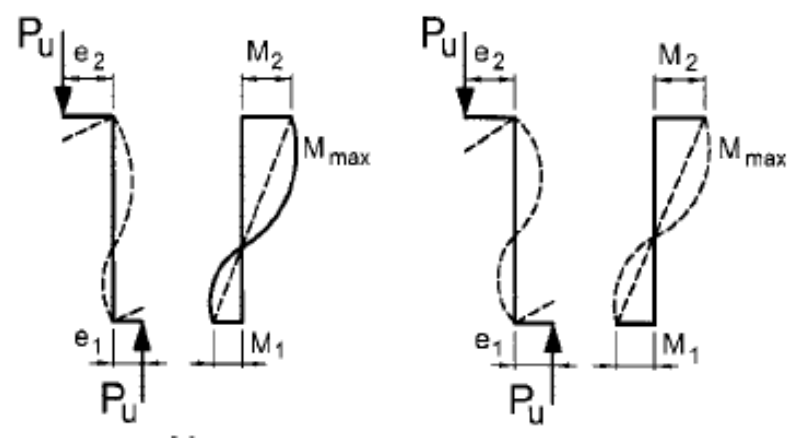

Fonte: TIKKA e MIRZA (2004).

Porém, a equação proposta por Austin (1961 apud TIKKA e MIRZA, 2004) era baseada em pilares de comportamento elástico. TIKKA e MIRZA (2004) verificaram que a Eq. (2-21) também é válida para pilares de concreto armado.

SOUZA et al (1992) propõem que o limite inferior de 0,4 para o valor de $\alpha_{b}$ poderia ser desconsiderado. Cabe salientar que o CEB/90 também desconsidera o limite inferior de 0,4. A norma americana AISC/1999 para estruturas de aço já abandonaram este limite inferior nas suas versões mais recentes. A norma ABNT NBR 6118:2014 adota a Eq. (2-21) mantendo o limite inferior de 0,4 . 


\subsection{SOLICITAÇÕES EM PILARES}

\subsubsection{Atuação da flexo-compressão}

Basicamente, os esforços solicitantes mais importantes que atuam ao longo de um lance de pilar são força normal, predominantemente de compressão, e momentos fletores em cada direção. O esforço total utilizado no dimensionamento pode ser subdividido em parcelas iniciais, globais, imperfeições, locais e decorrentes da fluência, ilustradas na Figura 2-13.

Estas parcelas de esforços são referidas basicamente aos momentos fletores $M_{x} e M_{y}$ atuantes no pilar em relação a direções principais da seção transversal. Comumente, é utilizada a seguinte expressão para a determinação da flexão total incluindo todos as parcelas:

$$
M_{\text {tot }}=M_{\text {inicial }}+M_{2 \text { global }}+M_{\text {imperfeições }}+M_{2 l o c a l}+M_{\text {fluência }}
$$

Usualmente, os esforços iniciais, os esforços globais de segunda ordem e os esforços provenientes de imperfeições geométricas globais são calculados por meio de modelos que contemplam toda a estrutura (modelo global), enquanto que para os esforços locais de segunda ordem, os esforços provenientes de imperfeições geométricas locais e os esforços devido à fluência são analisados por meio de modelos que tratam o lance de pilar de forma isolada (modelo local). Como o objeto de estudo deste estudo foi um pilar isolado, não foram abordados os momentos fletores decorrentes dos efeitos globais.

\subsubsection{Solicitações iniciais}

Em um pilar isolado, submetido à uma força normal excêntrica, os momentos iniciais podem ser expressos por:

$$
\begin{aligned}
& M_{S d, x}=N_{S d} e_{1, y} \\
& M_{S d, y}=N_{S d} e_{i, x}
\end{aligned}
$$


Figura 2-13 - Ilustração de esforços atuantes em um lance de pilar.

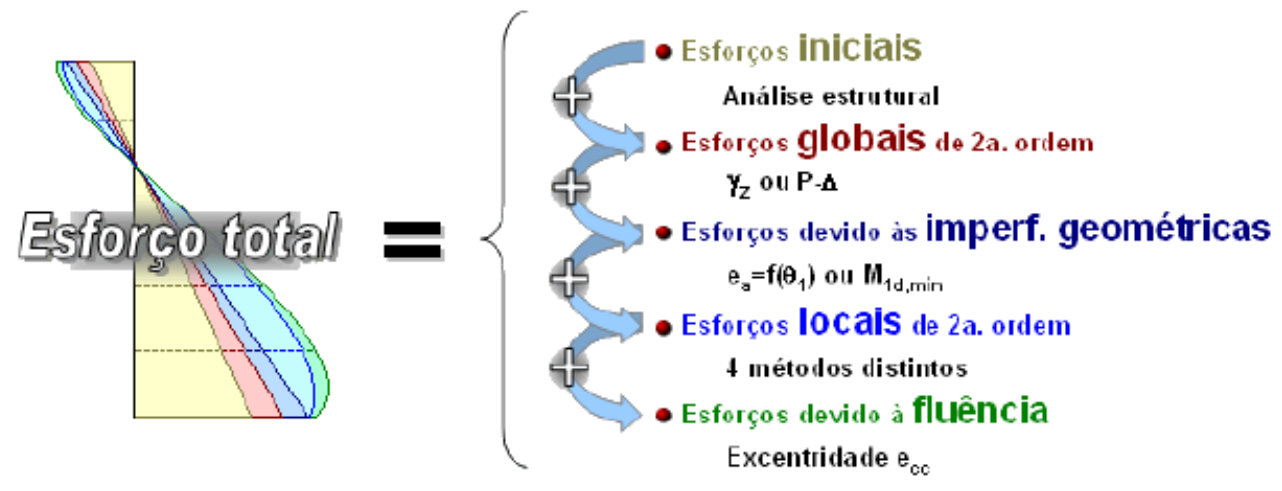

Fonte: KIMURA (2019).

\subsubsection{Imperfeições geométricas}

As estruturas de concreto durante a construção ficam sujeitas ao aparecimento de desvios geométricos, isto é, imperfeições na posição e forma dos eixos das peças, na forma e dimensões da seção transversal, etc. Estas falhas de construção, denominadas imperfeições geométricas, são praticamente inevitáveis e aleatórias, podendo ser grandes ou pequenas. Elas podem ser divididas em dois grupos: imperfeições globais e locais e é obrigatória a consideração destas imperfeições no dimensionamento de pilares de edifícios de concreto armado.

Enquanto as imperfeições globais estão relacionadas ao edifício como um todo e são avaliadas na modelagem global, as imperfeições geométricas locais são relacionadas aos lances dos pilares de um edifício e ocasionam esforços locais adicionais devido à presença da carga normal de compressão.

As imperfeições locais podem ser consideradas pela falta de retilineidade ou desaprumo do eixo do pilar, sendo calculadas conforme a Figura 2-14. É admitido para os casos usuais de estruturas reticuladas que a consideração apenas da falta de retilineidade ao longo do pilar seja suficiente (ABNT NBR 6118:2014). 
Figura 2-14 - Imperfeições geométricas locais: a) Elementos de travamento (tracionado ou comprimido); b) Falta de retilineidade no pilar e c) Desaprumo do pilar

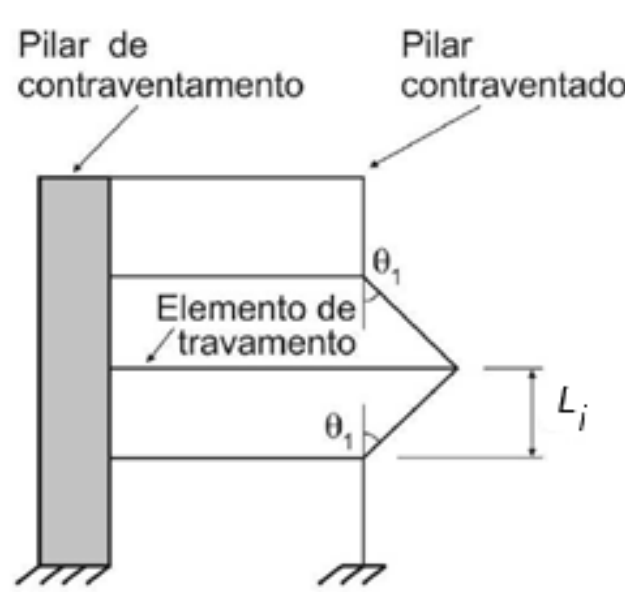

(a)

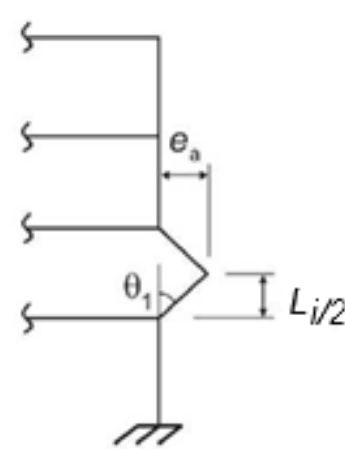

(b)

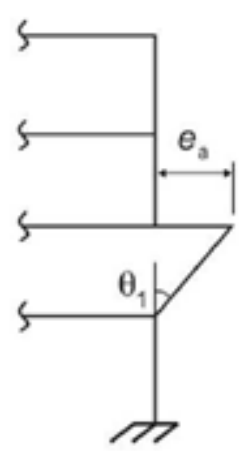

(c)

Fonte: ABNT NBR 6118:2014.

A simulação da imperfeição local é representada por um ângulo de inclinação $\theta_{1}$, o qual é calculado pela Eq. seguinte, respeitando os limites mínimo e máximo.

$$
\frac{1}{300} \leq \theta_{1}=\frac{1}{100 \sqrt{L_{i}}} \leq \frac{1}{200}
$$

Para o caso de falta de retilineidade, o valor da excentricidade acidental $e_{a}$ pode ser calculado com:

$$
e_{a}= \begin{cases}\theta_{1} L_{i} & \rightarrow \text { no topo e na base } \\ \theta_{1} \frac{L_{i}}{2} & \rightarrow \text { no centro }\end{cases}
$$

Onde $\theta_{l}$ é a rotação de desaprumo do elemento vertical e $L_{i}$ é o comprimento equivalente de um certo pilar na direção analisada.

Deve ser ressaltado que o efeito da imperfeição geométrica causada pela rotação $\theta_{1}$ não é simples de ser avaliado, uma vez que é difícil definir a sua direção e o seu sentido crítico de atuação. Usualmente, nos sistemas computacionais, o que se faz é considerar as imperfeições nas duas direções principais, por meio da definição de excentricidades adicionais (KIMURA, 2019). 
A norma ABNT NBR 6118:2003 introduziu um novo conceito para a consideração do efeito das imperfeições geométricas locais identificadas como momento mínimo, o qual consta no código americano ACI 318/95 com a seguinte afirmação: "A esbeltez é levada em consideração aumentando os momentos fletores nos extremos do pilar. Se os momentos atuantes no pilar são muito pequenos ou nulos, o projeto de pilares esbeltos deve ser baseado sobre uma excentricidade mínima".

A norma ABNT NBR 6118:2014 no seu item 11.3.3.4.3 permite que o efeito das imperfeições geométricas locais em um lance de pilar seja substituído, em estruturas reticuladas, pela consideração do momento mínimo de primeira ordem $M_{1 \text { d.mín }}$ obtido com:

$$
M_{1 d, \text { min }}=(0,015+0,3 h) N_{d}
$$

Sendo $N_{d}$ a força normal de cálculo e $h$ a altura da seção na direção paralela ao plano de flexão analisado, em metros.

É interessante apontar que na extinta norma ABNT NBR 6118:1980, as imperfeições geométricas locais eram consideradas por meio de excentricidade acidental adicional $e_{a}$ cujo valor era o maior entre $2 \mathrm{~cm}$ ou $h / 30$.

Atualmente, a norma ABNT NBR 6118:2014 conceitua que o momento mínimo, como o próprio nome diz, é um valor mínimo a ser atendido e não é mais um valor aditivo, enquanto que a excentricidade $e_{a}$ gerada pela rotação $\theta_{1}$ é sempre aditiva. São duas propostas totalmente distintas para solucionar o mesmo problema. Embora a aplicação de ambas as formulações esteja correta, o uso do momento mínimo de primeira ordem é mais comum.

PINTO (2017) apresentou um exemplo de aplicação considerando a imperfeição geométrica local pela excentricidade adicional e pelo momento mínimo e concluiu que há diferenças significativas entre eles, sendo assim, aquele autor afirmou que são necessários mais estudos para saber qual modelo de análise é mais adequado.

Uma discussão levantada sobre o momento mínimo de primeira ordem foi quanto a sua aplicação simultânea nas duas direções do pilar. À primeira vista, e também recorrendo a alguns exemplos de pilares calculados segundo a norma ACI/95 na literatura, foi notado que não devem ser aplicados os momentos mínimos totais nas duas direções simultaneamente. Diante das inúmeras questões relativas à aplicação de momento mínimo de primeira ordem, a comissão CT-301, responsável pela elaboração de comentários da ABNT NBR 6118:2003, 
propôs novo tipo de abordagem para o problema em questão, tal como foi posteriormente incorporado à norma ABNT NBR 6118:2014 (KIMURA, 2019).

A proposta consistiu em definir uma envoltória mínima de primeira ordem elíptica, tomada a favor da segurança para pilares de seção retangular de acordo com o indicado na Figura 2-15. A construção dessa envoltória é realizada pela obtenção de momentos mínimos de primeira ordem em flexão para cada direção $\left(M_{l d, m i n, x x}\right.$ e $\left.M_{1 d, m i n, y y}\right)$ e aplicação de função aproximadora elíptica indicada na Figura 2-15 para obter a envoltória para direções oblíquas quaisquer $\theta$. A verificação do momento mínimo é considerada atendida quando é obtida envoltória resistente que englobe a envoltória mínima de primeira ordem. Na prática, tal determinação é útil apenas para definir o coeficiente $\alpha_{b}$ para um certo lance de pilar e substituir o momento mínimo total quando da análise de pilares com índice de esbeltez menor do que o índice mínimo.

Figura 2-15 - Envoltória mínima de primeira ordem.

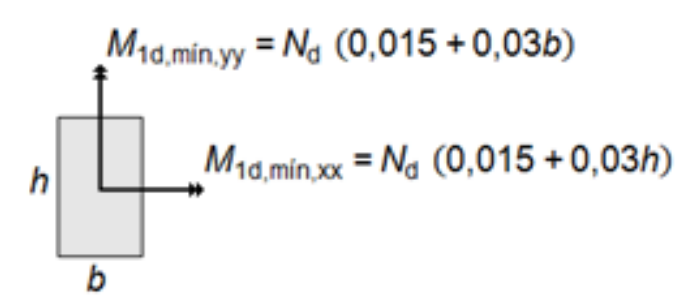

Seção transversal

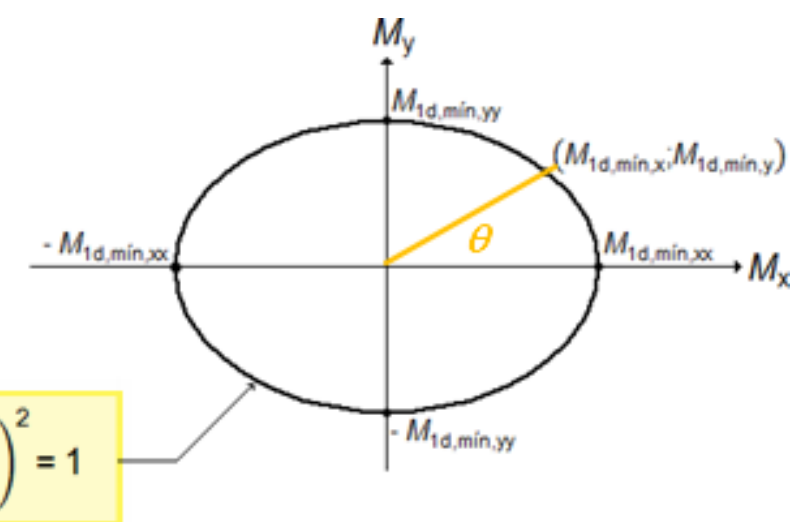

Envoltória mínima de $1^{\mathrm{a}}$ ordem

Sendo: $M_{1 \mathrm{~d}, \min , x \mathrm{x}}$ e $M_{1 \mathrm{~d}, \mathrm{~min}, \mathrm{yy}}$ as componentes em flexão composta normal e $M_{1 \mathrm{~d}, \min , \mathrm{x}}$ e $M_{1 \mathrm{~d}, \mathrm{~min}, \mathrm{y}}$ as componentes em flexão composta obliqua

Fonte: adaptado de ABNT NBR 6118:2014.

\subsubsection{Efeitos locais de segunda ordem}

Os efeitos locais de segunda ordem são obtidos considerando o lance de pilar como uma parte isolada da estrutura. A aplicação de momentos fletores no topo e na base do pilar 
faz com que o elemento deforme. Essa deformação, aliada à ação simultânea da carga normal de compressão, gera efeitos adicionais denominados efeitos locais de $2^{\mathrm{a}}$ ordem.

Segundo o item 15.7.4 da norma ABNT NBR 6118:2014, a análise global de segunda ordem fornece apenas os esforços nas extremidades das barras, devendo ser realizada uma análise dos efeitos locais de segunda ordem ao longo do pilar, conforme ilustrado na Figura 2-16.

Figura 2-16 - Representação de momentos de segunda ordem local em um lance de pilar.

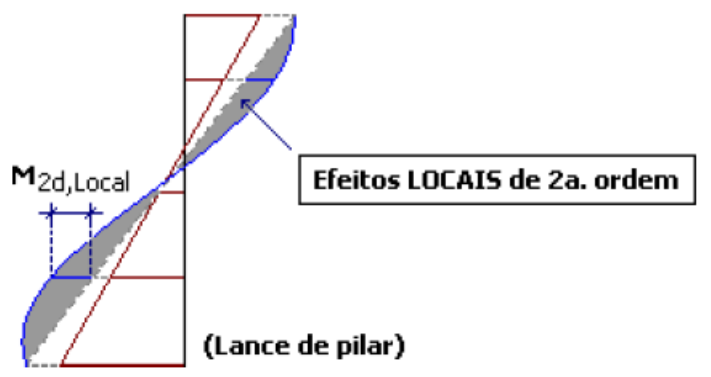

Fonte: KIMURA (2019)

Os elementos isolados, para fins de verificação local, devem ser formados pelas barras comprimidas retiradas da estrutura com comprimento $L_{e}$, e considerados bi rotulados, porém aplicando às suas extremidades os esforços obtidos através da análise global de segunda ordem (ABNT NBR 6118:2014).

A norma ABNT NBR 6118:2014 permite o uso de quatro métodos para análise local de segunda ordem:

a) Pilar padrão com curvatura $1 / r$ aproximada;

b) Pilar padrão com rigidez adimensional $\kappa(k a p a)$ aproximada;

c) Pilar padrão acoplado a diagrama $N, M, 1 / r$;

d) Método geral.

Os três primeiros métodos são considerados processos aproximados e são descritos no item 15.8.3.3 da ABNT NBR 6118:2014, enquanto que o método geral é um processo mais abrangente e rigoroso. Cada um desses métodos possui limitações próprias, por exemplo, na flexão composta reta, os métodos do pilar padrão com curvatura $1 / r$ e com rigidez adimensional $\kappa$ aproximada podem ser utilizados em pilares com esbeltez máxima igual a 90 . O método do pilar padrão acoplado a diagrama $N, M, 1 / r$ é limitado para esbeltez máxima de 140 . $\mathrm{O}$ método geral, por sua vez, pode ser usado até o limite máximo permito de 200 para pilares. 
Segundo o item 15.8.3.3.5 da norma ABNT NBR 6118:2014, quando a esbeltez de um pilar de seção retangular for menor ou igual a 90 nas duas direções principais, a análise na flexão composta oblíqua pode ser realizada com os processos aproximados simultaneamente em cada uma das duas direções.

Os quatro métodos estão descritos em pormenores no Capítulo 3 desse texto.

Quando houver a necessidade de avaliar os efeitos locais de segunda ordem em alguma das direções oblíquas da seção do pilar, a verificação do momento mínimo pode ser considerada atendida quando, no dimensionamento adotado, é obtida envoltória resistente que englobe a envoltória mínima com segunda ordem. De modo semelhante à envoltória de primeira ordem, a envoltória de segunda ordem utiliza mesma função aproximadora elíptica a partir dos momentos totais na flexão reta. Na realidade, para pilares com esbeltez acima da esbeltez mínima $\lambda_{l}$, só interessa o valor momento mínimo obtido com os dados da Figura 2-17 pela construção da envoltória mínima fornecida pela Eq. (2-24).

$$
\left(\frac{M_{d, t o t, \text { min }, \theta} \cos \theta}{M_{d, t o t, \text { min }, x x}}\right)^{2}+\left(\frac{M_{d, t o t, \text { min }, \theta} \operatorname{sen} \theta}{M_{d, t o t, \text { min }, y y}}\right)^{2}=1
$$

A prática de atendimento da envoltória total mínima na flexão oblíqua consiste em verificar se os pontos correspondentes às seções de base (A), de topo (B) e intermediária (C, considerada como crítica) ficam externos à região delimitada pela envoltória total mínima e internos à envoltória resistente. No exemplo ilustrado na Figura 2-18, os três pontos indicados atendem a ambas envoltórias.

Este momento total mínimo trata de impor um critério de projeto para dimensionamento de um lance de pilar com seção transversal e armadura constantes admitindo como crítica a seção intermediária com solicitações de segunda ordem obtidas a partir da solicitação de primeira ordem mínima. A determinação numérica é realizada através de um lance hipotético de pilar admitido com aplicação de Flexão Composta Reta em cada extremidade com momentos iguais ao momento mínimo de primeira ordem $M_{l d, \min }$ em cada direção principal e coeficiente $\alpha_{b}=1,0$. Este é o significado dos pequenos diagramas de momentos fletores apresentados à direita da Figura 2-17. Com estas hipóteses é obtida a envoltória para a seção intermediária, tomada como seção crítica. 
Figura 2-17 - Envoltória mínima para efeitos totais (primeira e segunda ordem).

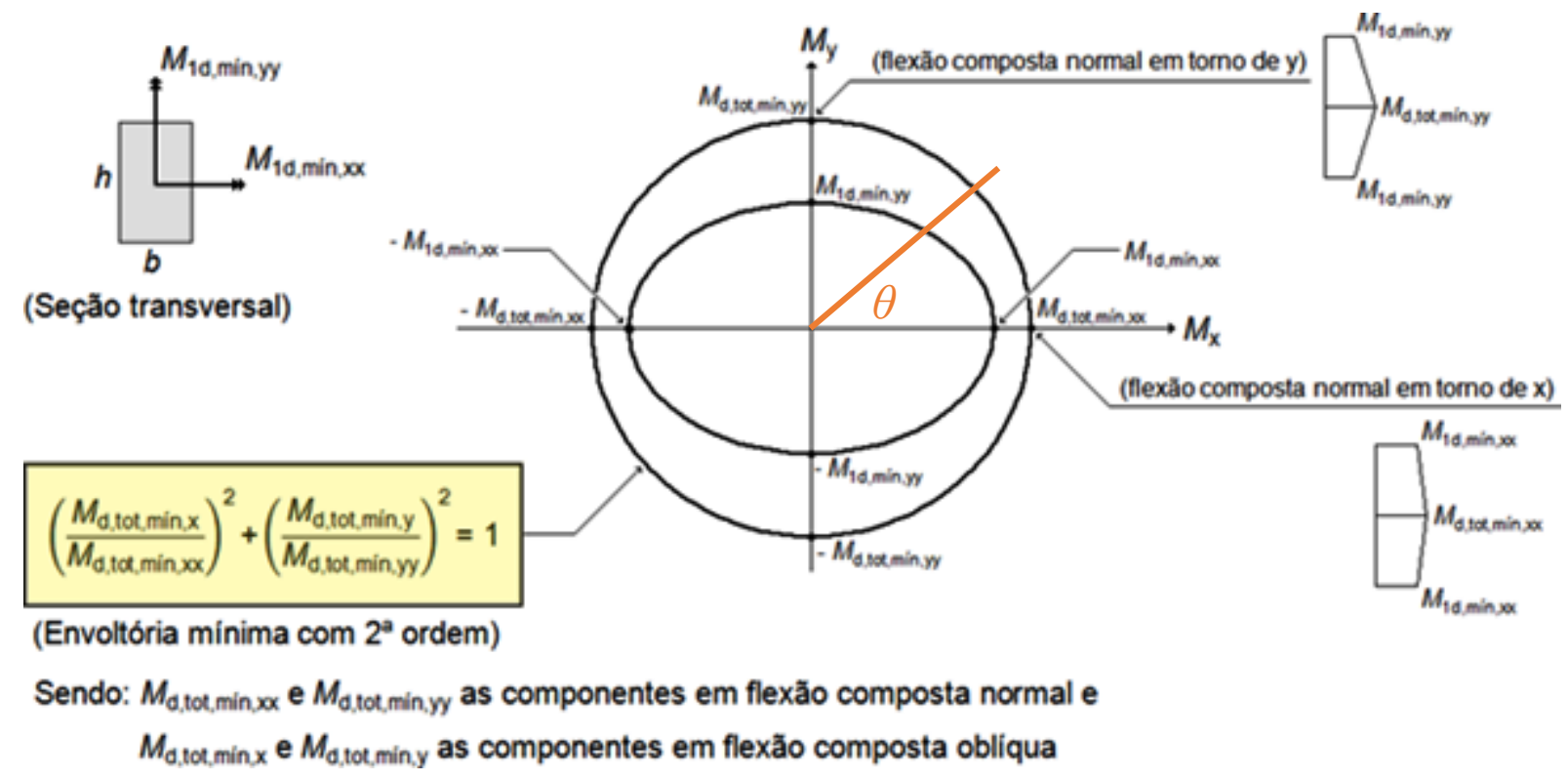

Fonte: adaptado de ABNT NBR 6118:2014.

Para o caso dos métodos aproximados, a envoltória mínima de segunda ordem é obtida a partir dos valores calculados em cada direção principal. No entanto, a determinação do momento total mínimo é realizada com o lance hipotético de momentos iguais em intensidade e em sentido nas extremidades do lance considerado.

Como alternativa algébrica para a verificação gráfica em questão, é razoável assumir que a direção da solicitação total coincide com a direção conhecida $\theta$ do momento solicitante de primeira ordem. Para um certo momento solicitante oblíquo $M_{S d, \theta}$ devem ser conhecidas as parcelas de momento total mínimo em cada direção ortogonal $\left(M_{d, t o t, m i n, x x}\right.$ e $\left.M_{d, t o t, m i n, y y}\right)$. Assim, é possível verificar o atendimento de momento total mínimo a partir de suas projeções sobre os eixos coordenados resolvendo a Eq. (2-24) pela imposição de única incógnita como sendo o módulo do vetor momento na direção $\theta$, tal como aqui sugerido na Figura 2-17: 
Figura 2-18 - Verificação de momentos fletores solicitantes.

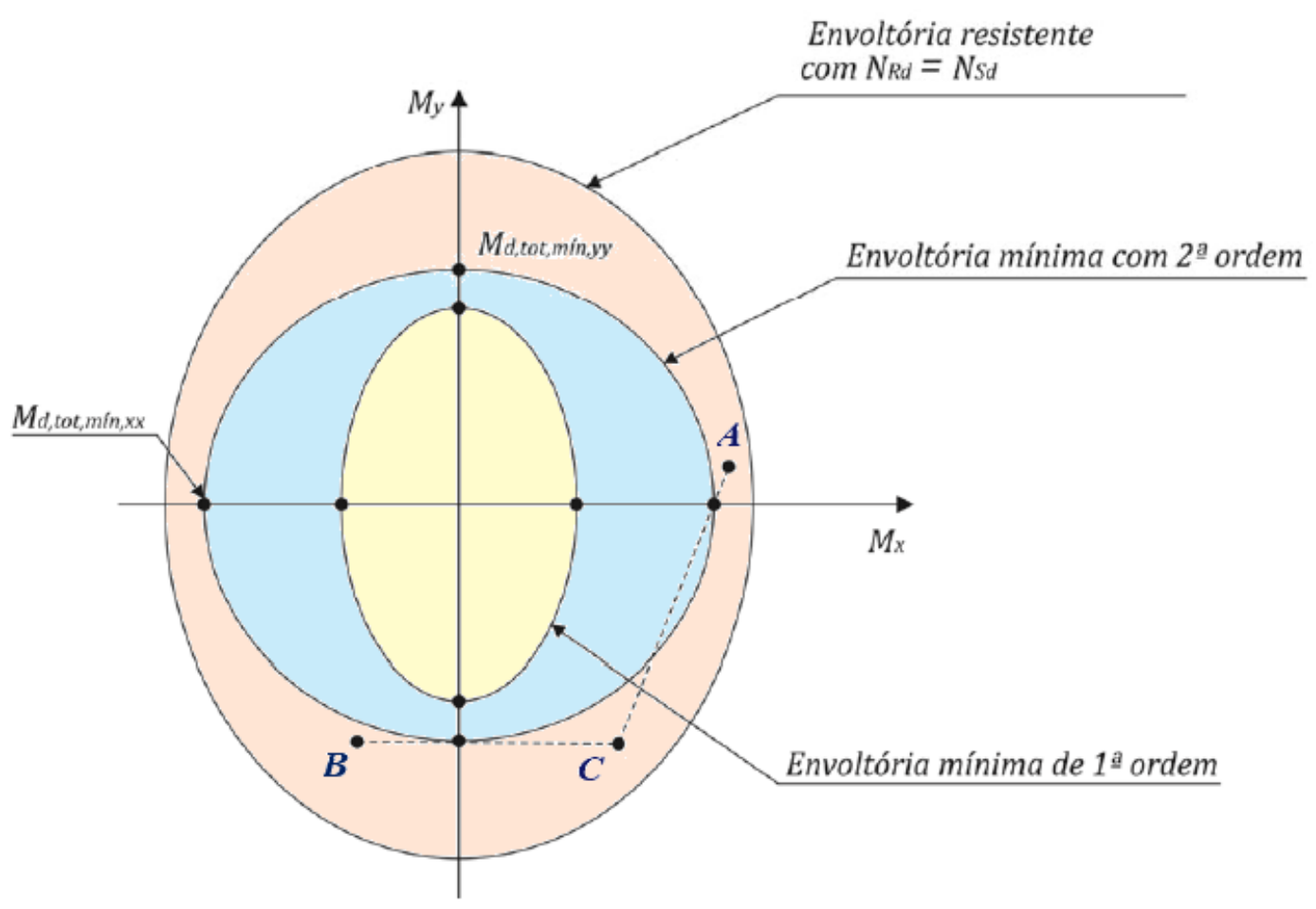

Fonte: adaptado de PINTO (2017).

$$
\begin{aligned}
& M_{d, t o t, \text { min }, \theta}{ }^{2}\left[\left(\frac{\cos \theta}{M_{d, t o t, \text { min }, x x}}\right)^{2}+\left(\frac{\operatorname{sen} \theta}{M_{d, t o t, \text { min }, y y}}\right)^{2}\right]=1 \\
& \therefore \quad M_{d, t o t, \text { in }, \theta}=\frac{1}{\sqrt{\left(\frac{\cos \theta}{M_{d, t o t, m i n, x x}}\right)^{2}+\left(\frac{\operatorname{sen} \theta}{M_{d, t o t, m i n, y y}}\right)^{2}}}
\end{aligned}
$$

Com relação à determinação do momento total mínimo, é importante salientar que o Comitê Técnico CT 301 responsável pela revisão da norma ABNT NBR 6118:2014 fomentou a publicação de texto com comentários adicionais, esclarecimentos e exemplos resolvidos para melhor entendimento de conceitos ao meio técnico (IBRACON, 2015). Nessa publicação, alguns exemplos resolvidos de pilares submetidos à flexão composta oblíqua são apresentados e, aparentemente, o momento total mínimo é resolvido apenas com o método de pilar padrão com acoplado a diagramas. 


\subsection{FLUÊNCIA}

A fluência é um fenômeno que ocorre no concreto sob tensão constante e solicitado por cargas de longa duração resultando no acréscimo de deformações ao longo do tempo. A norma brasileira considera a fluência através do coeficiente de fluência $\varphi\left(\mathrm{t}_{\infty}, \mathrm{t}_{0}\right)$. Nos casos onde não é necessária grande precisão, os valores de $\varphi\left(\mathrm{t}_{\infty}, \mathrm{t}_{0}\right)$ para elementos submetidos a tensões de compressão menores que $0,5 \mathrm{f}_{\mathrm{c}}$ podem ser extraídos por interpolação linear dos valores da Tabela 8.2 da ABNT NBR 6118:2014.

A fluência gera esforços adicionais no lance de pilar em virtude do aumento de deslocamentos decorrentes da mudança de curvatura quando a carga de compressão ou flexão é mantida constante. Segundo o item 15.8.4 da norma ABNT NBR 6118:2014, a consideração da fluência é obrigatória para análise de pilares com índice de esbeltez $\lambda>90$ e pode ser efetuada de maneira aproximada considerando a excentricidade adicional de fluência $e_{c c}$ dada pela expressão:

$$
e_{c c}=\left(\frac{M_{S g}}{N_{S g}}+e_{a}\right)\left[\exp \left(\frac{\varphi N_{S g}}{N_{e}-N_{S g}}\right)-1\right]
$$

Onde $M_{S g}$ e $N_{S g}$ são os esforços solicitantes na combinação quase permanente; $\varphi$ é o coeficiente de fluência; $E_{c i}$ é o módulo de deformação tangente do concreto, determinado segundo o item 8.1 da ABNT NBR 6118:2014; $I_{c}$ é a inércia bruta da seção de concreto; $A_{c}$ é a área bruta da seção de concreto; $L_{e}$ é o comprimento equivalente na direção mais esbelta.

A carga crítica de Euler definida em relação à maior esbeltez $\lambda$ do pilar por:

$$
N_{e}=\frac{\pi^{2}}{L_{e}^{2}} E_{c i} I_{c} \approx \frac{10}{L_{e}^{2}} E_{c i} I_{c}=\frac{10}{\lambda^{2}} E_{c i} A_{c}
$$

A excentricidade devida a imperfeições locais $e_{a}$ é definida pela Eq. (2-22) tomando a seção meio do vão como seção intermediária de referência.

Outro método para consideração da fluência, mais rigoroso, porém também aproximado, é baseado na correção do diagrama de tensão-deformação do concreto. Este método é apresentado por (FUSCO, 1981) utilizando a teoria linear da fluência, quando as tensões no concreto são suficientemente baixas. Sendo linear, é admitida uma função $\varphi$ de fluência independente da tensão aplicada. Como resultado, a deformação $\varepsilon_{c c}$ causada pela fluência é obtida 
multiplicando a deformação imediata do concreto $\varepsilon_{c}$ pela função $\varphi$ (CASAGRANDE, 2016) tal como indicado a seguir.

$$
\begin{gathered}
\varepsilon_{c}=\frac{\sigma_{c}}{E_{c}} \text { e } \varepsilon_{c c}=\varphi \varepsilon_{c} \\
\varepsilon_{c, t o t}=\varepsilon_{c}+\varepsilon_{c c} \\
\therefore \varepsilon_{c, t o t}=(1+\varphi) \varepsilon_{c}
\end{gathered}
$$

Sendo $\sigma_{c}$ a tensão de compressão no concreto; $E_{c}$ o módulo de deformação do concreto; $\varepsilon_{c}$ a deformação no concreto; $\varepsilon_{c c}$ a deformação no concreto devido à fluência; $\varepsilon_{c, t o t}$ a deformação total do concreto.

Com a consideração da fluência, o diagrama de tensão-deformação do concreto sofre um deslocamento horizontal, conforme apresentado na Figura 2-19. Pode ser obtido o diagrama normal-momento-curvatura relativo a este novo comportamento do concreto e, com isso, é possível avaliar os efeitos de segunda ordem.

É interessante apontar que enquanto a norma brasileira permite a dispensa de fluência para todos os pilares com esbeltez menor ou igual a 90, a norma europeia EN 1992:2004 só permite dispensar quando são atendidos simultaneamente os três critérios seguintes:

$$
\begin{aligned}
& \lambda \leq 75 \\
& \varphi \leq 2 \\
& e_{1} \geq h
\end{aligned}
$$

Figura 2-19 - Fluência no diagrama tensão-deformação.

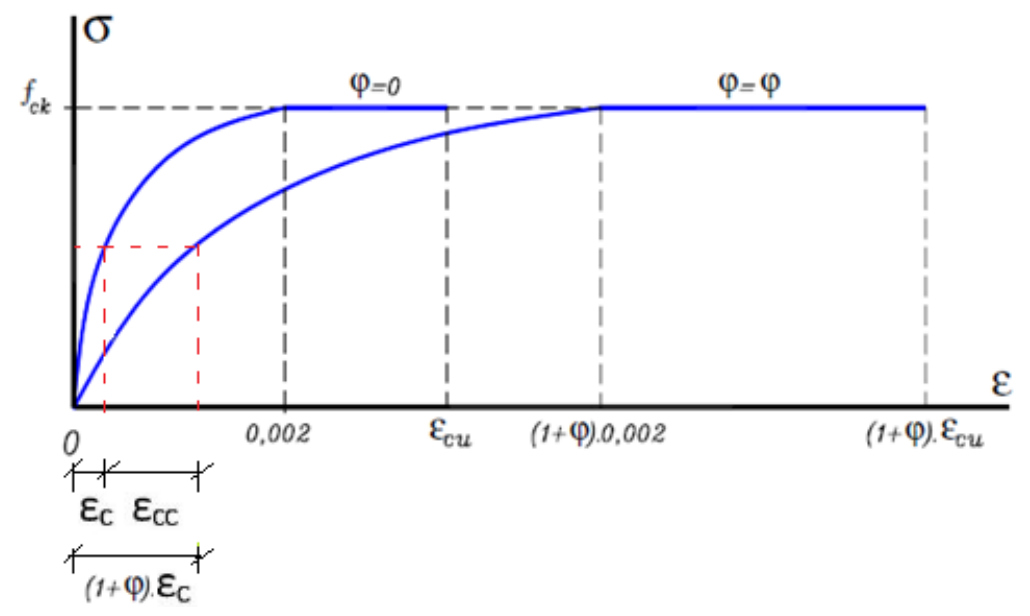

Fonte: AGUIAR (2000). 
Além de adotar limite de esbeltez menor em relação à norma brasileira, o código europeu EN 1992:2004 ainda especifica limite para o coeficiente de fluência e para a excentricidade mínima, o que implica em aproximar o problema da flexão composta para o problema da flexão simples. A norma europeia também prevê o uso de método mais rigoroso na consideração da fluência pelo ajuste do diagrama tensão-deformação, o que não acontece na ABNT NBR 6118:2014, que sugere somente o método simplificado da excentricidade adicional.

ARAÚJO (1984) e CASAGRANDE (2016) concluíram que o limite imposto pela norma brasileira exigindo a consideração da fluência apenas para pilares com esbeltez maior que 90 é imprudente.

Na seguinte pesquisa a consideração do efeito de fluência para os Métodos de Curvatura aproximada e de Rigidez aproximada foi realizada pela adição da excentricidade de fluência, em virtude da formulação destes métodos não permitir o uso do método mais rigoroso de consideração. Enquanto que para o Método acoplado a diagramas e Método Geral, a consideração foi feita através da correção do diagrama de tensão-deformação do concreto. 



\section{EFEITOS DE SEGUNDA ORDEM EM PILARES}

Neste Capítulo são apresentados os métodos descritos na norma ABNT NBR 6118:2014 para a avaliação dos efeitos locais de segunda ordem de pilar de concreto armado.

\subsection{MÉTODO DO PILAR PADRÃO}

O pilar padrão é definido como um pilar com distribuição de curvaturas que provoque um deslocamento lateral $a$ que deve ser determinado tal como a frente é indicado. Admitindo um elemento bi rotulado de comprimento $L$ exemplificado na Figura 3-1, a linha elástica pode ser convenientemente suposta como uma função senoidal para permitir facilidade no processo de derivação algébrica.

Figura 3-1 - Linha elástica senoidal.

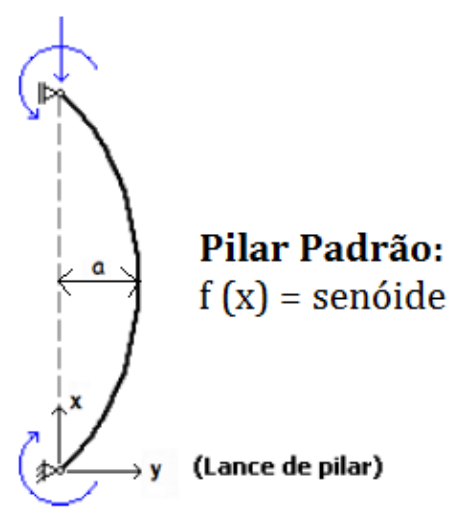

Fonte: KIMURA (2019).

Sendo assim, podem ser impostas as seguintes relações:

$$
y=-a \operatorname{sen} \frac{\pi}{L} x
$$




$$
\begin{gathered}
\frac{d y}{d x}=-a \frac{\pi}{L} \cos \frac{\pi}{L} x \\
\frac{d^{2} y}{d x^{2}}=a\left(\frac{\pi}{L}\right)^{2} \operatorname{sen} \frac{\pi}{L} x
\end{gathered}
$$

Com a equação simplificada da curvatura, esta pode ser imposta pela relação:

$$
\frac{1}{r}=\frac{d^{2} y}{d x^{2}}
$$

Portanto, a curvatura da seção meio de comprimento do pilar é expressa por:

$$
\left.\frac{1}{r}\right|_{x=L / 2}=\left.\frac{d^{2} y}{d x^{2}}\right|_{x=L / 2}=a\left(\frac{\pi}{L}\right)^{2}
$$

O deslocamento lateral máximo a para o caso básico de pilar bi rotulado pode ser escrito sob a forma:

$$
a=\left.\frac{L_{e}^{2}}{\pi^{2}} \frac{1}{r}\right|_{x=L / 2}
$$

Para o outro caso básico de pilar em balanço, o deslocamento lateral é:

$$
a=\left.\frac{l_{e}^{2}}{\pi^{2}} \frac{1}{r}\right|_{\text {base }}
$$

A linha elástica destes dois casos básicos de pilares é ilustrada na Figura 3-2. O deslocamento lateral máximo depende do comprimento do pilar e da sua curvatura e é uma função linear dessa curvatura na seção da base do pilar ou no meio do comprimento.

Identificando esse deslocamento lateral máximo de $e_{2}$, e impondo a simplificação usual de $\pi^{2}=10$, pode ser então fixada a excentricidade de segunda ordem como sendo:

$$
e_{2}=a=\frac{L_{e}^{2}}{10} \cdot \frac{1}{r}
$$

Portanto, a parcela de flexão correspondente ao efeito de segunda ordem local fica definida por:

$$
M_{2}=N \cdot e_{2}=N \frac{L_{e}^{2}}{10} \frac{1}{r}
$$


Figura 3-2 - Linha elástica de pilar em balanço e de pilar bi rotulado.

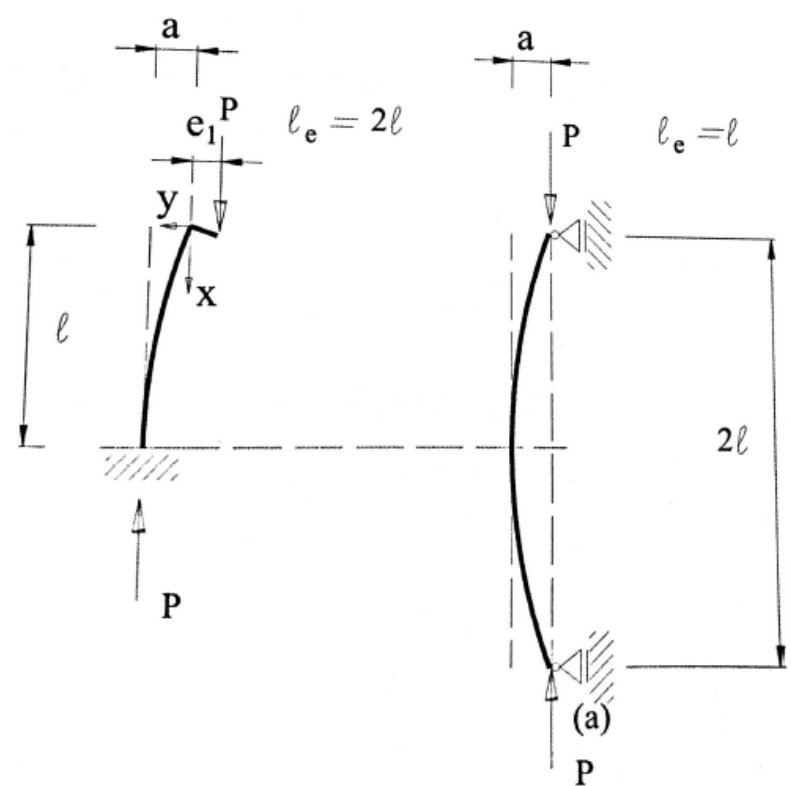

Fonte: CARVALHO e PINHEIRO (2009)

Da Eq. (3-1) é possível concluir que o momento fletor de segunda ordem na seção crítica é diretamente proporcional à curvatura dessa seção.

Impondo a forma final do pilar como uma senóide, é possível obter a solução analítica para o problema da não-linearidade geométrica. A norma ABNT NBR 6118:2014 apresenta três métodos aproximados para tratar a não-linearidade geométrica de forma idêntica. A diferença entre eles é a forma de considerar a não-linearidade física e a Figura 3-3 esquematiza os processos aproximados normatizados.

Figura 3-3 - Esquema para consideração de não linearidades em pilares.

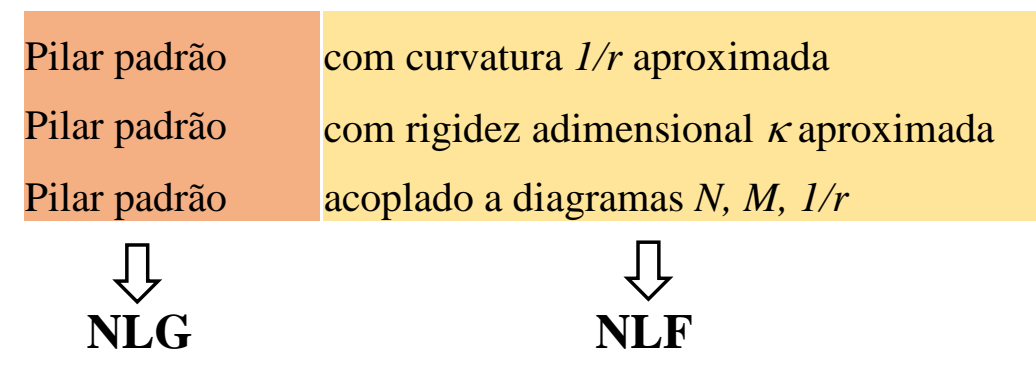

Fonte: Adaptado de KIMURA (2019).

Trabalhos como os de SCADELAI (2004), LEITÃO (2016) e PINTO (2017) apresentaram comparações entre os métodos de pilar padrão e o método geral para pilares com esbeltez 
até 90 e concluíram que os métodos aproximados constituem uma grande ferramenta de cálculo pela sua simplicidade e rapidez conduzindo a dimensionamento seguro. Entretanto, caso se disponha de um equipamento computacional e se pretenda obter resultados mais precisos, o método geral é sempre o mais adequado.

SCADELAI (2004) e PIRES (2006) concluíram que as limitações que a norma impõe para os métodos aproximados quanto ao índice de esbeltez é importante, pois no caso de pilares esbeltos, podem ser obtidos resultados contra a segurança em alguns casos.

Os métodos aproximados geralmente fornecem bons resultados e sua aplicação é bem mais simples que o método geral, porém, como consequência o dimensionamento de armadura é menos econômico. Cabe ao projetista escolher o método mais adequado para certo projeto de acordo com suas prioridades.

Os quatro métodos de cálculo são descritos a seguir.

\subsection{MÉTODO DO PILAR PADRÃO COM CURVATURA APROXIMA- DA}

Segundo a norma ABNT NBR 6118:2014 este método pode ser empregado apenas em pilares com $\lambda \leq 90$, seção constante e armadura simétrica e constante ao longo do seu eixo. A não linearidade geométrica é considerada supondo que a deformação da barra seja senoidal. A não linearidade física é considerada através de expressão aproximada da curvatura na seção crítica.

A curvatura de uma barra de concreto armado na situação deformada pode ser avaliada pela Eq. (2-11). Utilizando o valor adimensional $v$ para a força normal reduzida apresentado na Eq. (2-4), a Eq. (2-11) pode ser modificada para considerar o efeito da flexão composta quando do deslocamento lateral do pilar, novamente substituindo $d \approx h$ e ficando no formato:

$$
\frac{1}{r}=\frac{\varepsilon_{c}+\varepsilon_{s}}{(v+0,5) h}
$$

Neste método aproximado é considerado a favor da segurança, que a curvatura deve ter o maior valor possível e, portanto, as deformações do concreto e do aço deverão ser iguais àquelas correspondentes ao Estado Limite Último. Para o caso de concretos de classe até C50 MPa estas deformações são: 


$$
\begin{gathered}
\varepsilon_{c}=\varepsilon_{c u}=3,5 \% 0 \\
\varepsilon_{s}=\varepsilon_{y d}=\frac{f_{y d}}{E_{s}}
\end{gathered}
$$

Considerando aços CA-50 com tensão de escoamento igual $f_{y k}=500 M P a$ e coeficiente de minoração $\gamma_{s}=1,15$, resulta a deformação de escoamento:

$$
\varepsilon_{s}=\frac{f_{y d}}{E_{s}}=\frac{500 / 1,15}{210}=2,07 \%
$$

A expressão da curvatura crítica adotada na norma ABNT NBR 6118:2014 fica determinada substituindo as Eqs. (3-3) e (3-4) na Eq. (3-2) resultando em:

$$
\frac{1}{r}=\frac{3,5 \% \mathrm{o}+2,07 \% \mathrm{o}}{(v+0,5) h} \approx \frac{5 \% \mathrm{o}}{(v+0,5) h}
$$

O momento de segunda ordem é obtido por:

$$
M_{2 d}=\frac{L_{e}^{2}}{10} \cdot \frac{5 \% \text { o }}{(v+0,5) h} N_{d}
$$

Portanto, o momento fletor total máximo (primeira ordem e segunda ordem) da seção crítica resulta em:

$$
M_{S d, t o t}=\alpha_{b} M_{1 d, A}+\frac{L_{e}^{2}}{10} \frac{1}{r} N_{d} \geq M_{1 d, A}
$$

Impondo ainda os seguintes limites:

$$
\begin{gathered}
M_{S d, t o t} \geq M_{1 d, \text { min }} \\
\frac{1}{r}=\frac{5 \% 0}{(v+0,5) h} \leq \frac{5 \% \text { o }}{h}
\end{gathered}
$$

O limite da curvatura crítica foi indicado na ABNT NBR 6118:1980, na qual havia limite para $v+0,5 \geq 1$, ou seja, é possível obter o momento total simplificando a Eq. Eq. (2-7) como sendo:

$$
M_{S d, t o t}=\alpha_{b} M_{1 d, \mathrm{~A}}+\frac{N_{d}}{2.000} \frac{L_{e}^{2}}{f(v) h}
$$


com

$$
f(v)=\left\{\begin{array}{l}
1 \quad \rightarrow \text { para } v \leq 0,5 \\
v+0,5 \rightarrow \text { para } v>0,5
\end{array}\right.
$$

Separando a parcela exclusiva do efeito de segunda ordem local, pode ser escrito:

$$
M_{2 d}=\frac{N_{d}}{2.000} \frac{L_{e}^{2}}{f(v) h}
$$

\subsection{MÉTODO DO PILAR PADRÃO COM RIGIDEZ ADIMENSIONAL}

Este método pode ser empregado apenas para pilares com $\lambda \leq 90$, seção retangular constante e armadura simétrica e constante ao longo do seu eixo. A não linearidade geométrica é considerada supondo que a deformação da barra seja senoidal. A não linearidade física é considerada através de expressão aproximada da rigidez secante (ABNT NBR 6118:2014).

O momento total solicitante máximo no pilar é estimado por:

$$
M_{S d, t o t}=\frac{\alpha_{b} M_{1 d, A}}{1-\frac{v \lambda^{2}}{120 \cdot \kappa_{\text {aprox }}}} \geq M_{1 d, A}
$$

Neste método, o valor da rigidez adimensional $\kappa$ (kapa) é imposto de modo aproximado como sendo:

$$
\kappa_{a p r o x}=32\left(1+5 \frac{M_{R d, t o t}}{h \cdot N_{s d}}\right)
$$

No processo de dimensionamento é considerado $M_{R d, t o t}=M_{S d, t o t}$. No processo de verificação é obtido o momento total através de cálculo iterativo buscando a convergência dos parâmetros $\kappa_{\text {aprox }}$ e $M_{S d, t o t}$. A armadura neste caso deve ser previamente conhecida e o $M_{R d}$ é o momento fletor resistente calculado com essa armadura e para $N_{R d}=N_{S d}$.

Para a realização do dimensionamento não é necessária a iteração, pois admitindo $M_{R d, t o t}=M_{S d, t o t}$ e uma função aproximadora parabólica resulta na formulação a seguir:

$$
A M_{s d, t o t}^{2}+B M_{s d, t o t}+C=0
$$


sendo:

$$
\left\{\begin{array}{l}
A=5 h \\
B=h^{2} N_{s d}-\frac{N_{s d} \cdot L_{e}^{2}}{320}-5 h \cdot \alpha_{b} M_{1 d, A} \\
C=-N_{s d} h^{2} \alpha_{b} M_{1 d, A}
\end{array}\right.
$$

A norma ABNT NBR 6118:2014 sugere resolver a Eq. (3-11) para obter o momento total utilizando a fórmula de Báskara e desprezando a raiz indevida:

$$
M_{S d, t o t}=\frac{-B+\sqrt{B^{2}-4 A C}}{2 A}
$$

No entanto, esta última expressão pode ser simplificada com a utilização de alguns adimensionais para recair na formulação direta adimensional seguinte para seção retangular (MIGLIORE JUNIOR, 2018). De fato, é possível reescrever a Eq. (3-12) colocando-a da seguinte forma:

$$
M_{S d, t o t}=\left(\alpha_{b} \mathrm{e}_{1}+\mathrm{e}_{2}\right) N_{S d}=\frac{-B}{2 A}+\sqrt{\left(\frac{-B}{2 A}\right)^{2}-\frac{C}{A}}
$$

sendo $e_{1}$ e $e_{2}$ as excentricidades estaticamente equivalentes na seção crítica de dimensionamento de primeira e de segunda ordem, respectivamente.

Desenvolvendo os fatores envolvidos, resulta:

$$
\begin{gathered}
\frac{-B}{2 A}=\frac{N_{s d}}{10 h}\left(-h^{2}+\frac{L_{e}^{2}}{320}+5 h \alpha_{b} e_{1}\right)=\beta h N_{s d} \\
-\frac{C}{A}=\frac{h^{2} \alpha_{b} \mathrm{e}_{1} N_{s d}}{5 h}=0,2 h^{2} \xi_{1} N_{s d} \\
\beta h=\frac{\left(\frac{\lambda h}{\sqrt{12}}\right)^{2}}{10 \times h \times 320}+\frac{5}{10} \alpha_{b} \mathrm{e}_{1}-0,1 h \\
\frac{M_{S d, t o t}}{h N_{d}}=\frac{\alpha_{b} e_{1}+e_{2}}{h}=\beta+\sqrt{\beta^{2}+0,2 \xi_{1}}
\end{gathered}
$$


com:

$$
\left\{\begin{array}{l}
\xi_{1}=\alpha_{b} \frac{e_{1}}{h} \\
\lambda=\sqrt{12} \frac{L_{e}}{h} \\
\beta=\frac{\lambda^{2}}{38.400}+\frac{\xi_{1}}{2}-0,1
\end{array}\right.
$$

É interessante observar que a Eq. (3-13) representa a excentricidade total relativa para certa direção considerada e a parcela correspondente exclusivamente ao efeito de segunda ordem local por ser colocada na forma de:

$$
\begin{aligned}
& \frac{M_{S d, 2}}{h N_{S d}}=\frac{e_{2}}{h}=\beta-\xi_{1}+\sqrt{\beta^{2}+0,2 \xi_{1}} \\
\therefore \quad M_{S d, 2} & =\left(\beta-\xi_{1}+\sqrt{\beta^{2}+0,2 \xi_{1}}\right) h N_{S d}
\end{aligned}
$$

A expressão que apresenta o valor da rigidez adimensional $\kappa$ aproximada tem como origem as curvas de interação adimensionais Momento-Normal-Rigidez Secante. A partir dos valores encontrados nos ábacos, é construído o gráfico de $\mu / v$ e $\kappa / v$. Um exemplo realizado por Oliveira (2004) é ilustrado na Figura 3-4. Ao construir uma reta que ajusta de modo conservador os valores, é encontrada a expressão da rigidez adimensional $\kappa$ aproximada descrita na ABNT NBR 6118:2014:

$$
\kappa_{\text {aprox }}=32\left(1+5 \frac{\mu}{v}\right)
$$

Figura 3-4 - Gráfico para obtenção da expressão de к aproximado.

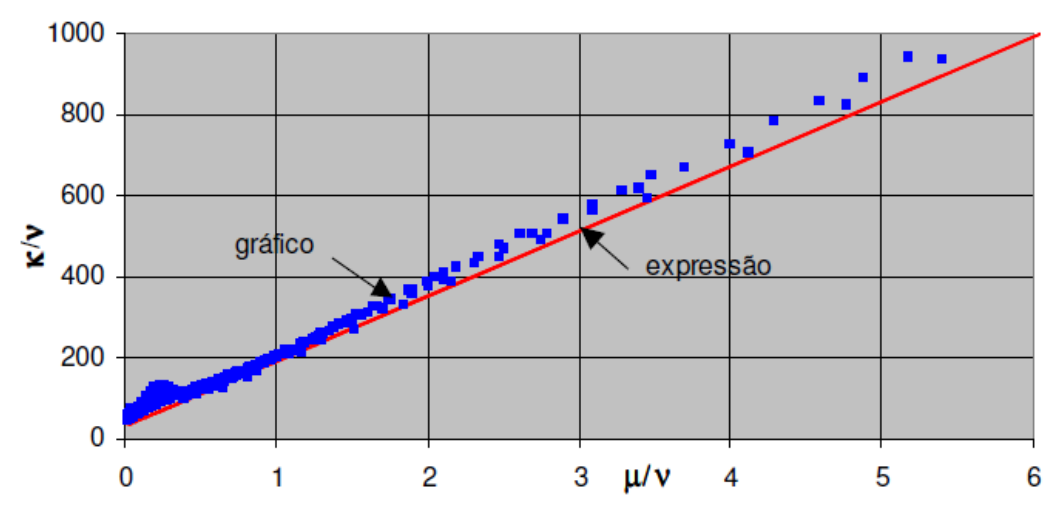

Fonte: Oliveira (2004). 


\subsection{MÉTODO DO PILAR PADRÃO ACOPLADO A DIAGRAMAS}

Este método foi idealizado por França (1991) e, segundo a norma ABNT NBR 6118:2014 pode ser empregado para pilares com $\lambda \leq 140$. Se $\lambda>90$, a consideração do efeito de fluência é obrigatória.

A não linearidade geométrica é considerada admitindo que a posição deformada da barra seja senoidal. A não linearidade física é considerada por meio da rigidez secante obtida através da linearização do diagrama $N, M, 1 / r$ (Figura 2-7). Para seções retangulares, a expressão para rigidez secante adimensional é-imposta como sendo (FRANÇA, 1991):

$$
\kappa=\frac{E I_{\mathrm{sec}}}{A_{c} h^{2} f_{c d}}
$$

$\operatorname{com} \frac{1}{r} E I_{\text {sec }}=\frac{M_{R d}}{\gamma_{f 3}}$

Obtendo a rigidez adimensional $\kappa$ é possível calcular o momento fletor total da seção crítica $M_{S d, t o t}$, apresentado pela Eq. (3-18). O momento total máximo no pilar é calculado pela amplificação do momento de primeira ordem $\alpha_{b} M_{1 d, A}$.

$$
M_{S d, t o t}=\frac{\alpha_{b} M_{1 d, A}}{1-\frac{v \lambda^{2}}{120 \gamma_{f 3} \kappa}}
$$

A rigidez secante é extraída a partir da construção de diagramas $N, M, 1 / r$. Outra possibilidade para obtenção dessa rigidez é através de ábacos de interação força normal-momento fletor. O procedimento para a construção desses ábacos é apresentado em FRANÇA (1991) que construiu ábacos para seção transversal retangular com três tipos de disposição de armaduras, conforme exemplificado na Figura 3-5. Dando continuidade a esse trabalho, OLIVEIRA (2004) organizou vários ábacos $v, \mu, \kappa$ para seção retangular, variando o tipo de arranjo de armaduras e o coeficiente de fluência $\varphi$. 
Figura 3-5 - Exemplo de ábaco $v, \mu, \kappa$

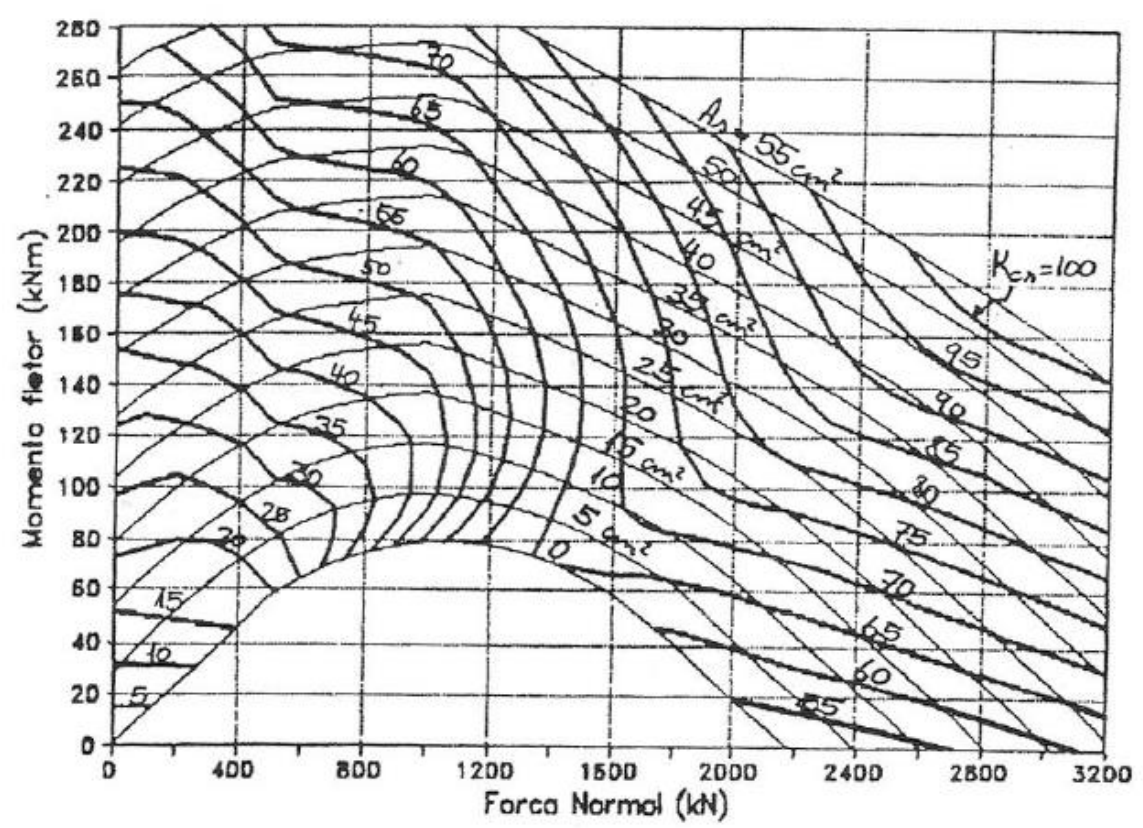

Fonte: FRANÇA (1991)

\subsection{MÉTODO GERAL}

O método geral consiste na análise não-linear de segunda ordem com discretização adequada da barra e com a consideração da relação momento-curvatura teórica em cada seção e a não-linearidade geométrica de maneira não aproximada. Segundo a norma ABNT NBR 6118: 2014 o método é obrigatório para $\lambda>140$ e pode ser aplicado a pilares com seção transversal qualquer.

Este método fornece uma solução teórica mais refinada. No entanto, quanto maior a precisão almejada, maior é a complexidade dos procedimentos de análise. Em geral, a consideração do comportamento não linear envolve métodos iterativos, cuja solução só pode ser obtida por meio de tentativas ou aproximações sucessivas.

Com o método geral é determinada inicialmente a relação momento-curvatura para certo arranjo de armadura. Na sequência, deve ser determinada a curva da deformada da peça analisada através da discretização adequada da barra em $n$ segmentos. Para isso, é necessário o emprego de métodos iterativos, sendo mais adotados o método das diferenças finitas e a 
analogia de Mohr. Ambos os processos são bastante precisos e fornecem resultados semelhantes.

O método iterativo consiste em aplicar o carregamento em parcelas (carregamento incremental) de modo que em cada etapa seja possível considerar o deslocamento da etapa anterior e, se for o caso, a variação da rigidez ao longo da peça. Em cada etapa o procedimento é linear. A carga crítica é alcançada quando a curva carga-deslocamento atinge o valor máximo, conforme ilustra a Figura 3-6 (CARVALHO \& PINHEIRO, 2009).

Figura 3-6 - Diagrama carga-deslocamento com carregamento incremental.

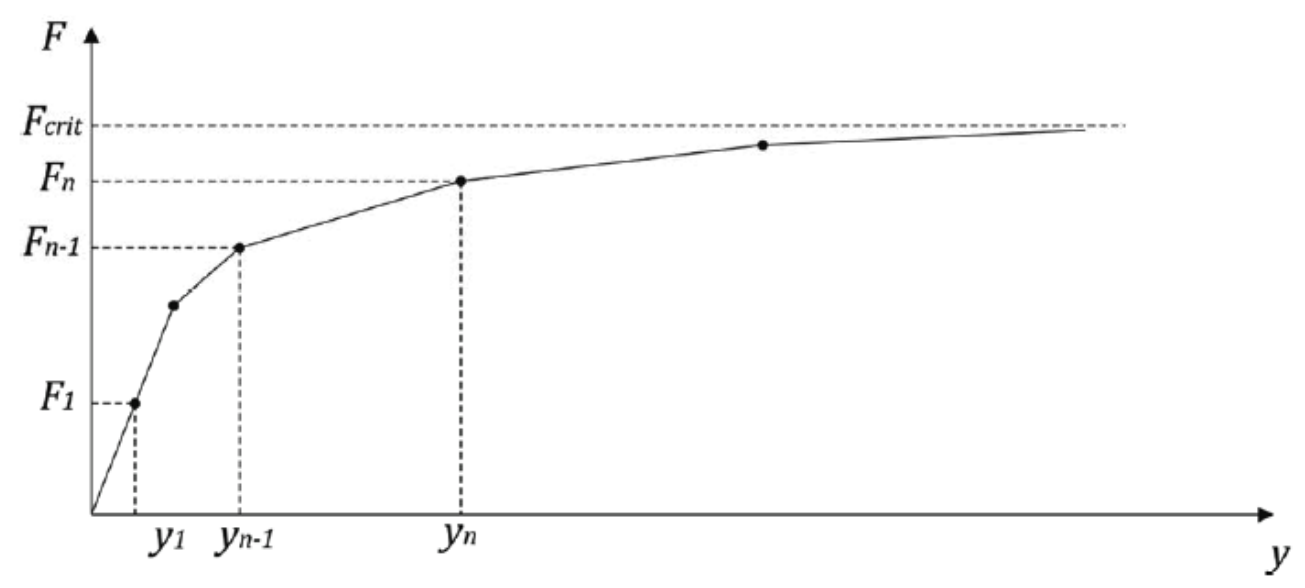

Fonte: CARVALHO e PINHEIRO (2009).

Na flexão oblíqua, a determinação da carga crítica é analisada nas direções independentes $x$ e $y$. A Figura 3-7 apresenta os diagramas de flechas de $w_{x}$ e $w_{y}$ a partir de valores de carga $F$. A carga crítica será determinada pelo diagrama que atingir primeiro o valor máximo.

\subsubsection{Diferenças finitas}

Na resolução numérica pelo método de diferenças finitas o pilar é segmentado em $n$ seções equidistantes. Quanto mais divisões, mais preciso será o resultado obtido. A fundamentação consiste na seguinte premissa: para um pilar engastado na base e livre no topo, não se conhece o valor do deslocamento no topo do pilar $a$ e é adotado um valor inicial arbitrário. Para este deslocamento no topo são determinados os deslocamentos ao longo de todo comprimento do pilar, expressos pela diferença $a-y_{i}$ posicionando o sistema de eixos cartesianos 
de referência conforme a Figura 3-8 na extremidade livre de um pilar engastado na base e livre no topo.

Figura 3-7 - Determinação da carga crítica na flexão oblíqua.

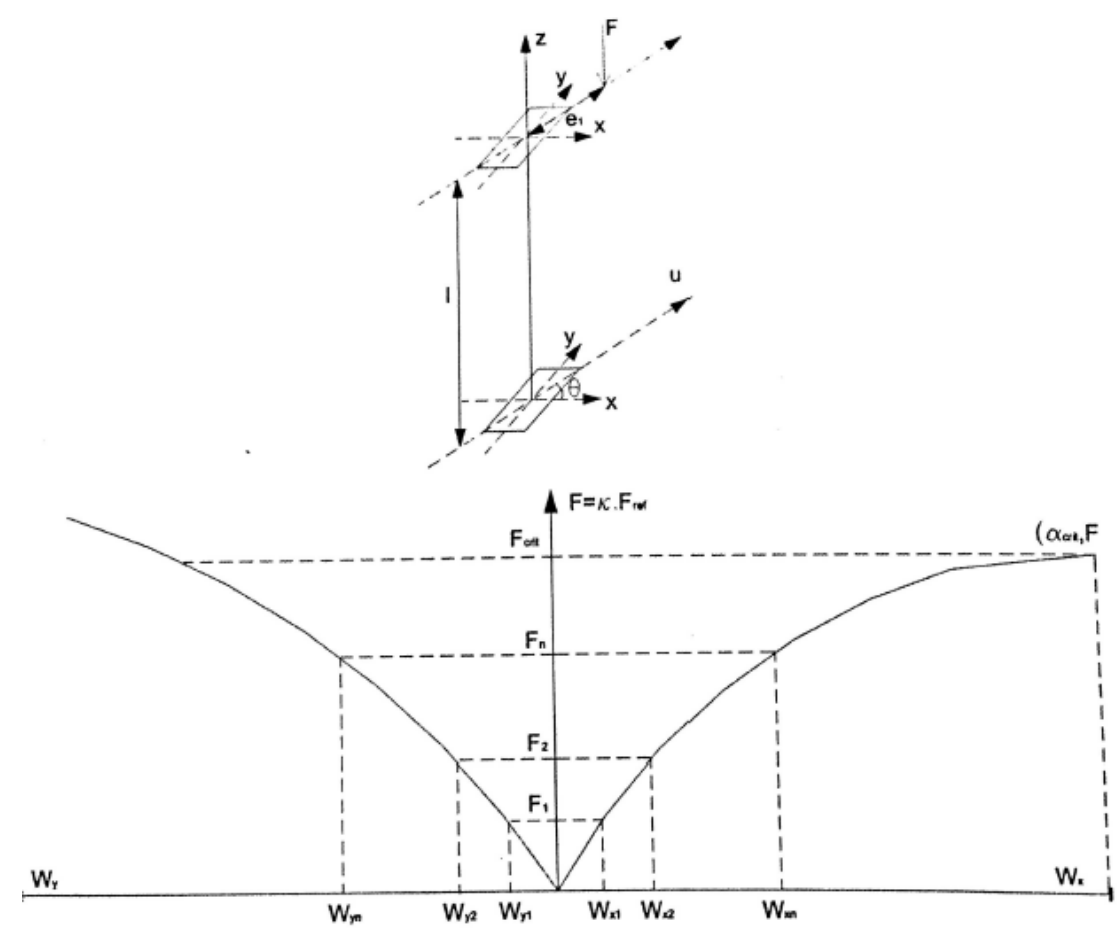

Fonte: CARVALHO e PINHEIRO (2009).

Impondo que o deslocamento final no topo do pilar deve ser nulo, pode ser adotado outro valor inicial para $a$ até que o deslocamento no topo seja efetivamente igual a zero.

Os deslocamentos em cada seção podem ser obtidos pelas Equações seguintes:

$$
\begin{gathered}
y_{1}=y_{0}-\left.\frac{\Delta x^{2}}{2} \frac{1}{r}\right|_{0} \\
y_{i+1}=2 y_{i}-y_{i-1}-\left.\Delta x^{2} \frac{1}{r}\right|_{i}
\end{gathered}
$$


Figura 3-8 - Discretização da deformada de pilar.

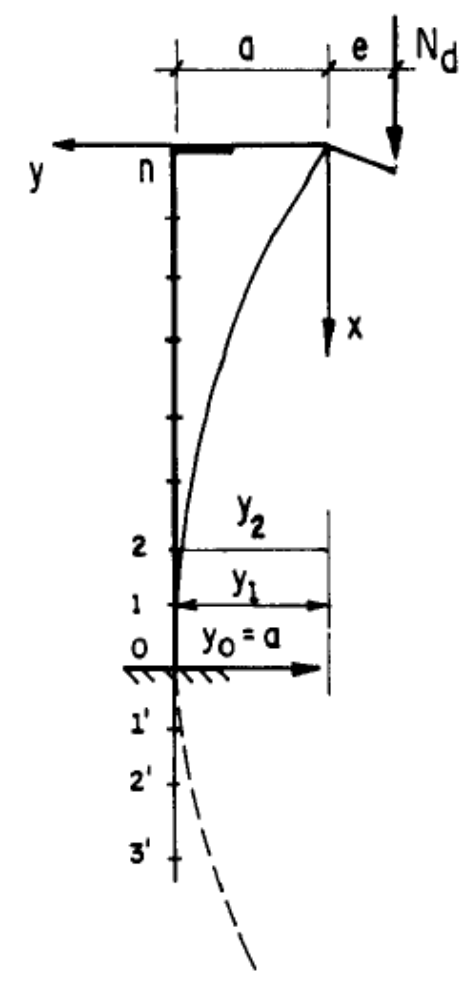

Fonte: (BACARJI, 1993)

BACARJI (1993) esclarece o processo de aplicação do método das diferenças finitas com as seguintes etapas:

a) O pilar é sub dividido em n trechos de comprimento $\Delta x=\frac{L}{n}$, onde L representa o comprimento total do pilar;

b) É arbitrado um valor qualquer para a flecha a no topo do pilar, resultando em $y_{0}=a$. Geralmente este valor inicial é adotado como sendo: $a=\left.\frac{L_{e}^{2}}{\pi^{2}} \frac{1}{r}\right|_{0} \approx \frac{L_{e}^{2}}{10} \frac{5 \% \mathrm{o}}{h} \approx \frac{L_{e}^{2}}{2.000 \mathrm{~h}}$;

c) Conhecendo a força normal, é calculado o momento fletor de segunda ordem na base engastada: $\left.M_{2 d}\right|_{0}=N_{d} \cdot a$;

d) Conhecendo a excentricidade inicial, é calculado o momento fletor total no engastamento pela expressão: $M_{0}=\left.M_{1 d}\right|_{0}+\left.M_{2 d}\right|_{0}$; 
e) A partir da relação momento-curvatura é obtida a curvatura $\left.\frac{1}{r}\right|_{0}$ correspondente ao momento fletor $M_{0}$;

f) Com as Eqs. (3-19) e (3-20) é calculado o valor de $y_{i}$;

g) Com o valor de $y_{i}$ o processo é repetido a partir do item c);

h) Na seção do topo é verificado se $y_{n}=0$ e, caso contrário, retorna-se ao item b) e arbitra-se um novo valor para a flecha a

A deformada teórica do pilar é obtida quando resultar $y_{n}=0$.

\subsubsection{Analogia de Mohr}

A analogia de Mohr é um processo de integração das curvaturas que apresenta boa precisão no valor da flecha e do momento fletor atuante quando utilizado adequadamente (RIBEIRO, 2011). Este processo foi desenvolvido a partir da semelhança entre a equação diferencial simplificada da linha elástica Eq. (3-21) e a equação diferencial da estática Eq. (3-22); das derivadas dos momentos Eq. (3-23) e dos deslocamentos Eq. (3-24) em relação à coordenada longitudinal $x$ (TIMOSHENKO, 1966), conforme as expressões seguintes:

$$
\begin{gathered}
\frac{d^{2} y}{d x^{2}}=-\frac{1}{r}=-\frac{M}{E I} \\
\frac{d^{2} M}{d x^{2}}=-q \\
\frac{d M}{d x}=V \\
\frac{d y}{d x}=\theta
\end{gathered}
$$

A partir dessas relações, é possível observar analogia entre os momentos fletores $M$ e deslocamentos $y$, entre força cortante $V$ e deslocamentos angulares $\theta$ e entre a carga imposta $q$ e a curvatura $1 / r$.

A analogia de Mohr considera um elemento de barra real como uma viga análoga ou conjugada e submetida a uma carga fictícia distribuída de valor $q^{\prime}=\frac{M}{E I}$, sendo $M$ o momento 
fletor atuante na barra real. A cortante $V^{\prime}$ na viga análoga será correspondente ao giro $\theta$ na barra real e o diagrama de momento $M^{\prime}$ corresponde à linha elástica $y$.

A viga análoga é uma viga que respeita as condições de deslocamento da barra original, conforme ilustra a Figura 3-9 para os vínculos nas extremidades de barras usuais.

A analogia de Mohr pode ser utilizada em peças de concreto armado desde que o carregamento fictício aplicado na viga conjugada seja igual a $q^{\prime}=1 / r$ e é necessário que essa curvatura seja obtida através da relação entre o momento real e os diagramas de momento fletorforça normal-curvatura.

Como exemplo, pode ser considerado o pilar bi rotulado à esquerda da Figura 3-10 com força de compressão $N_{d}$ e excentricidade $e$ em ambas as extremidades, cuja viga conjugada à direita da Figura está submetida a carga fictícia $w=1 / r$ constante em todo comprimento. O pilar pode ser dividido em $n$ segmentos de igualmente espaçados com $\Delta x=\frac{L}{n}$.

Figura 3-9 - Transformação de vínculos para obtenção da viga conjugada.

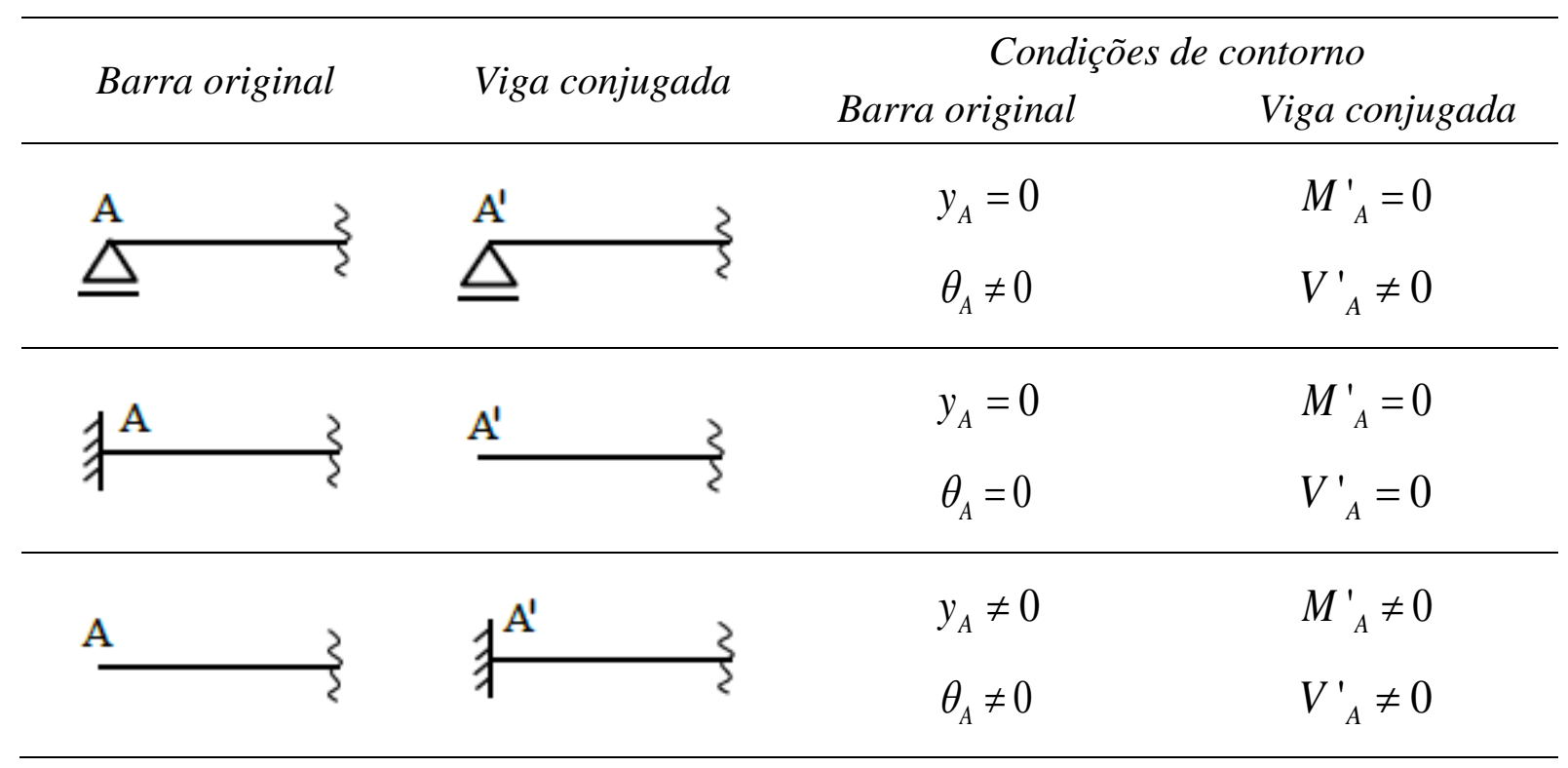

Fonte: Adaptado de RIBEIRO (2011). 
Figura 3-10 - Pilar bi rotulado real e pilar conjugado.

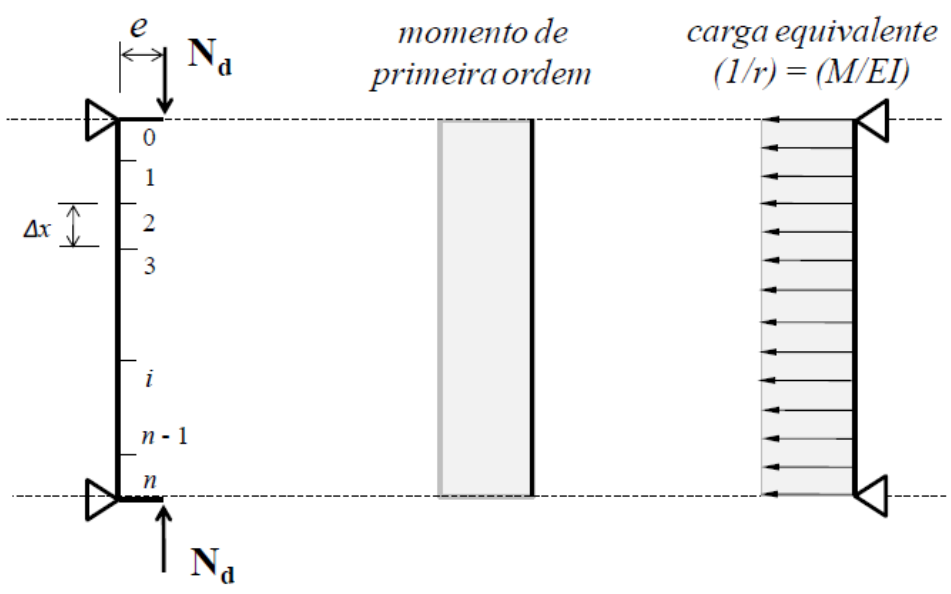

Fonte: RIBEIRO (2011)

O processo consiste em aplicar a distribuição de momentos como carregamento da barra conjugada e obter para cada seção o valor da resultante do carregamento. O diagrama de momentos de primeira ordem pode ser aplicado na viga conjugada como um conjunto de cargas parciais concentradas de intensidade:

$$
\begin{gathered}
w_{i}=w_{0}=w_{n}=\frac{1}{r} \frac{\Delta x}{2} \quad \text { para }\left\{\begin{array}{l}
i=0 \\
i=n
\end{array}\right. \\
w_{i}=\frac{1}{r} \Delta x \text { para }\left\{\begin{array}{l}
i \neq 0 \\
i \neq n
\end{array}\right.
\end{gathered}
$$

Essas cargas concentradas são denominadas "pesos elásticos". A Figura 3-11 apresenta à direita o diagrama de momentos do pilar análogo ou conjugado que corresponde à deformada do pilar.

Considerando a teoria de segunda ordem, isto é, considerando a deformação do elemento, o pilar apresentará novos momentos fletores:

$$
M_{2 d, i}=N_{d} y_{i}
$$

Sendo $M_{2 d, i}$ o momento fletor de segunda ordem na seção genérica $i$. Dessa forma, deve ser realizada nova determinação da deformada. O novo diagrama de momentos é dado pela expressão:

$$
M_{d i}=N_{d}\left(e+y_{i}\right)
$$


Figura 3-11 - Pesos elásticos e diagramas do pilar conjugado.

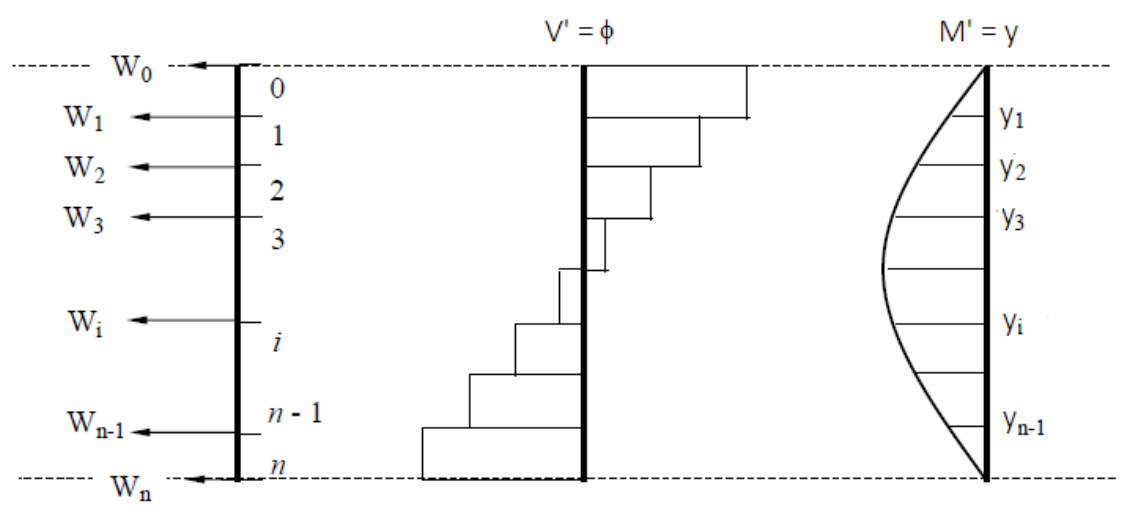

Fonte: RIBEIRO (2011).

A partir do diagrama atualizado de momentos fletores, é obtido o novo carregamento do pilar ou novo diagrama de curvatura, conforme a Figura 3-12.

Figura 3-12 - Momentos fletores de segunda ordem e novo carregamento.

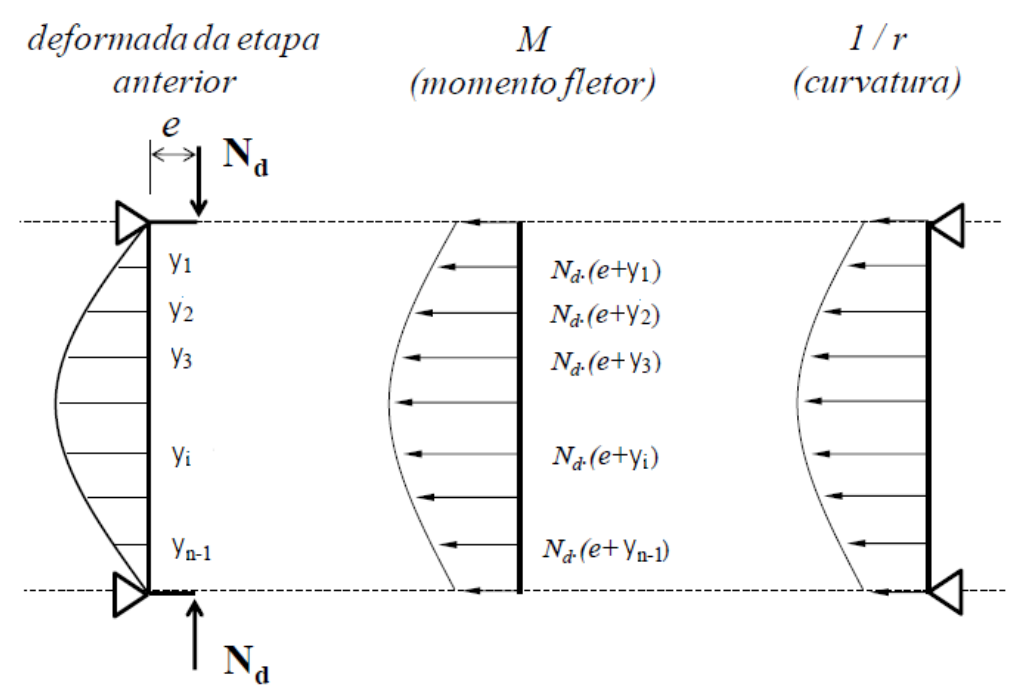

Fonte: RIBEIRO (2011).

Repetindo o procedimento, isto é, determinando novos pesos elásticos e o novo diagrama de momentos fletores $M^{\prime}$, é obtida a deformada da segunda iteração. Se resultar em valores diferentes de $y_{i}$, os momentos de segunda ordem são modificados e todo processo deve ser repetido. As iterações terminam quando a deformada da enésima iteração coincidir com 
a precedente, a menos de uma certa tolerância imposta. Ao final do processo, o pilar terá atingido uma forma fletida de equilíbrio estável. No entanto, se a deformada do pilar crescer continuamente, haverá instabilidade do elemento.

Segundo Loriggio (2009 apud RIBEIRO, 2011), uma das vantagens da analogia de Mohr é o fato desse processo possibilitar uma visualização da convergência para a posição em que o elemento esteja em equilíbrio, como representado na Figura 3-13 para o caso em que é adotado o deslocamento como critério de convergência.

Figura 3-13 - Ilustração do processo de convergência pela analogia de Mohr.

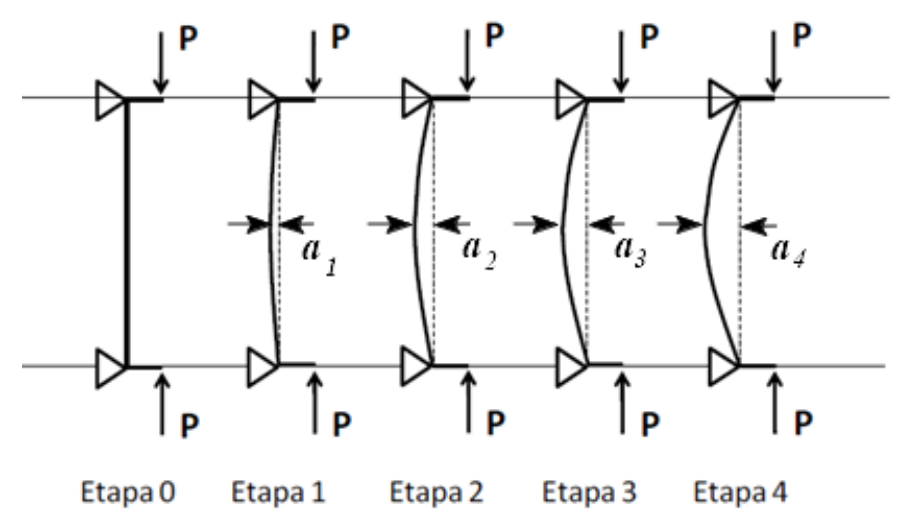

Fonte: Adaptado de RIBEIRO (2011)

\subsection{RESUMO DE MÉTODOS DE CÁLCULO}

Os diferentes métodos de cálculo de pilares indicados na norma ABNT NBR 6118:2014 possuem características diferentes e restrições de uso consagradas pela prática profissional ao longo dos anos.

Segundo o item 15.8.3.3.5 da citada norma, quando a esbeltez de um pilar de seção retangular submetido à flexão composta oblíqua for menor ou igual a 90 nas duas direções principais, podem ser aplicados os processos aproximados, simultaneamente, em cada uma das duas direções, ou método geral com efeitos de flexão aplicados no plano oblíquo.

Conhecendo a variação dos momentos totais (primeira e segunda ordens) conforme varia o plano de atuação do momento solicitante em relação aos eixos principais de inércia, para cada seção ao longo do eixo deve ser verificado se a resultante vetorial desses momentos solicitantes fica dentro da envoltória de momentos resistentes para a armadura escolhida. Essa 
verificação pode ser realizada em apenas três seções: nas duas extremidades e em um ponto intermediário onde se admite atuar concomitantemente os momentos $\mathrm{M}_{\mathrm{d}, \text { tot }}$ nas duas direções principais de inércia $x$ e $y$.

Os métodos aproximados de pilar padrão com curvatura aproximada e com rigidez aproximada permitem o cálculo manual para geometria de seção transversal simétrica e tendem a apresentar resultados mais conservadores. No entanto, o uso destes métodos permite obter como solução do problema apenas a área total de armadura necessária para o equilíbrio da seção no ELU, obrigatoriamente com arranjo simétrico de armadura.

Os métodos numéricos permitem maior liberdade geométrica de seção transversal e de armadura, mas obrigam ao uso de soluções computacionais e, eventualmente, lentas devido ao grande número de processamento envolvido para a obtenção de resultados. Como é necessário conhecer antecipadamente a armadura da seção transversal, estes são métodos para verificação de equilíbrio ou de capacidade resistente e não para dimensionamento de pilares.

A Figura 3-14 apresenta quadro com resumo elaborado por CARDOSO JUNIOR (2014) de algumas características de métodos permitidos pela norma brasileira vigente.

Figura 3-14 - Características de métodos de cálculo de pilares.

\begin{tabular}{|c|c|c|c|c|}
\hline Método & $\begin{array}{l}\text { Pilar padrão com } 1 / \mathrm{r} \\
\text { aproximada }\end{array}$ & $\begin{array}{l}\text { Pular padrão comk } \\
\text { aproximado }\end{array}$ & $\begin{array}{l}\text { Pilar padrão acophdo com } \\
\text { N-M- } 1 / \mathrm{r}\end{array}$ & Método geral \\
\hline Limite de Esbeltez & $\lambda \leq 90$ & $\lambda \leq 90$ & $\lambda \leq 140$ & $\lambda \leq 200$ \\
\hline $\begin{array}{l}\text { Não linearidade } \\
\text { geométrica }\end{array}$ & 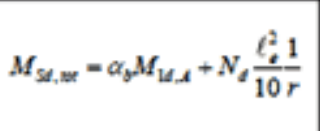 & $M_{S A, x x}=\frac{\alpha_{b} M_{l d, A}}{1-\frac{\lambda^{2}}{120 \kappa / v}}$ & $M_{S A, M=}=\frac{\alpha_{b} M_{L S A}}{1-\frac{\lambda^{2}}{120 \kappa / v}}$ & $\begin{array}{c}\text { Integração Numérica } \\
\text { ou P-8 }\end{array}$ \\
\hline $\begin{array}{l}\text { Não linearidade } \\
\text { física }\end{array}$ & $\frac{1}{r}=\frac{0,005}{h(v+0.5)}$ & 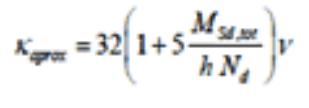 & $\kappa_{w e}=\frac{E I_{\text {iex }}}{A_{t} h^{2} \cdot f_{c t}}$ & $E I_{\text {sec }}$ \\
\hline $\begin{array}{l}\text { Armadura } \\
\text { conhecida }\end{array}$ & Não & Não & $\operatorname{Sin}$ & $\operatorname{Sin}$ \\
\hline $\begin{array}{c}\text { Permite o cálculo } \\
\text { manual } \\
\end{array}$ & $\operatorname{Sin}$ & $\operatorname{Sin}$ & Năo* & Năo \\
\hline $\begin{array}{c}\text { Disposição da } \\
\text { armadura } \\
\end{array}$ & Simétrica & Simétrica & Qualquer & Qualquer \\
\hline Tipo de seção & Quakuer & Retangular & Quakquer & Quakquer \\
\hline
\end{tabular}

* Pode ser resolvido manualmente por meio de ábacos $\nu-\mu-\omega-\kappa$. 



\section{SIMULAÇÕES NUMÉRICAS}

\subsection{PROGRAMA SECTRANS}

O programa utilizado para o desenvolvimento deste trabalho é denominado SecTrans e foi criado pelo Prof. Dr. Vladimir G. Haach, para fins exclusivamente acadêmicos. O código foi desenvolvido em linguagem Pascal, no ambiente de desenvolvimento Lazarus.

As principais funcionalidades do programa SecTrans são: cálculo do momento fletor resistente de seções de concreto armado e protendido e cálculo do equilíbrio de seções de concreto armado e protendido para determinado momento fletor. Neste sentido o programa fornece: o diagrama da variação do momento fletor resistente em função da força normal a que a seção transversal está sujeita; o diagrama de interação $M x-M y$; o diagrama de momento fletor em função da curvatura e métodos de verificação da estabilidade local de um determinado pilar sujeito a um único determinado conjunto de solicitações nas extremidades.

A operação básica do SecTrans começa pela inserção de dados de entrada, a saber: propriedades do concreto; dados geométricos da seção transversal do pilar; armadura passiva e armadura ativa; estes dados são admitidos constantes ao longo do comprimento de um lance de pilar. Na tela dados geométricos, as coordenadas de arestas de direção da seção transversal do pilar são introduzidas sentido anti-horário. A Figura 4-1 apresenta a tela de introdução de dados da seção transversal.

Posteriormente deve ser inserida a armadura passiva, a resistência característica ao escoamento e o módulo de elasticidade do aço, tal como ilustrado na Figura 4-2. A armadura é lançada por camada horizontal, inserindo as coordenadas, a quantidade de barras e o espaçamento entre elas.

O último item de dados de entrada é a inserção de propriedades do concreto, ilustrado na Figura 4-3. É possível escolher as propriedades de acordo com a norma ABNT NBR 
6118:2014, sendo necessária apenas a inserção da resistência característica à compressão do concreto.

Figura 4-1 - Entrada de dados da seção transversal de pilar do programa SecTrans.

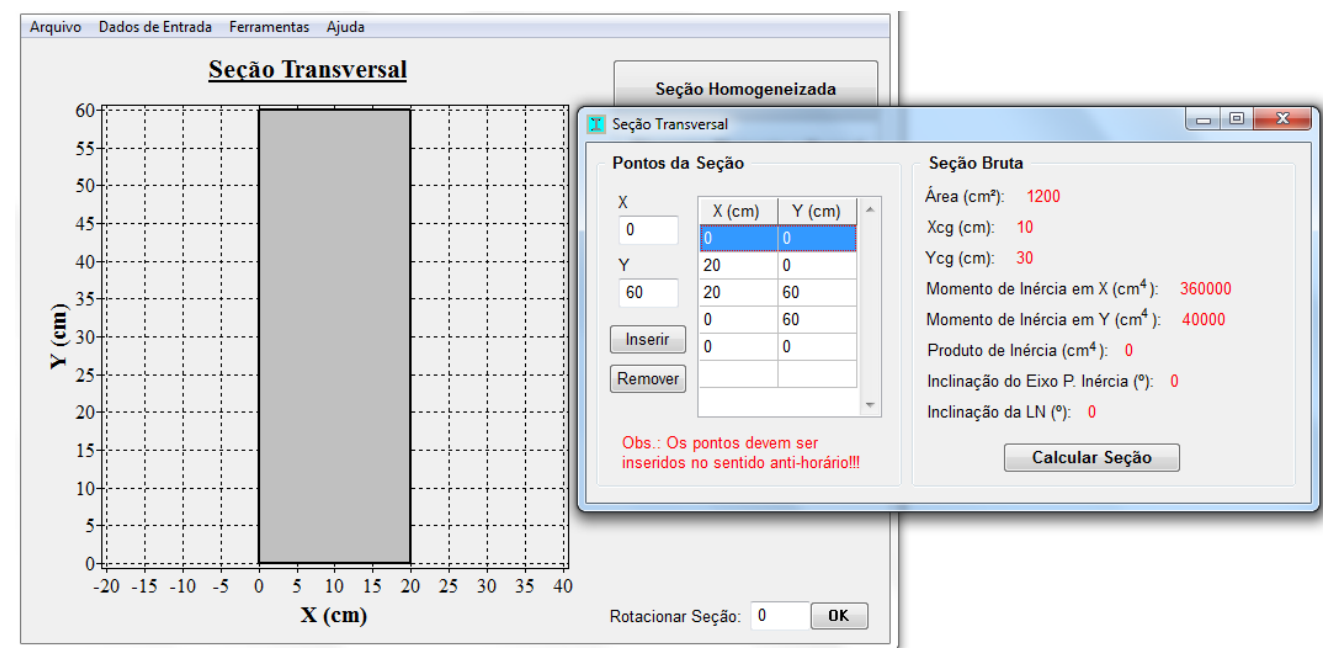

Fonte: Elaborado pela Autora.

Figura 4-2 - Inserção de armaduras passivas do programa SecTrans.

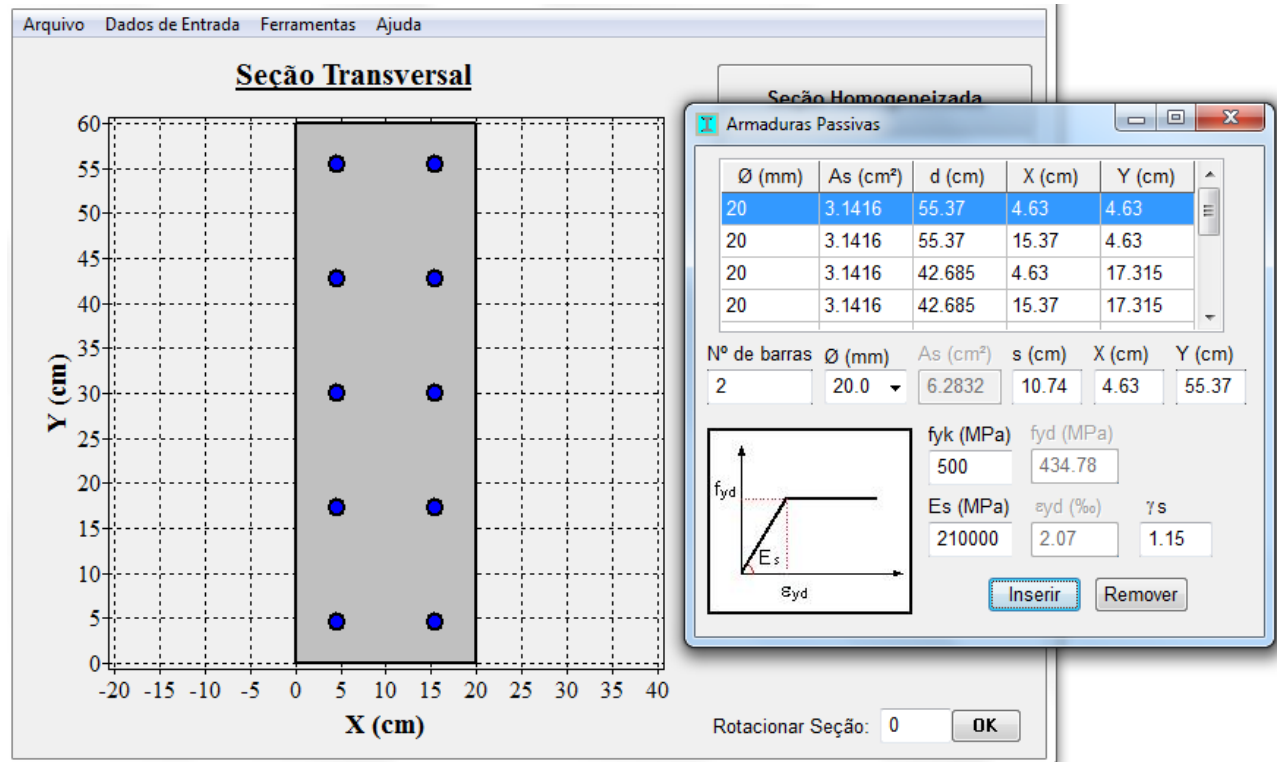

Fonte: Elaborado pela Autora.

Após a entrada de dados, o programa fornece diversas opções para construção de diagramas e informações sobre a seção transversal, dispostas em quatro itens: Seção Homogeneizada; Diagrama Momento-Normal; Diagrama de Interação $M x-M y$; Diagrama Momento- 
Curvatura; e Estabilidade Local. Na tela Seção Homogeneizada são calculadas as características geométricas da seção transversal no Estádio I e no Estádio II.

Figura 4-3 - Inserção das propriedades do concreto do programa SecTrans.

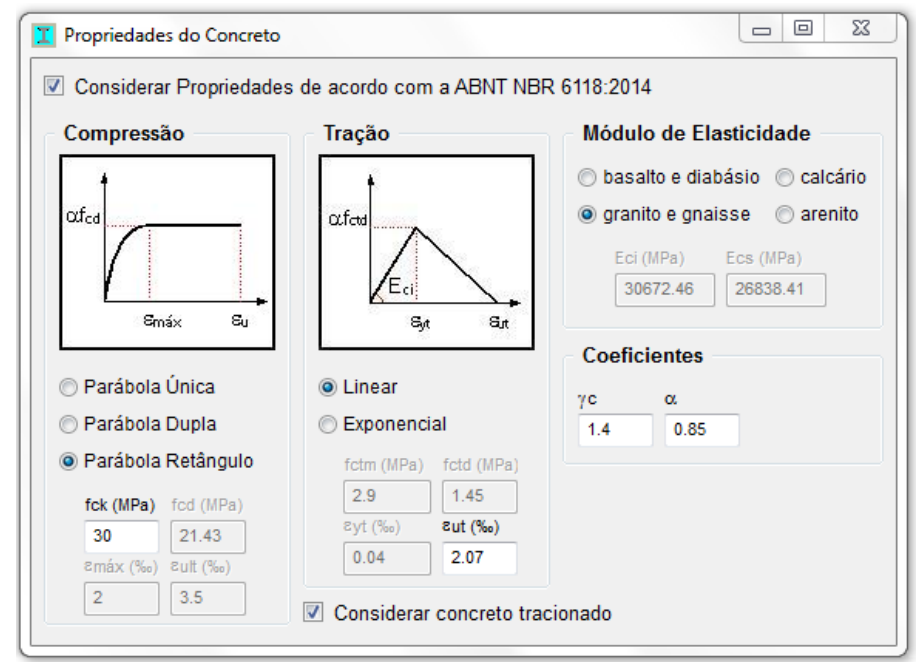

Fonte: Elaborado pela Autora.

$\mathrm{Na}$ tela Estabilidade Local são inseridos dados referente ao pilar analisado incluindo força normal de cálculo; comprimento do pilar; momentos solicitantes de cálculo na base e no topo; e condições de vinculação (bi apoiado ou em balanço). O programa permite a verificação da estabilidade de um pilar por três métodos: Método do pilar padrão com rigidez adimensional aproximada, Método do pilar padrão com curvatura aproximada e pelo Método geral. Escolhido o método, o programa fornece as envoltórias mínima e resistente, além de três pontos solicitantes (base, seção intermediária e topo do pilar) como forma de verificação das análises efetuadas. Ainda nesta aba, é fornecido relatório com todos os parâmetros utilizados no processamento. A Figura 4-4 e a Figura 4-5 apresentam a interface da aba de Estabilidade Local.

A envoltória elíptica interna em verde claro da Figura 4-4 mostra o momento mínimo de primeira ordem, a envoltória externa em rosa apresenta o momento mínimo total de segunda ordem de acordo com o método selecionado e as envoltórias azul e verde escuro são correspondentes ao momento resistente da seção. A linha mais externa azul corresponde à envoltória resistente da seção determinada por pontos discretos variando a posição da linha neutra e a curva suave interna e mais próxima em verde escuro é obtida através da formulação aproximada indicada na Eq. (2-7) podendo ser escolhido o expoente $\alpha=1,2$ (padrão do programa) 
ou outro valor. A linha curva em vermelho apresenta os momentos solicitantes totais segundo o Método Geral e os três pontos azuis claros são obtidos segundo um método aproximado escolhido e referidos à seção de base, seção intermediária e seção de topo do pilar.

Figura 4-4 - Diagramas de verificação de estabilidade do pilar do programa SecTrans.

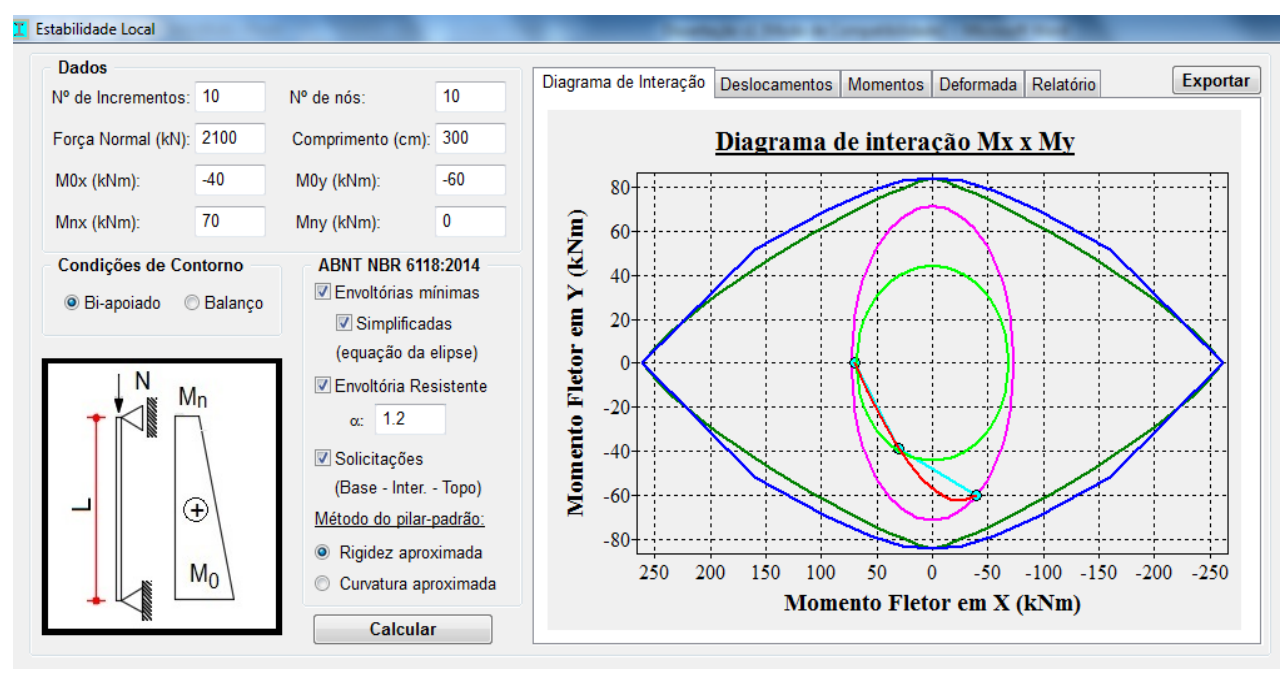

Fonte: Elaborado pela Autora.

A Figura 4-5 mostra a tela da aba Relatório com os resultados obtidos para um certo processamento em formato de tabela textual.

Figura 4-5 --Relatório de resultados processados do programa SecTrans.

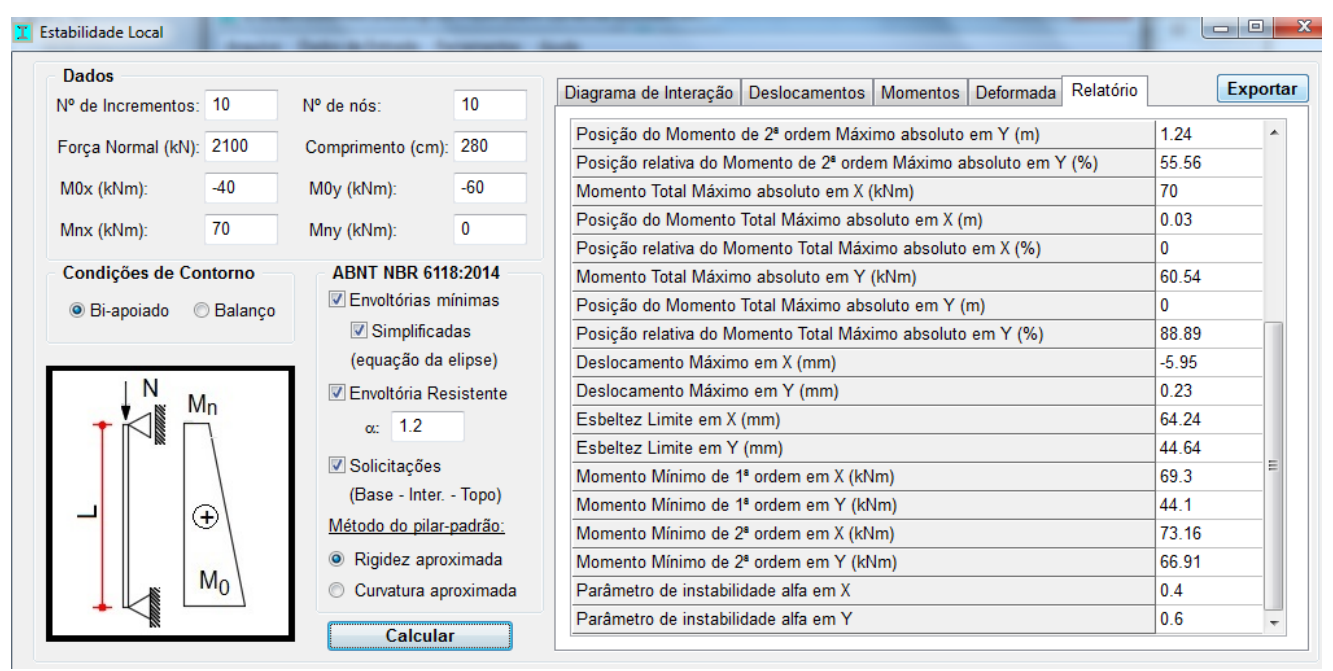

Fonte: Elaborado pela Autora. 


\subsection{AUTOMATIZAÇÃO DO PROGRAMA}

Para a obtenção de resultados variados deste texto, foi necessário alterar o programa fonte, pois este trata apenas de um único caso de lance de pilar.

A funcionalidade de Automatização consistiu em adicionar Etapas no programa original com a seguinte sequência:

a) Definição de Arquivo de Entrada de Dados

Foi criada uma opção para o usuário escolher um arquivo específico em texto puro em formato ANSI e possível de ser editado com o programa Notepad ® (também chamado de Bloco de Notas) em ambiente Windows ${ }^{\circledR}$, por exemplo. Os dados de entrada são formatados em sequência e com delimitadores para permitir conjuntos diferentes de variáveis em cada linha. Cada arquivo de dados corresponde a uma única seção transversal com geometria e armadura pré-determinada, resultando em nove arquivos correspondentes a três seções geométricas de concreto (seção 20x20; 60x20 e 100x20 cm²) e três taxas de armadura ( $\rho=2 \% ; 3 \%$ e 4\%). Para todos os arquivos de dados, foram fixadas as características mecânicas do concreto e do aço passivo e pilar bi rotulado.

b) Leitura de arquivo

Escolhido o arquivo de entrada de dados, a rotina identifica as variáveis a serem processadas e insere os dados em vetores específicos com número variável de posições. Para tanto, cada arquivo contém o índice de esbeltez $(\lambda=90 ; 115$ e 140), a normal reduzida $(\nu=0,3$; $0,4 ; 0,5$ e 0,6$)$, o momento reduzido $(\mu=0,05 ; 0,10$ e 0,15$)$, o ângulo do plano de flexão $\left(\theta=30^{\circ} ; 45^{\circ}\right.$ e $\left.60^{\circ}\right)$, a proporção entre momentos no topo e na base do lance de pilar ( -1; 0,5; 0; 0,5 e 1), o coeficiente de fluência ( $\varphi=0$ e 2) e o coeficiente de pico da tensão no concreto $\left(\alpha_{c}=0,85\right.$ e 1,10$)$. Os dois últimos conjuntos de dados são necessários para o programa tratar casos sem e com fluência e as situações correspondentes ao método aproximado acoplado a diagramas. Durante o processamento, foi observada a necessidade de separar os arquivos de dados em número diferente de variáveis por processamento em virtude do tempo de execução. Assim, o usuário pode separar conjuntos diferentes de variáveis de entrada, por exemplo, escolhendo apenas uma esbeltez ou duas normais reduzidas ou apenas um momento reduzido, etc. 
c) Inserção de valores em caixas de texto

Após a leitura de dados parametrizados, a rotina de Automatização transforma os valores inicias em valores absolutos e promove a inserção destes valores para processamento. Como alguns controles TextBox, CheckBox e RadioButton apresentados na Figura 4-3 e na Figura 4-4 possuem valores pré-definidos na abertura do programa SecTrans, foi necessário atualizar algumas opções das abas abaixo indicadas para efeito de processamento, a saber:

- Propriedades do concreto: escolha de agregado de granito; escolha de diagrama parábola retângulo; escolha de não considerar concreto tracionado; inserção de $f_{c k}$; escolha de não considerar Propriedades de acordo com ABNT NBR 6118:2014; inserção de deformações do concreto $\varepsilon_{\max }$ e $\varepsilon_{u l t}$ para considerar ou não a fluência pela multiplicação por $(1+\varphi)$;

- Estabilidade local: inserção de $\mathrm{N}^{\mathrm{o}}$ de incrementos = 1; inserção de Força Normal; inserção de Comprimento; inserção de Momentos $\mathrm{M}_{0}$ e $\mathrm{M}_{\mathrm{n}}$ nas direções x e y.

d) Processamento para Método de Curvatura aproximada, Rigidez aproximada e Geral

Concluída a etapa de inserção de dados, a rotina de Automatização modifica controles específicos do programa SecTrans na seguinte ordem:

- Aba Propriedades do Concreto: inserção de coeficiente de pico de concreto $\alpha_{c}=0,85$;

- Aba Início: inserção de Rotacionar Seção de $0^{\circ}$ e acionamento de Botão $O k$;

- Aba Estabilidade local: escolha de Curvatura aproximada e acionamento de Botão Calcular;

- Aba Estabilidade local: escolha de Rigidez aproximada e acionamento de Botão Calcular;

- Extração dos pontos das curvas de envoltórias geradas; criação de retas dos pontos solicitantes e a origem do sistema de coordenadas; localização da interseção destas retas com a envoltória resistente e armazenamento do ponto solicitante mais próximo da envoltória para cada método de cálculo;

- Extração de valores de interesse para Arquivo de saída. 
e) Processamento para Método Acoplado a Diagramas

- Aba Propriedades do Concreto: inserção de coeficiente de pico de concreto $\alpha_{c}=0,85$;

- Aba Início acionamento de Botão Diagrama Momento x Curvatura;

- Aba Diagrama Momento x Curvatura: inserção de Força Normal; acionamento de Botão > > e extração de Momento resistente M;

- Aba Propriedades do Concreto: inserção de coeficiente de pico de concreto $\alpha_{c}=1,10$;

- Aba Diagrama Momento x Curvatura: inserção de Força Normal; escolha de Variável M; acionamento de Botão >> e extração de pontos da curva de vetores interno. Com os pontos extraídos, a rotina de Automatização obtém a intersecção dessa curva com a reta horizontal de Momento resistente da etapa anterior, calcula e armazena a rigidez secante $E I_{s e c}$ e a rigidez adimensional aproximada $\kappa$,

- Aba Início: inserção de Rotacionar Seção de $90^{\circ}$ e acionamento de Botão $O k$;

- Loop a partir da primeira etapa deste processamento e extração de valores de interesse para Arquivo de saída.

f) Geração de Arquivo de Saída

Durante a obtenção de resultados, estes são armazenados em planilha em formato Excel para cada conjunto de dados iniciais reportando os valores de cada processamento e organizados na seguinte ordem:

- Dados iniciais: Dimensões h e b da seção transversal; taxa de armadura; esbeltezes iniciais $\lambda$ e limite $\lambda_{1}$ para cada direção principal $x$ e $y$; normal reduzida $v$; momento reduzido $\mu$; ângulo $\theta$; proporção entre momentos nas extremidades; coeficiente de fluência $\varphi$; momentos absolutos no topo e na base em cada direção;

- $\quad$ Resultados do Método Geral: coeficientes $\alpha_{b}$ em cada direção segundo a NBR 6118 e pelo Método Geral; momentos solicitantes máximos em cada direção; momento resultante e direção correspondente; componentes de momentos resistentes críticos em cada direção; momento resistente resultante e direção correspondente;

- Resultados do Método de Curvatura Aproximada: momentos solicitantes máximos em cada direção; momento resultante e direção correspondente; componentes de 
momentos resistentes críticos em cada direção; momento resistente resultante e direção correspondente;

- Resultados do Método de Rigidez Aproximada: momentos solicitantes máximos em cada direção; momento resultante e direção correspondente; componentes de momentos resistentes críticos em cada direção; momento resistente resultante e direção correspondente;

- Resultados do Método Acoplado a Diagramas: momentos solicitantes máximos em cada direção; momento resultante e direção correspondente; componentes de momentos resistentes críticos em cada direção; momento resistente resultante e direção correspondente;

- $\quad$ Rigidez adimensional $\kappa$ em cada direção principal $x$ e $y$.

g) Repetição do processamento

As etapas de c) até f) são repetidas até todas as variáveis definidas pelo usuário no mesmo Arquivo de Entrada de Dados serem processadas e enviados todos os resultados para o Arquivo de Saída.

\subsection{DEFINIÇÃO DE VARIÁVEIS}

Para analisar o comportamento de pilares foram avaliados oito parâmetros, a saber: relação entre lados da seção transversal retangular; índice de esbeltez; força normal reduzida; momento fletor reduzido; ângulo de atuação de momentos fletores; proporção entre momento fletor na base e no topo do pilar; taxa de armadura e coeficiente de fluência. No total, foram processados 9.720 casos de simulações diferentes.

Para todas as simulações foi adotado concreto com agregado graúdo de granito, resistência mecânica $f_{c k}=35 \mathrm{MPa}$, coeficiente de redução de resistência $\gamma_{c}=1,4$ e módulo de deformação tangente inicial $E_{c i}=33,1 \mathrm{GPa}$, estimado segundo a previsão teórica da $\mathrm{ABNT}$ NBR 6118:2014. As propriedades do concreto foram adotadas neste estudo por serem consideradas como representativas para edifícios atuais. 


\subsubsection{Seção transversal}

Neste estudo foram analisados pilares de seção transversal retangular com relação entre os lados maior e menor de 1:1, 3:1 e 5:1 fixando a menor dimensão em $20 \mathrm{~cm}$ na direção do eixo cartesiano vertical $y$. Estas dimensões estão ilustradas na Figura 4-6 e foram adotadas partindo da seção quadrada até o limite máximo permitido entre os lados de seção retangular para pilares de concreto armado.

Figura 4-6 - Geometria das seções transversais estudadas (dimensões em $\mathrm{cm}$ ).

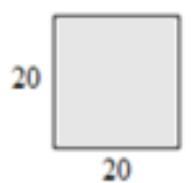

$1: 1$

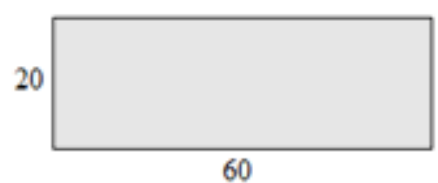

$3: 1$

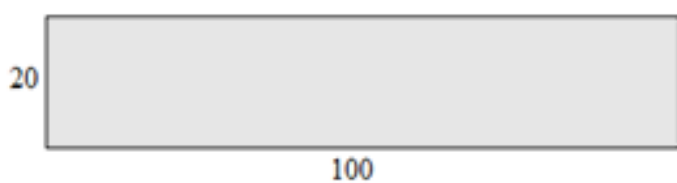

$5: 1$

Fonte: Elaborado pela Autora.

\subsubsection{Esbeltez de pilar}

Os pilares estudados foram estipulados com vínculos bi rotulados nas extremidades e índices de esbeltez máximo variando entre 90 e 140 correspondendo aos comprimentos especificados na Tabela 4-1.

Tabela 4-1 - Índice de esbeltez e comprimento equivalente de pilares estudados.

\begin{tabular}{cc}
\hline$\lambda$ & $\mathrm{L}_{\mathrm{e}}(\mathrm{cm})$ \\
\hline 90 & 520 \\
115 & 664 \\
140 & 808 \\
\hline
\end{tabular}

Fonte: Elaborado pela Autora.

\subsubsection{Taxa de armadura}

A taxa geométrica de armadura $\rho$ foi variada entre valores usuais de edifícios de concreto moldado no local de $2 \% ; 3 \%$ e $4 \%$. O tipo de aço considerado foi CA-50 e, para intro- 
dução de dados no programa SecTrans, foram inseridas barras longitudinais de bitola equivalente para manter a taxa de armadura igual e independente da geometria da seção transversal, para uma certa quantidade de barras em cada face.

O arranjo de barras longitudinais foi padronizado dispondo as barras ao longo da face de maior dimensão, respeitando o espaçamento entre barras da ordem de $12 \mathrm{~cm}$ e mantendo a simetria do arranjo. A posição do centroide da camada de barras em relação à face mais próxima foi fixada em $4 \mathrm{~cm}$, o que corresponde a valores usuais de cobrimento de $2,5 \mathrm{~cm}$, estribos de $6,3 \mathrm{~mm}$ e barras longitudinais com bitolas de $20 \mathrm{~mm}$.

Os arranjos de barras foram impostos segundo os critérios citados e resultaram nas quantidades de barra por face e demais informações apresentadas na Tabela 4-2. Como o programa SecTrans permite introduzir barras com área definida pelo usuário, a bitola das barras adotadas foi a indicada na última coluna da tabela citada para resultar na área total fixada e na quantidade de barras fixadas por face para determinada taxa geométrica de aço.

Tabela 4-2 - Arranjos de armadura para as seções transversais estudadas.

\begin{tabular}{cccccc}
\hline $\begin{array}{c}\text { Seção transver- } \\
\text { sal } \\
\left(\mathrm{cm}^{2}\right)\end{array}$ & $\begin{array}{c}\text { Taxa } \\
\text { geométrica } \\
(\%)\end{array}$ & $\begin{array}{c}\text { Área de aço } \\
\text { total }\left(\mathrm{cm}^{2}\right)\end{array}$ & $\begin{array}{c}\mathrm{N}^{\mathrm{o}} \text { de } \\
\text { barras por } \\
\text { face }\end{array}$ & $\begin{array}{c}\text { Espaçamento Bitola equi- } \\
(\mathrm{cm})\end{array}$ & \\
\hline \multirow{2}{*}{$20 \times 20$} & 2 & 4,00 & & & 16,0 \\
& 3 & 6,00 & 2 & 12,0 & 19,5 \\
& 4 & 8,00 & & & 22,6 \\
\hline \multirow{2}{*}{$60 \times 20$} & 2 & 12,00 & & & 17,5 \\
& 3 & 18,00 & 5 & 13,0 & 21,4 \\
& 4 & 24,00 & & & 24,7 \\
\hline \multirow{2}{*}{$100 \times 20$} & 2 & 20,00 & & & 16,8 \\
& 3 & 30,00 & 9 & 11,5 & 20,6 \\
& 4 & 40,00 & & & 23,8 \\
\hline
\end{tabular}

Fonte: Elaborado pela Autora. 


\subsubsection{Força normal reduzida}

Os valores de força normal reduzida $v$ foram variados entre 0,$3 ; 0,4 ; 0,5$ e 0,6 . A conversão para um valor numérico foi efetuada considerando as diversas áreas e o mesmo concreto.

Durante o planejamento deste estudo foi observado que o dimensionamento estrutural de pilares com taxa geométrica de armadura de até $4 \%$ e força normal reduzida maior que 0,6 não possuem solução prática devido ao esgotamento da capacidade resistente da seção ou por perda de equilíbrio do elemento estrutural. Portanto, para obter maior quantidade de resultados válidos a faixa de variação da força normal reduzida foi limitada em até 0,6.

\subsubsection{Momento fletor reduzido}

O momento fletor na base do pilar foi introduzido no programa por meio do momento fletor reduzido $\mu$ com variações de 0,$05 ; 0,1$ e 0,15 . A conversão para um valor numérico foi efetuada considerando cada geometria de seção e sempre adotando a menor dimensão da seção $h_{y}=20 \mathrm{~cm}$. A escolha destes momentos fletores reduzidos também se basearam nos resultados dos pré-processamentos realizados no planejamento deste estudo.

\subsubsection{Direção de momento fletor oblíquo}

Foram introduzidos momentos fletores solicitantes resultantes aplicados com ângulos de atuação de $30^{\circ}, 45^{\circ}$ e $60^{\circ}$ em relação ao eixo cartesiano horizontal $x$. Para tanto, os momentos fletores introduzidos na base do pilar foram decompostos nas duas direções ortogonais $x \mathrm{e}$ $y$ para efeito de introdução de dados no programa SecTrans. Não foram consideradas as direções de $0^{\circ}$ e $90^{\circ}$ por caracterizarem casos particulares de Flexo-compressão Reta.

\subsubsection{Proporção entre momentos da base e do topo de pilar}

O momento fletor do topo do pilar foi adotado como um valor proporcional ao momento da base. Para abranger diferentes tipos de diagrama de momentos fletores, foram consideradas cinco proporções para o momento no topo $\mathrm{M}_{\mathrm{B}}$ em relação ao momento na base $\mathrm{M}_{\mathrm{A}}:-1$; $-0,5 ; 0 ; 1$ e 0,5 . 


\subsubsection{Coeficiente de fluência}

De acordo com os trabalhos de CADAMURO JÚNIOR (1997) e CASAGRANDE (2016) o coeficiente de fluência frequentemente adotado na literatura tem valor igual a 2,0. Para analisar a importância do efeito da fluência no comportamento dos pilares-foram adotados coeficientes $\varphi=0$ (correspondendo a desprezar esse efeito) e $\varphi=2,0$ (correspondendo a considerar a fluência, tal como é obrigatório para pilares com esbeltez maior do que 90). 


\section{EXEMPLOS DE APLICAÇÃO}

\subsection{DADOS GERAIS}

Para ilustrar o desenvolvimento das etapas deste estudo a seguir é apresentado o detalhamento do roteiro utilizado para analisar um dentre todos os casos processados. Foi escolhida uma geometria de pilar representativa dentre as diversas variáveis envolvidas de modo a permitir ampliar o entendimento dos resultados obtidos.

O pilar escolhido é considerado bi rotulado tal como usual para edifício moldado no local com seção transversal de dimensões $60 \times 20 \mathrm{~cm}^{2}$ de concreto de classe $\mathrm{C} 35\left(\mathrm{f}_{\mathrm{ck}}=35 \mathrm{MPa}\right)$ com agregado de granito $\left(E_{c i}=33,1 \mathrm{GPa}\right)$ armado com barras de aço CA-50 $\left(f_{y k}=500 \mathrm{MPa}\right)$.

Foi imposta taxa geométrica de armadura $\rho=4,0 \%$ correspondendo à área total de aço de 48,00 $\mathrm{cm}^{2}$ composta por 5 barras em cada face de comprimento de $60 \mathrm{~cm}$ com área individual de cada barra de $4,80 \mathrm{~cm}^{2}$. Como esta área não é comercial, para as barras de aço foi adotado diâmetro equivalente de 24,7 mm para introdução no programa SecTrans. A distância do centroide da camada de armadura para a face mais próxima foi adotada como sendo $d^{\prime}=4$ cm, restando para o espaçamento horizontal a distância de $13 \mathrm{~cm}$ entre eixos de barras. A Figura 5-1 apresenta a geometria da seção transversal escolhida para os Exemplos de aplicação, bem como o arranjo de armadura longitudinal adotado. Por simplicidade, não estão mostrados os estribos complementares necessários para impedir a flambagem local das barras de aço mais distantes dos cantos.

Arbitrando para a normal reduzida o valor de $v=0,3$, a Força Normal de compressão de cálculo a ser aplicada no topo do pilar fica determinada pela Eq. (2-4) e é de intensidade:

$$
N_{d}=v A_{c} f_{c d}=0,3 \times(60 \times 20) \times 2,5=900 \mathrm{kN}
$$


Figura 5-1 - Geometria da seção transversal do Exemplo de aplicação.

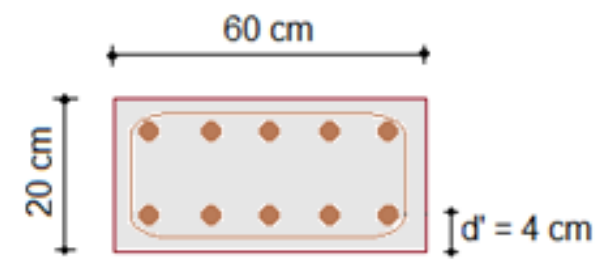

Fonte: Elaborado pela Autora.

Impondo para o momento reduzido o valor de $\mu_{\theta}=0,05$ e a menor dimensão da seção transversal o valor de $h_{y}=20 \mathrm{~cm}$, o Momento Fletor atuante na base do pilar ficou determinado pela definição da Eq. (2-5) e resultou na intensidade de:

$$
M_{d, \theta}=\mu_{\theta} A_{c} h f_{c d}=0,05 \times(60 \times 20) \times 0,20 \times 2,5=30,00 \mathrm{kN} . \mathrm{m}
$$

Escolhendo para atuação da flexão na base do pilar o ângulo $\theta=45^{\circ}$, a decomposição do momento resultante em cada direção principal de inércia da seção resulta nas componentes de momentos na direção $x$ (paralela à maior dimensão da seção) e na direção $y$ (menor dimensão da seção) de intensidades:

$$
\begin{aligned}
& M_{d, x}=M_{\theta d} \cos \left(45^{\circ}\right)=30,00 \times \frac{\sqrt{2}}{2}=21,21 \mathrm{kN} \cdot \mathrm{m} \\
& M_{d, y}=M_{\theta d} \operatorname{sen}\left(45^{\circ}\right)=30,00 \times \frac{\sqrt{2}}{2}=21,21 \mathrm{kN} . \mathrm{m}
\end{aligned}
$$

Fixando a proporção entre os momentos na base do pilar e no topo como sendo de -1 para representar situação próxima a edifícios usuais, as parcelas de momento fletor no topo são de sinal contrário ao sinal de momentos na base do pilar.

A Figura 5-2 representa a direção de flexão aplicada nas extremidades do lance de pilar considerado nos Exemplos de Aplicação e a Figura 5-3 ilustra os diagramas de momentos fletores para as duas direções principais de inércia da seção transversal. 
Figura 5-2 - Flexão atuante nas extremidades do lance de pilar.
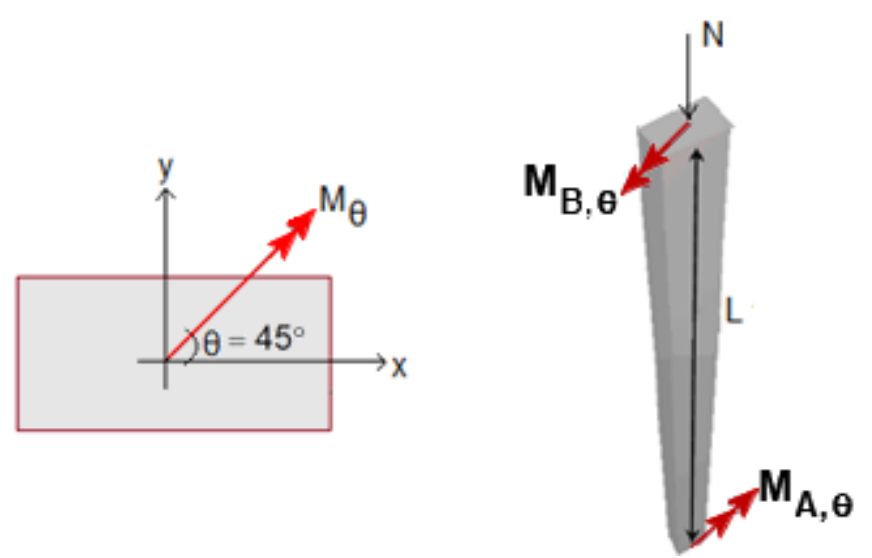

Fonte: Elaborado pela Autora.

Figura 5-3 - Momentos fletores na base e no topo do pilar.

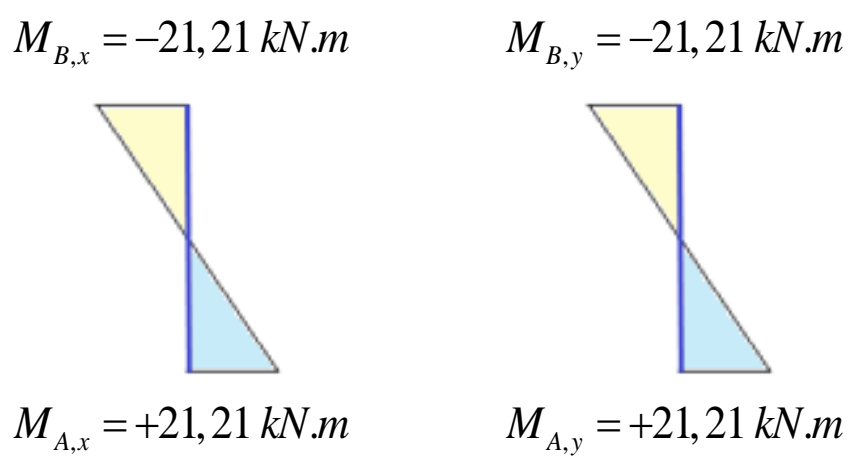

Fonte: Elaborado pela Autora.

\subsubsection{Momento mínimo de primeira ordem e coeficiente $\alpha_{b}$}

De acordo com o estabelecido no item 11.3.3.4.3 da ABNT NBR 6118:2014, a verificação de efeitos locais deve também verificar atendimento aos momentos mínimos de primeira ordem para cada direção. Este momento mínimo independe da esbeltez ou do método de cálculo e, a partir de Eq. (2-23) resulta em:

$$
\begin{aligned}
M_{1 d, \text { min }, x} & =\left(0,015+0,3 \times h_{y}\right) N_{d} \\
& =(0,015+0,3 \times 0,2) \times 900=18,90 \mathrm{kN} . \mathrm{m} \\
M_{1 d, \text { min }, y} & =\left(0,015+0,3 \times h_{x}\right) N_{d} \\
& =(0,015+0,3 \times 0,6) \times 900=29,70 \mathrm{kN} . \mathrm{m}
\end{aligned}
$$


Obviamente, o momento total mínimo de segunda ordem deve ser igual ou superior ao valor de momento mínimo de primeira ordem aqui determinado.

\subsubsection{Coeficiente $\alpha_{b}$}

Assumindo que não atuam cargas laterais importantes ao longo do comprimento do pilar, tal como é usual em edifícios convencionais, o item 15.8.2 da ABNT NBR 6118:2014 avalia o coeficiente $\alpha_{b}$ em conformidade com a Tabela 2-1 deste texto e, neste caso, é determinado para qualquer direção principal de inércia por:

$$
\alpha_{b}=0,6+0,4 \frac{M_{B}}{M_{A}}=0,6+0,4 \frac{(-21,21)}{21,21}=0,2
$$

Atendendo simultaneamente ao limite absoluto inferior $\left(\alpha_{b}=0,4\right)$ e a condição de momentos menores que o valor mínimo $\left(\alpha_{b}=1,0\right)$, em definitivo o coeficiente $\alpha_{b}$ é fixado para cada direção como sendo:

$$
\begin{aligned}
& \alpha_{b x}=0,4 \\
& \alpha_{b y}=1,0
\end{aligned}
$$

\subsubsection{Esbeltez limite}

Os esforços locais de segunda ordem em elementos isolados podem ser desprezados quando a esbeltez em certa direção for menor que o valor limite $\lambda_{1}$ definido na Eq. (2-20) resultando nos seguintes limites para cada direção:

$$
\begin{gathered}
\lambda_{1 x}=66,2 \geq 35 \rightarrow \text { atende } \\
\lambda_{1 y}=25,5 \geq 35 \rightarrow \text { não atende } \\
\therefore \quad \lambda_{1 y}=35,0
\end{gathered}
$$

Segundo o disposto na norma ABNT NBR 6118:2014, sendo a esbeltez maior do que a esbeltez limite $\lambda_{1}$ na direção $x$ e $y$ é obrigatório determinar os efeitos de segunda ordem local nessa direção. De modo oposto, para algumas situações, na direção y o efeito de segunda ordem local pode ser desprezado, tal como ocorrido nos Exemplos de aplicação 1 e 2. 
Assim procedendo, o momento total (primeira + segunda ordem) foi calculado pelos quatro métodos apresentados no Capítulo 3. Após o cálculo do momento total, foi determinado o momento crítico da seção para cada método de cálculo. Em particular, é entendido por momento crítico um ponto no diagrama de interação $M_{x}-M_{y}$ correspondente a um momento solicitante oblíquo mais próximo da envoltória resistente, seja esse ponto correspondente a uma seção longitudinal da base $\mathrm{A}$, do topo $\mathrm{B}$ ou intermediária $\mathrm{C}$ do pilar.

Os Exemplos de aplicação 1, 2, 3 e 4 possuem a mesma geometria e mesmas ações externas aplicadas, sendo diferenciados entre si na esbeltez, a saber; a) $\lambda=90$ para os Exemplos 1 e 2; b) $\lambda=115$ para o Exemplo 3; c) $\lambda=140$ para o Exemplo 4. Como os casos analisados implicam em pilares com esbeltez maior ou igual a 90, o efeito da fluência foi considerado nos Exemplos 2, 3 e 4. No Exemplo 1 não foi considerado o efeito da fluência, a título de registrar e comparar os valores calculados com os resultados do Exemplo 2,

Para registro das operações analíticas e numéricas necessárias durante a obtenção dos resultados dos Exemplos de aplicação, o passo a passo com o formulário aqui utilizado é apresentado com detalhes no Apêndice A deste texto.

\subsection{RESUMO DE RESULTADOS}

As tabelas seguintes resumem os resultados para os momentos solicitantes resultantes totais críticos obtidos com cada um dos métodos estudados, indica o fator de amplificação devido ao efeito de segunda ordem em relação ao momento de primeira ordem máximo aplicado, a direção do momento resultante a partir de suas componentes e, na última coluna, a intensidade de momento total mínimo a ser atendido. $O$ fator de amplificação $\chi$ foi obtido pela relação:

$$
\chi=\frac{M_{S d, t o t}}{M_{S 1 d}}
$$

Em particular, a Tabela 5-1 e a Tabela 5-2 tratam da mesma esbeltez de pilar $(\lambda=90)$, apenas diferenciando a consideração ou não da fluência, respectivamente.

Comparando os valores de momentos solicitantes totais obtidos com o Método de Curvatura aproximada e de Rigidez Adimensional Aproximada com e sem a consideração da fluência para a seção intermediária, é possível observar acréscimo de 15\% a $20 \%$ nos resultados. Tais desvios podem ser significativos e são contra a segurança quando desprezado esse efeito. 
Tabela 5-1 - Resumo de resultados para momento total do Exemplo 1.

\begin{tabular}{ccccc}
\hline $\begin{array}{c}\text { Método de } \\
\text { cálculo }\end{array}$ & $\begin{array}{c}\mathrm{M}_{\mathrm{Sd}, \mathrm{tot}, \theta} \\
(\mathrm{kN} . \mathrm{m})\end{array}$ & $\begin{array}{c}\text { Amplificação } \\
\chi\end{array}$ & $\begin{array}{c}\text { Direção } \theta \\
\text { (graus) }\end{array}$ & $\begin{array}{c}\mathrm{M}_{\mathrm{d}, \mathrm{tot}, \mathrm{min} \theta} \\
(\mathrm{kN} . \mathrm{m})\end{array}$ \\
\hline Curvatura & 72,41 & 2,41 & 17,0 & 39,36 \\
Rigidez & 58,08 & 1,94 & 21,4 & 38,15 \\
Acoplado & 30,00 & 1,00 & 45,0 & 30,57 \\
Geral & 30,00 & 1,00 & 45,0 & 27,79 \\
\hline
\end{tabular}

Fonte: Elaborado pela Autora.

Tabela 5-2 - Resumo de resultados para momento total do Exemplo 2.

\begin{tabular}{ccccc}
\hline $\begin{array}{c}\text { Método de } \\
\text { cálculo }\end{array}$ & $\begin{array}{c}\mathrm{M}_{\mathrm{Sd}, \mathrm{tot}, \theta} \\
(\mathrm{kN} . \mathrm{m})\end{array}$ & $\begin{array}{c}\text { Amplificação } \\
\chi\end{array}$ & $\begin{array}{c}\text { Direção } \theta \\
\text { (graus) }\end{array}$ & $\begin{array}{c}\mathrm{M}_{\mathrm{d}, \mathrm{tot}, \min \theta} \\
(\mathrm{kN} . \mathrm{m})\end{array}$ \\
\hline Curvatura & 83,14 & 2,77 & 23,4 & 52,98 \\
Rigidez & 69,48 & 2,32 & 28,4 & 50,80 \\
Acoplado & 30,00 & 1,00 & 45,0 & 33,72 \\
Geral & 30,00 & 1,00 & 45,0 & 32,89 \\
\hline
\end{tabular}

Fonte: Elaborado pela Autora.

A Tabela 5-3 e a Tabela 5-4 apresentam resultados com fluência para as esbeltezes de $\lambda=115$ e $\lambda=140$, respectivamente. Em particular, para o Exemplo de Aplicação 4 não foram apresentados resultados do Método Acoplado, pois estes foram considerados inválidos pelas razões discutidas no item seguinte. Para o Método Geral, não foi possível obter diretamente a envoltória de Momento total mínimo por falta de equilíbrio durante o processamento com o programa SecTrans e na Tabela 5-4 a célula correspondente está identificada com valor inválida. Isto se deve ao fato de que a curvatura dupla considerada nestes Exemplos é semelhante ao caso b) da Figura 2-11 e a determinação do momento total mínimo assume uma situação hipotética com curvatura simples correspondente ao caso a) da mesma Figura 2-11. 
Tabela 5-3 - Resumo de resultados para momento total do Exemplo 3.

\begin{tabular}{ccccc}
\hline $\begin{array}{c}\text { Método de } \\
\text { cálculo }\end{array}$ & $\begin{array}{c}\mathrm{M}_{\mathrm{Sd}, \mathrm{tot}, \theta} \\
(\mathrm{kN} . \mathrm{m})\end{array}$ & $\begin{array}{c}\text { Amplificação } \\
\chi\end{array}$ & $\begin{array}{c}\text { Direção } \theta \\
(\text { graus })\end{array}$ & $\begin{array}{c}\mathrm{M}_{\mathrm{d}, \mathrm{tot}, \mathrm{min} \theta} \\
(\mathrm{kN} . \mathrm{m})\end{array}$ \\
\hline Curvatura & 147,13 & 4,90 & 33,0 & 104,44 \\
Rigidez & 128,21 & 4,27 & 25,9 & 81,18 \\
Acoplado & 65,58 & 2,19 & 21,7 & 46,58 \\
Geral & 30,00 & 1,00 & 45,0 & 43,19 \\
\hline
\end{tabular}

Fonte: Elaborado pela Autora.

Tabela 5-4 - Resumo de resultados para momento total do Exemplo 4.

\begin{tabular}{ccccc}
\hline $\begin{array}{c}\text { Método de } \\
\text { cálculo }\end{array}$ & $\begin{array}{c}\mathrm{M}_{\text {Sd,tot, } \theta} \\
(\mathrm{kN} . \mathrm{m})\end{array}$ & $\begin{array}{c}\text { Amplificação } \\
\chi\end{array}$ & $\begin{array}{c}\text { Direção } \theta \\
\text { (graus) }\end{array}$ & $\begin{array}{c}\mathrm{M}_{\mathrm{d}, \text { tot,min } \theta} \\
(\mathrm{kN} . \mathrm{m})\end{array}$ \\
\hline Curvatura & 231,04 & 7,70 & 33,8 & 160,47 \\
Rigidez & 216,65 & 7,22 & 26,0 & 130,76 \\
Acoplado & & Inválido & \\
Geral & 30,00 & 1,00 & 45,0 & Inválido \\
\hline
\end{tabular}

Fonte: Elaborado pela Autora.

A Figura 5-4 apresenta os valores calculados para o coeficiente de amplificação $\chi$ dos Exemplos de Aplicação 2 a 4, pois todos estes consideram o coeficiente de fluência $\varphi$. Não foi apresentado valor para a esbeltez $\lambda=140$ com o Método Acoplado por não terem sido obtidos valores válidos nos cálculos aqui efetuados.

Desta mesma Figura 5-4 também permite ser observado que o fator de amplificação cresce de modo quase linear com a esbeltez $\lambda$ para os métodos aproximados de Curvatura e de Rigidez e o Método Geral não conduziu a valores na seção intermediária maiores do que os valores da seção de extremidade para os Exemplos aqui analisados, os quais consideram momentos nas extremidades de mesma intensidade, mas de sinais opostos. Para outras combinações de solicitações nas extremidades, o Método Geral pode conduzir a momentos de segunda ordem maiores do que aqueles aplicados nas extremidades. 
Figura 5-4 - Amplificação do momento inicial com fluência.

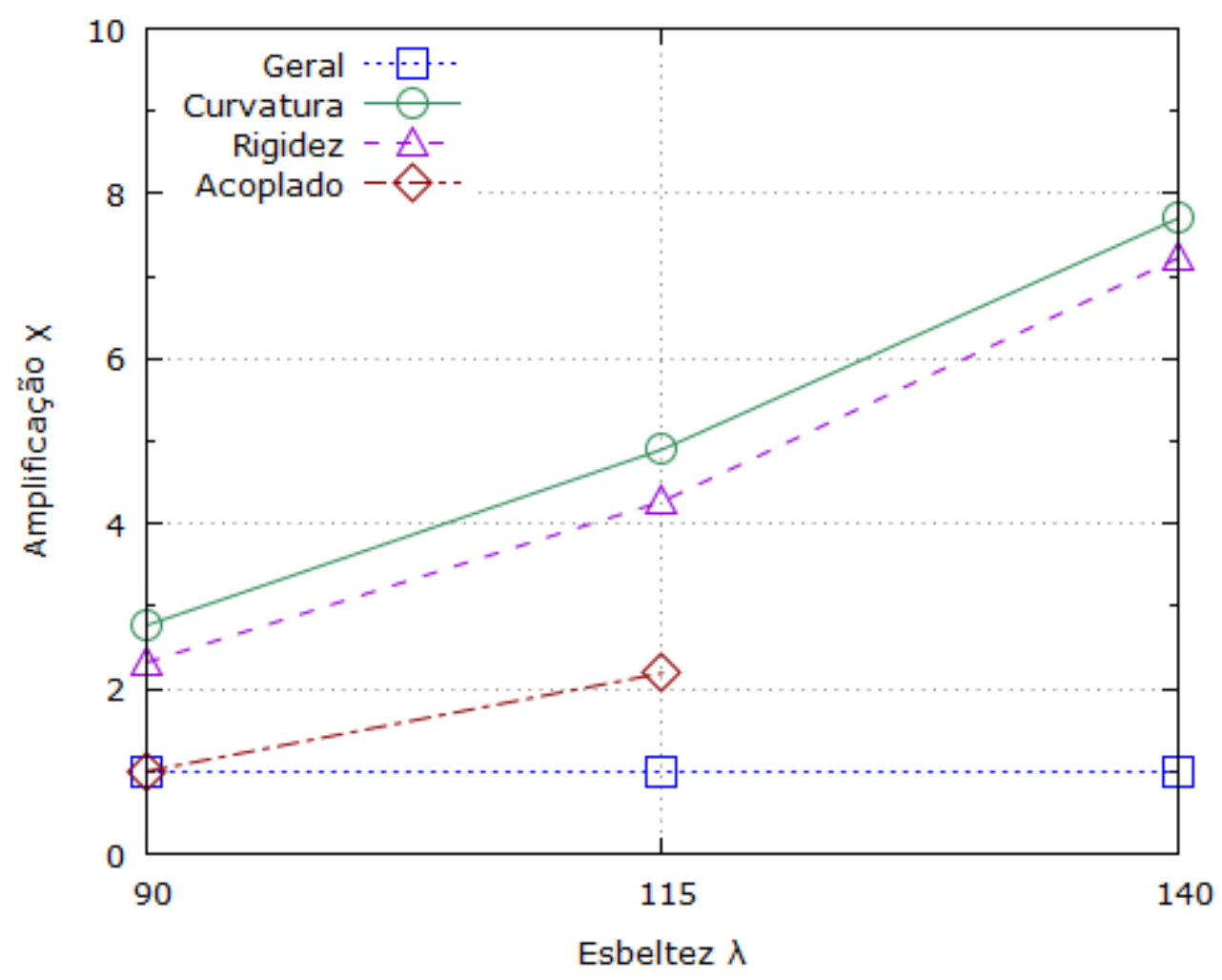

Fonte: Elaborado pela Autora.

Os métodos aproximados (Curvatura e Rigidez) apresentam resultados conservadores para o momento total em relação ao método geral com fator de amplificação $\chi$ entre 1,9 a 7,7 vezes a intensidade do momento máximo oblíquo aplicado.

A previsão da direção do momento total na seção crítica com todos os métodos simplificados desvia em muito da direção inicialmente aplicada de flexão por incluir efeitos adicionais de segurança. A consideração dos efeitos adicionais de segunda ordem pode ser obrigatória em uma direção e não ser obrigatória na direção ortogonal, conforme a relação entre as dimensões da seção retangular e o próprio comprimento do lance de pilar. Isto pode ocorrer quando as dimensões da seção transversal são muito diferentes entre si e as vinculações nas extremidades são iguais, resultando em esbeltez diferentes, ou seja, o pilar pode ser muito esbelto em uma direção e pouco esbelto em outra.

Os efeitos adicionais sendo diferentes em cada direção ampliam mais a componente de flexão na direção mais esbelta, distorcendo as parcelas do momento resultante e, como conse- 
quência, a direção resultante do plano de flexão. Este desvio tende a ser tanto maior quanto mais alongada é a seção transversal.

Comparando os resultados de momentos solicitantes totais previstos pelos métodos de curvatura aproximada e de rigidez aproximada é possível observar que estes são próximos entre si com redução de $6 \%$ a $25 \%$ a favor do método de rigidez aproximada. A mesma situação não ocorre quando são comparados os valores de momento mínimo, onde o método de rigidez aproximada apresenta valores quase sempre maiores e chegando a ser até $64 \%$ maior.

A comparação de valores do momento total mínimo em relação ao momento total solicitante mostra que, quanto maior a esbeltez, mais importante é a verificação de atendimento do momento mínimo de segunda ordem. De fato, nos Exemplos de Aplicação 2 e 3, o momento total mínimo é superior ao momento máximo para efeito de dimensionamento com o Método Geral.

A Tabela 5-5 resume os valores da normal reduzida de Euler obtida para os Exemplos de Aplicação analisados e detalhados no Apêndice A. Como foi mantida constante a normal reduzida aplicada com $v=0,3$, é também apresentada na última coluna a razão entre a normal de Euler e a normal aplicada. Desta última coluna pode ser inferido que, quanto maior a esbeltez, menor deve ser essa relação para não ultrapassar a capacidade resistente da seção. Esta situação ficou mais evidente quando da análise de resultados das simulações efetuadas ocorrendo muitas situações onde não foi possível obter segurança com certas geometrias de pilar. A Figura 5-5 mostra a Tabela 5-5 graficamente, apresentando a variação da relação $v_{\mathrm{e}} / v$ de acordo com a esbeltez.

Tabela 5-5 - Valores da normal reduzida de Euler para os Exemplos de Aplicação com

$$
v=0,3 \text {. }
$$

\begin{tabular}{cccc}
\hline Exemplo & Esbeltez & $v_{\mathrm{e}}$ & $v_{\mathrm{e}} / v$ \\
\hline 1 e 2 & 90 & 1,63 & 5,4 \\
3 & 115 & 1,00 & 3,3 \\
4 & 140 & 0,68 & 2,3 \\
\hline
\end{tabular}

Fonte: Elaborado pela Autora. 
Figura 5-5 - Relação entre a normal reduzida de Euler $v_{e}$ e a normal reduzida aplicada $v=0,3$ dos Exemplos de Aplicação.

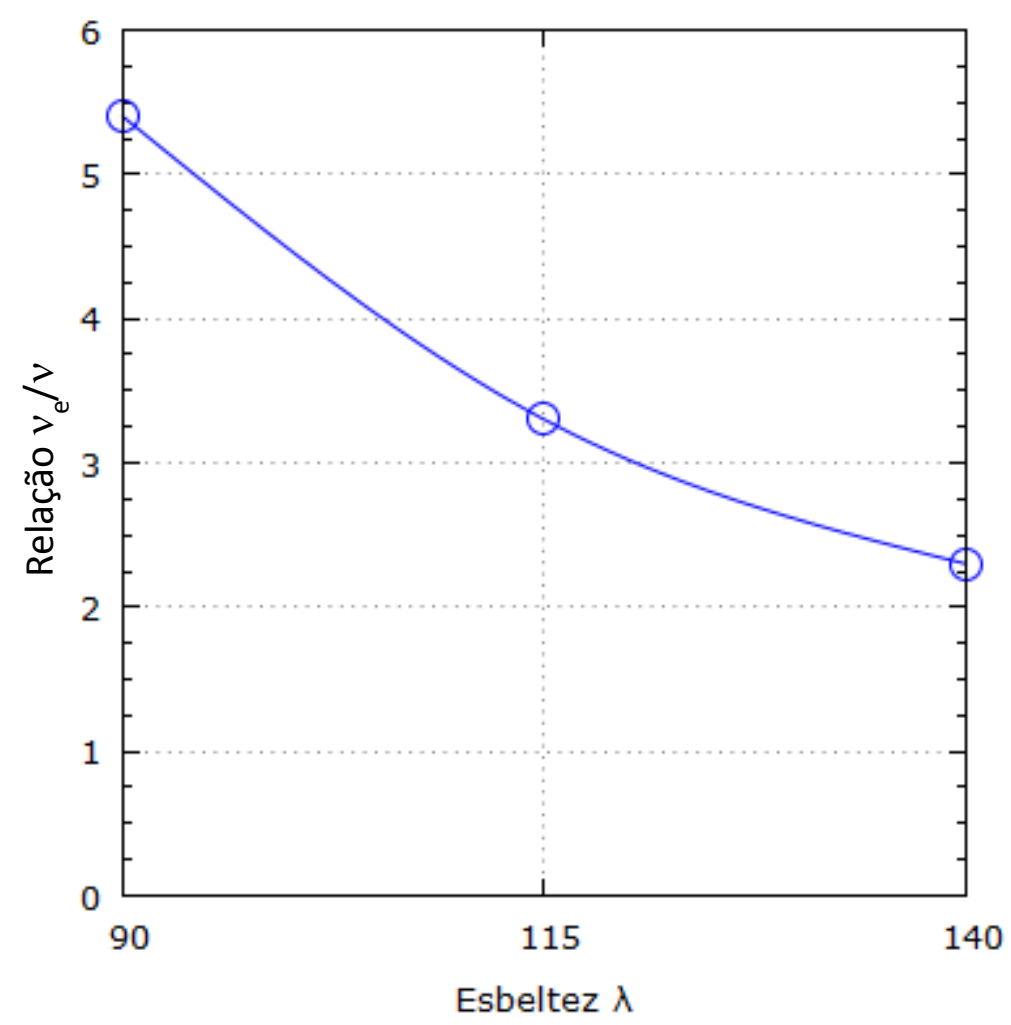

Fonte: Elaborado pela Autora.

A partir da força normal de Euler definida na Eq.(2-27), pode ser obtida a normal reduzida de Euler como função exclusiva das propriedades mecânicas do concreto e da esbeltez através da Eq. (5-3):

$$
v_{e}=\frac{N_{e}}{f_{c d} A_{c}} \approx \frac{10}{\lambda^{2}} \frac{E_{c i}}{f_{c d}}=\frac{10}{\lambda^{2}} \frac{5.600}{\sqrt{f_{c k}}} \gamma_{c}
$$

Como neste estudo foi considerado concreto classe C35 moldado no local de modo convencional com $\gamma_{c}=1,4$, a Eq. (5-3) resulta em:

$$
v_{e}=\frac{10 \times 5.600 \times 1,4}{\lambda^{2} \sqrt{35}}=\frac{13.252}{\lambda^{2}}
$$

Dividindo a Eq. (5-4) pelas forças normais reduzidas aplicadas nas simulações realizadas, podem ser obtidas as curvas da Figura 5-6. Alguns pontos das curvas estão em destaque para identificar a faixa de esbeltez estudada. Nesta figura pode ser observada a tendência de- 
crescente das relações obtidas para um valor limite inferior entre 0,3 e 0,6 conforme a intensidade da normal aplicada e quando a esbeltez tende a 190.

Figura 5-6 - Variação da relação $v_{e} / v$ com a esbeltez máxima $\lambda$.

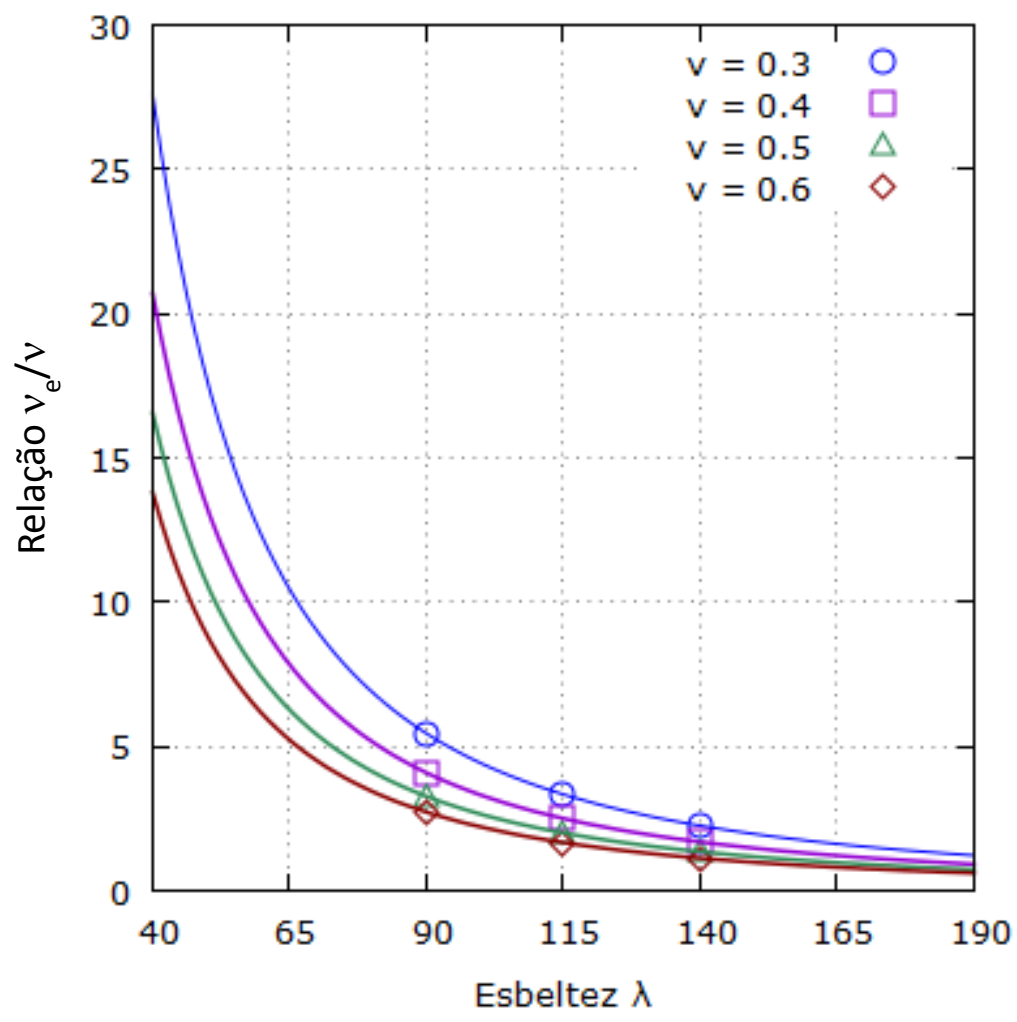

Fonte: Elaborado pela Autora.

Como o efeito da fluência é tanto maior quanto maior é a relação entre a força normal de Euler $v_{e}$ e a força normal efetivamente aplicada $v$, a tendência indicada na Figura 5-6 sugere acréscimo importante do efeito da fluência e, portanto, também da intensidade do momento total de segunda ordem, segundo o inverso do quadrado da esbeltez máxima do lance de pilar.

Na prática, a tendência prevista pode servir como orientação da importância da fluência segundo a intensidade da força normal aplicada e a respectiva esbeltez, mantendo a intensidade das demais variáveis envolvidas. Tomando como referência os resultados do Exemplo de Aplicação mostrados na última coluna Tabela 5-5 para normal reduzida $v=0,3$ o efeito da fluência tende a crescer na proporção de $5,4 / 2,3 \approx 2,3$ vezes quando a esbeltez aumenta na proporção de $140 / 90 \approx 1,6$ vezes. 


\subsection{RIGIDEZ ADIMENSIONAL MÍNIMA}

A aplicação do método do pilar padrão acoplado a diagramas implica em resolver a Eq.(3-9) abaixo reproduzida.

$$
M_{S d, t o t}=\frac{\alpha_{b} M_{1 d, A}}{1-\frac{v \lambda^{2}}{120 \cdot \kappa_{\text {aprox }}}} \geq M_{1 d, A}
$$

Ocorre que o denominador apresenta uma subtração que pode conduzir a valores negativos e, portanto, absurdos na medida em que o momento total deve coincidir em direção e sentido com o momento aplicado e sempre ser maior do que este último.

Para impedir a ocorrência de valores negativos, deve ser atendida a relação seguinte:

$$
\frac{v \lambda^{2}}{120 \gamma_{f 3} \kappa}<1
$$

Interpretando esse resultado, para a obtenção de valores válidos para o momento total é necessário atender a uma certa rigidez adimensional mínima, a qual fica determinada quando adotado $\gamma_{f 3}=1$ por:

$$
\kappa_{\min }>\frac{v \lambda^{2}}{120}
$$

Caso não seja atendida rigidez adimensional mínima para alguma condição geométrica e estática de um certo lance de pilar, o resultado obtido com a Eq.(3-9) é inválido.

A Figura 5-7 apresenta a variação da rigidez adimensional $\kappa_{\min }$ em função da esbeltez $\lambda$ e da força norma reduzida $v$ segundo a previsão da Eq.(5-5) para validade do método do pilar padrão acoplado a diagramas. Segundo essa previsão, $\kappa_{\min }$ varia diretamente com a normal reduzida e com o quadrado da esbeltez sendo tanto maior quanto maiores estas parcelas.

Quando da análise dos resultados das simulações numéricas deste estudo, foram observados alguns casos onde não foi válida a determinação do momento total para uma direção de flexão pelo não atendimento da rigidez adimensional mínima nessa direção. Para esses casos não foram computados os valores para o momento total resultante na direção oblíqua. 
Figura 5-7 - Valores mínimos da rigidez adimensional $\kappa_{\text {min }}$.

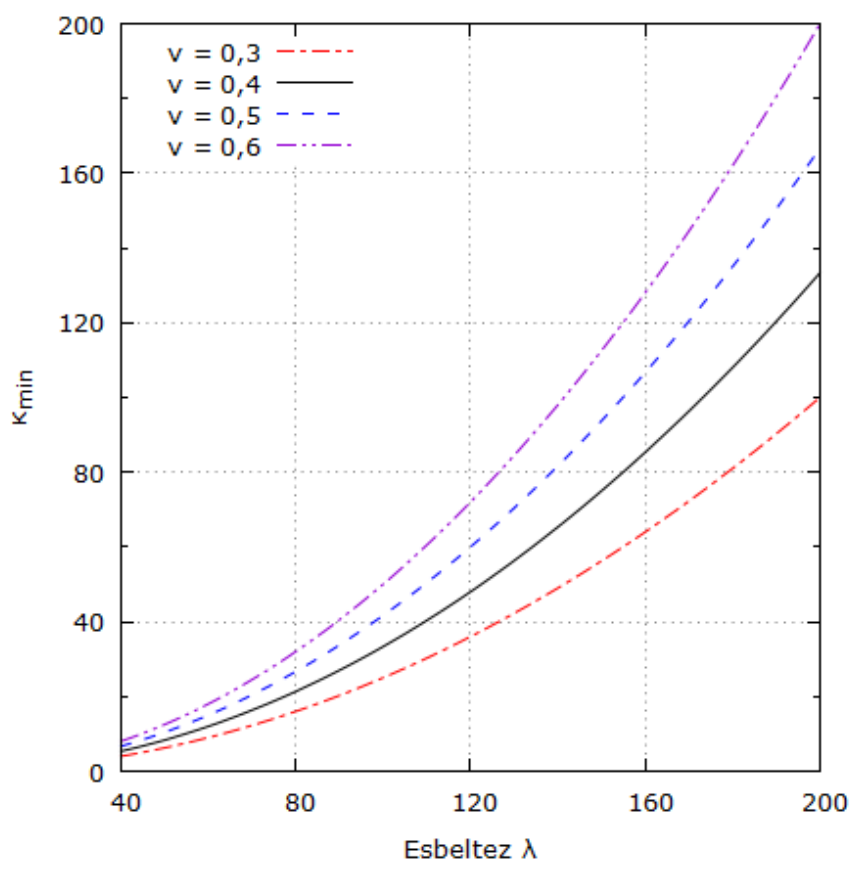

Fonte: Elaborado pela Autora.

Como a obtenção da rigidez adimensional $\kappa$ depende também da resistência $f_{c d}$ do concreto, é possível construir relações dimensionais dividindo os dois lados da Eq. (5-5) pela resistência de cálculo do concreto, ou seja:

$$
\frac{\kappa_{\min }}{f_{c d}}>\frac{v \lambda^{2}}{120} \frac{\gamma_{f}}{f_{c k}}
$$

Assumindo o fator de minoração da resistência do concreto como sendo $\gamma_{c}=1,4$, podem ser construídos gráficos para certo valor da normal reduzida $v$ em função da classe de resistência do concreto. Como exemplo, a Figura 5-8 e a Figura 5-9 apresentam gráficos para valores arbitrários de $v=0,4$ e $v=0,6$ respectivamente, para concretos de resistência C20 a C50 variando a faixa de esbeltez entre 40 e 200, em concordância com a Eq. (5-6).

A consequência da relação indicada na Eq. (5-6) é que o valor da rigidez adimensional mínima $\kappa_{\min }$ deve ser tanto maior quanto menor o valor da resistência do concreto $f_{c d}$ para certa esbeltez $\lambda$. Da mesma forma, aumentando a intensidade da força normal, deve ser aumentada a rigidez adimensional para certa esbeltez na mesma proporção. 
Figura 5-8 - Valores mínimos da relação $\kappa_{\min } / f_{c d}$ para $v=0,4$.

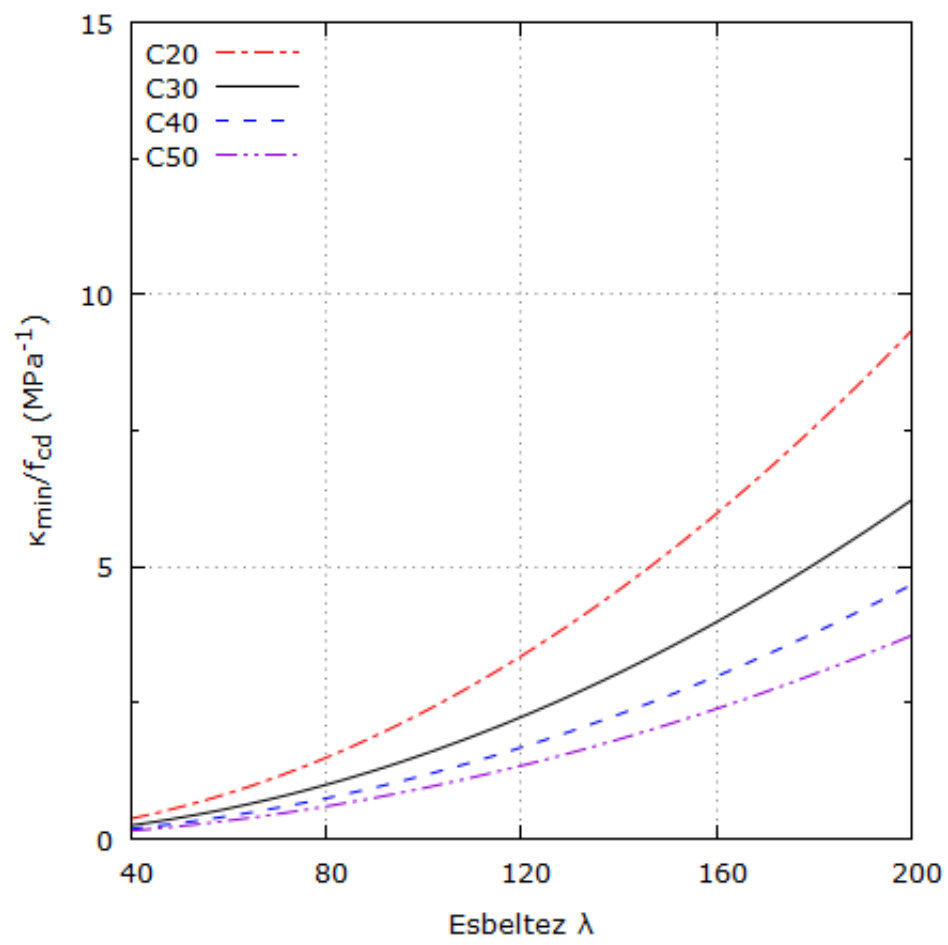

Fonte: Elaborado pela Autora.

Figura 5-9 - Valores mínimos da relação $\kappa_{\text {min }} / f_{c d}$ para $v=0,6$.

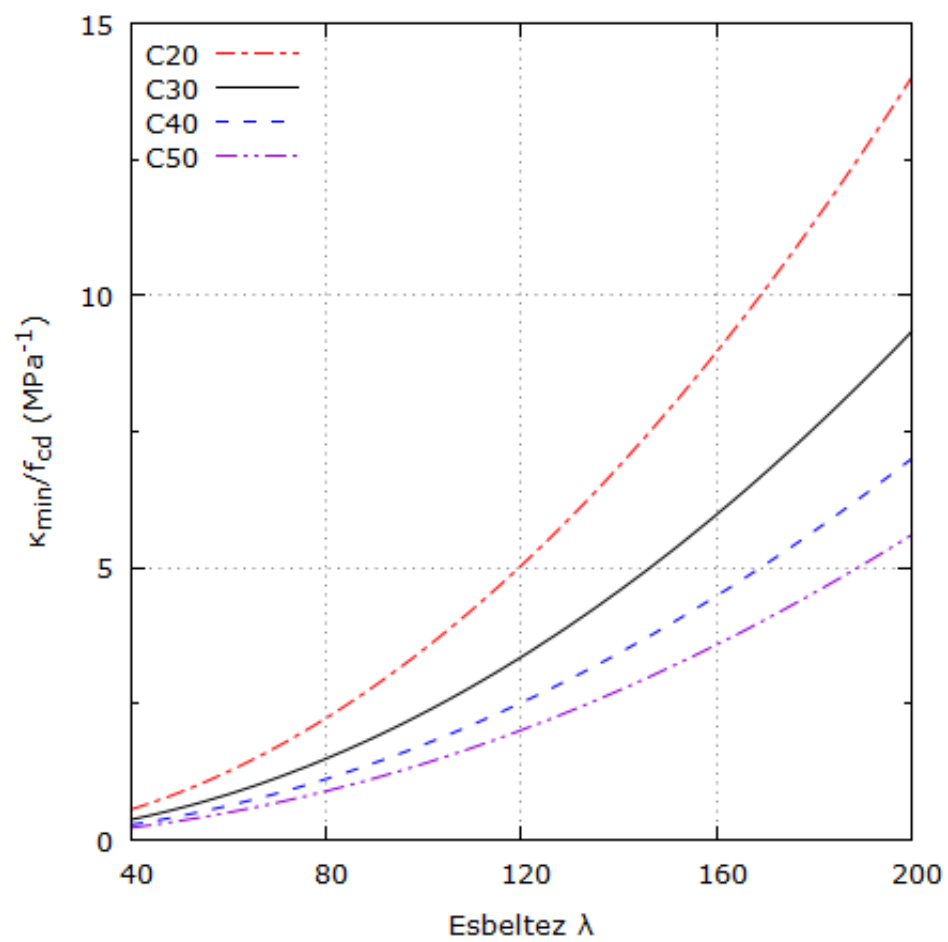

Fonte: Elaborado pela Autora. 


\section{RESULTADOS E DISCUSSÃO}

\subsection{CONSIDERAÇÕES INICIAIS}

Neste trabalho foram processadas 9.720 situações diferentes de flexão, geometrias e arranjos de armadura. Para efeito de comparação, metade das situações envolveu a consideração de fluência.

Como a utilização do programa SecTrans só permitiu obter resultados pelo Método Geral quando da ocorrência de equilíbrio ou de suficiente capacidade resistente da seção transversal com o arranjo de armadura adotado, muitos casos processados foram considerados como inválidos. Dos 4.860 processamentos envolvendo o Método Geral e o efeito de fluência, apenas 1.362 situações apresentaram resultados válidos e as demais 3.498 situações foram invalidadas por falta de equilíbrio ou por falta de capacidade resistente, pois a versão atual do programa SecTrans não permite identificar a condição determinante da interrupção do processamento.

\subsection{EFEITO DA FLUÊNCIA SOBRE A SOLICITAÇÃO TOTAL}

Este trabalho foi também motivado pelo interesse de avaliar a importância da fluência sobre os resultados numéricos do momento solicitante total de segunda ondem para lances de pilar com esbeltezes entre 90 e 140. Como forma de comparação, foram calculados os momentos solicitantes $M_{S}$ segundo os Métodos aproximados e o Método Geral para a seção crítica do lance de pilar com e sem a consideração da fluência, pois esta promove maior deformação das fibras comprimidas da seção transversal.

A Figura 6-1 apresenta os valores obtidos para o momento solicitante considerando esse efeito e segundo cada método de cálculo. 
Figura 6-1 - Relação entre momentos totais com e sem fluência.

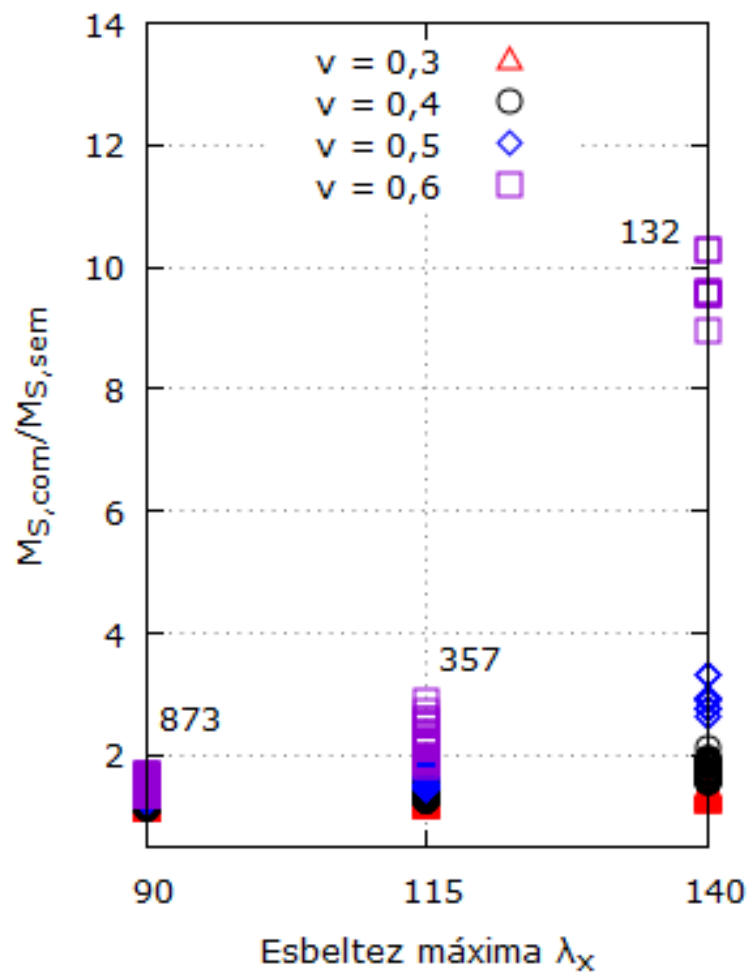

a) Método de Curvatura aproximada

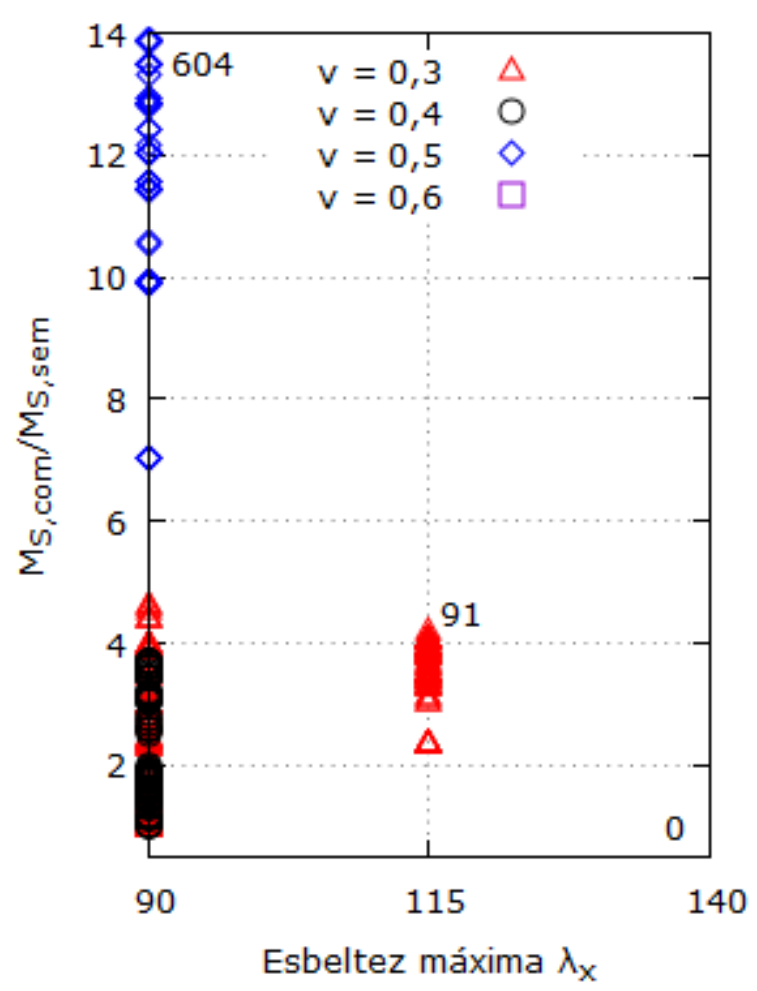

c) Método Acoplado a diagramas

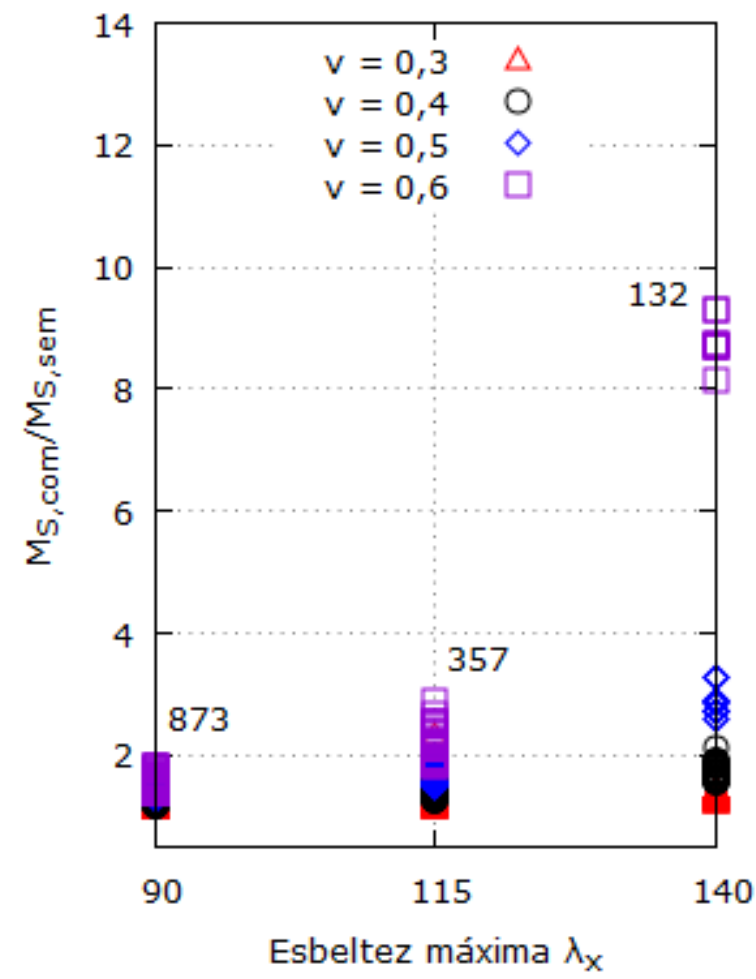

b) Método de Rigidez aproximada

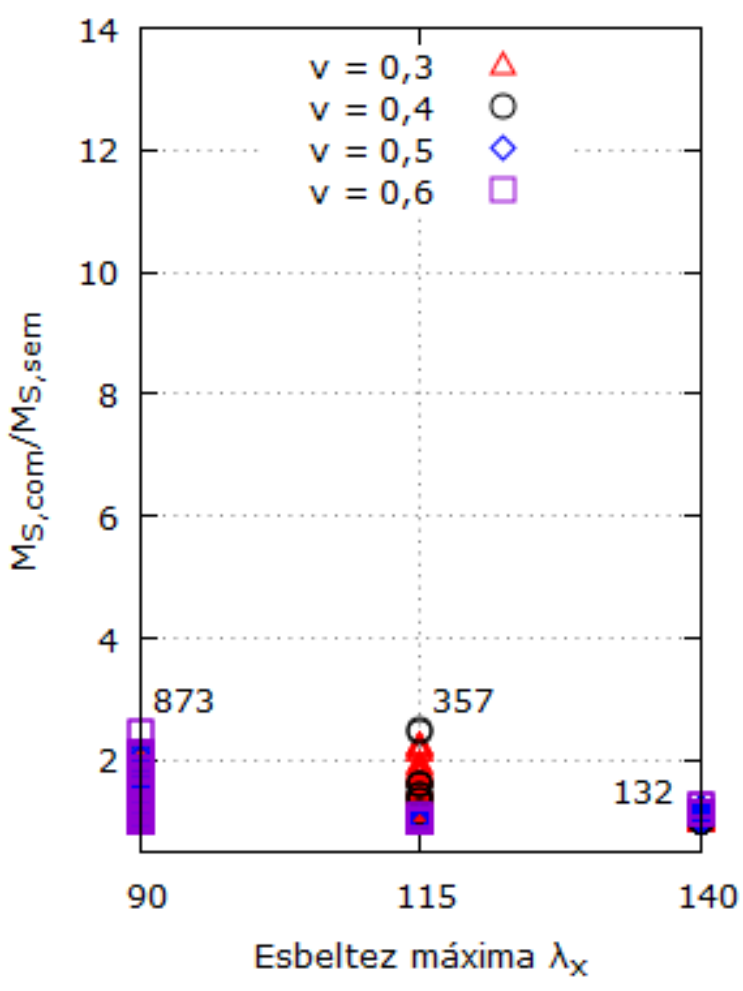

d) Método Geral

Fonte: Elaborado pela Autora. 
Do total de 1.362 situações válidas, para a esbeltez de 90 foram encontradas 873 situações válidas e, para as esbeltezes de 115 e 140, foram encontrados 357 e 132 situações, respectivamente. Com os dados iniciais adotados, foi verificado que o número de casos válidos é tanto menor quanto maior a esbeltez imposta. Isto implica que pilares mais longos necessitam de maiores dimensões da seção transversal, maior resistência do concreto ou maior quantidade de armadura longitudinal para suportarem a solicitação imposta.

Deve ser ressaltado que, apesar da norma técnica ABNT NBR 6118:2014 dispensar a consideração da fluência para pilares com esbeltez de até 90, alguns resultados encontrados neste estudo mostraram valores do momento total solicitante de até 2,5 maiores quando comparados com o momento total desprezando o efeito da fluência.

A Figura 6-1a apresenta a relação entre momentos solicitantes totais com e sem fluência para o Método da Curvatura. A maior relação encontrada para esbeltez de 90 foi igual a 1,71 e para a esbeltez de 115 e 140, de 2,87 e 10,28, respectivamente. O efeito da fluência torna-se mais significativo com o aumento da esbeltez. Na esbeltez de 140, nove relações destoaram das demais e correspondem a seções quadradas, normal reduzida igual a 0,6 e proporção entre os momentos na base e no topo igual a -1 .

O Método da Rigidez aproximada, ilustrado na Figura 6-1b, apresentou relações muito semelhantes ao Método de Curvatura. Na esbeltez de 140 também foram encontradas as mesmas nove situações com relações bem discrepantes, com valor máximo igual a 9,32. É de notar que, os valores de momento total entre o Método de Curvatura e de Rigidez são próximos entre si, mas sempre menores para o segundo método.

No Método Acoplado a diagramas, apresentado na Figura 6-1c, foi encontrada menor quantidade de situações válidas em comparação com os demais métodos. Este fato é decorrência de muitos casos serem invalidados por não possuírem rigidez necessária para satisfazer a Eq. (3-9). Essa questão é discutida no item 5.3 desse texto. Sendo assim, para a esbeltez de 90 foram encontradas 604 situações válidas e, para as esbeltezes de 115 e 140, foram encontradas 91 e 0 situações, respectivamente.

Há uma variedade maior de valores encontrados nas relações para este método aproximado. A razão principal é devido ao valor da rigidez $\kappa$, a qual depende diretamente da rigidez secante e esta variável aparentou ser muito sensível com a suavização ou não da curva Normal-Momento-Curvatura. Uma pequena variação no valor da rigidez secante causa uma pequena variação no valor da rigidez $k$, o qual por sua vez, corresponde a grande diferença no 
momento total encontrado pela Eq. (3-9). As relações máximas entre os momentos com e sem fluência obtidas com o Método Acoplado foram de 13,85 para esbeltez de 90 e 4,22 para esbeltezes de 115. O valor das relações foi menor para índices de esbeltez maiores, provavelmente em razão de muitos casos terem sido invalidados. Para esbeltez de 90 não foram encontrados casos com normal reduzida $v=0,6$ e para esbeltez de 115 só foram encontrados casos com normal reduzida $v=0,3$ e com taxa de armadura igual a $4 \%$.

Da Figura 6-1d pode ser observado que a fluência amplifica o momento total solicitante em até 2,5 vezes para as esbeltezes de 90 e 115, quando do processamento com o Método Geral. Para a esbeltez de 140, provavelmente a amplificação do momento total pode ser da mesma ordem de grandeza, apesar de não terem sido encontradas amplificações acima de 1,3 em razão da menor quantidade de resultados com equilíbrio.

\subsection{EFEITO DA FLUÊNCIA SOBRE A CAPACIDADE RESISTENTE}

No processamento efetuado foi determinada a capacidade resistente da seção transversal para uma determinada geometria e um determinado arranjo de armadura e esta capacidade aumentou quando as deformações do concreto $\varepsilon_{c 2}$ e $\varepsilon_{c u}$ são majoradas pelo coeficiente de fluência $\varphi$ tal como ilustrado na Figura 2-19 e pela relação abaixo reproduzida:

$$
\varepsilon_{c, t o t}=(1+\varphi) \varepsilon_{c}
$$

A Tabela 6-1 apresenta os valores calculados do momento resultante resistente para seção transversal com relação entre os lados $b / h=1$ mantendo constante a classe de resistência de concreto C35 e variando a taxa de armadura, a força normal reduzida e a direção do plano de atuação do momento inicial de primeira ordem. A última coluna apresenta a relação entre os momentos resistentes da seção transversal com e sem a consideração do efeito de fluência adotado de $\varphi=2,0$ e as duas colunas anteriores apresentam os resultados absolutos desse momento resistente oblíquo com e sem a consideração deste efeito. De modo equivalente, a Tabela 6-2 apresenta os resultados para seção transversal com relação entre lados $b / h=3$ e a Tabela 6-3 para $b / h=5$. 
Tabela 6-1 - Momento resistente para seção transversal com $b / h=1$.

\begin{tabular}{|c|c|c|c|c|c|}
\hline$\rho \%$ & $v$ & $\theta\left({ }^{O}\right)$ & $\begin{array}{r}M_{R d, \theta} \text { com } \\
\text { fluência }(k N . m)\end{array}$ & $\begin{array}{c}M_{R d, \theta} \quad \text { sem } \\
\text { fluência }(k N . m)\end{array}$ & $\begin{array}{c}\text { relação entre } \\
\text { momentos com e } \\
\text { sem fluência }\end{array}$ \\
\hline 2 & 0,3 & 30 & 36,52 & 33,36 & 1,0947 \\
\hline 2 & 0,4 & 30 & 36,40 & 32,48 & 1,1207 \\
\hline 2 & 0,5 & 30 & 35,34 & 31,15 & 1,1345 \\
\hline 2 & 0,6 & 30 & 33,93 & 29,22 & 1,1612 \\
\hline 2 & 0,3 & 45 & 32,35 & 32,23 & 1,0037 \\
\hline 2 & 0,4 & 45 & 33,02 & 31,35 & 1,0533 \\
\hline 2 & 0,5 & 45 & 33,37 & 30,08 & 1,1094 \\
\hline 2 & 0,6 & 45 & 36,35 & 28,27 & 1,2858 \\
\hline 2 & 0,3 & 60 & 36,52 & 33,36 & 1,0947 \\
\hline 2 & 0,4 & 60 & 36,40 & 32,48 & 1,1207 \\
\hline 2 & 0,5 & 60 & 35,34 & 31,15 & 1,1345 \\
\hline 2 & 0,6 & 60 & 33,93 & 29,22 & 1,1612 \\
\hline 3 & 0,3 & 30 & 45,92 & 41,00 & 1,1200 \\
\hline 3 & 0,4 & 30 & 45,71 & 39,62 & 1,1537 \\
\hline 3 & 0,5 & 30 & 44,13 & 37,94 & 1,1632 \\
\hline 3 & 0,6 & 30 & 42,58 & 35,94 & 1,1848 \\
\hline 3 & 0,3 & 45 & 39,70 & 39,56 & 1,0035 \\
\hline 3 & 0,4 & 45 & 40,25 & 38,18 & 1,0542 \\
\hline 3 & 0,5 & 45 & 40,62 & 36,60 & 1,1098 \\
\hline 3 & 0,6 & 45 & 40,79 & 34,70 & 1,1755 \\
\hline 3 & 0,3 & 60 & 45,92 & 41,00 & 1,1200 \\
\hline 3 & 0,4 & 60 & 45,71 & 39,62 & 1,1537 \\
\hline 3 & 0,5 & 60 & 44,13 & 37,94 & 1,1632 \\
\hline 3 & 0,6 & 60 & 42,58 & 35,94 & 1,1848 \\
\hline 4 & 0,3 & 30 & 55,37 & 48,64 & 1,1384 \\
\hline 4 & 0,4 & 30 & 55,31 & 46,92 & 1,1788 \\
\hline 4 & 0,5 & 30 & 53,25 & 44,96 & 1,1844 \\
\hline 4 & 0,6 & 30 & 51,39 & 42,81 & 1,2004 \\
\hline 4 & 0,3 & 45 & 47,07 & 46,92 & 1,0032 \\
\hline 4 & 0,4 & 45 & 47,53 & 45,18 & 1,0520 \\
\hline 4 & 0,5 & 45 & 47,88 & 43,33 & 1,1050 \\
\hline 4 & 0,6 & 45 & 48,10 & 41,29 & 1,1649 \\
\hline 4 & 0,3 & 60 & 55,37 & 48,64 & 1,1384 \\
\hline 4 & 0,4 & 60 & 55,31 & 46,92 & 1,1788 \\
\hline 4 & 0,5 & 60 & 53,25 & 44,96 & 1,1844 \\
\hline 4 & 0,6 & 60 & 51,39 & 42,81 & 1,2004 \\
\hline
\end{tabular}


Tabela 6-2 - Momento resistente para seção transversal com $b / h=3$.

\begin{tabular}{|c|c|c|c|c|c|}
\hline$\rho \%$ & $v$ & $\theta\left({ }^{o}\right)$ & $\begin{array}{r}M_{R d, \theta} \text { com } \\
\text { fluência }(k N . m)\end{array}$ & $\begin{array}{c}M_{R d, \theta} \quad \text { sem } \\
\text { fluência }(k N . m)\end{array}$ & $\begin{array}{c}\text { relação entre } \\
\text { momentos com e } \\
\text { sem fluência }\end{array}$ \\
\hline 2 & 0,3 & 30 & 129,95 & 123,83 & 1,0494 \\
\hline 2 & 0,4 & 30 & 132,63 & 121,65 & 1,0903 \\
\hline 2 & 0,5 & 30 & 128,71 & 115,70 & 1,1124 \\
\hline 2 & 0,6 & 30 & 116,88 & 108,14 & 1,0808 \\
\hline 2 & 0,3 & 45 & 146,93 & 138,09 & 1,0640 \\
\hline 2 & 0,4 & 45 & 149,10 & 136,49 & 1,0924 \\
\hline 2 & 0,5 & 45 & 146,78 & 130,51 & 1,1247 \\
\hline 2 & 0,6 & 45 & 137,13 & 122,66 & 1,1180 \\
\hline 2 & 0,3 & 60 & 180,32 & 167,24 & 1,0782 \\
\hline 2 & 0,4 & 60 & 183,27 & 166,55 & 1,1004 \\
\hline 2 & 0,5 & 60 & 180,87 & 160,30 & 1,1283 \\
\hline 2 & 0,6 & 60 & 174,03 & 151,04 & 1,1522 \\
\hline 3 & 0,3 & 30 & 169,61 & 161,73 & 1,0487 \\
\hline 3 & 0,4 & 30 & 173,42 & 162,40 & 1,0679 \\
\hline 3 & 0,5 & 30 & 173,73 & 156,57 & 1,1096 \\
\hline 3 & 0,6 & 30 & 168,09 & 149,42 & 1,1249 \\
\hline 3 & 0,3 & 45 & 191,43 & 179,69 & 1,0653 \\
\hline 3 & 0,4 & 45 & 195,07 & 180,24 & 1,0823 \\
\hline 3 & 0,5 & 45 & 195,49 & 175,21 & 1,1157 \\
\hline 3 & 0,6 & 45 & 191,92 & 167,88 & 1,1432 \\
\hline 3 & 0,3 & 60 & 235,48 & 217,29 & 1,0837 \\
\hline 3 & 0,4 & 60 & 238,95 & 217,88 & 1,0967 \\
\hline 3 & 0,5 & 60 & 240,31 & 213,51 & 1,1255 \\
\hline 3 & 0,6 & 60 & 236,43 & 205,56 & 1,1502 \\
\hline 4 & 0,3 & 30 & 193,99 & 183,45 & 1,0575 \\
\hline 4 & 0,4 & 30 & 196,06 & 179,75 & 1,0907 \\
\hline 4 & 0,5 & 30 & 194,14 & 171,11 & 1,1346 \\
\hline 4 & 0,6 & 30 & 184,44 & 162,25 & 1,1368 \\
\hline 4 & 0,3 & 45 & 218,84 & 201,96 & 1,0836 \\
\hline 4 & 0,4 & 45 & 219,54 & 198,91 & 1,1037 \\
\hline 4 & 0,5 & 45 & 218,91 & 190,56 & 1,1488 \\
\hline 4 & 0,6 & 45 & 212,79 & 181,28 & 1,1738 \\
\hline 4 & 0,3 & 60 & 267,15 & 241,66 & 1,1055 \\
\hline 4 & 0,4 & 60 & 269,27 & 239,83 & 1,1228 \\
\hline 4 & 0,5 & 60 & 268,96 & 231,46 & 1,1620 \\
\hline 4 & 0,6 & 60 & 263,07 & 220,95 & 1,1906 \\
\hline
\end{tabular}


Tabela 6-3 - Momento resistente para seção transversal com $b / h=5$.

\begin{tabular}{|c|c|c|c|c|c|}
\hline$\rho \%$ & $v$ & $\theta\left({ }^{O}\right)$ & $\begin{array}{r}M_{R d, \theta} \text { com } \\
\text { fluência }(k N . m)\end{array}$ & $\begin{array}{c}M_{R d, \theta} \quad \text { sem } \\
\text { fluência }(k N . m)\end{array}$ & $\begin{array}{l}\text { relação entre } \\
\text { momentos com e } \\
\text { sem fluência }\end{array}$ \\
\hline 2 & 0,3 & 30 & 224,78 & 217,17 & 1,0350 \\
\hline 2 & 0,3 & 45 & 264,32 & 250,92 & 1,0534 \\
\hline 2 & 0,3 & 60 & 343,42 & 321,29 & 1,0689 \\
\hline 2 & 0,4 & 30 & 230,79 & 212,60 & 1,0856 \\
\hline 2 & 0,4 & 45 & 269,51 & 246,27 & 1,0944 \\
\hline 2 & 0,4 & 60 & 348,71 & 317,17 & 1,0994 \\
\hline 2 & 0,5 & 30 & 221,43 & 201,29 & 1,1001 \\
\hline 2 & 0,5 & 45 & 261,64 & 234,68 & 1,1149 \\
\hline 2 & 0,5 & 60 & 342,95 & 304,15 & 1,1276 \\
\hline 2 & 0,6 & 30 & 197,55 & 187,09 & 1,0559 \\
\hline 2 & 0,6 & 45 & 237,82 & 219,53 & 1,0833 \\
\hline 2 & 0,6 & 60 & 320,73 & 286,13 & 1,1209 \\
\hline 3 & 0,3 & 30 & 282,28 & 270,70 & 1,0428 \\
\hline 3 & 0,3 & 45 & 329,65 & 310,80 & 1,0606 \\
\hline 3 & 0,3 & 60 & 426,85 & 394,87 & 1,0810 \\
\hline 3 & 0,4 & 30 & 287,00 & 264,01 & 1,0871 \\
\hline 3 & 0,4 & 45 & 333,74 & 303,93 & 1,0981 \\
\hline 3 & 0,4 & 60 & 431,06 & 388,34 & 1,1100 \\
\hline 3 & 0,5 & 30 & 278,47 & 250,17 & 1,1131 \\
\hline 3 & 0,5 & 45 & 327,63 & 289,62 & 1,1312 \\
\hline 3 & 0,5 & 60 & 426,81 & 371,88 & 1,1477 \\
\hline 3 & 0,6 & 30 & 254,55 & 234,72 & 1,0845 \\
\hline 3 & 0,6 & 45 & 306,29 & 273,22 & 1,1210 \\
\hline 3 & 0,6 & 60 & 409,29 & 353,19 & 1,1588 \\
\hline 4 & 0,3 & 30 & 338,84 & 324,15 & 1,0453 \\
\hline 4 & 0,3 & 45 & 394,48 & 370,59 & 1,0645 \\
\hline 4 & 0,3 & 60 & 509,99 & 468,42 & 1,0887 \\
\hline 4 & 0,4 & 30 & 342,99 & 316,24 & 1,0846 \\
\hline 4 & 0,4 & 45 & 397,85 & 362,65 & 1,0971 \\
\hline 4 & 0,4 & 60 & 513,35 & 460,76 & 1,1141 \\
\hline 4 & 0,5 & 30 & 335,45 & 300,62 & 1,1159 \\
\hline 4 & 0,5 & 45 & 393,66 & 346,13 & 1,1373 \\
\hline 4 & 0,5 & 60 & 510,00 & 441,84 & 1,1543 \\
\hline 4 & 0,6 & 30 & 312,76 & 283,84 & 1,1019 \\
\hline 4 & 0,6 & 45 & 374,92 & 328,45 & 1,1415 \\
\hline 4 & 0,6 & 60 & 497,28 & 421,53 & 1,1797 \\
\hline
\end{tabular}


A Figura 6-2 mostra graficamente os valores relativos do momento resistente da seção transversal variando a força normal reduzida para cada taxa de armadura considerada e a Figura 6-3 mostra os mesmos resultados quando é variada a relação $b / h$ entre os lados da seção transversal retangular para cada taxa de armadura.

Os resultados obtidos mostram que a capacidade resistente da seção transversal na flexo-compressão aumenta quando é considerado o efeito da fluência quando comparado com a mesma seção transversal sem a consideração da fluência, podendo chegar a até cerca de 30\% a mais de capacidade para as geometrias e normais consideradas. A explicação para esse acréscimo de capacidade resistente está relacionada à maior curvatura assumida para certa configuração de seção transversal quando as deformações do concreto são maiores.

Da observação da Figura 6-2 pode ser constatado que o aumento da capacidade resistente é tanto maior quanto maior a força normal reduzida e da Figura 6-3 pode ser constatado que o aumento da capacidade resistente é tanto maior quanto menor a relação entre os lados da seção retangular. Aparentemente, tanto o momento reduzido quanto a taxa de armadura têm pouca influência sobre esse aumento de capacidade resistente, mantidas as demais condições.

Figura 6-2 - Momentos totais relativos com e sem fluência em relação à normal reduzida.

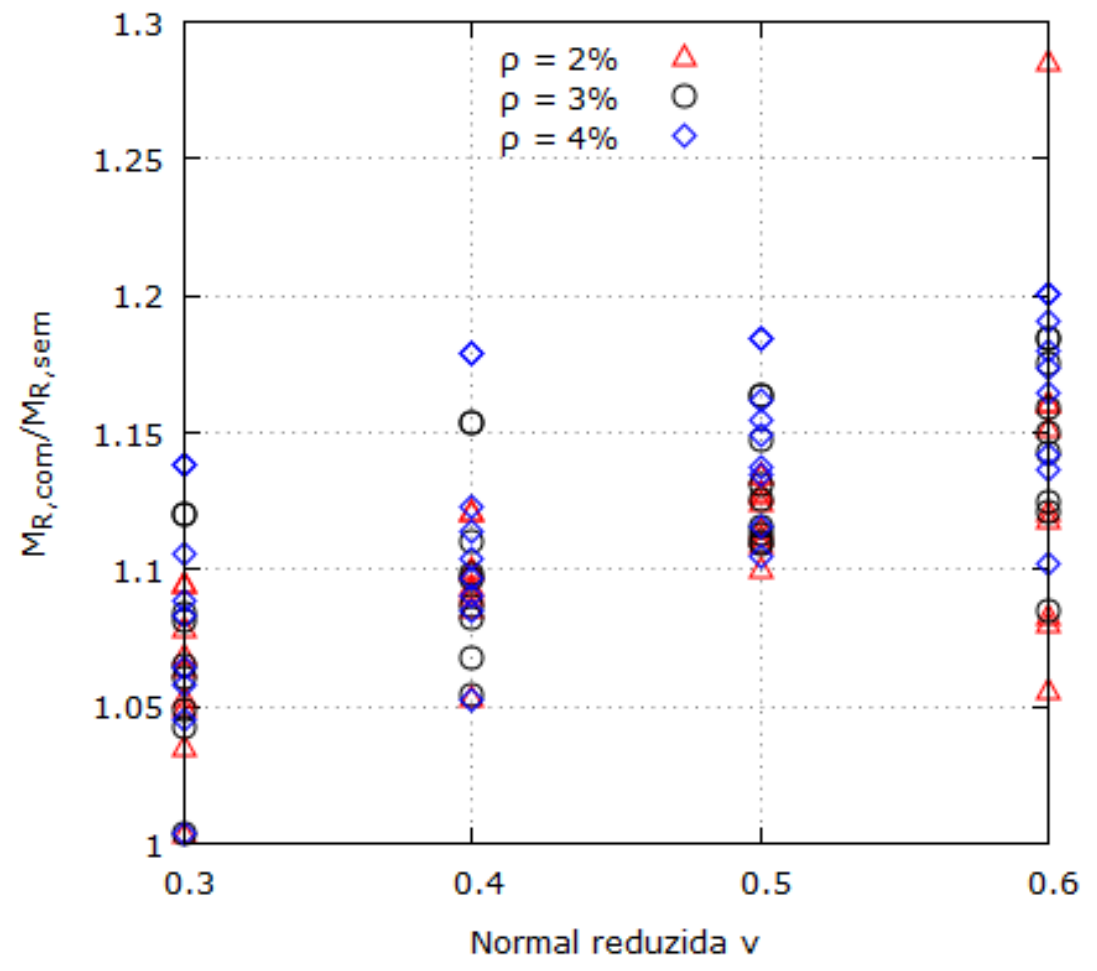

Fonte: Elaborado pela Autora. 
Figura 6-3 - Momentos totais relativos com e sem fluência em relação à taxa de armadura.

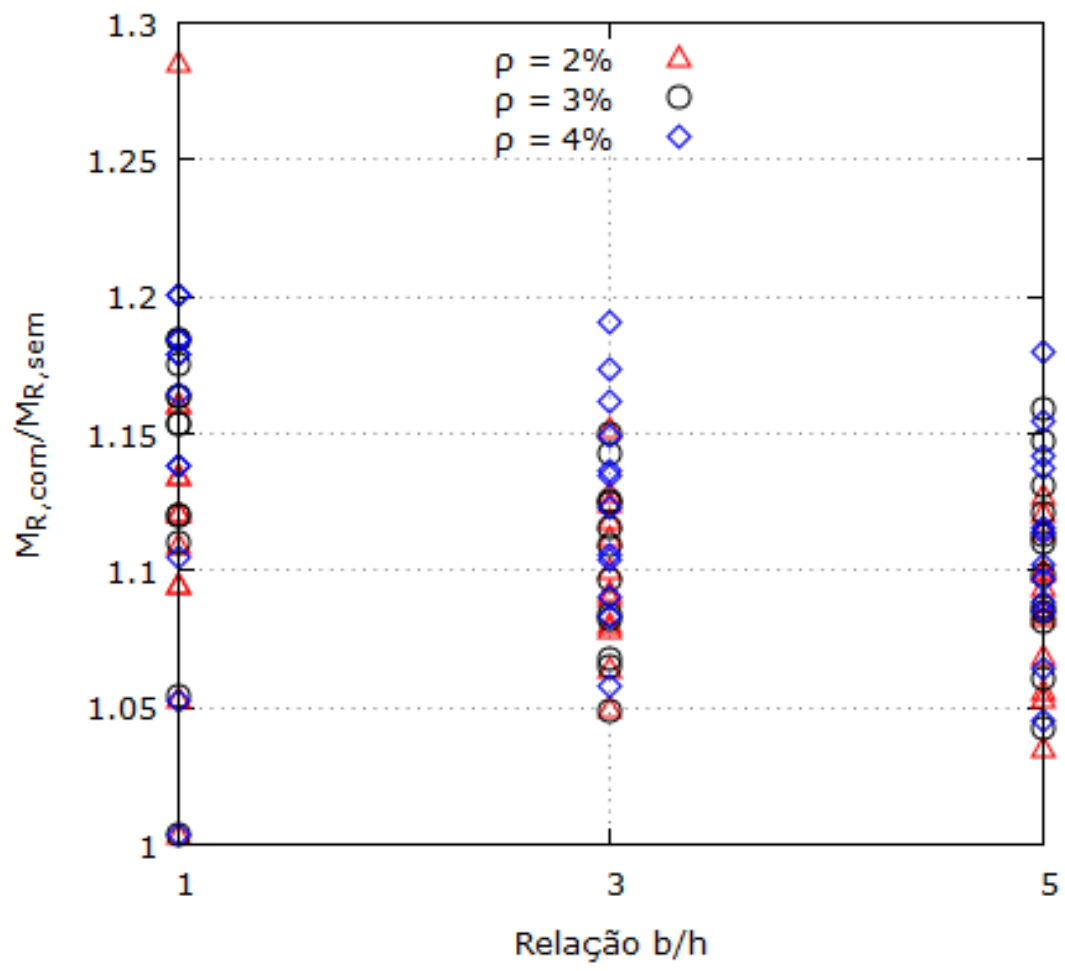

Fonte: Elaborado pela Autora.

Do ponto de vista conceitual, parece dúbio admitir a hipótese de maior momento resistente oblíquo da seção transversal quando é considerado simultaneamente um efeito prejudicial ao lance de pilar devido à fluência. Ocorre que o aumento da deformação por fluência aumenta a curvatura de um pilar e os efeitos de segunda ordem pela redução da rigidez secante. Na prática, a capacidade resistente da seção transversal já admite, pelo menos indiretamente, que o concreto armado fletido sofre aumento de deformação ao longo do tempo acompanhado por redução da tensão de pico.

Tomando como comparação o resultado do Exemplo de Aplicação 3 com taxa de armadura $\rho=4 \%$ e relação entre lados de $b / h=3$, a Figura 6-4 reproduz parcialmente a Figura A-1 com os valores de momentos solicitantes devido ao efeito da fluência indicados pelos três pontos conectados entre si e correspondentes às seções de base, de topo e intermediária. A linha de envoltória mais externa corresponde à resistência da seção considerando aumento da deformação do concreto pela fluência e a linha traceja corresponde à envoltória resistente convencional. Os valores de momentos últimos apresentados no gráfico indicam os máximos resistentes para casa situação e apresentam desvio de cerca de 5\%, para o caso em análise. 
Figura 6-4 - Momentos totais relativos com e sem fluência relação à taxa de armadura.

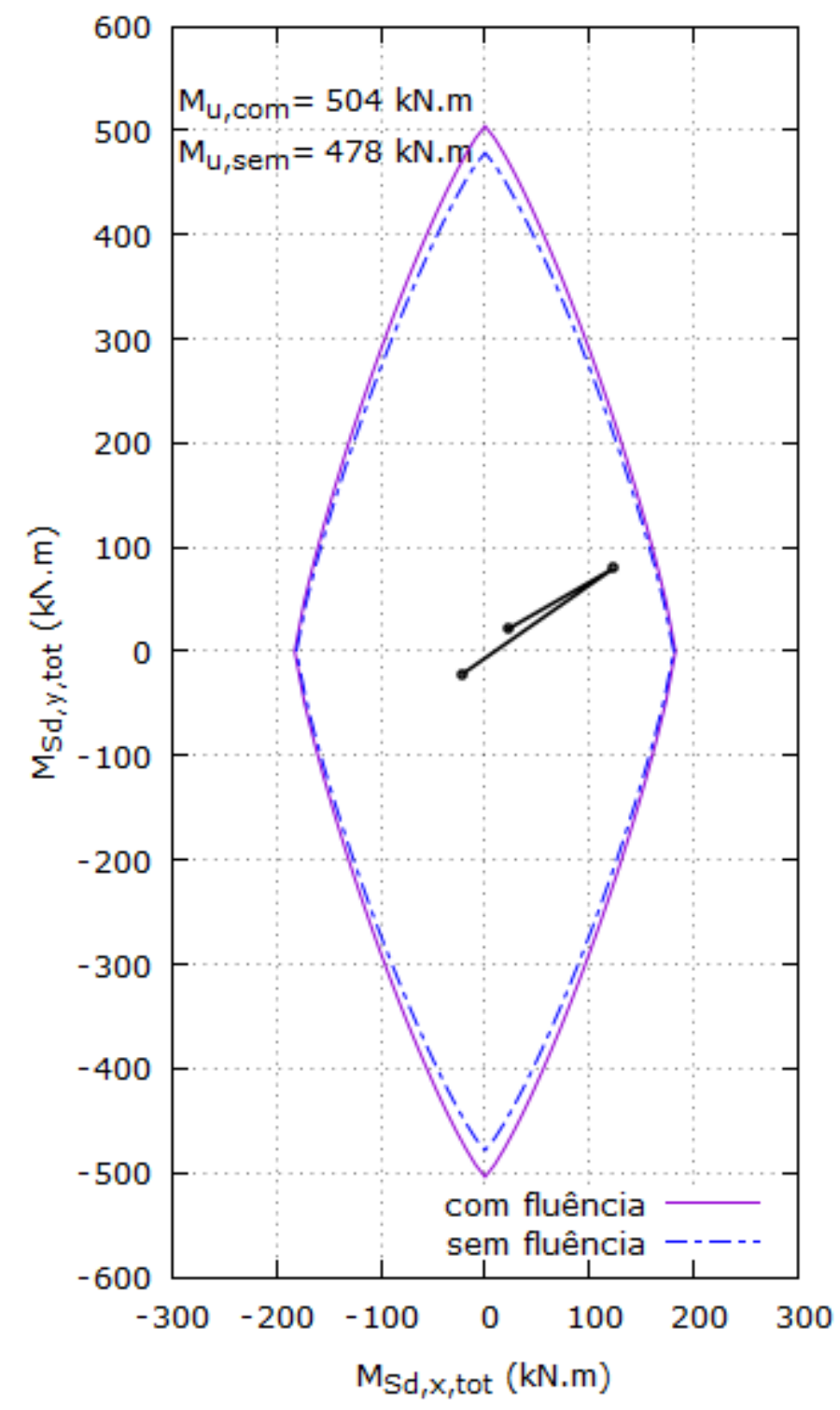

Fonte: Elaborado pela Autora.

Conforme a geometria da seção transversal, a taxa de armadura e a inclinação do momento de primeira ordem atuante, é possível que a solicitação de uma determinada seção transversal ultrapasse a envoltória resistente convencional, sem, no entanto, ultrapassar a envoltória mais externa.

Tendo em vista a procura de resultados mais conservadores, as relações seguintes determinadas neste trabalho tomaram como referência que a capacidade resistente da seção transversal na flexo-compressão é calculada sem considerar o aumento de deformações do concreto pela fluência para a obtenção do momento último em cada direção. 


\subsection{AMPLIFICAÇÃO DA SOLICITAÇÃO}

Para avaliar os efeitos de segunda ordem obtidos segundo cada método de cálculo, foi definida a amplificação $\chi$, a qual representa a razão entre o momento total incluindo efeitos de segunda ordem e o momento fletor inicial aplicado. A Figura 6-5 apresenta a influência da esbeltez e da normal reduzida na amplificação $\chi$ da flexão inicial segundo os métodos aproximados e o Método Geral para os 1.362 casos em que houve equilíbrio por este último método. Tal como anteriormente, ao lado de cada coluna estão apresentados o número de casos válidos obtidos.

A Figura 6-5a e a Figura 6-5b mostram que os Métodos de Curvatura aproximada e de Rigidez aproximada apresentam níveis semelhantes de magnitude de ampliação da solicitação inicial para todos os casos. É possível notar que esses métodos quando comparados com o Método Geral indicado na Figura 6-5d são cada vez mais conservadores com o aumento da normal reduzida e o aumento da esbeltez. Para os dois métodos aproximados citados, a amplificação é razoavelmente conservadora para as esbeltezes de 90 e 115 e, no entanto, são excessivamente conservadores para normais reduzidas de 0,5 e 0,6 com esbeltez de 140, podendo chegar a valores de amplificação maiores que 100 em alguns casos. Estas situações excessivamente conservadoras têm as seguintes características comuns: seção quadrada, proporção entre os momentos da base e do topo igual a -1 e normal reduzida igual a 0,6.

As situações válidas para o Método Acoplado são mostradas na Figura 6-5c. A amplificação é da mesma ordem de grandeza dos outros dois métodos aproximados para os casos com normal reduzida de 0,3. Entretanto, o Método Acoplado é mais conservador que os outros dois métodos conforme a normal reduzida aumenta para até 0,5 , pois não foram obtidos valores válidos acima desta normal aplicada. 
Figura 6-5 - Amplificação da flexão inicial variando a esbeltez e a normal reduzida.

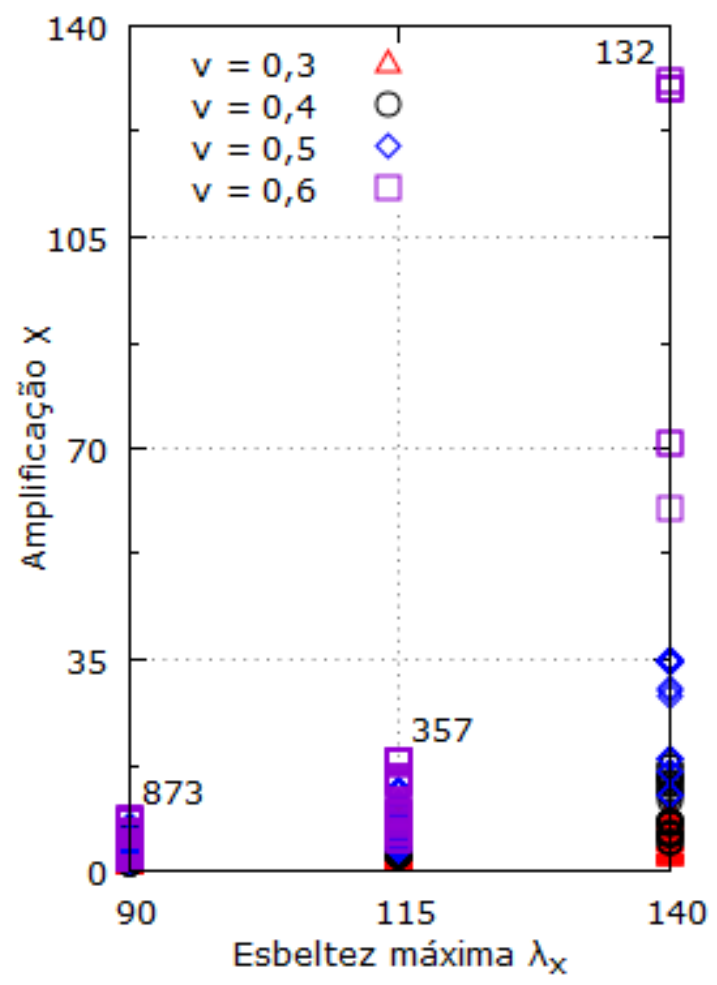

a) Método de Curvatura aproximada

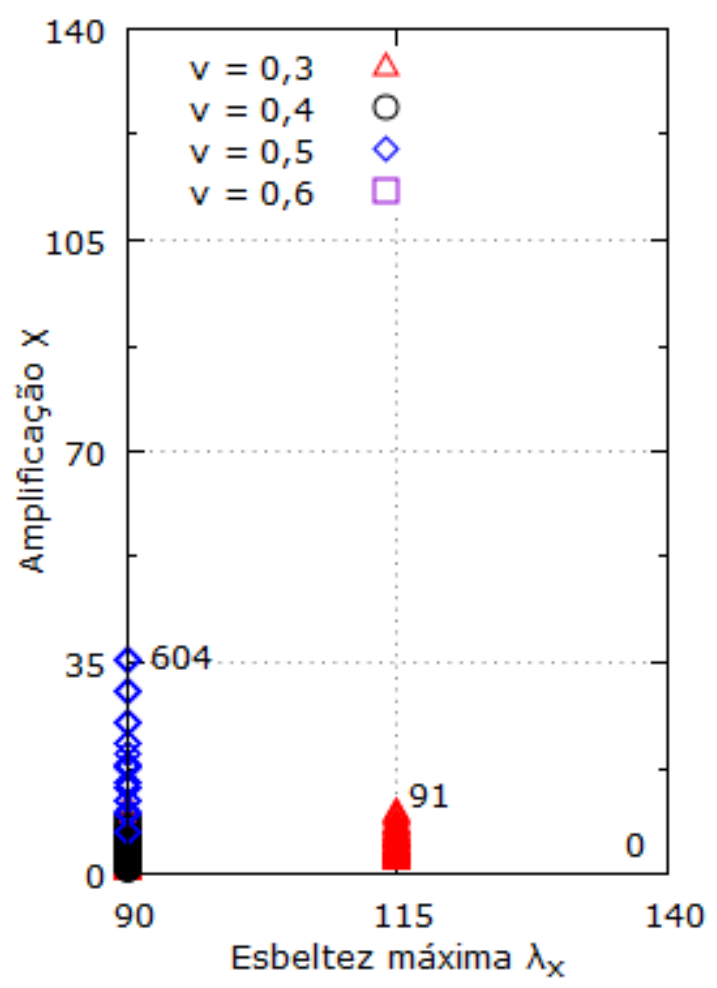

c) Método Acoplado a diagramas

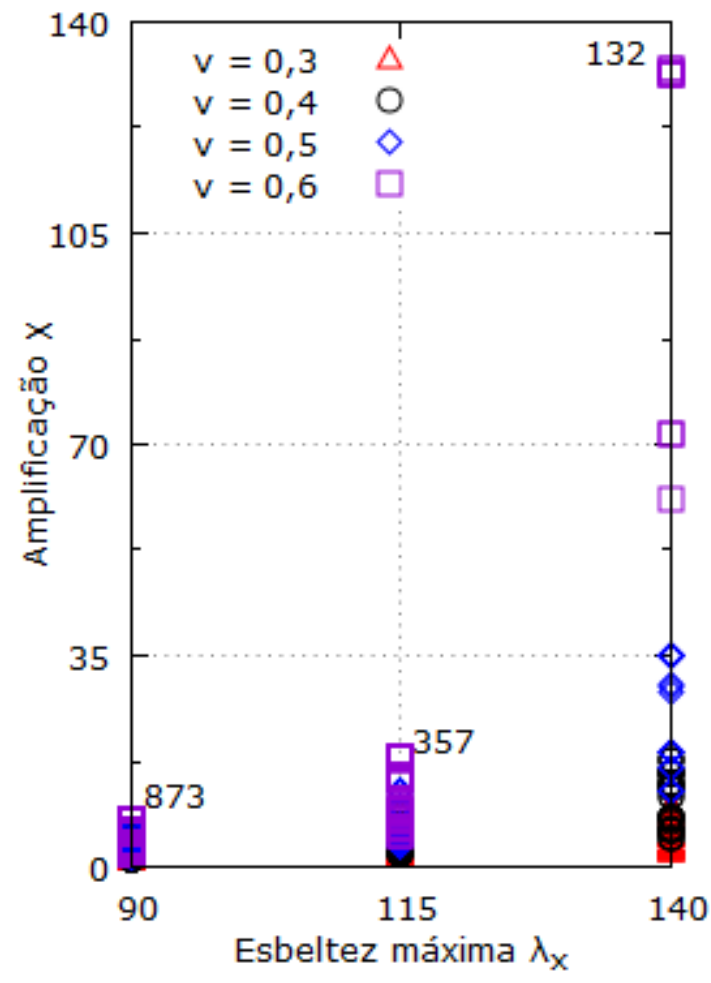

b) Método de Rigidez aproximada

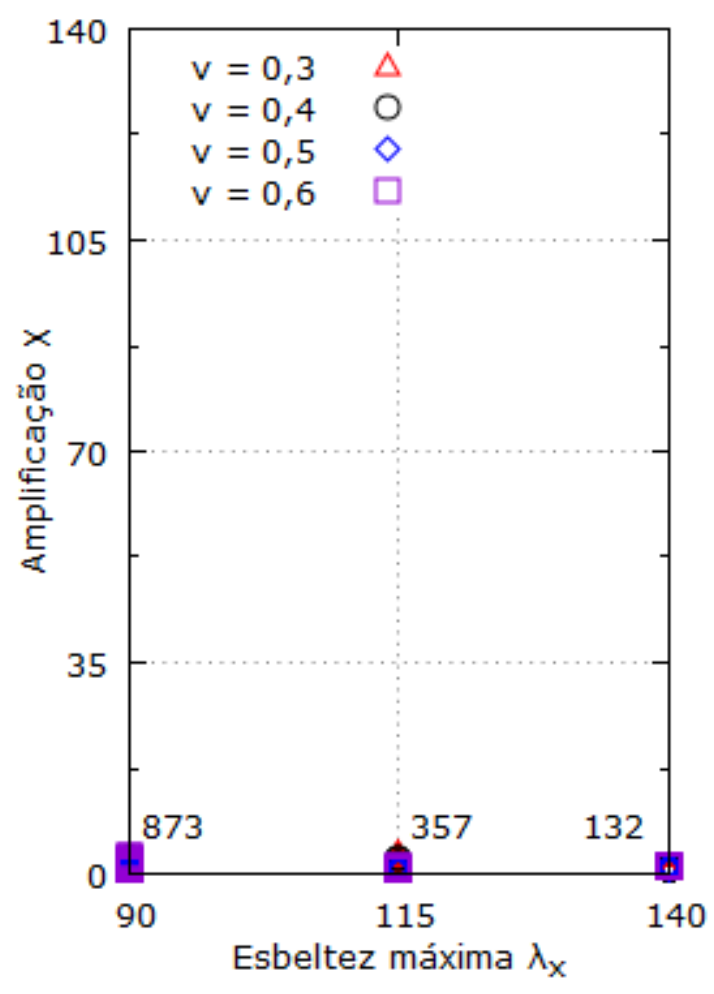

d) Método Geral

Fonte: Elaborado pela Autora. 


\subsection{RELAÇÃO ENTRE MÉTODOS APROXIMADOS E O MÉTODO GERAL}

Para avaliar a possibilidade de calcular efeitos de segunda ordem em pilares solicitados à flexão oblíqua com esbeltezes entre 90 e 140 considerando duas flexo-compressões normais independentes, ou seja, com os métodos aproximados presentes na norma ABNT NBR 6118:2014, foram calculados o momento total solicitante $M_{S d}$ de cada método e o momento resistente último $M_{R d}$ de cada seção. O Método Geral considera as direções acopladas e aparenta estar mais próximo da realidade, razão pela qual foi considerado o método de referência para comparação de resultados.

A Figura 6-6 apresenta um diagrama esquemático Normal-Momento indicando o momento solicitante aplicado de primeira ordem $M_{l d}$ de certa seção crítica (ponto A) e o momento solicitante total $M_{S d}$ com o efeito de segunda ordem (ponto B) cuja direção pode ser diferente da direção da flexão inicial conforme a intensidade das componentes obtidas em cada direção quando da inclusão de efeitos de segunda ordem. Nesta mesma Figura está indicado o ponto C correspondente ao momento resistente $M_{R d}$ na direção $\theta$ de flexão oblíqua inicial. A segurança do pilar é atendida quando a relação $M_{S d} / M_{R d}$ é inferior a 1 , sendo neste texto os valores calculados para a direção inicial. Esta hipótese foi adotada em razão da obtenção de direções resultantes para os momentos solicitantes totais muito diferentes da direção inicial, tal como relatado nos Exemplos de Aplicação.

Figura 6-6-Representação de momentos solicitantes e envoltória resistente.

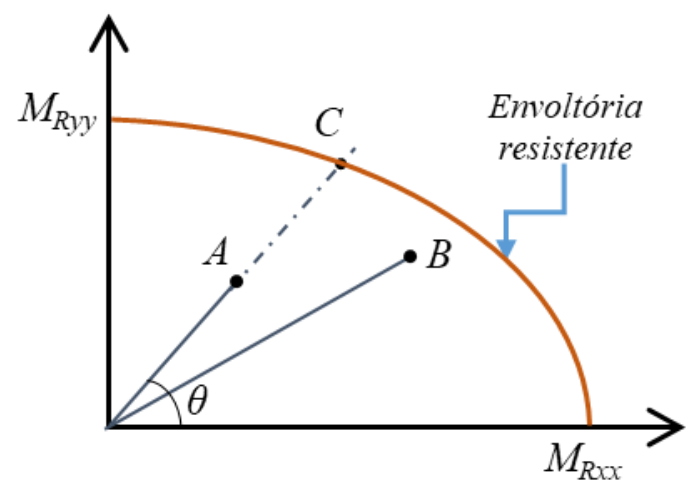

Fonte: Adaptado de Ceccon (2008). 
A consideração da direção do momento solicitante é importante quando as componentes de solicitação são obtidas de modo diferente conforme sejam diferentes a vinculação ou a proporção entre os momentos de extremidade de um determinado lance de pilar. Caso a seção transversal fosse circular, não haveria dúvida quanto à direção do plano de flexão a ser considerado, pois a capacidade resistente seria independente da direção da flexão. No entanto, havendo seção retangular e, principalmente, mais alongada do que outra seção, o momento resistente aumenta quando o plano de flexão se aproxima da direção mais resistente.

Caso ocorresse apenas flexão reta paralela a uma ou a outra direção principal de inércia, também não haveria dúvida quanto à direção do plano de flexão a ser considerada. Por outro lado, havendo flexão oblíqua em seção retangular, pode ocorrer que a resistência à flexão seja maior em uma direção do que na outra. Caso as componentes do momento solicitante total conduzam a uma direção resultante diferente daquela correspondente ao plano de flexão inicial, pode haver conclusão equivocada quanto à direção correta do momento resultante.

Este fato pode ser observado na Tabela 5-1 com os resultados do Exemplo de Aplicação 1. Tomando como referência o momento total resultante previsto segundo o Método da Curvatura aproximada, a direção da flexão oblíqua é de 17,0 em razão da não obrigatoriedade de cálculo do efeito de segunda ordem na direção menos esbelta e também pela obtenção do coeficiente $\alpha_{b}$ diferente em cada direção. No entanto, sabendo que a direção de flexão inicial adotada foi de $45^{\circ}$ e que as vinculações nas extremidades do lance de pilar são iguais, é razoável supor que a direção total solicitante mantenha proximidade com a direção inicial. Porém, isto não foi observado na quase totalidade de casos estudados neste trabalho.

Caso o desvio entre a direção do momento total solicitante fosse pequeno em relação à direção de flexão inicial, seria coerente determinar a verificação do momento solicitante com a direção resultante obtida a partir das componentes de flexão. Como critério neste trabalho foi inicialmente adotado que desvios maiores do que um terço da diferença entre a faixa de ângulos estudada seria inaceitável. No caso, o desvio não poderia ultrapassar o máximo de $5^{\circ}$. Entretanto, após a análise dos resultados processados, poucos casos atenderam a este critério, tendo sido abandonado no transcorrer dos estudos e fixada a direção de flexão coincidente com a direção inicial.

Como ilustração da influência do desvio angular, a Figura 6-7 apresenta a envoltória resistente do Exemplo de Aplicação 3 com linha tracejada. Na mesma figura, foi determinada a capacidade resistente máxima na flexão composta oblíqua quando da atuação de momento 
solicitante de mesma intensidade do momento resistente. Esta direção foi identificada por uma linha reta contínua associada ao ângulo de $45^{\circ}$.

Figura 6-7 - Variação da direção da flexão com a resistência da seção.

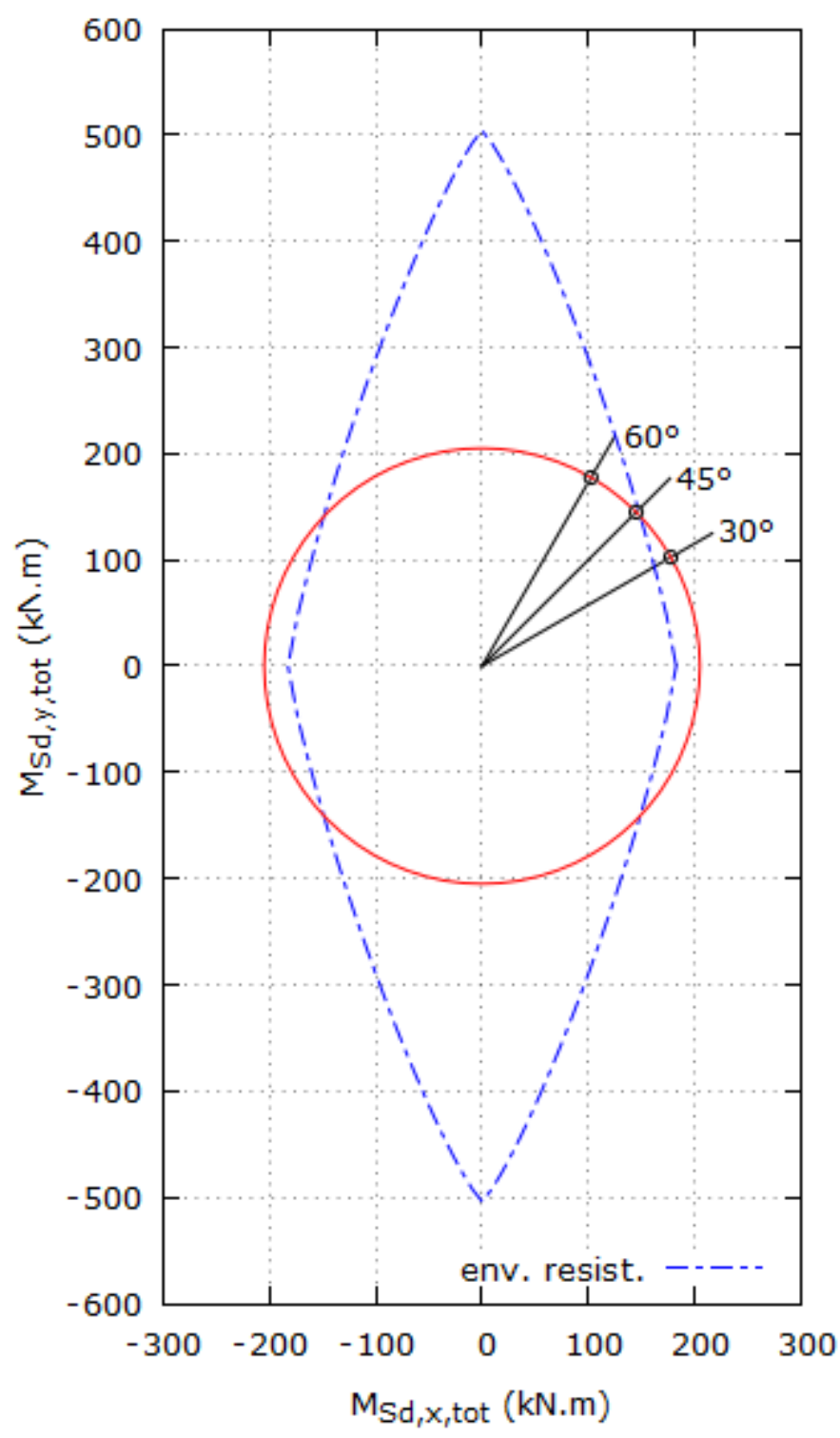

Fonte: Elaborado pela Autora.

Para a situação considerada de seção retangular com relação $b / h=3$ e taxa de armadura $\rho=4 \%$, pode ser observado que o momento resistente na flexão composta reta paralela à direção $y$ é cerca de 2,6 vezes superior ao momento resistente na outra direção. Como resultado dessa diferença de resistências, a envoltória resistente é mais alongada em uma direção do que na outra. 
Impondo hipoteticamente que a direção do plano de flexão varie de $15^{\circ}$ em relação ao ângulo inicialmente imposto, é possível concluir que a seção transversal resiste quando o desvio é no sentido anti-horário e convergente à direção da maior resistência. De modo oposto, sendo o desvio no sentido horário, a mesma intensidade de momento atuante não é mais capaz de suportar a flexão aplicada.

O círculo central de linha contínua da mesma figura foi construído com raio arbitrário e coincidente com a capacidade resistente da seção para a direção de $45^{\circ}$. Enquanto o círculo está circunscrito à envoltória resistente, qualquer desvio de inclinação do momento solicitante é indiferente com relação à capacidade ou não de suportar a solicitação. Para as regiões onde o círculo indicado está externo à envoltória resistente, é desejável que o desvio entre o momento inicial e o momento solicitante total seja o menor possível para não comprometer a segurança do lance de pilar.

Esta última observação é tanto mais importante quanto mais alongada é a seção transversal, podendo ser assumido que no caso de seção alongada, menor é o desvio aceitável entre o momento inicial e o momento solicitante total. Ou seja, o desvio aceitável é dependente da forma mais ou menos alongada da envoltória resistente.

Mantendo os mesmos dados de referência é possível obter o momento resistente pela envoltória obtida para cada direção $\theta$ do plano de flexão através da relação seguinte:

$$
M_{R d, \theta}=\frac{1}{\sqrt[1,2]{\left(\frac{\cos \theta}{M_{R d, x x}}\right)^{1,2}+\left(\frac{\operatorname{sen} \theta}{M_{R d, x x}}\right)^{1,2}}}
$$

sendo $M_{R d, x x}=182,54$ kN.m e $M_{R d, y y}=503,92$ kN.m os momentos resistentes na flexão composta reta do Exemplo de Aplicação 3.

Variando o ângulo $\theta$ da direção de flexão para a mesma envoltória resistente da Figura 6-7 é possível obter os valores da Tabela 6-4. A última coluna indica a variação do momento em relação à referência de ângulo de $45^{\circ}$. Nesse caso particular, desvio de $15^{\circ}$ na direção do plano de flexão resulta em acréscimo de capacidade resistente da ordem de $20 \%$ e redução da ordem de $10 \%$ quando o desvio ocorre no sentido oposto. Deve ser ressaltado que estes resultados estão vinculados às características do exemplo estudado e podem variar de modo significativo para outras condições. 
Tabela 6-4 - Momento resistente segundo a direção de flexão do Exemplo de Aplicação 3.

\begin{tabular}{ccc}
\hline Direção $\theta$ & $M_{R d, \theta}(k N . m)$ & Valor relativo \\
\hline $30^{\circ}$ & 187,21 & $90,0 \%$ \\
$35^{\circ}$ & 192,39 & $92,5 \%$ \\
$40^{\circ}$ & 199,25 & $95,8 \%$ \\
$45^{\circ}$ & 208,03 & $100,0 \%$ \\
$50^{\circ}$ & 219,13 & $105,3 \%$ \\
$55^{\circ}$ & 233,04 & $112,0 \%$ \\
$60^{\circ}$ & 250,48 & $120,4 \%$ \\
\hline
\end{tabular}

Fonte: Elaborado pela Autora.

A Figura 6-8 apresenta a variação da relação entre o ângulo do plano de flexão calculado pelas componentes de momento e o ângulo de flexão inicial tomando como referência a relação entre os lados da seção retangular $b / h$ e separando os valores segundo a esbeltez máxima $\lambda_{x}$ imposta.

Quando a relação entre os ângulos se aproxima de 1, entende-se que é pequeno o desvio do ângulo do momento total considerando os efeitos de segunda ordem em relação ao plano de flexão inicial. De modo inverso, quanto mais a relação entre ângulos se afasta de 1 , maior é o desvio entre o plano inicial e o plano resultante com o efeito de segunda ordem.

Considerando a Figura 6-8a) e a Figura 6-8b), é possível observar que os resultados dos métodos aproximados de Curvatura e de Rigidez são próximos entre si e com relação entre ângulos variando entre 0,25 e 1,6. É possível observar que, para seção transversal quadrada, ou seja, $b / h=1$, a dispersão de resultados é menor do que para relação entre lados entre 3 e 5 .

Tomando como referência um hipotético ângulo de $45^{\circ}$, a tendência observada indica que o plano de flexão pode variar de modo aproximado entre $11^{\circ}$ e $72^{\circ} \mathrm{com}$ desvios de até $34^{\circ}$ em relação ao ângulo inicial. Para relação entre lados $b / h \geq 3$ o desvio angular tende a ser no sentido da redução do ângulo inicial e esta situação pode estar associada à diferença de resistência nas direções ortogonais, pois foram considerados válidos apenas os resultados com equilíbrio pelo Método Geral. 
Figura 6-8 - Relação entre os ângulos calculados em relação aos ângulos iniciais de flexão, de acordo com o alongamento da seção transversal.

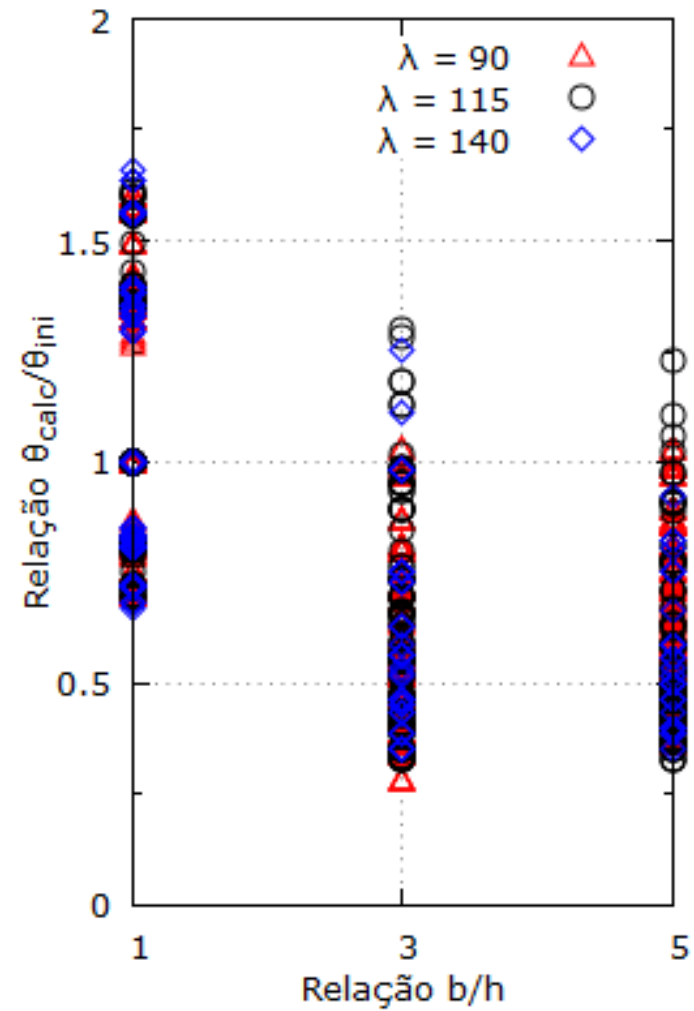

a) Curvatura Aproximada

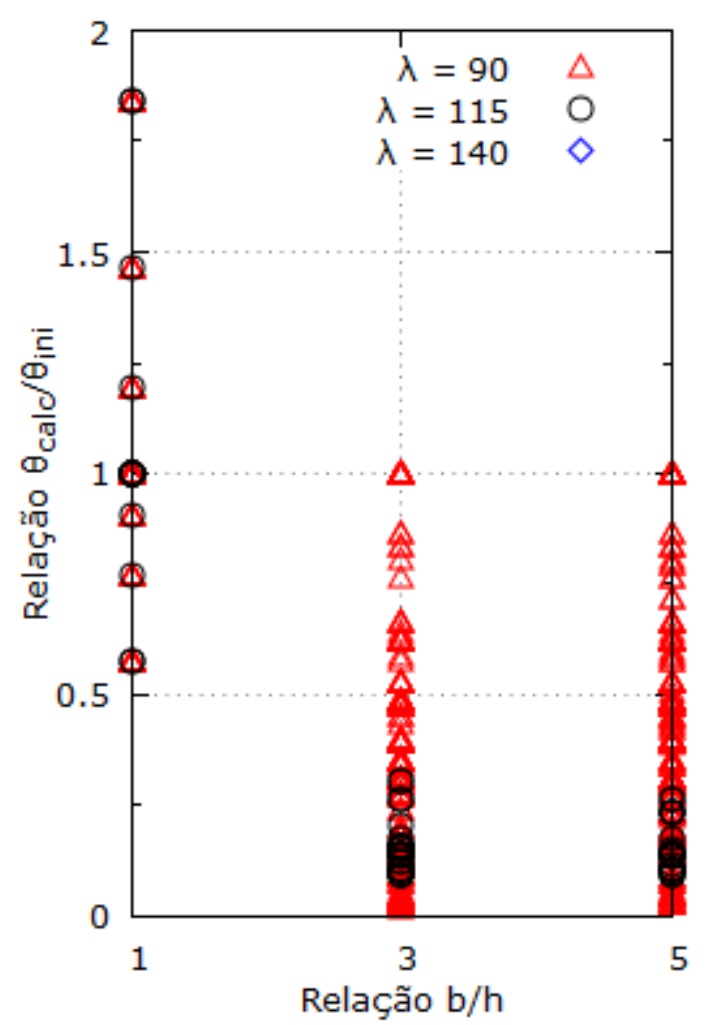

c) Acoplado a diagramas

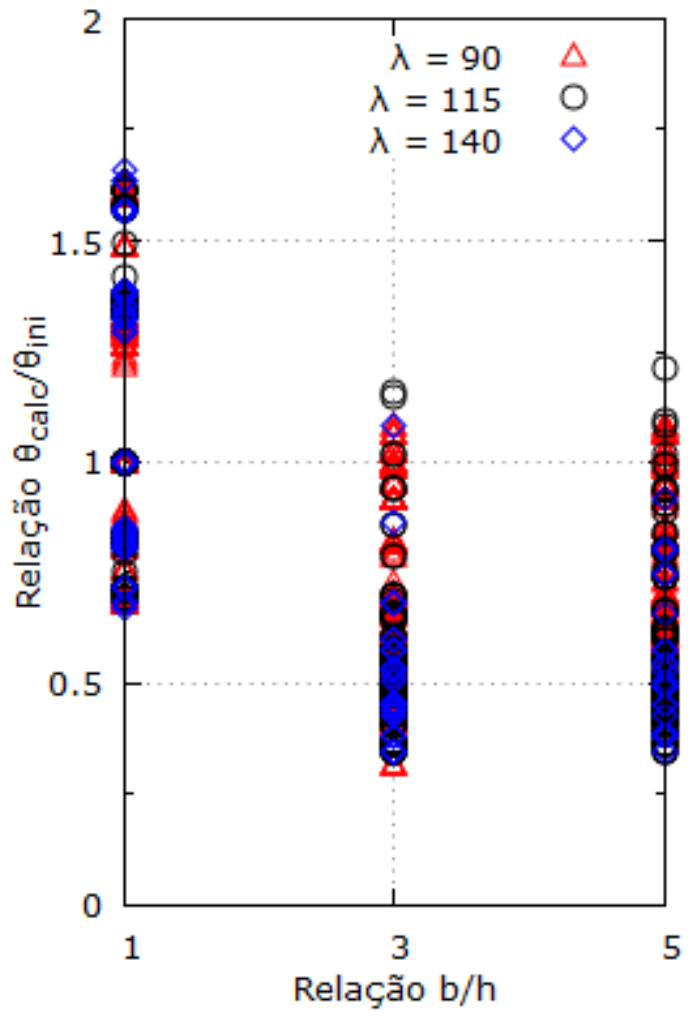

b) Rigidez Aproximada

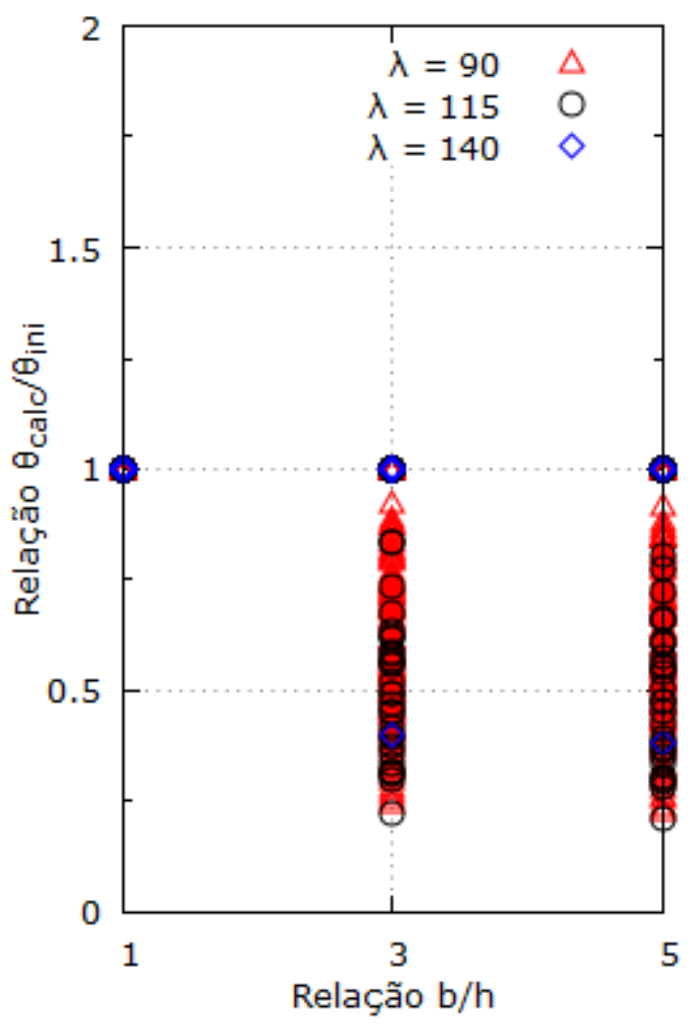

d) Método Geral

Fonte: Elaborado pela Autora. 
Para o caso do método aproximado Acoplado a diagramas, a observação da Figura 6-8c) mostra dispersão de resultados entre o ângulo resultante final e o ângulo de flexão inicial entre 0,03 e 1,8 e, ou seja, desvios angulares maiores do que para os métodos aproximados anteriores. Novamente tomando como referência ângulo inicial de $45^{\circ}$, o ângulo resultante do momento total pode variar entre $1,4^{\circ}$ e $81^{\circ}$.

Para exemplificação do grande desvio angular observado, foi escolhido um caso extremo dentre todos casos analisados. Este caso extremo selecionado corresponde à relação entre lados $b / h=3$, taxa de armadura $\rho=4 \%$, esbeltez máxima $\lambda_{x}=90$, normal reduzida $\nu=0,5$, momento reduzido $\mu=0,1$, ângulo de $\theta=45^{\circ}$ e proporção entre momentos nas extremidades de 0,5. Com estes dados iniciais, não há efeito de segunda ordem a ser calculado na direção menos esbelta resultando em:

$$
M_{S d, t o t, y}=\alpha_{b y} M_{1 d, A y}=1,0 \times 42,42=42,42 \mathrm{kN} . \mathrm{m}
$$

A rigidez adimensional na direção mais esbelta é calculada como sendo $\kappa_{x}=34,74$. Para este caso particular, a componente de momento total de segunda ordem na direção x é:

$$
M_{S d, t o t, x}=\frac{\alpha_{b x} M_{1 d, A x}}{1-\frac{v \lambda^{2}}{120 \kappa_{x}}}=\frac{0,8 \times 42,42}{1-\frac{0,5 \times 90^{2}}{120 \times 34,74}}=1.190,85 \mathrm{kN} . \mathrm{m}
$$

Com as componentes conhecidas, a direção calculada para o momento resultante é:

$$
\theta_{\text {calc }}=\operatorname{arctg} \frac{M_{S d, t o t, y}}{M_{S d, t o t, x}}=\operatorname{arctg} \frac{42,42}{1.190,85}=2,0^{\circ}
$$

Em relação à direção inicial, o desvio angular é $43^{\circ}$ e a relação entre os ângulos calculado e inicial é 0,04 .

A rigidez adimensional mínima calculada segundo a Eq. (5-5) é próxima da rigidez anteriormente obtida e possui intensidade igual a $\kappa_{\min }=33,75$. Como já comentado anteriormente, quando a rigidez adimensional fica próxima de um certo valor mínimo, o resultado do momento total de segunda ordem pelo método aproximado Acoplado a diagramas tende a um valor exagerado, neste caso de intensidade 28 vezes maior do que o momento inicial nessa direção. Sendo uma componente do momento resultante muito maior do que a outra, o ângulo calculado a partir destas componentes apresenta grande desvio em relação ao ângulo inicial.

Pelos resultados da Figura 6-8 d), pode ser verificado que o Método Geral apresenta tendência de menor dispersão do ângulo resultante em comparação com os métodos aproxi- 
mados. É importante destacar que, para seção quadrada, não foram observados desvios entre o ângulo inicial e final. Para relação entre lados $b / h \geq 3$ a relação entre ângulos variou de 0,25 a 1. Mais uma vez considerando uma direção hipotética de $45^{\circ}$ para seção transversal retangular com $b / h \geq 3$, o desvio angular fica entre 0 e $34^{\circ}$.

Estes resultados justificam a utilização do ângulo inicial para a consideração da resistência da seção transversal quando da aplicação da flexão oblíqua em virtude de ser exagerado o desvio angular quando são consideradas direções independentes de flexão.

As análises seguintes foram realizadas por meio de gráficos com relações entre momentos solicitantes e resistentes $M_{S d} / M_{R d}$ calculadas segundo os Métodos aproximados e o Método Geral, tal como representado na Figura 6-9. Esta representação gráfica é análoga à feita por Ceccon (2008), onde o autor avaliou a possibilidade de considerar o desacoplamento das rigidezes em pilares solicitados à flexão composta oblíqua. Apesar da semelhança de forma, neste estudo os valores apresentados são referentes aos métodos de cálculo presentes na ABNT NBR 6118:2014 e tomam como referência para comparação o Método Geral.

Figura 6-9-Representação de gráfico entre momentos totais solicitantes e resistentes.

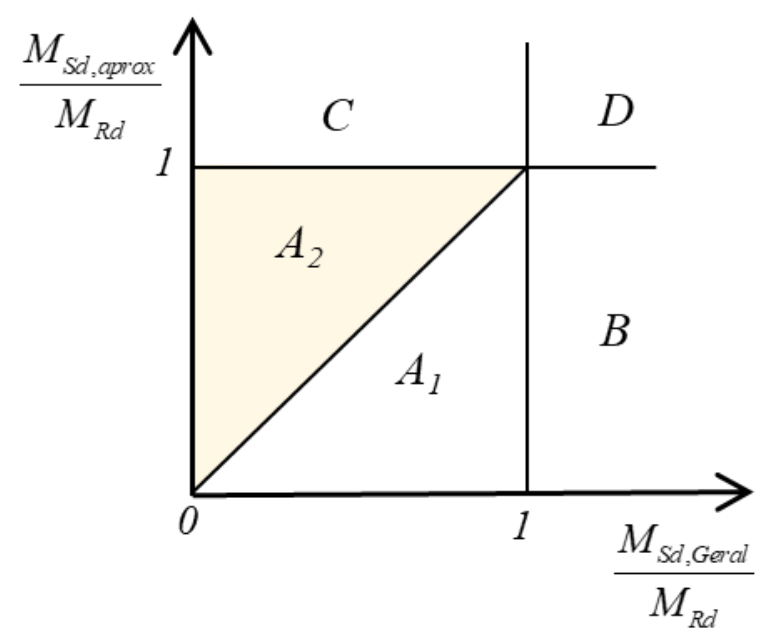

Fonte: Adaptado de Ceccon (2008).

Adaptando as observações de Ceccon (2008), os gráficos podem destacar cinco regiões, a saber:

a) Na região $\mathrm{A} 1$, os valores de momentos totais calculados por um método aproximado são inferiores aos valores calculados pelo Método Geral. No entanto, a segurança estrutural é confirmada por ainda apresentarem valores solicitantes inferiores ao valor resis- 
tente. Nesta região, os resultados de um certo método aproximado são mais arrojados por serem menores do que os valores previstos pelo Método Geral.

b) A região A2 indica valores para os quais o lance de pilar apresenta momento total de segunda ordem calculado por um método aproximado com intensidade superior ao valor calculado pelo Método Geral, mas com a segurança necessária não sendo ultrapassada. Esta região sugere que os resultados por um certo método aproximado são mais conservadores do que os resultados previstos pelo Método Geral. Esta é a situação mais aconselhável.

c) A região B mostra resultados obtidos com o Método Geral sem segurança estrutural apesar de aparentar segurança com um certo método aproximado. Neste trabalho não foram localizados pontos nesta região, pois lances de pilar com solicitações calculadas com o Método Geral e maiores do que as resistências foram consideradas sem equilíbrio com o programa SecTrans. Valores nesta região são indesejáveis, pois a utilização de um certo Método aproximado conduz a resultados imprudentes.

d) A região C indica situações para as quais os valores calculados com o Método Geral apresentam segurança, mas não apresentam segurança com o Método aproximado. Isso indica que o Método aproximado é mais conservador e levaria a descartar a utilização de um lance de pilar que poderia ser aproveitado com os resultados do Método Geral. Esta situação é a favor da segurança embora contra a economia. A região C seria a segunda região mais desejada para obtenção de resultados com um certo método aproximado.

e) Por último, a região D representa o caso de um lance de pilar sem segurança estrutural seja com valores de momentos totais calculados pelo método aproximado ou pelo Método Geral. Neste caso é indiferente a utilização de um ou outro método, uma vez que ambos dariam a informação de que o lance de pilar deve ser alterado em sua geometria de seção transversal, na classe de resistência do concreto ou no arranjo de armação.

Destaca-se que não foi possível obter resultados nas regiões B e D, pois o programa SecTrans interrompe o processamento quando há esgotamento da capacidade resistente pelo Método Geral.

As figuras a seguir apresentadas foram construídas com escala logarítmica para obter todos gráficos com mesma faixa de variação, pois foram observados valores destoantes da 
nuvem de pontos obtida com os Métodos de Curvatura aproximada e de Rigidez aproximada quando comparados com os resultados do Método Geral.

\subsubsection{Curvatura}

A comparação entre o Método da Curvatura aproximada e o Método Geral é apresentada na Figura 6-10 e na Figura 6-11 para os seguintes parâmetros: esbeltez, normal reduzida, momento reduzido, taxa de armadura, ângulo de atuação dos momentos e proporção entre os momentos base e topo. Pode-se notar que independente do parâmetro estudado, todos os casos resultam nas regiões desejáveis A2 e C em que o Método de Curvatura aproximada é sempre conservador e nas situações em que o momento resistente é maior que o solicitante, a segurança estrutural estaria verificada pelo Método Geral.

A Figura 6-10a apresenta a influência do aumento da esbeltez do pilar. Nota-se que os valores calculados pelo Método da Curvatura se tornam cada vez mais conservadores conforme se aumenta a esbeltez. Para esbeltez de 90, há um número significativo de casos dentro da região A2 em que o método aproximado é seguro e conservador, porém a quantidade de situações dentro dessa região diminui com esbeltez de 115 e quase desaparece para casos com esbeltez de 140. A razão da pouca quantidade obtida de casos para esbeltez de 140 foi devido ao Método Geral não ter apresentado equilíbrio.

A influência da normal reduzida é semelhante à da esbeltez conforme pode ser visto na Figura 6-10b. O Método de Curvatura aproximada é cada vez mais conservador para valores crescentes de solicitação normal de compressão. Existem vários casos com normal reduzida de 0,3 e 0,4 dentro da região A2, mas o número de situações nessa região diminui conforme a normal reduzida é aumentada. Para alguns casos de normal reduzida de 0,6 , o momento fletor solicitante final pelo método aproximado é até 100 vezes maior que o calculado pelo Método Geral.

O padrão da influência do momento reduzido é diferente do discutido anteriormente. A Figura 6-10c mostra que há valores de momento reduzido de todas as magnitudes nas regiões A2 e C em quantidade semelhante. Entretanto, pode ser notado que o Método de Curvatura aproximada é cada vez menos conservador conforme a magnitude dos momentos reduzidos aumenta, isto é, os momentos solicitantes finais calculados por este método se aproximam dos valores do Método Geral como pode ser visto pelo deslocamento dos pontos para a direita conforme a magnitude do momento reduzido. 
Figura 6-10 - Solicitação relativa pelo Método de Curvatura aproximada.

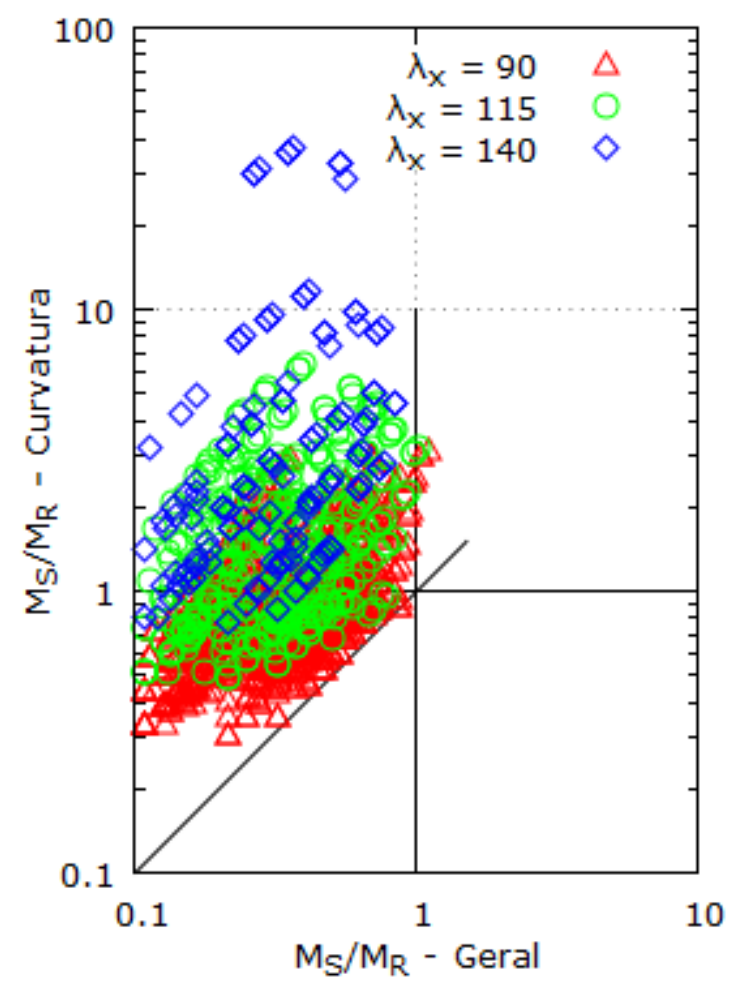

a) Variando a esbeltez máxima

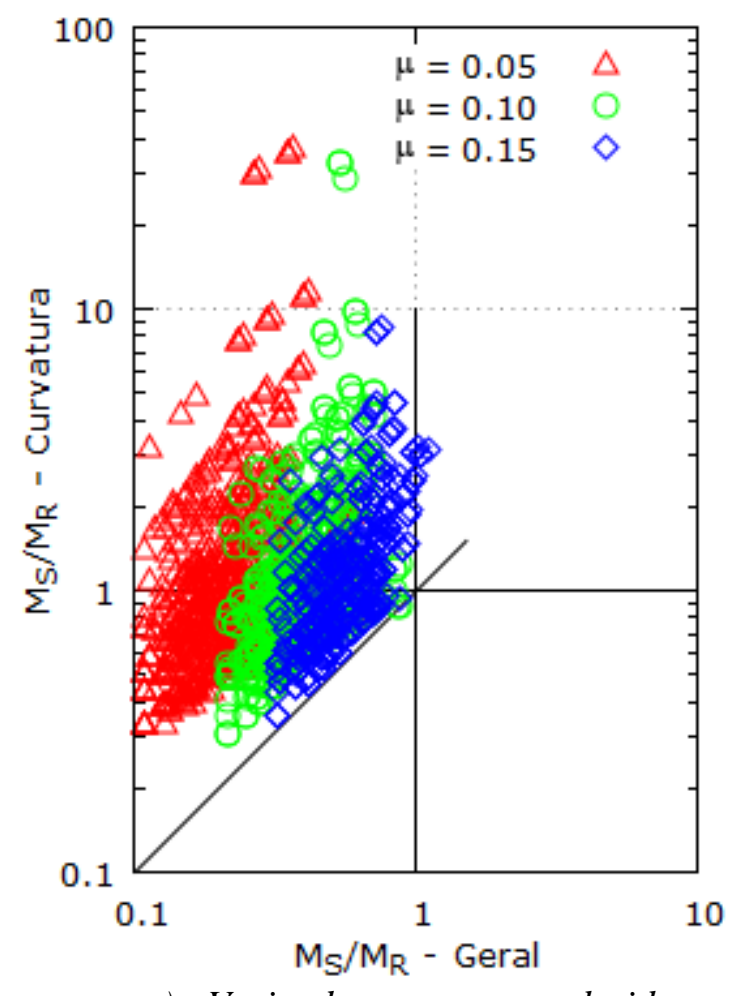

c) Variando o momento reduzido

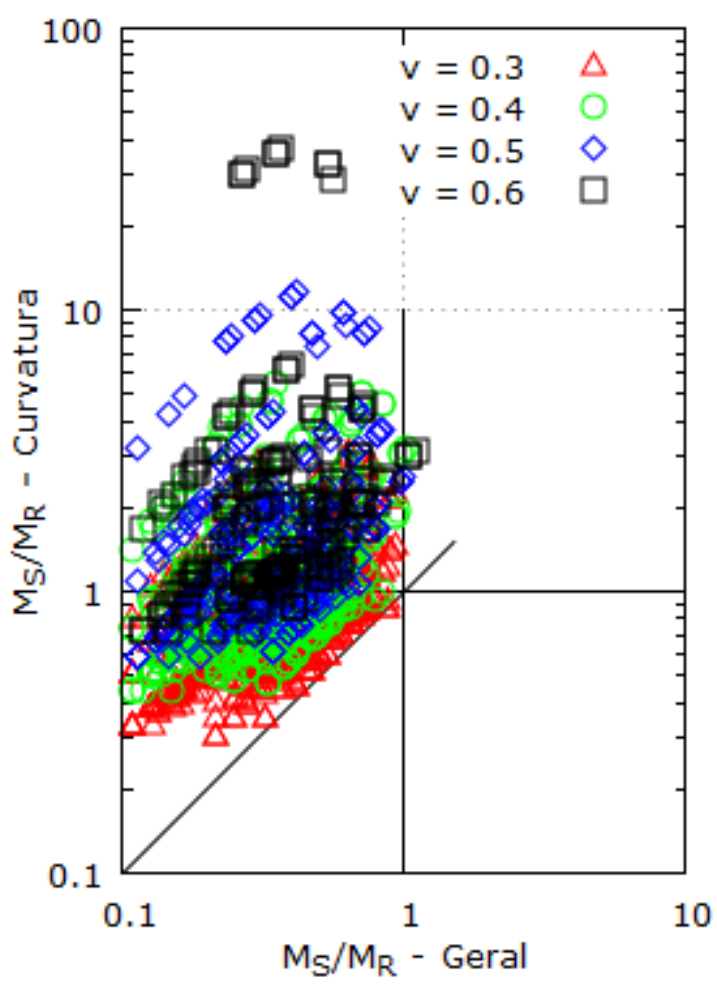

b) Variando a normal relativa

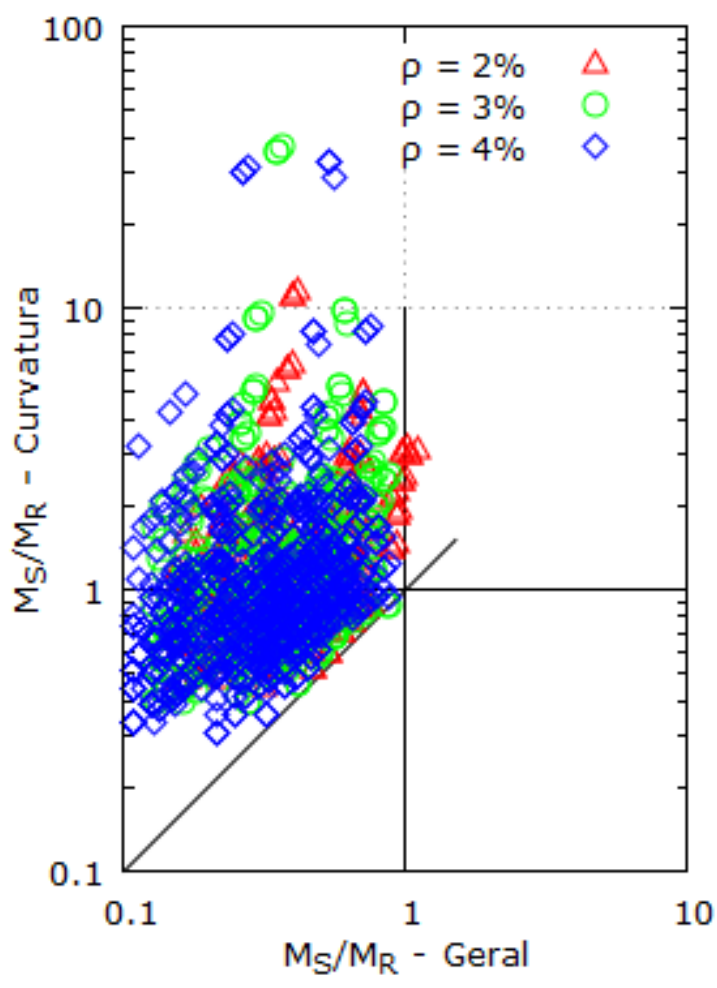

d) Variando a taxa de armadura

Fonte: Elaborado pela Autora. 
Figura 6-11 - Solicitação relativa pelo Método de Curvatura aproximada (continuação).

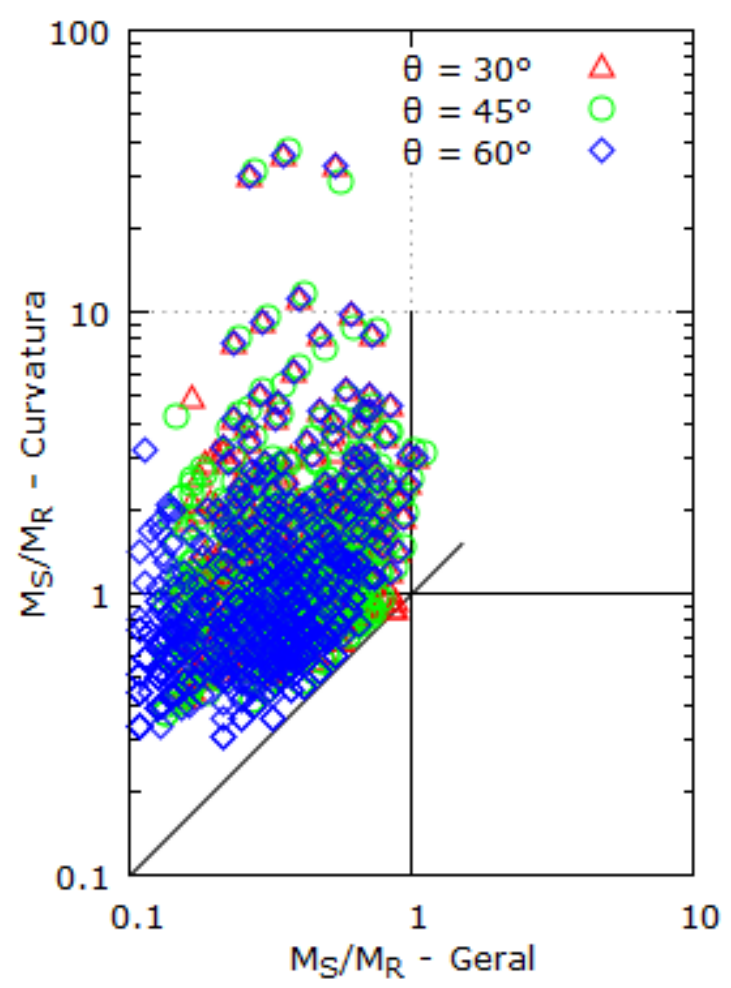

a) Variando a direção

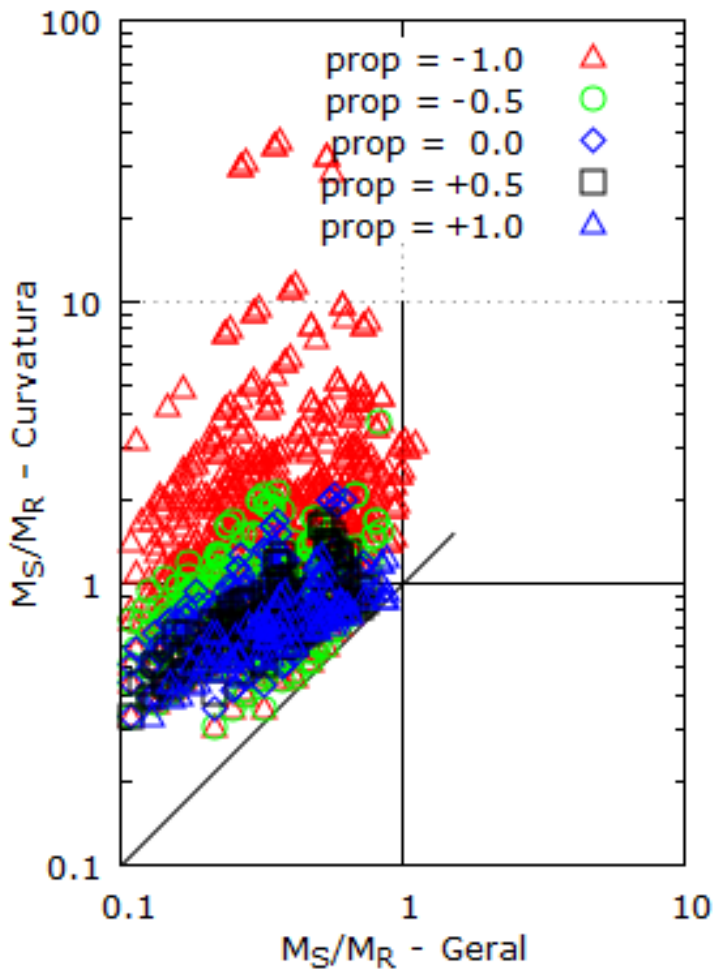

b) Variando a proporção

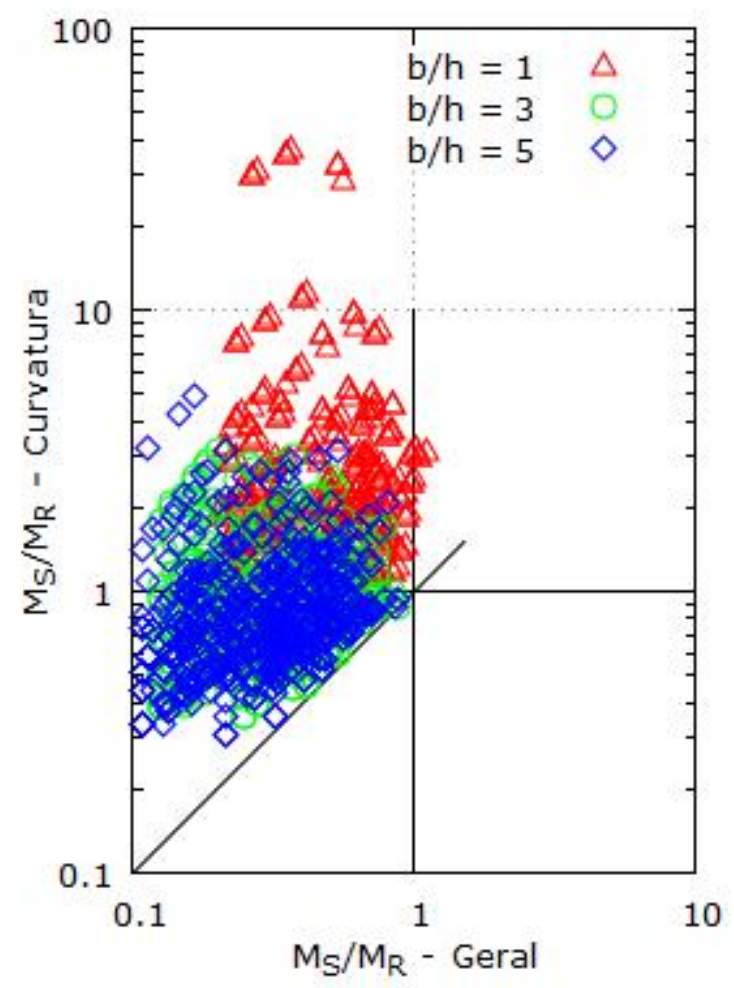

c) Variando a relação entre os lados da seção

Fonte: Elaborado pela Autora. 
A influência da taxa de armadura e do ângulo atuante é mostrada respectivamente na Figura 6-10d e Figura 6-11a. Pode ser visto que não há nenhum padrão para estes parâmetros. Há situações para todos os valores dessas variáveis em diferentes níveis das regiões A2 e C, exceto casos extremamente conservadores (ordem de grandeza de 100 vezes mais) com taxa de armadura de $2 \%$ (quadrante superior da Figura 6-10d).

A Figura 6-11b apresenta o efeito da variação da proporção entre os momentos da base e o topo. Pode ser notado que os casos se situam dentro ou relativamente perto da região A2 para todos os valores dessa proporção de momentos, exceto para casos de curvatura dupla com relação de momentos igual 1. Nestas últimas situações (prop = -1), o Método de Curvatura aproximada é muito mais conservador.

Por último, a Figura 6-11c mostra o comportamento da relação $b / h$ para este método aproximado de cálculo. Foi encontrado número de casos semelhantes para as três relações. Há valores em quantidade semelhantes nas áreas A2 e C, no entanto na área A2 apenas 6\% dos casos possuem seção quadrada, sendo o restante dos casos igualmente divididos entre as seções retangulares. Os pilares com seção quadrada estão predominantemente na área $\mathrm{C}$, de forma a apresentar casos muito conservadores. Portanto, os casos com seções transversais retangulares resultaram em valores mais satisfatórios.

\subsubsection{Rigidez}

O Método da Rigidez Aproximada apresentou resultados muito semelhantes aos obtidos pelo Método da Curvatura, para todas as variáveis analisadas. Desta forma, não serão apresentados todos os gráficos novamente para este método. Dos gráficos apresentados no item anterior, dois parâmetros que se destacaram foram o índice de esbeltez e a normal reduzida.

A Figura 6-12 apresenta essas duas situações para o Método da Rigidez aproximada. As duas variáveis $\lambda$ e $v$ apresentaram comportamento semelhante, uma vez que a relação Msd/Mrd para o método aproximado aumentou a medida que os valores de esbeltezes e normais reduzidas foram maiores. O Método aproximado aparenta mais aceitável para esbeltezes de 90 e 115 e normais reduzidas iguais a 0,3 e 0,4. Por outro lado, para esbeltez igual a 140 e normal reduzida de 0,6 , o efeito de segunda ordem é exagerado para o método aproximado, chegando a ser cerca de 100 vezes o valor obtido pelo Método Geral. 
Figura 6-12 - Solicitação relativa pelo Método de Rigidez.

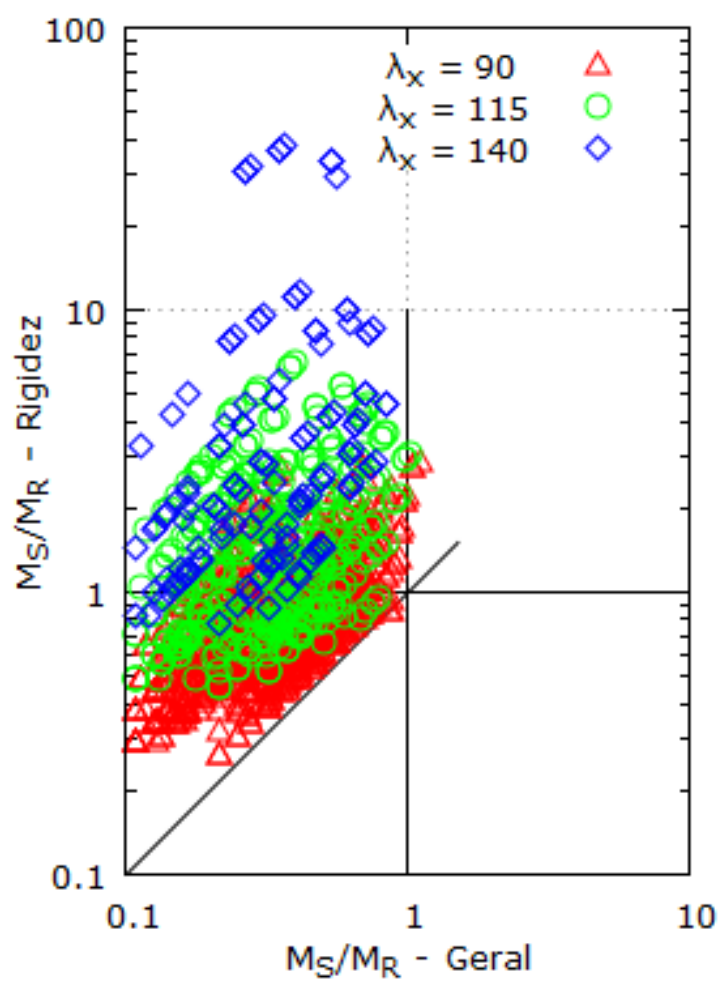

a) Variando a esbeltez máxima

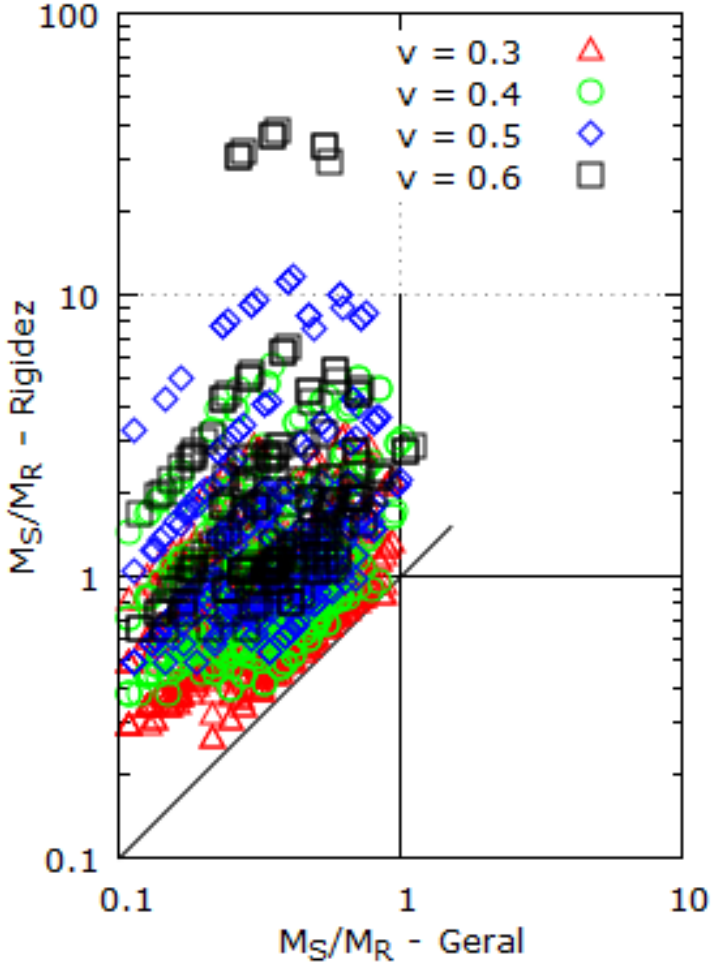

b) Variando a normal reduzida

Fonte: Elaborado pela Autora.

De forma a analisar o comportamento do Método de Rigidez aproximada diante das três relações b/h variadas, foram construídos três gráficos ilustrados na Figura 6-13.

Figura 6-13 - Solicitação relativa pelo Método de Rigidez segundo a relação b/h.

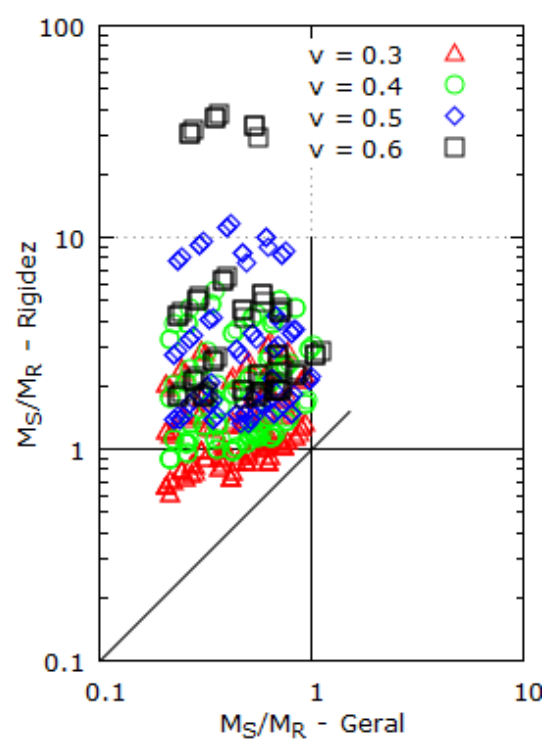

a) $b / h=1$

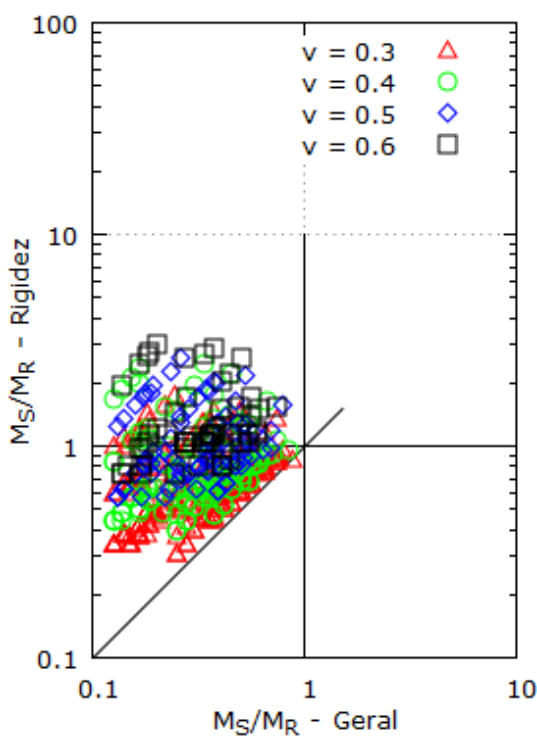

b) $b / h=3$

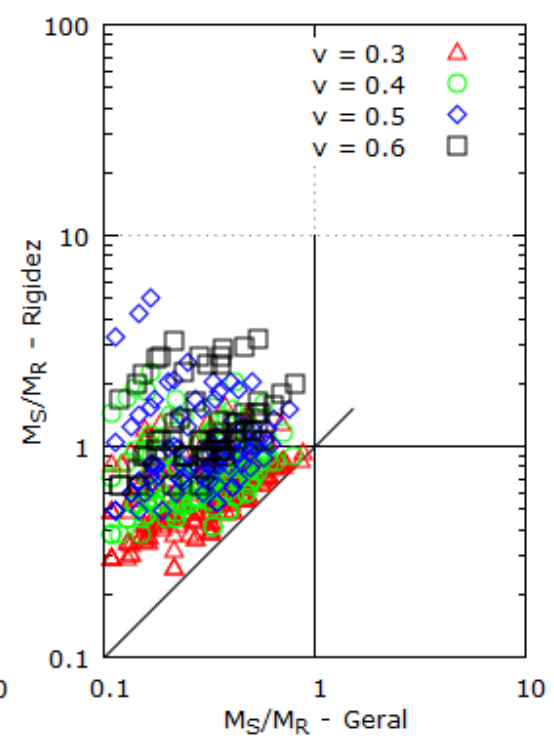

c) $b / h=5$

Fonte: Elaborado pela Autora. 
Para todos os valores estudados de relações $b / h$, o efeito da normal reduzida foi semelhante, sendo cada vez mais conservador para valores crescentes de solicitação normal de compressão. Os resultados obtidos para as seções quadradas foram mais elevados que os obtidos para as seções retangulares. A Figura 6-13a mostra que para seções quadradas, 83\% dos casos ficaram na região $\mathrm{C}$ e que na região A2 foram obtidos valores apenas com normais reduzidas iguais a 0,3 e 0,4. Além disso, para normal reduzida igual a 0,6 houve algumas situações com valores exagerados.

Já a Figura 6-13b e c apresentaram resultados mais semelhantes entre si e diferentes dos encontrados para as seções quadradas. Para as seções retangulares, a nuvem de pontos foi deslocada verticalmente para baixo, ficando mais concentrada na região A2 com obtenção de maiores quantidades de resultados seguros, mas ainda conservadores. Portanto, foi possível concluir que os pilares retangulares apresentaram melhor comportamento pela maior aproximação de resultados com o Método Geral.

\subsubsection{Acoplado}

A Figura 6-14 e a Figura 6-15 apresentam os resultados do Método Acoplado a diagramas quando comparado ao Método Geral, retratando o comportamento de cada variável. A Figura 6-14a mostra o efeito da esbeltez do pilar, sendo que para este método de cálculo foram encontrados resultados apenas para esbeltez de 90 e 115, não sendo obtidos casos válidos para esbeltez de 140. A justificativa para não validação desses casos foi discutida no item 5.3.

É possível notar que os valores calculados pelo Método Acoplado foram menos conservadores do que os obtidos pelo Método de Curvatura e de Rigidez. Dos 695 casos encontrados do Método Acoplado, 438 casos pertencem à região A2 e 257 à região C. Ou seja, 63\% dos resultados estão localizados na região mais desejável, indicando que o método é seguro e conservador. Das 438 situações pertencentes à A2, 398 possuem esbeltez de 90 e estão concentradas próximas à reta de $45^{\circ}$, indicando que os valores do Método Acoplado são próximos ou iguais ao do Método Geral. Os valores referentes a esbeltez de 115 afastam um pouco dessa reta, sendo, portanto, mais conservadores e provavelmente se fossem encontrados valores para esbeltez de 140, estes pertenceriam à região C e com resultados mais elevados. 
A influência da normal reduzida é semelhante à da esbeltez máxima conforme pode ser visto na Figura 6-14b. O Método Acoplado é cada vez mais conservador para valores crescentes de solicitação normal de compressão, não sendo encontrados resultados para a normal reduzida mais elevada $v=0,6$. A maioria dos casos com normal reduzida de 0,3 e 0,4 está dentro da região $\mathrm{A} 2$, já para normal reduzida de 0,5 todos os resultados estão na região $\mathrm{C}$, indicando valores mais conservadores e de até 35 vezes maior que o calculado pelo Método Geral.

O comportamento do momento reduzido difere do observado para a esbeltez e normal reduzida. A Figura 6-14c mostra que há valores de momento reduzido de todas as magnitudes nas regiões A2 e C. Entretanto, pode ser notado que o método aproximado é cada vez menos conservador conforme a magnitude dos momentos reduzidos aumenta, isto é, os momentos solicitantes finais calculados por este método se aproximam dos valores do Método Geral como pode ser visto pelo deslocamento dos pontos para a direita conforme a magnitude do momento reduzido.

Comparando a Figura 6-14c com o gráfico do Método de Curvatura aproximada, ilustrado na Figura 6-10c, os resultados obtidos pelo Método Acoplado para qualquer valor de momento reduzido estão deslocados para baixo, no sentido do quadrante A2 e aproximando da linha de $45^{\circ}$. Isto indica que os resultados obtidos pelo Método Acoplado apresentam valores menos conservadores e mais próximos do Método Geral.

A influência da taxa de armadura é mostrada na Figura 6-14d. Dos 695 casos apresentados, 421 possuem taxa de armadura igual a 4\%, 192 casos para taxa de $3 \%$ e 82 para taxa de $2 \%$. A razão da maioria dos casos possuírem taxa de armadura mais elevada é devido ao fato do programa SecTrans não ter apresentado equilíbrio pelo Método Geral com valores baixos de armadura. A Figura 6-14d não mostra um padrão para esta variável além da predominância da taxa de armadura de $4 \%$. 
Figura 6-14 - Solicitação relativa pelo Método Acoplado a diagramas.

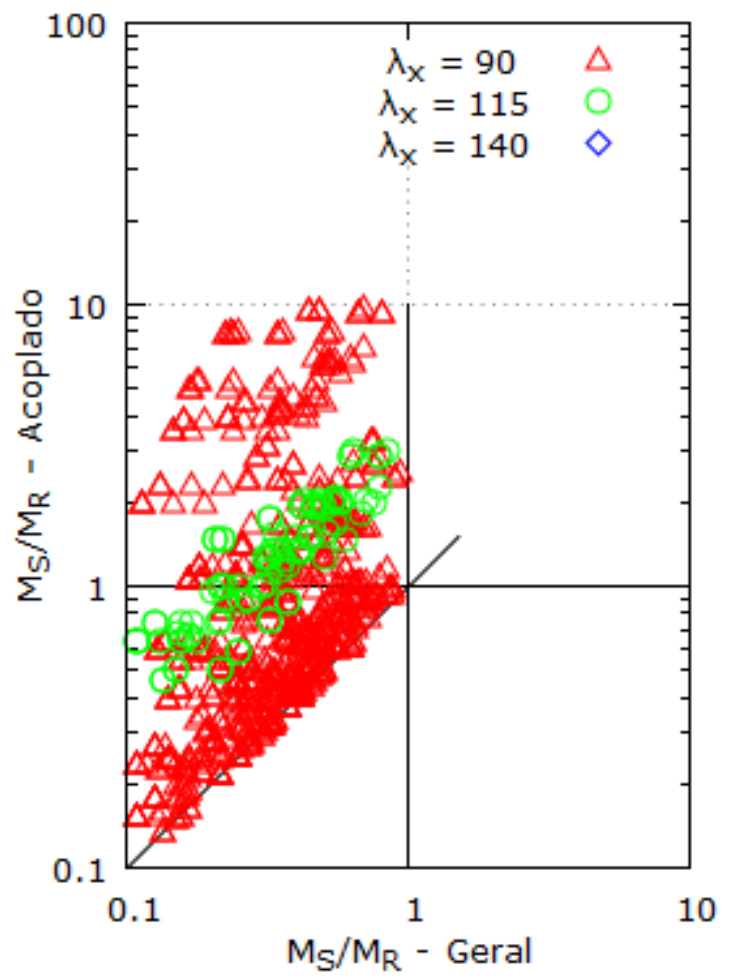

a) Variando a esbeltez máxima

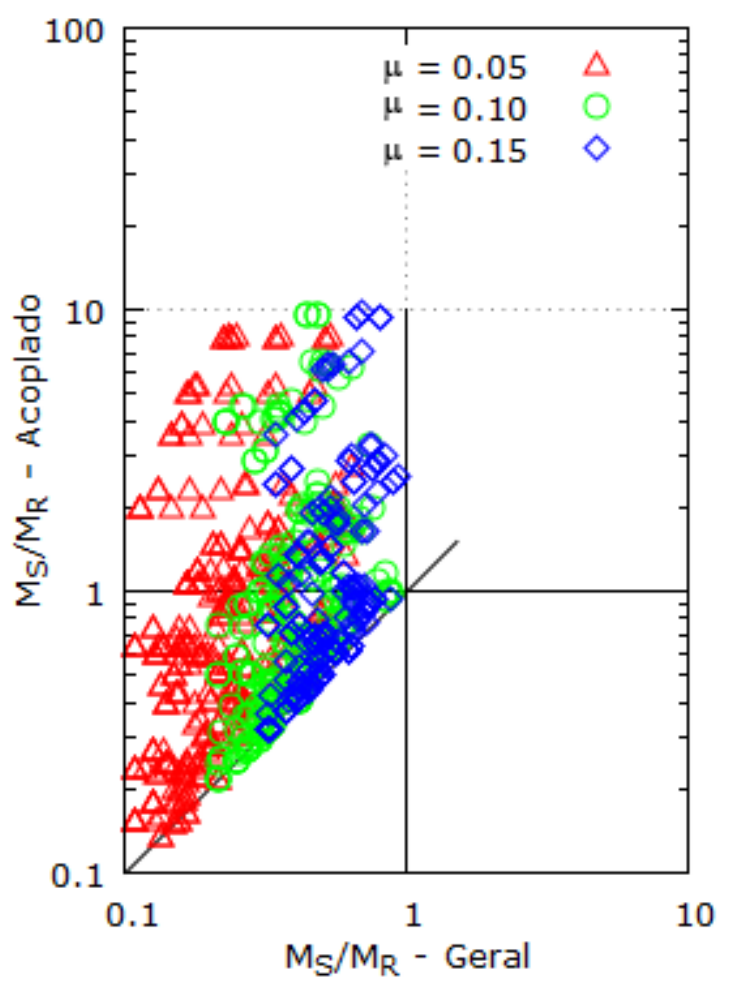

c) Variando o momento reduzido

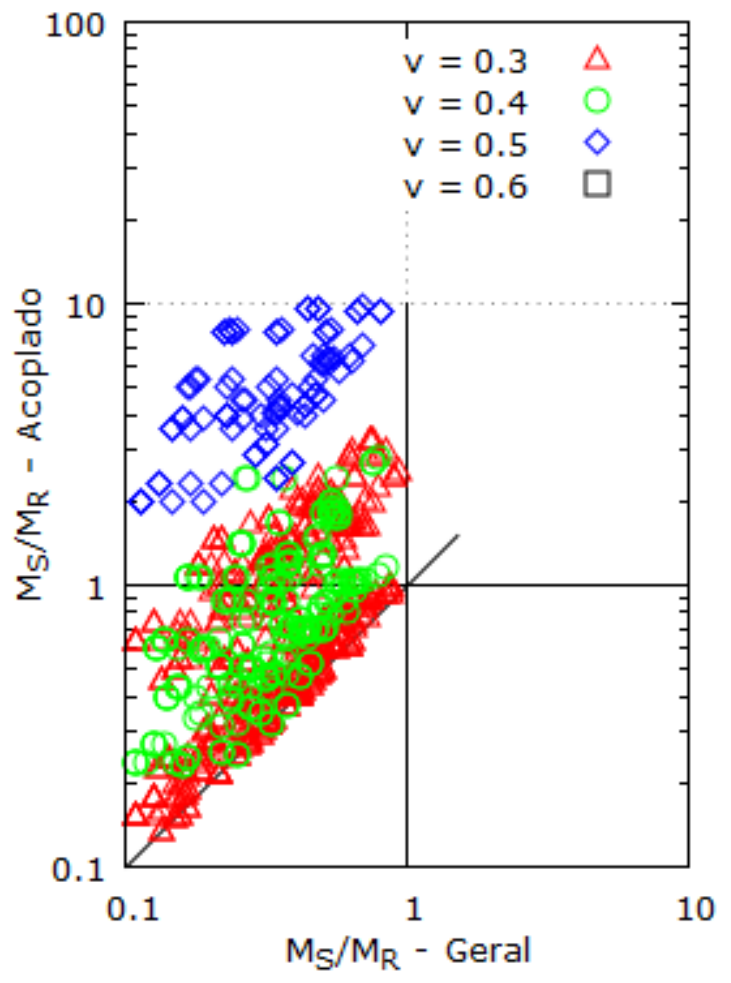

b) Variando a normal relativa

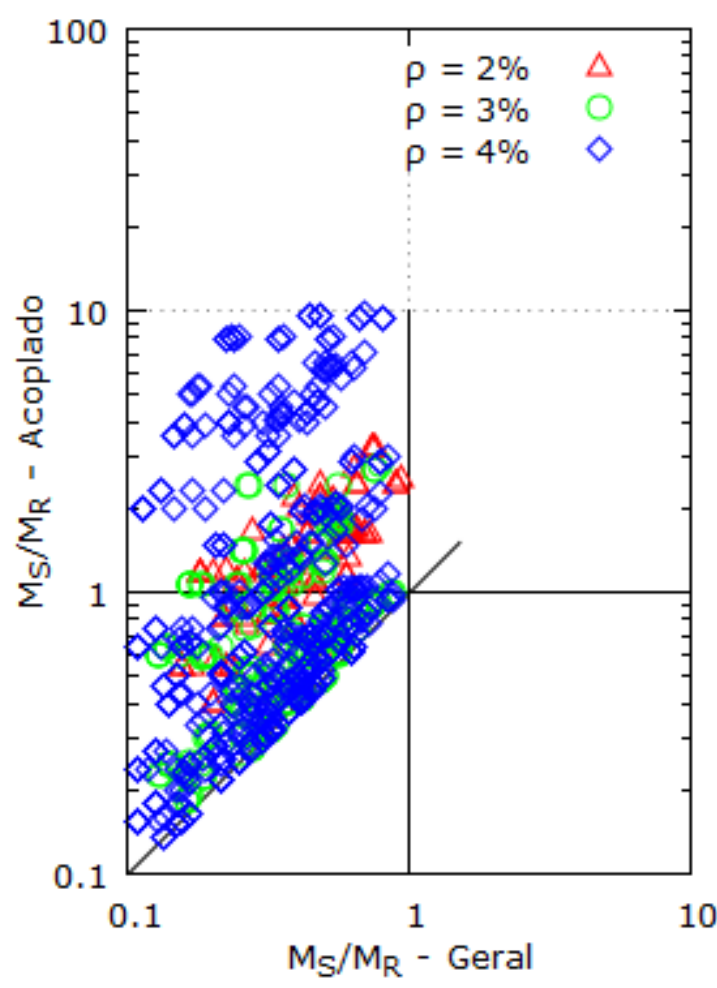

d) Variando a taxa de armadura

Fonte: Elaborado pela Autora. 
Figura 6-15 - Solicitação relativa pelo Método Acoplado a diagramas (continuação).

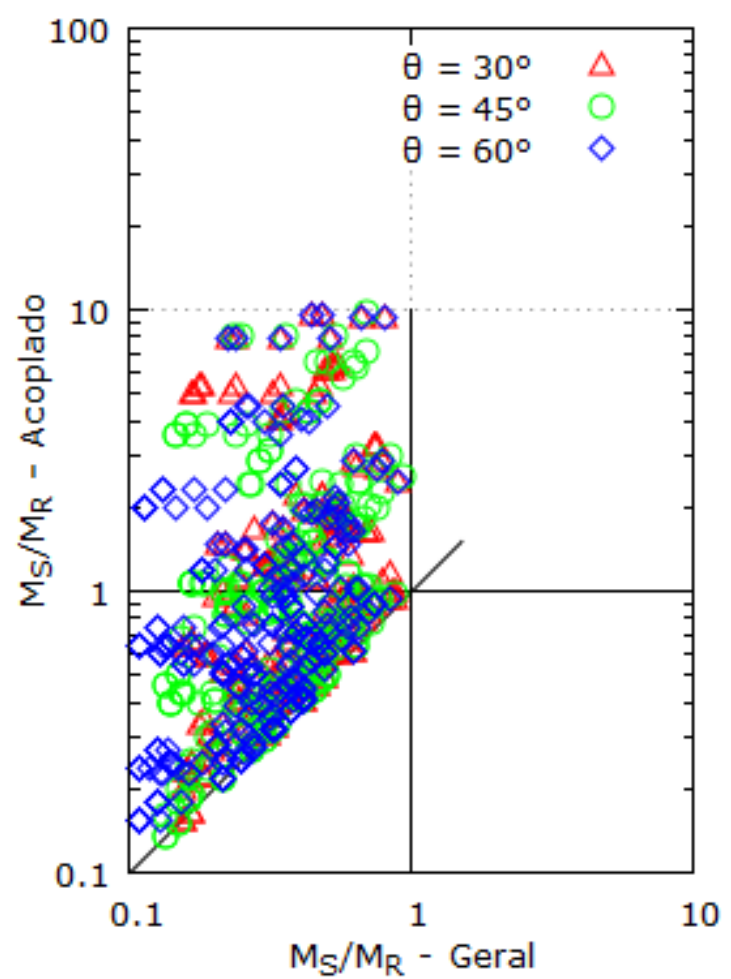

a) Variando a direção

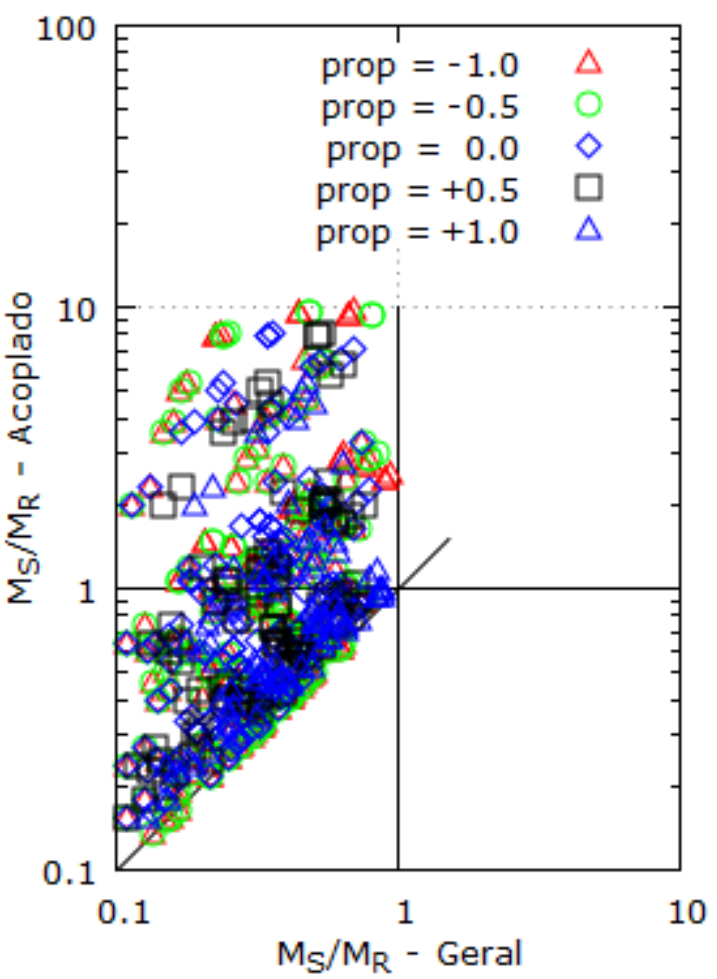

b) Variando a proporção

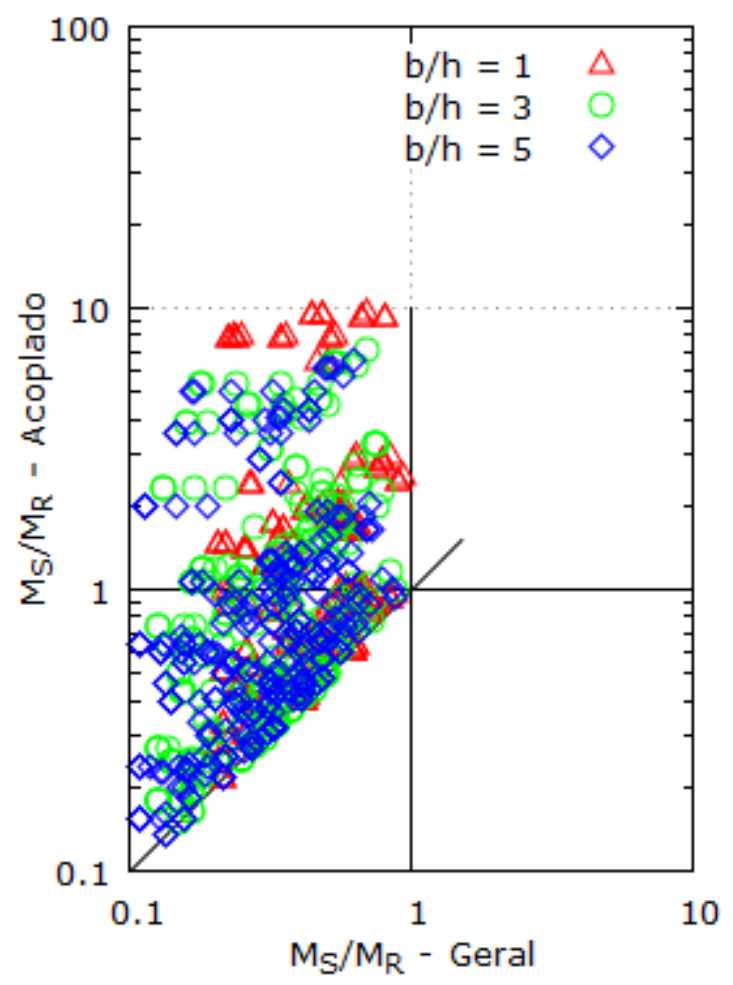

c) Variando a relação entre os lados da seção

Fonte: Elaborado pela Autora. 
A Figura 6-15a mostra que, igual para o Método de Curvatura e de Rigidez, o ângulo de atuação dos momentos aplicados não apresenta uma tendência para o Método acoplado. Há situações para todos valores dessas variáveis em diferentes níveis das regiões A2 e C.

A Figura 6-15b e Figura 6-15c apresentam a influência da proporção de momentos aplicados no lance de pilar e da relação $b / h$ da seção transversal. Diferentemente do observado para o Método de Curvatura e de Rigidez, para o Método Acoplado estas duas variáveis não apresentaram um padrão no comportamento, sendo possível observar toda a faixa de valores dessas variáveis ao longo das regiões A2 e C e de maneira não uniforme.

Dentre todos os valores encontrados para este processo de cálculo, houve 71 casos em que o momento solicitante crítico obtido pelo Método Acoplado a diagramas foi igual ou bem próximo ao calculado pelo Método Geral, o que não aconteceu para nenhum dos casos obtidos pelo Método de Curvatura aproximada e Rigidez aproximada. Todos esses casos possuem índice de esbeltez igual a 90, conforme visto na Figura 6-14a.

\subsection{RESUMO COMPARATIVO}

A Tabela 6-5 apresenta a quantidade de resultados válidos obtidos em cada região da Figura 6-9 para cada método de cálculo analisado. Dentre todas as regiões, a região A2 é preferível, pois significa que o lance de pilar possui segurança estrutural e pode ser calculado pelo método aproximado de cálculo.

Praticamente os três métodos aproximados resultaram em valores distribuídos entre as áreas A2 e C. Novamente ressalta-se que não foi encontrado valor nas áreas B e D em razão da interrupção do programa SecTrans pela perda de estabilidade ou pela falta de capacidade resistente. Deve ser atentado para o fato de que outro programa computacional pode apresentar resultados nessas duas áreas.

O Método de Curvatura aproximada apresentou os resultados mais conservadores dentre os três métodos, sendo aproximadamente 52\% dos casos na região A2 e $48 \%$ na região C.

No Método de Rigidez aproximada os resultados foram levemente menos conservadores que o Método de Curvatura, sendo aproximadamente $60 \%$ dos casos obtidos na região A2 e aproximadamente $40 \%$ na região $C$.

Por último, com menos casos válidos devido a rigidez adimensional mínima, o Método Acoplado a diagramas apresentou aproximadamente $63 \%$ dos casos na região A2 e $37 \%$ na 
região C. Entre os três métodos, o Método Acoplado mostrou ser o menos conservador e com valores mais próximos aos encontrados pelo Método Geral.

Tabela 6-5 - Quantidade de casos válidos encontrados em cada região.

\begin{tabular}{cccc}
\hline \multirow{2}{*}{ Região } & \multicolumn{2}{c}{ Métodos aproximados da ABNT NBR 6118:2014 } \\
& Curvatura & Rigidez & Acoplado \\
\hline A1 & 0 & 0 & 0 \\
A2 & 712 & 781 & 438 \\
B & 0 & 0 & 0 \\
C & 656 & 587 & 257 \\
D & 3 & 3 & 0 \\
\hline Total & 1371 & 1371 & 695 \\
\hline
\end{tabular}

Fonte: Elaborado pela Autora.

Por fim, para avaliar a diferença entre os valores obtidos pelos Métodos Aproximados em comparação aos resultados do Método Geral, foram construídos quatro gráficos ilustrados na Figura 6-16. Novamente os gráficos possuem escala logarítmica, pois para o Método de Curvatura e Rigidez foram encontrados valores elevados e essa escala permitiu melhor visualização dos dados.

Como já visto em análises anteriores, quanto maior a esbeltez, maior é o valor da solicitação total de um Método Aproximado em relação ao Método Geral, podendo chegar a valores 100 vezes maiores que o resultado obtido pelo Método Geral. O mesmo comportamento pode ser atribuído à normal reduzida.

Para o Método Acoplado não foram encontrados valores válidos pelo não atendimento da rigidez adimensional mínima $\kappa_{\text {mín }}$ para qualquer valor de normal reduzida quando a esbeltez é da ordem de 140. Para a situação de esbeltez de 90, somente foram observados valores válidos para normal reduzida de até 0,5 . No caso de esbeltez de 115 , somente foram obtidos resultados válidos para normal reduzida de intensidade igual a 0,3. 
Figura 6-16 - Solicitação total por Método Aproximado em relação ao Método Geral.

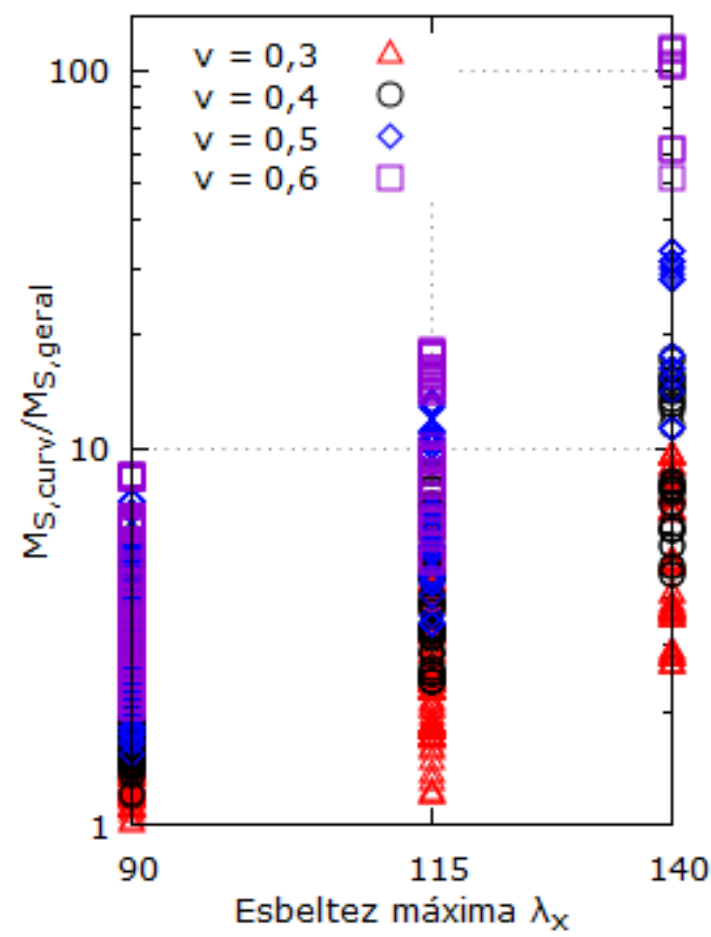

a) Curvatura Aproximada

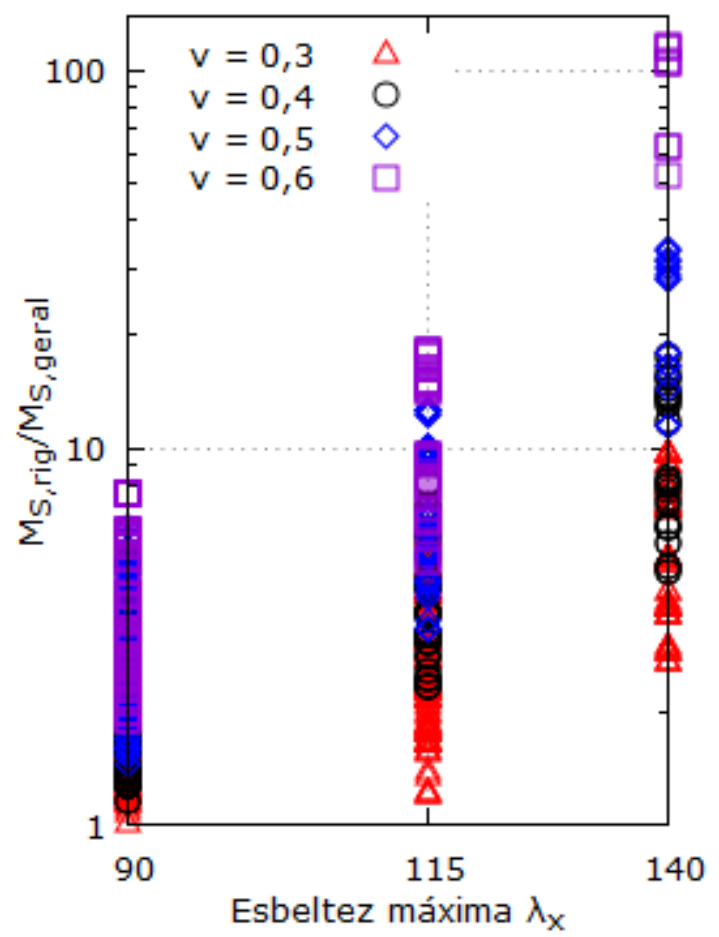

b) Rigidez Aproximada

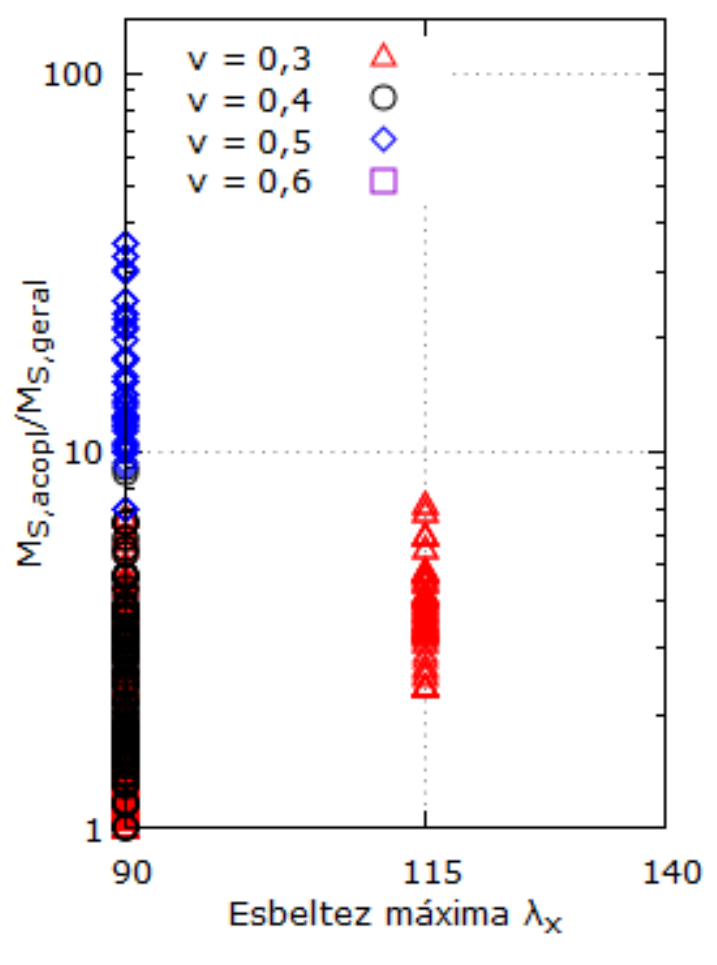

c) Acoplado a Diagramas

Fonte: Elaborado pela Autora. 
Os valores obtidos pelos Métodos Aproximados se distanciam dos valores encontrados pelo Método Geral a medida que a normal reduzida aumenta, ou seja, os Métodos Aproximados apresentam comportamento menos exagerado para normais reduzidas mais baixas (entre 0,3 e 0,4$)$.

A partir das análises aqui efetuadas, é possível observar que todos os métodos aproximados resultam em valores maiores do momento total solicitante em relação ao Método Geral. Com o método de Curvatura Aproximada, todos os valores de momento total solicitante resultaram maiores quando comparados com os demais métodos.

Para todos os resultados do Método de Rigidez aproximada, foi observada ocorrência de valores com a mesma tendência do Método de Curvatura aproximada, porém com valores absolutos ligeiramente menores. Comparando estes dois métodos entre si, a maior diferença percentual encontrada foi de $20 \%$, sendo o valor obtido pelo método de Curvatura aproximada sempre maior.

Considerando apenas os resultados válidos do Método Acoplado a Diagramas, os resultados obtidos foram, em geral, conservadores e menos distantes dos resultados do Método Geral para força normal reduzida igual a 0,3 e 0,4 . Por outro lado, para força normal reduzida igual a 0,5 os resultados válidos do Método Acoplado a diagramas são mais pessimistas do que os métodos anteriores, chegando a ser seis vezes maiores do que os resultados calculados com os Métodos de Curvatura ou de Rigidez aproximada. 


\section{CONSIDERAÇÕES FINAIS}

\subsection{CONCLUSÕES}

O objetivo principal deste trabalho foi avaliar a viabilidade de utilização de métodos aproximados descritos na ABNT NBR 6118:2014 para análise de lances de pilar com índice de esbeltez entre 90 e 140 em comparação com a utilização do Método Geral. Para atingir este objetivo foram realizadas simulações numéricas utilizando o programa SecTrans.

Para analisar o comportamento de lances de pilar foram avaliados oito parâmetros: relação entre lados da seção transversal retangular; índice de esbeltez; força normal reduzida; momento fletor reduzido; ângulo de atuação de momentos fletores; proporção entre momento fletor na base e no topo do pilar; taxa de armadura e coeficiente de fluência. No total, foram processados 9.720 casos de simulações diferentes. Para efeito de comparação, metade das situações envolveu a consideração de fluência.

Para entendimento das análises foram realizados Exemplos de Aplicação detalhando uma das diversas simulações realizadas. Foi observado nestes exemplos que a previsão da direção do momento total na seção crítica através de todos os métodos aproximados desvia em muito da direção inicialmente aplicada de flexão por incluir efeitos adicionais de segurança. A consideração dos efeitos adicionais de segunda ordem em uma direção pode ser obrigatória e não ser obrigatória na direção ortogonal, conforme a relação entre as dimensões da seção retangular, o comprimento do lance de pilar e a relação entre os momentos iniciais aplicados nas extremidades do lance de pilar. Os efeitos adicionais sendo diferentes em cada direção ampliam mais a componente de flexão na direção mais esbelta, distorcendo as parcelas do momento resultante e, como consequência, a direção resultante do plano de flexão. Este desvio tende a ser tanto maior quanto mais alongada é a seção transversal. 
A partir dos Exemplos de aplicação foi possível concluir que a verificação de atendimento do momento mínimo de segunda ordem cresce de importância com o aumento da esbeltez.

Foi observado que a relação entre a força normal reduzida de Euler e a força normal reduzida aplicada diminui com o aumento do quadrado da esbeltez máxima do lance de pilar, apontando que esta relação não deve ultrapassar um certo limite inferior. Esta situação ficou mais evidente quando da análise de resultados das simulações efetuadas ocorrendo muitas situações onde não foi possível obter segurança com certas geometrias de pilar.

A partir da análise dos resultados dos Exemplos de Aplicação foi observado que a rigidez adimensional $\kappa$ calculada com o Método Acoplado a Diagramas deve atender a uma certa rigidez adimensional mínima $k_{\min }$ para a obtenção de valores válidos com este método aproximado em razão da resolução analítica da Eq.(3-9). Esta rigidez mínima varia diretamente com a normal reduzida e com o quadrado da esbeltez. Foi observado que esta rigidez adimensional mínima pode ser utilizada como forma preliminar de validação do Método Acoplado a diagramas.

Foi constatada a sensibilidade na obtenção da rigidez adimensional $\kappa$ conforme a quantidade de pontos calculados par uma certa seção resistente quando da interpolação da curva Normal-Momento-Curvatura. Uma pequena variação no valor da rigidez secante encontrada através do diagrama conduz a pouca variação no valor da rigidez $\kappa$, mas acarreta em desvios significativos na obtenção do momento total encontrado pela Eq. (3-9).

O reduzido número de casos válidos encontrados está relacionado com a obtenção de equilíbrio pelo Método Geral com o programa SecTrans referente e ao atendimento da rigidez adimensional mínima.

Foi verificado que o número de casos válidos é tanto menor quanto maior a esbeltez imposta mantida as demais condições estudadas e implicando que pilares mais esbeltos necessitam de maiores dimensões da seção transversal, maior resistência à compressão do concreto e maior quantidade de armadura longitudinal.

Foi analisado o efeito do coeficiente de fluência sobre o resultado do momento total solicitante de segunda ordem comparando os resultados para $\varphi=0$ e $\varphi=2$ com proporção de 0,75 entre solicitações iniciais e quase permanentes. Para esbeltez $\lambda=90$ foram observados resultados do momento total de até 2,5 vezes maior quando calculado pelo Método Geral com e sem fluência, apesar da ABNT NBR 6118:2014 dispensar a consideração da fluência para 
pilares com esbeltez de até 90. Quando da utilização do Método Acoplado a diagramas, a relação entre momentos chegou a ser até 14 vezes maior.

Foi verificado que a consideração da fluência acarreta aumento da capacidade resistente de certa seção transversal e este trabalho sugere a sua não consideração para obtenção da envoltória resistente como medida prudente e conservadora.

As variáveis consideradas mais importantes para obtenção de padrão de comportamento foram índice de esbeltez máxima, normal reduzida, momento reduzido e a relação entre lados da seção transversal $b / h$. Por outro lado, as variáveis como taxa de armadura, relação entre momentos nas extremidades e ângulo de atuação de momentos iniciais apresentaram muita dispersão de resultados e não indicaram padrão ou tendência de comportamento.

O comportamento da variável força normal reduzida é semelhante à da variável esbeltez na disposição de resultados segundo a representação gráfica da Figura 6-9 e os métodos aproximados são mais conservadores para valores crescentes de solicitação normal de compressão e de esbeltez.

Os métodos aproximados são menos conservadores e tendem a ficarem mais próximos aos resultados do Método Geral conforme a magnitude dos momentos reduzidos aumenta.

Analisando o comportamento da relação entre os lados da seção transversal foi possível perceber que as seções quadradas apresentaram valores mais conservadores para o momento total solicitante quando comparados às seções retangulares.

Foi possível concluir que todos os métodos aproximados resultam em valores maiores do momento total solicitante em relação ao Método Geral para as situações consideradas válidas e tiveram comportamento mais adequado para esbeltez de $\lambda=90$ e $\lambda=115$ e para normais reduzidas baixas $(v=0,3$ e $v=0,4)$, apresentando valores menos exagerados em relação ao Método Geral.

Os maiores valores de momentos totais solicitantes de segunda ordem foram encontrados no Método de Curvatura aproximada. No método de Rigidez aproximada foi observada a ocorrência de valores com a mesma tendência do método da Curvatura, porém com valores absolutos ligeiramente menores. No Método Acoplado a Diagramas os resultados obtidos também foram conservadores, no entanto menos distantes dos resultados do Método Geral para os casos com força normal reduzida igual a 0,3 e 0,4 e, portanto, mais próximos do Método Geral do que os demais métodos, a menos dos resultados para força normal reduzida igual a 0,5 , onde o método foi o mais conservador. 
A partir dos casos válidos obtidos, é possível concluir que os métodos aproximados descritos na ABNT NBR 6118:2014 teoricamente poderiam ser utilizados para cálculo de pilares com esbeltez entre 90 e 140 e com parâmetros pertencentes aos limites estudados $(v, \mu$, etc), no entanto supostamente inviáveis do ponto de vista econômico por conduzirem, na maioria dos casos, a esforços solicitantes totais de segunda ordem muito exagerados em relação ao Método Geral. Esta constatação pode inviabilizar o uso prático dos métodos aproximados na flexão oblíqua quando é disponível rotinas de cálculo adequadas considerando o Método Geral com resultados teoricamente mais precisos.

\subsection{RECOMENDAÇÕES PARA TRABALHOS FUTUROS}

Dos estudos realizados, podem ser apresentadas algumas sugestões para futuras investigações envolvendo condições aqui não abordadas.

Parece adequado sugerir modificar o programa SecTrans para apresentar resultados de momento total solicitante quando da ocorrência de capacidade da seção fora da envoltória resistente acoplada às direções ortogonais.

A análise do efeito de fluência induz que seria desejável investigar a influência deste efeito para esbeltezes menores do que 90.

Sugere-se estudar a envoltória mínima de segunda ordem imposta pela norma ABNT NBR 6118:2014, pois em muitas situações analisadas, os valores impostos podem ser exagerados quando comparados com os resultados do Método Geral.

De modo semelhante, parece interessante investigar com mais detalhe os resultados de momento total solicitante de segunda para a relação entre momentos de extremidade no lance de pilar como sendo igual ou próximo a -1, pois o Método Geral induz que a seção crítica não é a seção intermediária para estas situações.

Neste estudo teórico, o Método Geral foi utilizado como referência para obtenção de comparações com os métodos aproximados e parece razoável investigar o resultado do próprio método através da confrontação de resultados experimentais, sejam estes disponíveis na literatura ou obtidos em ensaios específicos. 


\section{REFERÊNCIAS}

ACI-318. Building code requirements for reinforced concrete. Detroit: American Concrete Institute, 1995. $371 \mathrm{p}$.

ABNT. NBR 6118:1980 - Projeto e execução de obras de concreto armado. Rio de Janeiro: ABNT, 1980. $53 \mathrm{p}$.

ABNT. NBR 6118:2003 - Projeto de estruturas de concreto - Procedimento. Rio de Janeiro: ABNT, 2003. 170 p.

ABNT. NBR 6118:2014 - Projeto de estruturas de concreto - Procedimento. Rio de Janeiro: ABNT, 2014. 238 p.

AGUIAR, E. A. B. Projeto de pilares de concreto de alto desempenho. São Carlos: EESCUSP, 2000. 202 p. Disponível em: <https://teses.usp.br/teses/disponiveis/18/18134/tde05062018-115208/publico/Dissert_Aguiar_EduardoAB.pdf >. Acesso em: 20 agosto 2019. Dissertação (Mestrado).

AISC. Load and Resistance Factor Design Specification for Steel Buildings. Chicago: American Institute of Steel Construction, 1999. (with errata incorporated as of September 4, 2001).

ARAÚJO, J. M. Dimensionamento de pilares esbeltos de concreto armado. Porto Alegre: UFRGS, 1984. 176 p. Disponível em: <http://www.lume.ufrgs.br/handle/10183/1346>. Acesso em: 20 agosto 2019. Dissertação (Mestrado).

BACARJI, E. Análise de estruturas de edifícios: projeto de pilares. São Carlos: EESC-USP, 1993. 187 p. Disponível em: <http://web.set.eesc.usp.br/static/data/producao/1993ME_EdgarBacarji.pdf>. Acesso em: 20 agosto 2019. Dissertação (Mestrado).

CADAMURO JÚNIOR, I. W. Dimensionamento de pilares esbeltos de concreto armado com seção qualquer solicitados por flexão composta oblíqua. São Carlos: EESC-USP, 1997. Disponível em: <http://web.set.eesc.usp.br/static/data/producao/1997ME_IsmaelWilsonCadamuroJunior.pdf> . Acesso em: 20 agosto 2019. Dissertação (Mestrado).

CARDOSO JÚNIOR, S. D. Sistema computacional para análise não linear de pilares de concreto armado. São Paulo: POLI-USP, 2014. 55 p. Disponível em: 〈www.pcalc.com.br〉. Acesso em: 20 agosto 2019. Monografia (Especialização).

CARVALHO, R. C.; PINHEIRO, L. M. Cálculo e detalhamento de estruturas usuais de concreto. São Paulo: Pini, v. 2, 2009.

CASAGRANDE, A. F. Consideração da fluência no cálculo dos efeitos de segunda ordem em pilares de concreto armado. Florianópolis: UFSC, 2016. 127 p. Disponível em: 
<https://repositorio.ufsc.br/xmlui/handle/123456789/175830>. Acesso em: 20 agosto 2019. Dissertação (Mestrado).

CEB. FIP Model Code 1990 - Final draft, Bulletin d'information n. 203, 204 e 205. Paris: Comité Euro-International du Béton, 1990. 455 p.

CECCON, J. L. Análise dos efeitos de segunda ordem em pilares solicitados a flexão oblíqua composta. São Paulo: POLI-USP, 2008. Disponível em: $<$ http://www.teses.usp.br/teses/disponiveis/3/3144/tde-07112008-105053/pt-br.php>. Acesso em: 20 agosto 2019. Tese (Doutorado).

CHEREN, M. Contribuição ao estudo dos pilares com seção transversal em formato geométrico de ' $L$ ' considerando a não-linearidade física e geométrica. São Paulo: POLIUSP, 2010. 236 p. Disponível em: <http://www.teses.usp.br/teses/disponiveis/3/3144/tde23052011 113436/pt-br.php>. Acesso em: 20 agosto 2019. Dissertação (Mestrado).

EUROPEAN COMMITIEE FOR STANDARDIZATION (CEN). EN 1992-1-1 Eurocode 2: Design of concrete structures - Part 1-1: General rules and rules for buildings, 2004. 227 p.

FRACALOSSI, I. Clássicos da Arquitetura: Centro de mecanização do Banco do Brasil. Archdaily, 2013. Disponível em: <https://www.archdaily.com.br/br/01-156395/classicos-daarquitetura-centro-de-mecanizacao-do-banco-do-brasil-slash-irmaos-roberto >. Acesso em: 20 agosto 2019.

FRANÇA, R. L. S. Relações momento-curvatura em peças de concreto armado submetidas a flexão oblíqua composta. São Paulo: POLI-USP, 1984. Dissertação (Mestrado).

FRANÇA, R. L. S. Contribuição ao estudo dos efeitos de segunda ordem em pilares de concreto armado. São Paulo: POLI-USP, 1991. 202 p. Tese (Doutorado).

FUSCO, P. B. Estruturas de concreto: solicitações normais. Rio de Janeiro: Guanabara Dois, 1981. 464 p.

IBRACON (Ed.). ABNT NBR 6118:2014 Comentários técnicos e exemplos de aplicação. São Paulo: Ibracon, 2015. 480 p. ISBN 978-85-98576-24-4

KETTERMANN, A. C. Efeito da deformabilidade dos pilares no estudo do estado-limite último de instabilidade. Florianópolis: UFSC, 2001. 196 p. Disponível em: <https://repositorio.ufsc.br/handle/123456789/83285>. Acesso em: 20 agosto 2019. Dissertação (Mestrado).

KIMURA, A. Informática aplicada a estruturas de concreto armado. São Paulo: Oficina de Textos, 2018. 428 p.

KIMURA, A. Cálculo de pilares de concreto armado. São Paulo: ABECE, 2019. Apostila.

LEITÃO, E. M. M. Estudo comparativo de métodos aproximados para análise do efeito de segunda ordem em pilares esbeltos de concreto armado sob flexão composta reta. Belo Horizonte: DEES-UFMG, 2016. Disponível em: <http://pos.dees.ufmg.br/diss_defesas_detalhes.php?aluno=1036>. Acesso em: 20 agosto 2019. Dissertação (Mestrado).

MIGLIORE JUNIOR, A. R. Formulário de sugestão de revisão da ABNT NBR 6118. São Paulo. 2018. Comunicação pessoal ao CT301 - Comitê IBRACON/ABECE de Projeto de estruturas de concreto.

OLIVEIRA, P. H. A. S. Processo aproximado para consideração da não-linearidade física de pilares em concreto armado. São Paulo: POLI-USP, 2004. 125 p. Disponível em: 
<http://www.teses.usp.br/teses/disponiveis/3/3144/tde-26092005-220547/pt-br.php>. Acesso em: 20 agosto 2019. Dissertação (Mestrado).

PEREIRA, A. Projeto ótimo de pórticos planos com restrição à flambagem. Rio de Janeiro: PUC-Rio,. 2002. 99p. Dissertação (Mestrado).

PINTO, V. S. Dimensionamento de pilares de concreto com seção transversal retangular usando envoltórias de momentos. São Carlos: EESC-USP, 2017. 314 p. Disponível em: $<$ http://www.teses.usp.br/teses/disponiveis/18/18134/tde-03072017-094059/pt-br.php>. Acesso em: 20 agosto 2019. Dissertação (Mestrado).

PIRES, S. L. Análise de pilares de concreto armado submetidos à flexão normal composta considerando as não-linearidades física e geométrica. Campinas: Unicamp, 2006. 100 p. Disponível em: <http://www.bibliotecadigital.unicamp. br/document/?code=000782358>. Acesso em: 20 agosto 2019. Dissertação (Mestrado).

RIBEIRO, K. Diagramas para verificação de pilares retangulares em concreto armado submetidos à flexão composta normal. Florianópolis: UFSC, 2011. 308 p. Disponível em: <https://repositorio.ufsc.br/bitstream/handle/123456789/95091/289075.pdf?sequence=1>.

Acesso em: 20 agosto 2019. Dissertação (Mestrado).

SCADELAI, M. A. Dimensionamento de pilares de acordo com a NBR 6118: 2003. São Carlos: $\quad$ EESC-USP, 2004. 124 p. Disponível em: <http://web.set.eesc.usp.br/static/data/producao/2004ME_MuriloAlessandroScadelai.pdf>. Acesso em: 20 agosto 2019. Dissertação (Mestrado).

SOUZA, T. J. M. Considerações sobre os efeitos locais de $2^{\text {a }}$ ordem. V Simpósio EPUSP sobre estruturas de concreto. São Paulo: POLI-USP. 2003.

SOUZA, T. J. M.; GUIMARÃES, G. B.; DUMONT, N. A. Índice de esbeltez limite em colunas de concreto armado. Téchne, São Paulo, n. 35, p. 46-49, 1992.

TIKKA, T. K.; MIRZA, S. A. Equivalent uniform moment miagram factor for reinforced concrete columns. ACI Structural Journal, 2004. 1-11.

TIMOSHENKO, S. P. Resistência dos materiais. Rio de Janeiro: LTC, v. 1, 1966. 451 p. reimpressão de 1978. 



\section{APÊNDICE A}

Para obtenção dos resultados dos Exemplos de aplicação do Capítulo 5 foi seguida a metodologia apresentada neste Apêndice como forma de registrar as equações utilizadas. De modo a considerar também o efeito da fluência para os diversos métodos de cálculo considerados, esta Autora arbitrou apresentar apenas os resultados numéricos do Exemplo de Aplicação 3, ou seja, maior esbeltez da seção transversal de $\lambda_{x}=115$ e mantendo todos os demais valores iniciais.

Para comodidade numérica foi adotado o valor da resistência de cálculo do concreto como sendo:

$$
f_{c d}=\frac{3,5}{1,4}=2,5 \mathrm{kN} / \mathrm{cm}^{2}
$$

Para não tornar o texto longo e repetitivo no detalhamento dos Exemplos de aplicação quando da apresentação de certa Equação, esta é apresentada com suas variáveis identificadas e os valores parciais para obtenção do resultado são também apresentados. Na sequência, não sendo alteradas as variáveis da Equação e nem os valores parciais, estes foram omitidos e apresentados apenas os resultados finais considerados relevantes.

\section{A.1 PILAR PADRÃO COM CURVATURA APROXIMADA}

Tal como recomendado na norma ABNT NBR 6118:2014, o método em si desconsidera o efeito da fluência e assim foram obtidos os momentos totais (primeira + segunda ordem) para cada direção e, da Eq. (3-7), pode ser obtido para $v=0,3$ :

$$
f(v)=1
$$

Impondo para a maior esbeltez do pilar de seção retangular a quantidade $\lambda_{x}=90$, o comprimento equivalente do lance de pilar fica determinado invertendo a Eq. (2-16) e resulta no valor: 


$$
L_{e}=\lambda_{x} \frac{h_{y}}{\sqrt{12}}=115 \times \frac{0,20}{\sqrt{12}}=6,64 \mathrm{~m}
$$

Definido o comprimento equivalente, a esbeltez na direção ortogonal é menor e, para a seção retangular, resulta em:

$$
\lambda_{y}=\lambda_{x} \frac{h_{y}}{h_{x}}=115 \frac{20}{60}=38,3
$$

\section{A.1.1 Carga crítica de Euler}

A avaliação do efeito de fluência para os métodos que não a consideram diretamente deve ser realizada para cada direção, porém considerando a carga crítica obtida pela Eq. (2-27) para a direção mais esbelta, cuja intensidade para este Exemplo é:

$$
N_{e}=\frac{10}{\lambda^{2}} E_{c i} A_{c}=\frac{10}{115^{2}} \times 33,1 \times 10^{6} \times(0,6 \times 0,2)=3.003 k N
$$

É interessante registrar o valor correspondente à normal reduzida para essa carga crítica como sendo:

$$
v_{e}=\frac{N_{e}}{A_{c} f_{c d}}=\frac{3.003}{(60 \times 20) \times 2,5}=1,00
$$

\section{A.1.2 Momento total em $x$}

O momento total nessa direção deve considerar o momento mínimo de primeira ordem, os efeitos locais de segunda ordem e o efeito de fluência, ficando determinado pela Eq. (3-6), tal como segue. Como os resultados apresentados foram obtidos através de processamento computacional com variáveis de precisão dupla, podem ocorrer eventuais divergências nas últimas casas decimais com cálculo manual devido a erros numéricos de arredondamento ou de truncamento de valores. Por conveniência, foi determinado em separado o efeito exclusivo de segunda ordem deste método de cálculo como sendo $M_{2 d, x}$ para aproveitamento de valores nas passagens algébricas posteriores.

Como a esbeltez adotada para esta direção $\lambda_{x}=115$ é superior ao limite $\lambda_{1 x}=66,2$, é obrigatório considerar efeitos locais de segunda ordem. 


$$
\begin{gathered}
M_{2 d, \mathrm{x}}=\frac{N_{d}}{2.000} \frac{L_{e}^{2}}{f(v) h_{y}} \\
=\frac{900}{2.000} \frac{6,64^{2}}{1,0 \times 0,2}=99,19 \mathrm{kN} . \mathrm{m} \\
M_{S d, t o t, \mathrm{x}}=\alpha_{b x} M_{1 d, \mathrm{~A}, \mathrm{x}}+M_{2 d, \mathrm{x}}=0,4 \times 21,21+99,19=107,67 \mathrm{kN} . \mathrm{m}
\end{gathered}
$$

No caso dos métodos de análise de pilar padrão com curvatura aproximada ou rigidez adimensional aproximada, a avaliação do efeito da fluência não é inerente ao próprio e deve ser realizada segundo a adição de momento adicional aos valores já determinados.

Para tanto, deve ser determinada excentricidade $e_{a}$ devido à falta de retilineidade com a rotação $\theta_{l}$ tomada para seção de referência no meio do lance de pilar com a Eq. (7-1), o que resulta em:

$$
\begin{gathered}
\theta_{1}=\frac{1}{100 \sqrt{6,64}}=\frac{1}{257,67}\left\{\begin{array}{l}
\geq \frac{1}{300} \\
\leq \frac{1}{200}
\end{array}\right. \\
e_{a}=\frac{1}{257,67} \times \frac{664}{2}=1,29 \mathrm{~cm} \\
e_{c c, y}\left(\frac{0,4 \times 2.121}{900}+1,29\right)\left[\exp \left(\frac{2,0 \times 0,75 \times 900}{3.003-0,75 \times 900}\right)-1\right]=1,75 \mathrm{~cm} \\
M_{c c, \mathrm{x}}=e_{c c, y} N_{d}=\frac{1,75}{100} \times 900=15,78 \mathrm{kN} \cdot \mathrm{m} \\
M_{S d, t o t, \mathrm{x}}=\alpha_{b x} M_{1 d, \mathrm{~A}, \mathrm{x}}+M_{2 d, \mathrm{x}}+M_{c c, \mathrm{x}} \\
=0,4 \times 21,21+99,19+15,78=123,45 \mathrm{kN} . \mathrm{m}
\end{gathered}
$$

O resultado acima pode ser aceito por ser superior ao momento mínimo de primeira ordem. 


\section{A.1.3 Momento total em y}

Como a esbeltez para esta direção $\lambda_{y}=38,33$ também é superior ao limite $\lambda_{1 y}=35$, é obrigatório considerar efeitos locais de segunda ordem.

$$
\begin{gathered}
e_{c c, x}=\left(\frac{1,0 \times 2.121}{900}+1,29\right)\left[\exp \left(\frac{2,0 \times 0,75 \times 900}{3.003-0,75 \times 900}\right)-1\right]=2,86 \mathrm{~cm} \\
M_{c c, y}=\frac{2,86}{100} \times 900=25,78 \mathrm{kN.m} \\
M_{S d, t o t, y}=\alpha_{b y} M_{1 d, \mathrm{~A}, y}+\frac{N_{d}}{2.000} \frac{L_{e}^{2}}{f(v) h_{x}}+M_{c c, \mathrm{x}} \\
=1,0 \times 21,21+\frac{900}{2.000} \times \frac{6,64^{2}}{1 \times 0,6}+25,78=80,05 \mathrm{kN} . \mathrm{m}
\end{gathered}
$$

\section{A.1.4 Momento total resultante}

Para efeito de dimensionamento da seção mais crítica do lance de pilar o momento solicitante oblíquo fica determinado a partir da resultante vetorial de suas componentes, tal como segue:

$$
M_{S d, t o t, \theta}=\sqrt{123,45^{2}+80,05^{2}}=147,13 k N . m
$$

Este momento total na direção oblíqua é amplificado em relação ao máximo momento solicitante de primeira ordem por um fator aqui identificado por $\chi$ com intensidade de:

$$
\chi=\frac{147,13}{30,0}=4,90
$$

O fator de amplificação foi inserido neste texto apenas para relacionar o momento que deve ser usado para dimensionamento da seção de pilar em comparação com o momento aplicado inicial na seção intermediária de certa direção.

A direção do momento resultante fica conhecida a partir das componentes obtidas nos itens anteriores:

$$
\theta=\operatorname{arctg}\left(\frac{80,05}{123,45}\right)=33,0^{\circ}
$$




\section{A.1.5 Envoltória de momento mínimo total}

Para avaliação da envoltória de momento mínimo total, podem ser tomadas as seguintes parcelas nas direções ortogonais e, neste caso, sempre considerando o valor de $\alpha_{b}=1,0$ :

$$
\begin{gathered}
M_{1 d, \min , x x}=18,90 \mathrm{kN} . \mathrm{m} \\
M_{d, t o t, \min , x x}=\alpha_{b} M_{1 d, \min , x x}+M_{2 d, x}+M_{c c x} \\
=1,0 \times 18,90+99,19+15,78=133,86 \mathrm{kN} . \mathrm{m} \\
M_{1 d, \min , y y}=29,70 \mathrm{kN} . \mathrm{m} \\
M_{d, t o t, \min , y y}=\alpha_{b} M_{1 d, \min , y y}+M_{2 d, y}+M_{c c y} \\
=1,0 \times 29,70+33,06+25,78=88,54 \mathrm{kN} . \mathrm{m}
\end{gathered}
$$

Com as parcelas anteriores resulta o momento mínimo total para a direção inicial de aplicação da flexão de $\theta=45^{\circ}$ como sendo:

$$
M_{d, t o t, \min , \theta}=\frac{1}{\sqrt{\left(\frac{\cos 45^{\circ}}{133,86}\right)^{2}+\left(\frac{\operatorname{sen} 45^{\circ}}{88,54}\right)^{2}}}=104,44 \mathrm{kN} . \mathrm{m}
$$

Como o momento solicitante total foi superior ao valor obtido pelo momento total mínimo, fica então atendida a envoltória total mínima.

Os momentos solicitantes totais obtidos com esse método de cálculo estão representados no gráfico da Figura A-1. A linha contínua mais externa corresponde à envoltória resistente da seção transversal para Força Normal de compressão de 900 kN e independe da solicitação de flexão aplicada. As elipses internas correspondem às envoltórias de momento mínimo de primeira e de segunda ordem, respectivamente com linha contínua e tracejada.

Os três pontos conectados pela linha poligonal também apresentada no mesmo gráfico correspondem às solicitações de flexão da seção de base, intermediária e de topo. Claramente, a intensidade da flexão na seção intermediaria corresponde ao ponto mais afastado dos indicados.

A rigor, a direção do momento resultante na seção intermediária deveria ser de $45^{\circ}$. No entanto, o ângulo obtido a partir das componentes de solicitação é diferente e indica apenas 
um valor de cálculo a ser observado, sem relação direta com a direção do momento oblíquo real por se tratar de uma situação hipotética com diferentes valores do coeficiente $\alpha_{b}$ em cada direção.

Figura A-1 - Resultados com o Método de Curvatura aproximada.

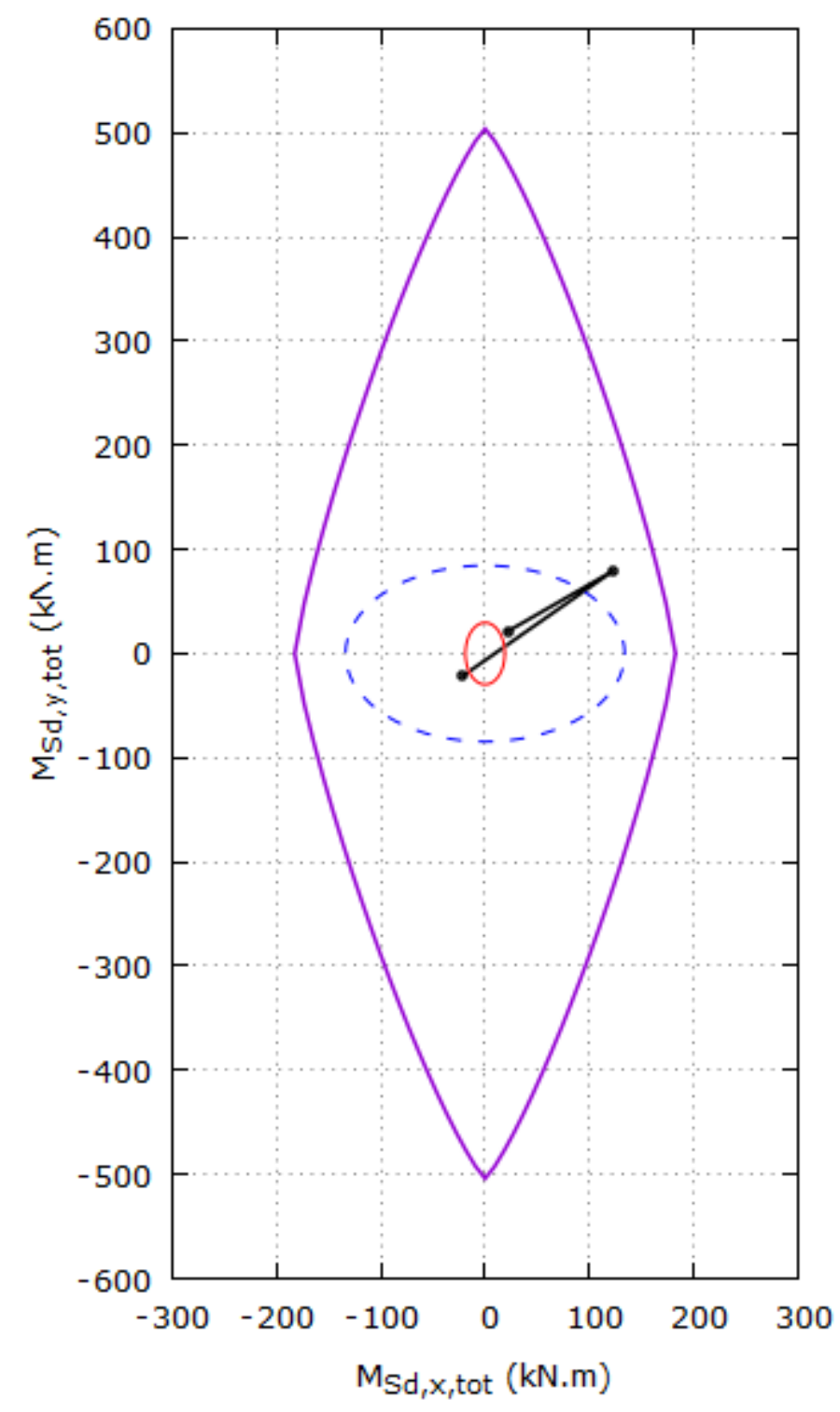

Fonte: Elaborado pela Autora.

\section{A.2 PILAR PADRÃO COM RIGIDEZ ADIMENSIONAL}

Este processo também não considera diretamente o efeito da fluência e é desenvolvido a seguir para o Exemplo de aplicação 3. 


\section{A.2.1 Efeito adicional da fluência}

$$
\begin{aligned}
& M_{c c, \mathrm{x}}=15,78 \mathrm{kN} . \mathrm{m} \\
& M_{c c, y}=25,78 \mathrm{kN} . \mathrm{m}
\end{aligned}
$$

\section{A.2.2 Momento total em $\mathrm{x}$}

A solução para o problema nessa direção pode ser efetuada através dos adimensionais indicados nas Eqs. (3-14) para serem introduzidos na Eq. (3-13)Como os resultados parciais envolvem coeficientes com valores pequenos, é mais apurado utilizar pelo menos três algarismos significativos para obtenção dos resultados seguintes separando o efeito de segunda ordem para posterior utilização:

$$
\left\{\begin{array}{l}
\xi_{1 y}=\alpha_{b x} \frac{e_{1 y}}{h_{y}}=0,4 \times \frac{21,21}{900 \times 0,2}=0,0471 \\
\beta_{y}=\frac{\lambda_{x}^{2}}{38.400}+\frac{\xi_{1 y}}{2}-0,1=\frac{115^{2}}{38.400}+\frac{0,0471}{2}-0,1=0,2680
\end{array}\right.
$$

Com a excentricidade relativa determinada, o respectivo momento parcial é obtido diretamente obtendo o valor do momento total:

$$
\begin{gathered}
\xi_{2 y}=\beta_{y}-\xi_{1 y}+\sqrt{\beta_{y}{ }^{2}+0,2 \xi_{1 y}} \\
=0,2680-0,0471+\sqrt{0,2680^{2}+0,2 \times 0,0471}=0,5059 \\
M_{2 d, x}=\xi_{2 y} h_{y} N_{d}=0,5059 \times 0,20 \times 900=91,05 \mathrm{kN} . \mathrm{m} \\
M_{S d, t o t, x}=\alpha_{b x} M_{1 d, x}+M_{2 d, x}+M_{c c, \mathrm{x}} \\
=0,4 \times 21,21+91,05+15,78=115,32 \mathrm{kN} . \mathrm{m}
\end{gathered}
$$




\section{A.2.3 Momento total em y}

$$
\begin{gathered}
\left\{\begin{array}{c}
\xi_{1 x}=\alpha_{b y} \frac{e_{1 x}}{h_{x}}=0,4 \times \frac{21,21}{900 \times 0,6}=0,0393 \\
\beta_{x}=\frac{\lambda_{y}^{2}}{38.400}+\frac{\xi_{1 x}}{2}-0,1=\frac{115^{2}}{38.400}+\frac{0,0393}{2}-0,1=-0,0421 \\
\xi_{2 x}=\beta_{x}-\xi_{1 x}+\sqrt{\beta_{x}^{2}+0,2 \xi_{1 x}} \\
=-0,0421-0,0393+\sqrt{(-0,0421)^{2}+0,2 \times 0,0393}=0,0167 \\
M_{2 d, y}=\xi_{2 x} h_{x} N_{d}=0,0167 \times 0,60 \times 900=9,04 \mathrm{kN} . \mathrm{m} \\
M_{S d, t o t, y}=\alpha_{b y} M_{1 d, \mathrm{~A}, y}+M_{2 d, x}+M_{c c, y} \\
=1,0 \times 21,21+9,04+25,78=56,03 \mathrm{kN} . \mathrm{m}
\end{array}\right.
\end{gathered}
$$

\section{A.2.4 Momento total resultante}

Apresentando os resultados obtidos no gráfico da Figura A-2 é possível observar a maior proximidade da seção intermediária (ponto C) com a envoltória de momentos resistentes.

A obtenção do momento resultante solicitante resulta em:

$$
\begin{gathered}
M_{S d, t o t, \theta}=\sqrt{115,32^{2}+56,03^{2}}=128,21 k N . m \\
\chi=\frac{128,21}{30,0}=4,27 \\
\theta=\operatorname{arctg}\left(\frac{56,03}{115,32}\right)=25,9^{\circ}
\end{gathered}
$$

\section{A.2.5 Envoltória de momento mínimo total}

Tal como na seção anterior, o valor de 128,21 kN.m pode ser entendido como momento solicitante de um certo lance de pilar e a direção de $25,9^{\circ}$ não determina a direção original 
da flexão. Avaliando a envoltória de momento mínimo total como sendo exclusivamente a parcela de segunda ordem, podem ser admitidas as seguintes componentes a partir da Eq. $(3-15)$ :

$$
\begin{gathered}
M_{2 d, x}=91,05 \mathrm{kN} . \mathrm{m} \\
M_{d, t o t, m i n, x x}=\alpha_{b} M_{1 d, \min , x x}+M_{2 d, x}+M_{c c, \mathrm{x}} \\
=1,0 \times 18,90+91,05+15,78=125,73 \mathrm{kN} . \mathrm{m} \\
M_{d, t o t, m i n, y y}=\alpha_{b} M_{1 d, \min , y y}+M_{2 d, y}+M_{c c, y} \\
=1,0 \times 29,70+9,04+25,78=64,52 \mathrm{kN} . \mathrm{m} \\
M_{2 d, y}=9,04 \mathrm{kN} . \mathrm{m} \\
\sqrt{\left(\frac{\cos 45^{\mathrm{o}}}{125,73}\right)^{2}+\left(\frac{\operatorname{sen} 45^{\circ}}{64,52}\right)^{2}}=81,18 \mathrm{kN} . \mathrm{m}
\end{gathered}
$$

\section{A.3 PILAR PADRÃO ACOPLADO A DIAGRAMAS}

\section{A.3.1 Momento total em $x$}

Neste método o efeito da fluência pode ser considerado por meio da correção do diagrama de tensão-deformação do concreto, bastando ajustar as deformações no concreto com o coeficiente de fluência $\varphi$. Este diagrama influencia no cálculo da rigidez adimensional $\kappa$, a qual depende do diagrama momento-normal-curvatura para obtenção da rigidez secante.

O programa SecTrans fornece o diagrama momento-normal-curvatura de modo gráfico e através de arquivo de saída no formato texto com todos pontos utilizados na construção desse gráfico. Assim, foi possível reproduzir os diagramas tal como aqui apresentados para obtenção da rigidez secante $\mathrm{EI}_{\mathrm{sec}} \mathrm{e}$, consequentemente, da rigidez adimensional $\kappa$. 
Figura A-2 - Resultados com o Método de Rigidez adimensional.

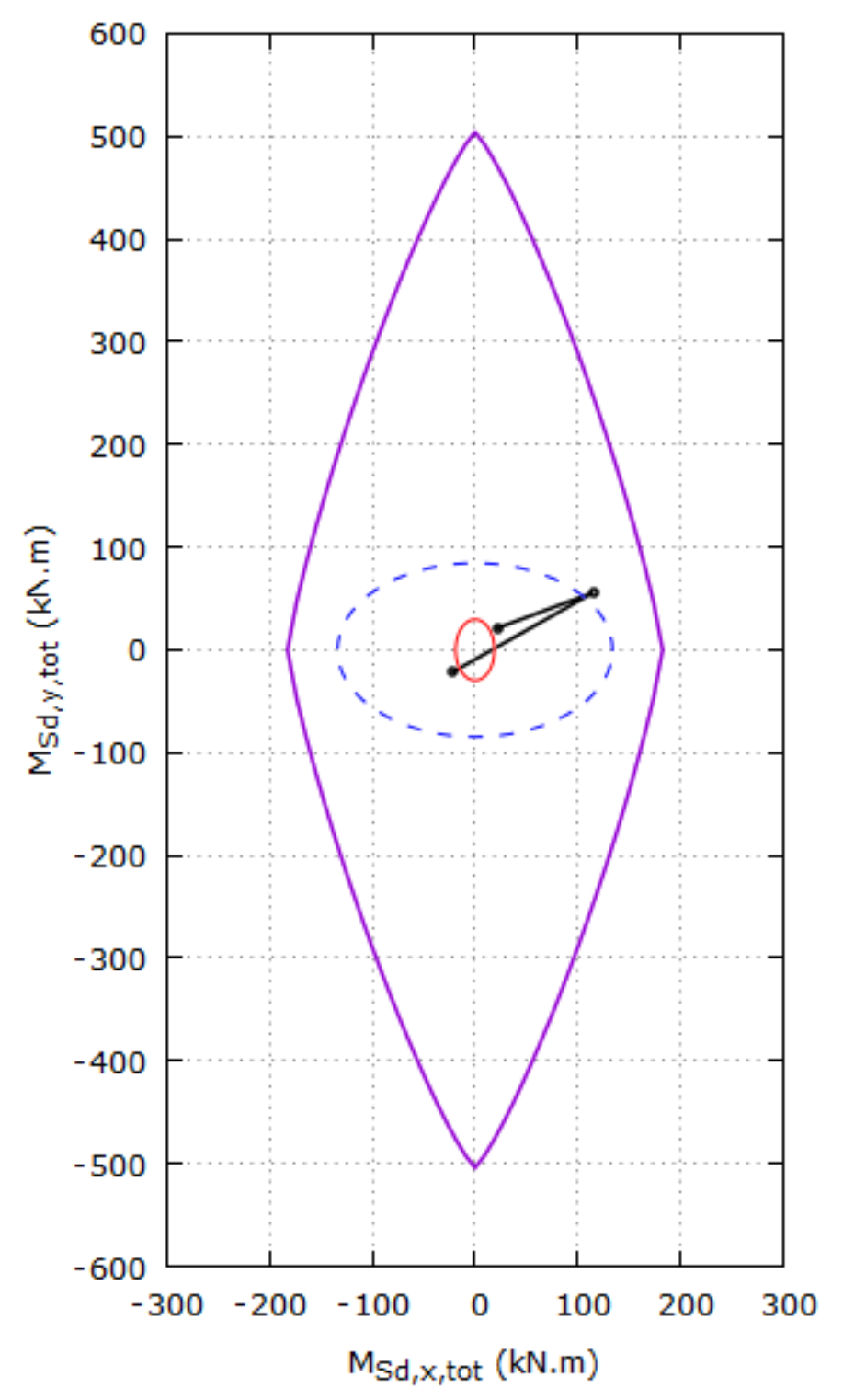

Fonte: Elaborado pela Autora.

Construído o diagrama apresentado na Figura A-3 é possível obter o momento último de 182,53 kN.m com a posição final da curva de $0,85 . f_{c d}$. 
Figura A-3 - Diagrama momento-normal-curvatura para direção $x$

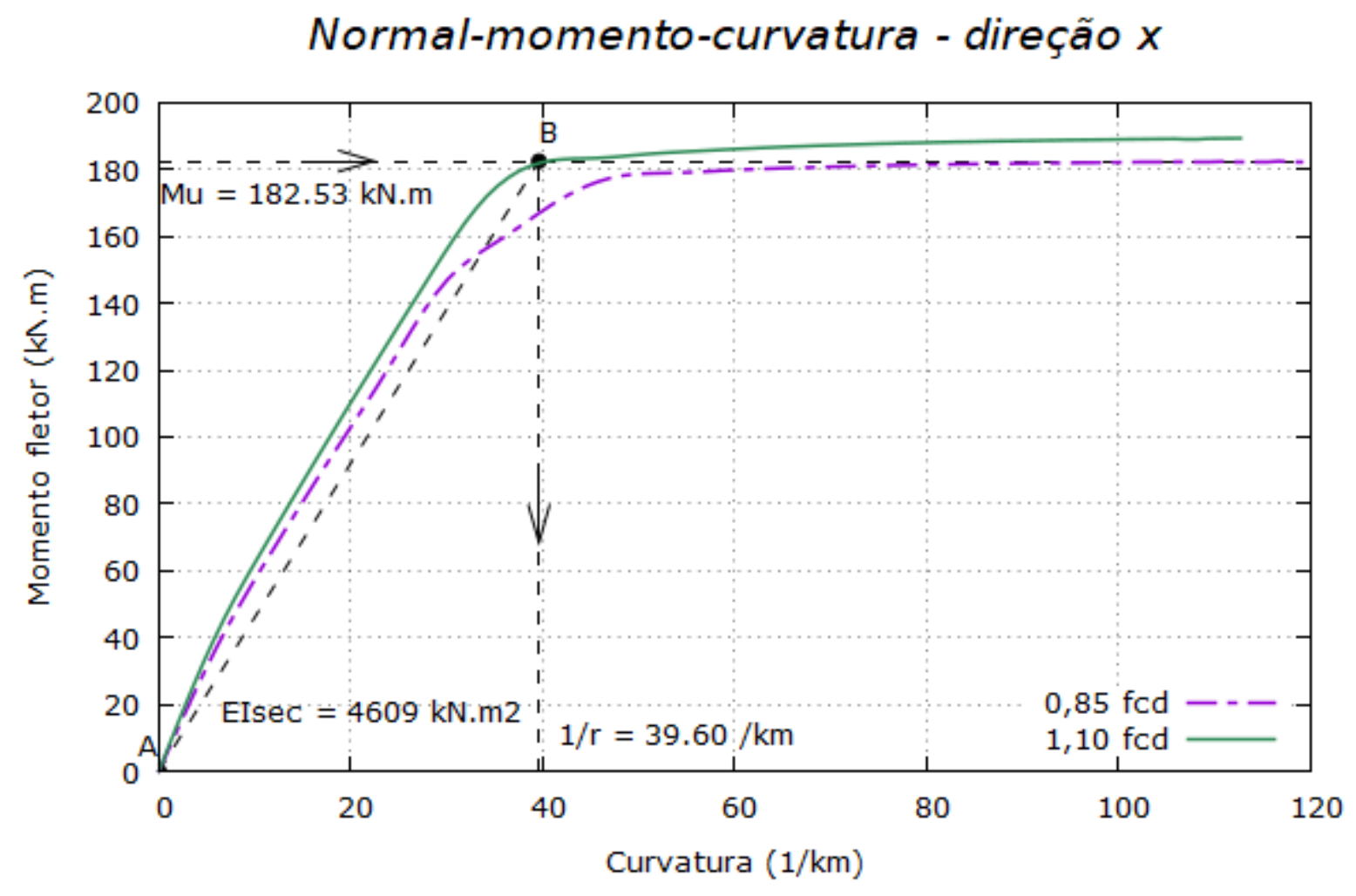

Fonte: Elaborado pela Autora.

O ponto B apresentado no diagrama é a intersecção da reta horizontal do momento último com a curva de $1,1 . f_{c d}$, cujas coordenadas são a curvatura de $39,60 \mathrm{~km}^{-1}$ e o momento fletor de 182,53 kN.m. A rigidez secante é a inclinação da reta ligando o ponto A com a origem do sistema de coordenadas com o valor de:

$$
E I_{\mathrm{sec}, x}=\frac{182,53 \mathrm{kN} \cdot \mathrm{m}}{39,60 \mathrm{~km}}=4.609 \mathrm{kN} \cdot \mathrm{m}^{2}
$$

A rigidez adimensional $\kappa$ é obtida com a Eq.(3-17). Neste estudo foi considerado, a favor da segurança, o valor para o coeficiente de ponderação $\gamma_{f 3}=1,0$ obtendo:

$$
\kappa_{x}=\frac{E I_{\text {sec }, x}}{A_{c} h_{y}^{2} f_{c d}}=\frac{4.609}{(60 \times 20) \times 20^{2} \times 2,5} \times 10^{4}=38,41
$$

A confrontação com a rigidez adimensional mínima $\kappa_{\min }$ prevista pela Eq. (5-5) resulta em: 


$$
\begin{aligned}
& \kappa_{x}>\kappa_{\min , x}=\frac{v \lambda_{x}^{2}}{120} \\
& 38,41>\frac{0,3 \times 115^{2}}{120}=33,06 \rightarrow \text { atende }
\end{aligned}
$$

Atendida a verificação, pode ser determinado o momento total nesta direção como sendo:

$$
M_{S d, t o t, x}=\frac{0,4 \times 21,21}{1-\frac{0,3 \times 115^{2}}{120 \times 1 \times 38,41}}=60,94 \mathrm{kN} . \mathrm{m}
$$

\section{A.3.2 Momento total em y}

O valor da rigidez na direção y foi determinado de modo análogo da direção $x$ e foram encontradas as coordenadas do ponto B como sendo curvatura de $15,91 \mathrm{~km}^{-1}$ obtida para o momento último de 503,74 kN.m.

Assim procedendo, resultaram os valores apresentados a seguir para as rigidezes secante e relativa, para o momento total e para o fator de amplificação.

$$
\begin{gathered}
E I_{\mathrm{sec}, y}=\frac{503,74 \mathrm{kN} . \mathrm{m}}{15,91 \mathrm{~km}^{-1}}=31.661 \mathrm{kN} \cdot \mathrm{m}^{2} \\
\kappa_{y}=\frac{E I_{\mathrm{sec}, y}}{A_{c} h_{x}^{2} f_{c d}}=\frac{31.661}{(20 \times 60) \times 60^{2} \times 2,5} \times 10^{4}=29,32
\end{gathered}
$$

A verificação do atendimento da rigidez adimensional mínima $\kappa_{\min }$ resulta em:

$$
\begin{aligned}
& \kappa_{y}>\kappa_{\text {min }, y}=\frac{v \lambda_{y}^{2}}{120} \\
& 29,32>\frac{0,3 \times 38,3^{2}}{120}=3,67 \rightarrow \text { atende }
\end{aligned}
$$

Validada a rigidez, pode ser calculado o momento total por:

$$
M_{S d, t o t, y}=\frac{1,0 \times 21,21}{1-\frac{0,3 \times 38,3^{2}}{120 \times 1 \times 29,32}}=24,24 \mathrm{kN} . \mathrm{m}
$$


Figura A-4 - Diagrama normal-momento-curvatura para direção y.

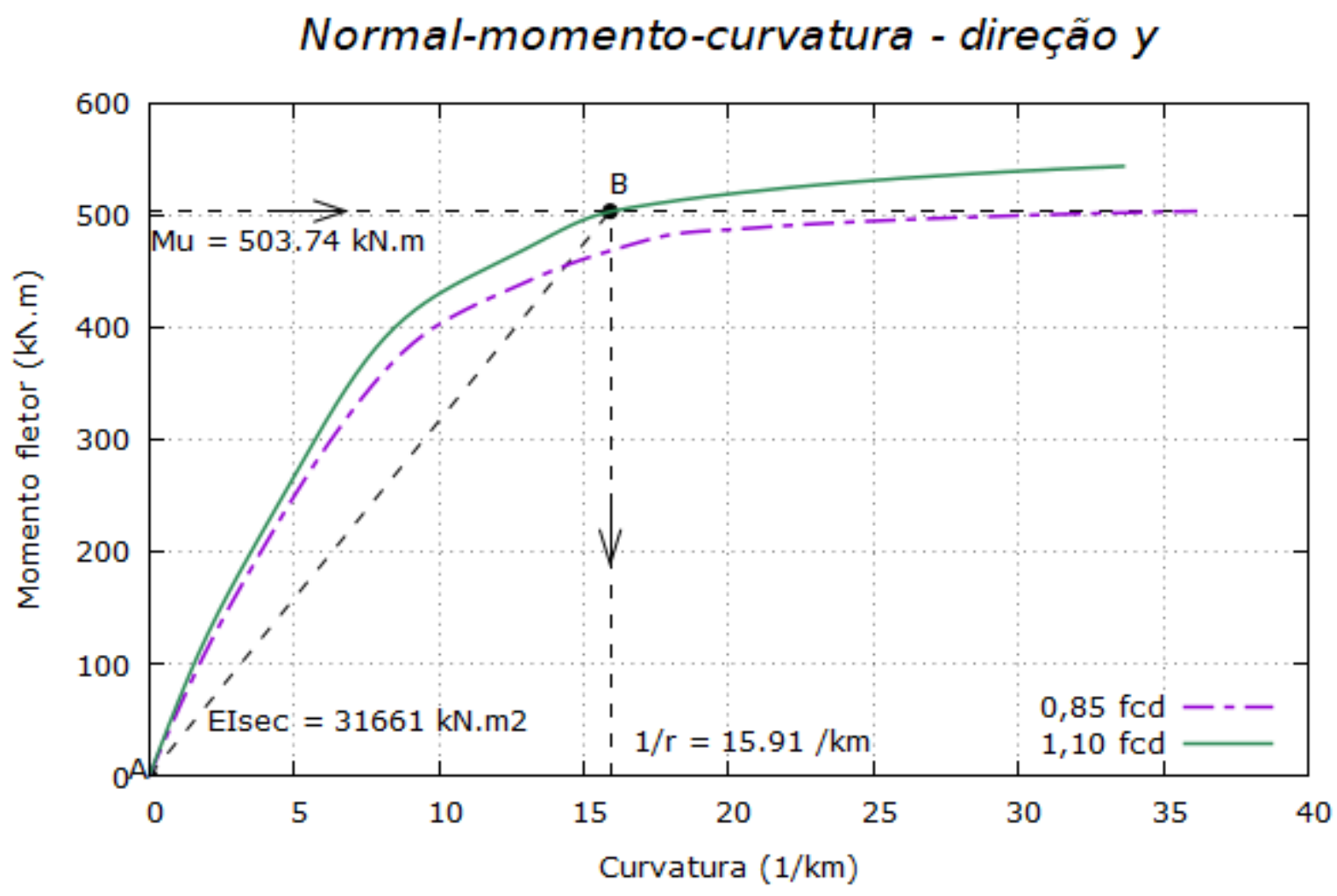

Fonte: Elaborado pela Autora.

\section{A.3.3 Momento total resultante}

O momento resultante solicitante e sua direção bem como o fator de amplificação são obtidos por:

$$
\begin{gathered}
M_{S d, t o t, \theta}=\sqrt{60,94^{2}+24,24^{2}}=65,58 \mathrm{kN} \cdot \mathrm{m} \\
\chi=\frac{65,58}{30,0}=2,19 \\
\theta=\operatorname{arctg}\left(\frac{24,24}{60,94}\right)=21,7^{\circ}
\end{gathered}
$$




\section{A.3.4 Envoltória de momento mínimo total}

$$
\begin{gathered}
M_{1 d, \text { min }, x x}=18,90 \mathrm{kN} . \mathrm{m} \\
M_{d, t o t, \text { min }, x x}=\frac{1,0 \times 18,90}{1-\frac{0,3 \times 115^{2}}{120 \times 1 \times 38,41}}=135,75 \mathrm{kN} . \mathrm{m} \\
M_{1 d, \text { min }, y y}=29,70 \mathrm{kN} . \mathrm{m} \\
M_{d, t o t, \text { min }, y y}=\frac{1,0 \times 29,70}{1-\frac{0,3 \times 38,3^{2}}{120 \times 1 \times 29,32}}=33,95 \mathrm{kN} . \mathrm{m}
\end{gathered}
$$

Substituindo as parcelas anteriores na Eq. (7-2) resulta o momento mínimo total para a direção de $45^{\circ}$ como sendo:

$$
\begin{aligned}
& M_{d, t o t, \text { min }, \theta}=\frac{1}{\sqrt{\left(\frac{\cos \theta}{M_{d, t o t, \text { min }, x x}}\right)^{2}+\left(\frac{\operatorname{sen} \theta}{M_{d, t o t, m i n, y y}}\right)^{2}}} \\
& =\frac{1}{\sqrt{\left(\frac{\cos 45^{\circ}}{135,75}\right)^{2}+\left(\frac{\operatorname{sen} 45^{\circ}}{33,95}\right)^{2}}}=46,58 \mathrm{kN.m}
\end{aligned}
$$


Figura A-5 - Resultados com o Método Acoplado a diagramas.

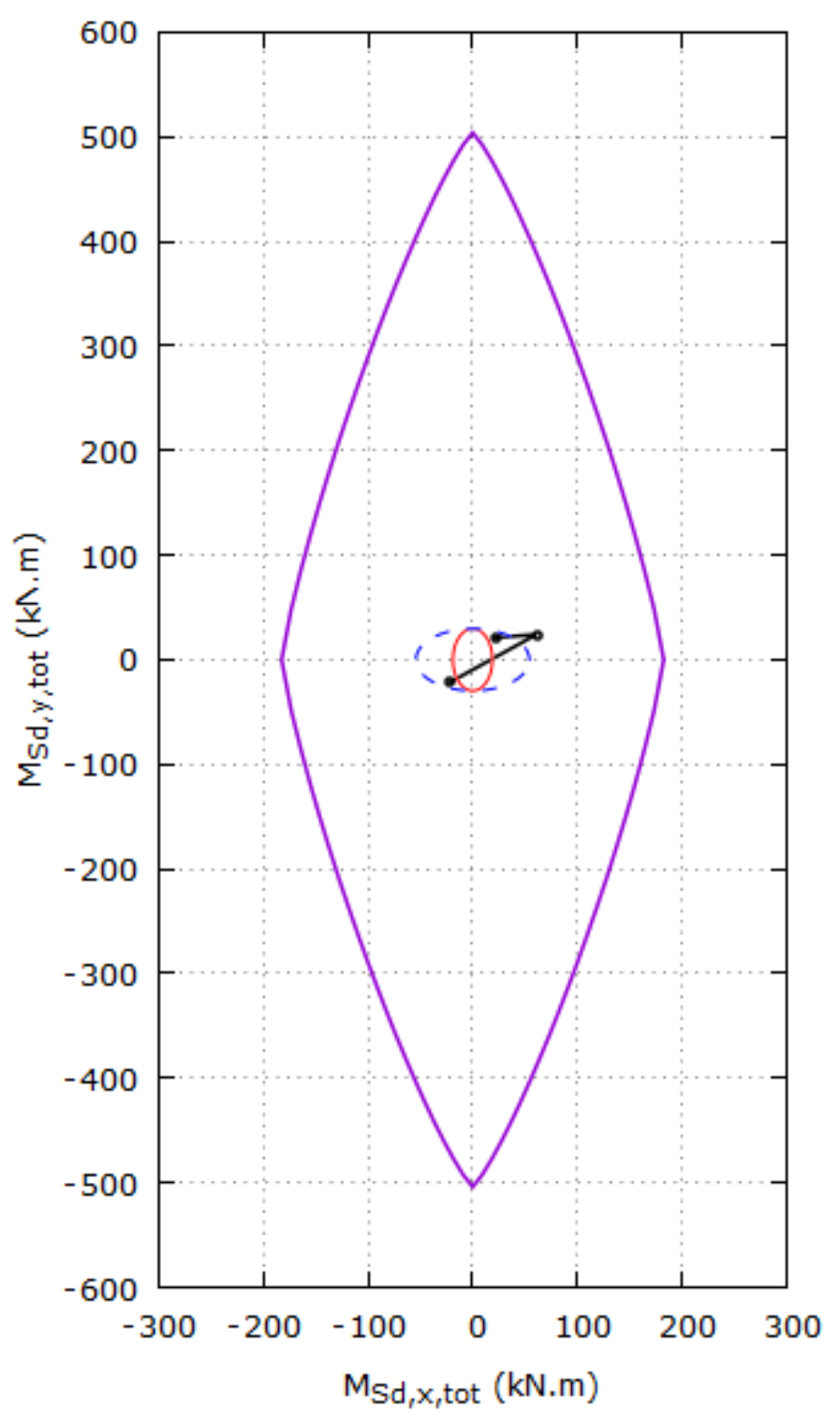

Fonte: Elaborado pela Autora. 


\section{A.4 MÉTODO GERAL}

\section{A.4.1 Momento total}

Para utilização do método geral, o programa SecTrans discretiza o pilar em $n$ segmentos e calcula o momento total na direção oblíqua por meio da Analogia de Mohr. Com o método geral podem então ser consideradas as direções $x$ e $y$ como acopladas e não independentes, como são considerados nos métodos aproximados. A Figura 96 apresenta os momentos totais obtidos pelo SecTrans ao longo do pilar (discretizado em 10 segmentos).

Figura A-6 - Momentos totais ao longo do pilar pelo método geral.

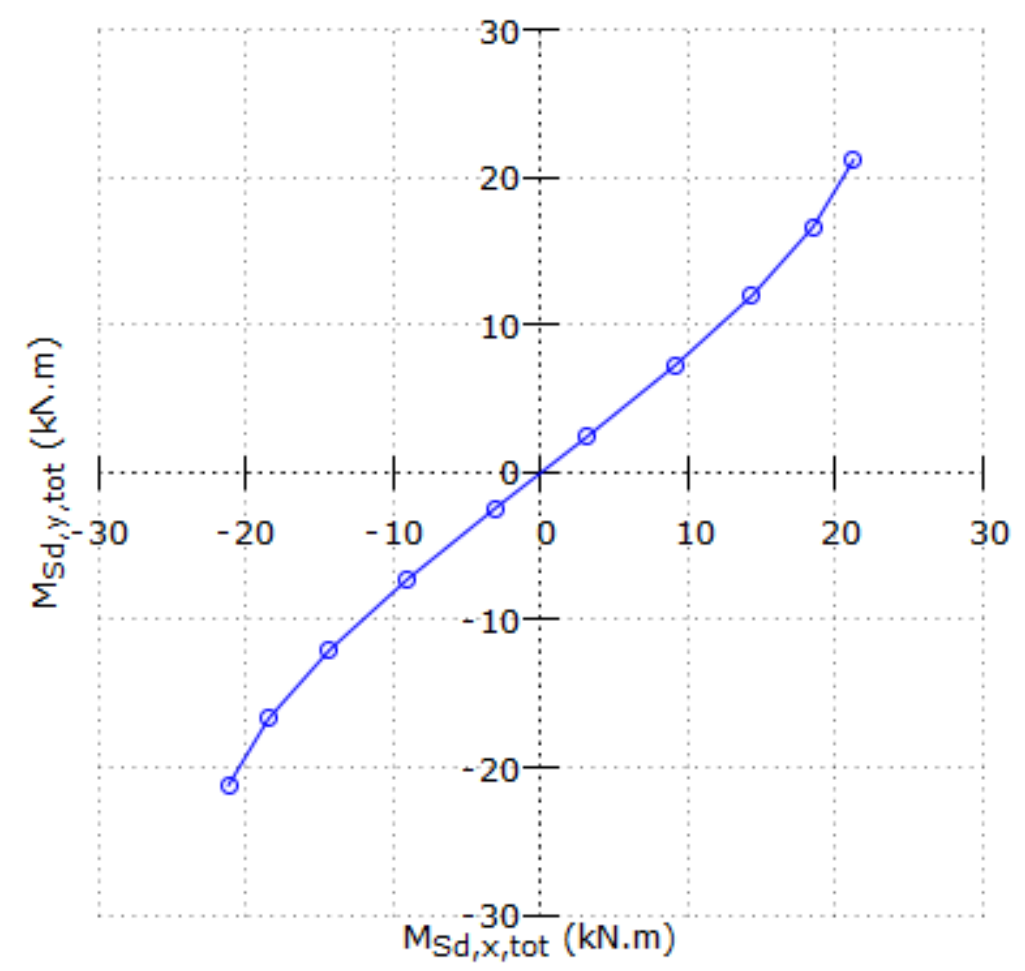

Fonte: Elaborado pela Autora.

No caso de utilização do método geral, o ponto mais crítico (ponto mais próximo da envoltória resistente) neste Exemplo de aplicação é a base ou topo do pilar, pois ambos estão com a mesma distância para a envoltória resistente em razão da simetria da solicitação e da resistência nas extremidades do pilar. Sendo assim, os momentos totais coincidem com os momentos de primeira ordem; o momento resultante possui a mesma direção do momento 
inicialmente aplicado de $45^{\circ}$ e o fator de amplificação é unitário, ou seja, o acréscimo de momento de segunda ordem é nulo para efeito de dimensionamento.

$$
M_{S d, t o t, \theta}=30,00 k N . m
$$

\section{A.4.2 Envoltória de momento mínimo total}

$$
\begin{aligned}
& M_{1 d, \min , x x}=18,90 \mathrm{kN} . \mathrm{m} \\
& M_{d, t o t, \min , x x}=81,55 \mathrm{kN} . \mathrm{m} \\
& M_{1 d, \min , y y}=29,70 \mathrm{kN} . \mathrm{m} \\
& M_{d, t o t, \min , y y}=32,94 \mathrm{kN} . \mathrm{m}
\end{aligned}
$$

Substituindo as parcelas anteriores na Eq. (7-3) resulta o momento mínimo total para a direção de $45^{\circ}$ como sendo:

$$
\begin{aligned}
M_{d, \text { tot, } \min , \theta} & =\frac{1}{\sqrt{\left(\frac{\cos \theta}{M_{d, t o t, m i n, x x}}\right)^{2}+\left(\frac{\operatorname{sen} \theta}{M_{d, t o t, \min , y y}}\right)^{2}}} \\
& =\frac{1}{\sqrt{\left(\frac{\cos 45^{\circ}}{81,55}\right)^{2}+\left(\frac{\operatorname{sen} 45^{\circ}}{32,94}\right)^{2}}}=43,19 \mathrm{kN} . \mathrm{m}
\end{aligned}
$$

Deve-se ressaltar nesse caso que, como o momento solicitante máximo foi inferior ao valor do momento total mínimo, o dimensionamento da seção transversal deve ser feito com o valor mínimo. 